\title{
Cigarette smoking, COPD and psychological problems : the use of antidepressants for smoking cessation in patients with COPD
}

Citation for published version (APA):

Wagena, E. J. (2005). Cigarette smoking, COPD and psychological problems : the use of antidepressants for smoking cessation in patients with COPD. [Doctoral Thesis, Maastricht University]. Universiteit Maastricht. https://doi.org/10.26481/dis.20050513ew

Document status and date:

Published: 01/01/2005

DOI:

10.26481/dis.20050513ew

Document Version:

Publisher's PDF, also known as Version of record

Please check the document version of this publication:

- A submitted manuscript is the version of the article upon submission and before peer-review. There can be important differences between the submitted version and the official published version of record.

People interested in the research are advised to contact the author for the final version of the publication, or visit the DOI to the publisher's website.

- The final author version and the galley proof are versions of the publication after peer review.

- The final published version features the final layout of the paper including the volume, issue and page numbers.

Link to publication

\footnotetext{
General rights rights.

- You may freely distribute the URL identifying the publication in the public portal. please follow below link for the End User Agreement:

www.umlib.nl/taverne-license

Take down policy

If you believe that this document breaches copyright please contact us at:

repository@maastrichtuniversity.nl

providing details and we will investigate your claim.
}

Copyright and moral rights for the publications made accessible in the public portal are retained by the authors and/or other copyright owners and it is a condition of accessing publications that users recognise and abide by the legal requirements associated with these

- Users may download and print one copy of any publication from the public portal for the purpose of private study or research.

- You may not further distribute the material or use it for any profit-making activity or commercial gain

If the publication is distributed under the terms of Article 25fa of the Dutch Copyright Act, indicated by the "Taverne" license above, 
CIGARETTE SMOKING, COPD AND

PSYCHOLOGICAL PROBLEMS 
The studies described in this thesis are in part supported by the Health Research and Development Council (ZorgOnderzoek Nederland), The Netherlands (grant no. 2200.0111) and the Netherlands Asthma Foundation (NAF grant no. 3.2.00.21).

The publication of this thesis was financially supported by the Netherlands Asthma Foundation, Pulmonary Rehabilitation Centre Hormerheide, the Department of Respiratory Medicine (University Hospitall Maastricht), the Partnership 'Stop mer Roken', Solvay Pharmaceuticals B.V., PT Medical B.V. (Strategic partner of Micro Medical Ltd.), De Friesland Zorgverzekeraar, Lundbeck B.V., Boehringer Ingelheim B.V., Pfizer B.V., and Novartis Pharma B.V.

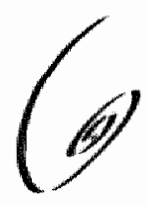

CIGARETTE SMOKING, COPD AND PSYCHOLOGICAL PROBLEMS

The use of antidepressants for smoking cessation in patients with COPD

Edwin J. Wagena

COVER AND LAY-OUT PRODUCTION

ISBN: 90-9019247-6

C. 2005, E.J. Wagena
E.J. Wagena and V.J. Wagena junior Datawyse 


\section{CIGARETTE SMOKING, COPD \\ AND PSYCHOLOGICAL PROBLEMS}

The use of antidepressants for smoking cessation in patients with COPD

\section{PROEFSCHRIFT}

ter verkrijging van de graad van doctor aan de Universiteit Maastricht, op gezag van de Rector Magnificus, Prof. mr. G.P.M.F. Mols, volgens het besluit van het College van Decanen,

in het openbaar te verdedigen op vrijdag 13 mei 2005 om 14.00 uur

door

EDWIN JACOB WAGENA 


\section{PROMOTORES}

Prof. dr. C.P. van Schayck

Prof dr. E.F.M. Wouters

BEOORDELINGSCOMMISSIE

Prof. dr. I.A. Knottnerus (voorzitter)

Prof. dr. A. Arntz

Prof. dr. D. Postma (Rijksuniversiteit Groningen)

Prof. dr. F.J. van Schooten

Prof. dr. R. West (University College London)

The work presented in this thesis was conducted at the Care and Public Health Research Institute (CAPHRI), which participates in the Netherlands School of Primary Care Research (CaRe), acknowledged in 1995 by the Royal Dutch Academy of Science (KNAW). The author gratefully acknowledges the collaboration with the Department of Epidemiology of Maastricht University (dr. L.G.P.M. van Amelsvoort, dr. IJ. Kant and dr. G. Swaen). 


\section{Contents}

\section{CHAPTER $\mathbb{1}$}

Intraduction

\section{CHAPTER 2}

Psychological distress and depressed mood in employees with asthma, chronic bronchitis or emphysema: A population-based observational study on prevalence and the relationship with smoking cigarettes

\section{CHAPTER 3}

Risk of depression and anxiety in employees with chronic bronchitis: The modifying effect of cigarette smoking

\section{CHAPTER 4}

Chronic bronchitis, cigarette smoking and the subsequent onset of depression and anxiety: Results from a prospective population-based cohort study

\section{CHAPTER 5}

Depression in patients with COPD: Are somatic symptoms more indicative of depression compared with cognitive and affective symptoms?

\section{CHAPTER 6}

The efficacy of bupropion for smoking cessation in relation to pharmaceutical industry sponsorship and methodological quality: A systematic review and meta-analysis

\section{CHAPTER 7}

Should nortriptyline be used as a first-line aid to help smokers quit? A systematic review and meta-analysis

\section{CHAPTER 8}

The efficacy of smoking cessation strategies in patients with chronic obstructive pulmonary disease: A systematic review 


\section{CHAPTER 9}

The efficacy of bupropion and nortriptyline for smoking cessation among people who are at risk for or have chronic obstructive pulmonary disease: A randomized, placebocontrolled trial

\section{CHAPTER 10}

General Discussion

Samenvatting (Dutch Summary)

Dankwoord (Acknowledgements in Dutch)

About the author

List of publications 


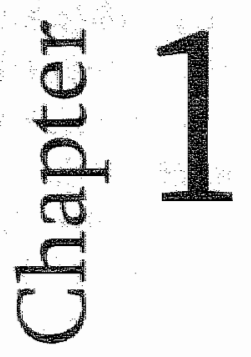

\section{Introduction}

Parts of the introduction have been published in THORAX, 2001; $56(8)$ :

587-588 and DRUG SAFETY, 2003; 26 (6): 381-403 


\section{SMOKING AND COPD}

Smoking and pulmonary diseases such as chronic bronchitis or emphysema (i.e. chronic obstructive pulmonary disease [COPD]) are causally related [1] However, it was not until 1964 that the US Surgeon General's report warned about a potential causal relation between smoking and emphysema. [1] Since then mumerous studies have shown that cigarette smoking accelerates the rate of decline in pulmonary function.[2-8] Moreover, estimates show that smoking accounts for at least $90 \%$ of COPD cases. $[9,10]$ COPD is generally progressive, especially if a person continuous to smoke.[11] Although not all smokers develop clinically significant COPD, recent epidemiological studies have shown that most smokers, if they live long enough and smoke enough, will develop airflow limitation.[12] The contribution of smoking cigarettes to COPD morbidity and mortality far outweighs that of other factors, such as occupational dusts and chemicals, air pollution and infections.[1]

Since smoking is the main cause for developing COPD, this chronic illness is largely preventable. Smoking cessation is not only the most effective way to reduce the risk of developing COPD. In smokers who already have a decreased pulmonary function, smoking cessation is the only intervention which has shown to reduce the rate of decline in forced expiratory volume (FEV $)$ for both men and women. $[2,3,7$, 13-15] Smoking cessation improves long-term prognosis[16], it can reduce the symptoms of cough and sputum production[17], as well as the reactivity of the airways.[18]

\section{NICOTINE ADDICTIION}

It has been recognized for many years, both in the medical literature[19] and by the tobacco industry[20], that nicotine addiction plays a major part in the motivation of people to smoke cigarettes.[21, 22] Nicotine addiction can be considered a syndrome characterized by compulsive drug-seeking behaviour that mainly results in damage to health.[23] Addiction can be recognized by tolerance to and physiological dependence on a drug of abuse, in this case nicotine.[24] The effects of nicotine on the brain include increased expression of brain nicotine receptors, changes in regional brain glucose metabolism, and the release of catecholamines. [25] These effects result in neuroadaptation, which is manifested as the development of tolerance and physiological dependence.[26] Tolerance represents an adaptation to repeated exposure to nicotine such that the pharmacological response is diminished.[27] Physiological dependence is a state manifested by the withdrawal syndrome when drug-taking is terminated or significantly reduced. The withdrawal syndrome is characterized by depressed mood, insomnia, irritability, frustration or anger, anxiety, difficulty concentrating, 
restlessness, decreased heart rate, and increased appetite or weight gain. [27] Symptoms of nicotine withdrawal are non-specific, and vary widely in intensity and duration.[28] These symptoms are intensified by abrupt abstinence from nicotine, and begin as the drug disappears from the body through metabolism and excretion. $[23,25]$ The potential for abuse or addiction to nicotine is determined by the magnitude of the positive reinforcing effects and the speed of drug delivery to the brain. $[29,30]$ Generally, the more quickly the drug is delivered to the brain, the greater the potential for abuse.[29] Nicotine from a smoked cigarette reaches the brain in 10 to 20 seconds.[31, 32] The cigarette can therefore be considered an extremely efficient nicotine delivery device, delivering the optimum dose of nicotine rapidly to the brain.[33]

\section{SMOKING CESSATION AND COPD}

Many patients with COPD continue to smoke despite knowing about or experiencing the health consequences of tobacco use.[28] Others who try to quit repeatedly fail. Most of the international scientific and clinical. community assume that only a small number of patients with COPD is able to quit smoking even with intensive behavioural and pharmacological assistance.[34] This can only be explained if tolerance to and physiological dependence on nicotine are considered not the only problems that nicotine addicts have to overcome when trying to quit. If quitting smoking would be all about dealing with tolerance and dependence; treatment of smokers who want to quit would consist of detoxification, a process that allows the body to cleanse itself while the individual receives medication to block withdrawal symptoms. [23] Moreover, in that case, there would be no reason to assume for example, that smokers with COPD would have more difficulties quitting smoking compared with smokers without a chronic illness. As O'Brien stated earlier, detoxification is, at best, a first step in beginning treatment.[23] Quitting smoking does not seem to be a particularly significant accomplishment, but preventing relapse is. Patients with COPD, who still smoke, are therefore expected to experience additional barriers for success if they try to quit smoking. Many believe that these patients already would have quit smoking if they could. One barrier for a successful quit attempt could well be the presence of psychological problems like depression or anxiety. In addition to the reinforcing and dopaminestimulating properties $[35,36]$ that nicotine shares with other psychostimulant drugs of abuse, such as amphetamine and cocaine, nicotine also exerts a positive effect on depression as well as anxiety.[37] Research has shown that the presence of depression is independently associated with failure to quit smoking and relapse.[3842] Furthermore, studies in smokers have shown that nicotine can reduce anxiety and relieve stress. $[43,44]$ The findings suggest that smokers might continue smoking 
to regulate anxiety and depression. $A$ high prevalence of psychological problems like depression or anxiety in patients with COPD, especially in those patients who smoke, might prevent them from achieving prolonged abstinence from smoking.

\section{OUTLINE OF THIS THESIS}

In the first part of this thesis we focus on the relation between cigarette smoking, COPD and psychological problems (see figure). We do not address the relation between cigarette smoking and $C O P D$, since numerous studies have already shown that smoking cigarettes is causally related to the development of COPD. When we started the research presented in this thesis; it was unclear whether psychological problems are more prevalent in patients with COPD compared with the general population, or in patients with other chronic illnesses. Van Ede and colleagues concluded in their review that the empirical evidence for a significant risk of depression in patients with COPD remains inconclusive, mainly due to the poor methodological quality of most of the published studies. [45] Furthermore, there is some evidence, which seems to indicate that the prevalence of anxiety disorders; particularly generalised anxiety disorder and panic disorder, is higher in patients with COPD than in the general population.[46] Yet, most of these studies have major drawbacks, such as the absence of a control group and very small sample sizes.[46] Instead, we will study the presence and incidence of psychological problems such as depression and anxiety in patients with COPD compared to other chronically ill patients and/or people without a chronic illness. Furthermore, because a positive association between psychological problems and cigarette smoking has been well established[40,42,47,48], we also looked into the modifying effect of cigarette smoking.

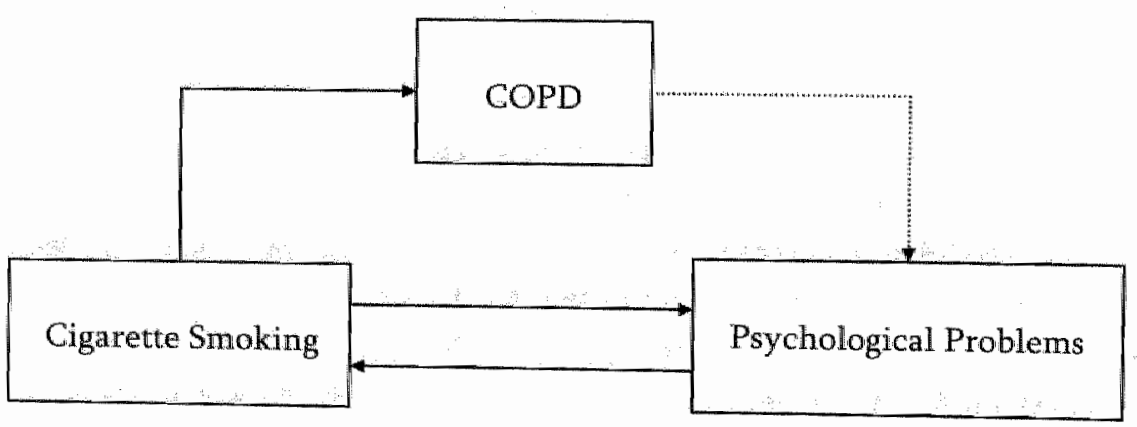

FIGURE

Relation between cigarette smoking, COPD and psychological problems 
In chapter 2 we study the presence of psychological distress and depressed mood in patients with asthma or COPD compared to patients with heart disease, hypertension or myocardial infarction, patients with rheumatoid arthritis, and people who report not to suffer from any chronic illness. Since we cannot distinguish between subjects with asthma and those with COPD in chapter 2, we investigated in chapter 3 whether the prevalence of depression and anxiety in a population-based sample was different in subjects with COPD compared to that in subjects without any respiratory complaints and those with asthma. Chapter 4 is devoted to studying whether the presence of COPD predicts the subsequent onset of depression or anxiety compared to healthy subjects, and if the incidence of depressed or anxious cases is different for smokers and non-smokers.

According to the $4^{\text {th }}$ edition of the Diagnostic and Statistical Manual of Mental Disorders (DSM-IV-TR ${ }^{\mathrm{TM}}$ )[49], a (major) depressive disorder can be characterized by the presence of somatic symptoms like fatigue or loss of energy, insomnia, and somatic preoccupation. In chapter 5 we study whether somatic symptoms are specifically indicative of depression in patients with severe or very severe COPD (stages III and IV according to the Global Initiative for Chronic Obstructive Lung Disease (GOLD) [11,50], as compared with the symptoms reported by patients with mild or moderate COPD (stages I and II) and subjects at risk for COPD (stage 0).

In the second part of this thesis we mainly focus on the use of antidepressants for smoking cessation in patients with COPD. The observation that: 1) smoking patients with COPD seem to be at increased risk of depression,[51-53] 2) nicotine addiction is often accompanied by co-morbid depression or depressive symptoms, $[54,55]$ and 3) nicotine may have antidepressant effects and regulate mood, $[37,56,57]$ provides a rationale for the use of antidepressant drugs for smoking cessation in this patient population. In chapter 6 we present the results of a systematic review and meta-analysis to evaluate the efficacy of bupropion sustained release for smoking cessation. Before the Dutch Medicines Evaluation Board (MEB) authorized bupropion in 1999 for the indication smoking cessation (trade name Zyban), this drug was registered in the United States in 1985 as antidepressant (trade name Wellbutrin). The Netherlands was the first country of the European Union to register bupropion as therapy for smoking cessation. One year after the first study of bupropion was published[58], Hall and colleagues presented in 1998 their results of a randomized trial evaluating the efficacy of nortriptyline for smoking cessation[59]. The authors concluded that nortriptyline was a promising adjunct for smoking cessation, but much less attention has been paid to this drug compared to bupropion. In chapter 7 we present the results of our systematic review and meta-analysis on the efficacy of nortriptyline for smoking cessation. Although smoking cessation is 
widely mentioned as the most important measure in patients with COPD, little is known about the effectiveness of existing smoking cessation interventions specifically in these patients. The efficacy of pharmacological interventions, behavioural interventions and combinations of both in patients with COPD is evaluated in chapter 8. In chapter 9 we study the efficacy of bupropion and nortriptyline for smoking cessation in patients at risk for COPD or with existing COPD, in a randomised, placebo-controlled trial. 


\section{References}

1. US. Surgeon General. The Health Consequences of Snuking: Chronic Obstructive Lung Disease. 1984, US Department of Health and Human Services: Washington DC.

2. Burchfiel, C, E. Marcus, J. Curb, et all. Effects of smoking and smoking cessation on longitudinal decline in pulmonary function. Am J Respir Crit Care Med, 1995; 151 (6): 1778-1785.

3. Camilli; A.E., B Burrows, R. Knudson, et al. Longitudinal changes in forced expiratory volume in one second in adwilts. Am Rev Respix Dis, 1987; 135: 794-799.

4. Fletcher, C.M., R. Peto, C.M. Tinker, et al. The natural history of chronic bronchitis and emphysema. 1976, Oxford: Oxford University Press.

5. Muers, M.F., Quitting smoking and langs. Iancet, 1999; 354:177-178.

6. Pelkonen, M., I.-L. Notkola, H. Tukiainen, et al. Smoking cessation, decline in pulmonary function and total mortality: a 30 year follow up study among the Finnish cohorts of the Seven Countries Study. Thorax, 2001; 56 (9): 703-707.

7. Xu, X, D.W. Dockery, J.H. Ware, et al. Effects of cigarente smoking on rate of loss of pulmonary function in adults: a longitudinal assessment. Am Rev Respir Dis, 1992; 146: 1345 1348.

8. Tashkin, D.P., R. Detels, M. Simmons, et al. The UCLA population studies of chronic obstructive respiratory disease: XI. Impact of air pollution and smoking on annual change in forced expiratory volume in one second. Am J Respir Crit Care Med, 1994: 149: 1209-1217.

9. Roche, N. and G.J. Huchon. Current issues in the management of chronic obstructive pulmonary disease. Respirology, 1997; 2: 215-229.

10. US Department of Health and Human. Services, The health consequences of smoking: chronic obstructive lung disease. 1984, Office on Smoking and Health, Department of Health and Human Services: Rockville MD.

11. Pauwels, R.A., A.S. Buist, P.M. Calverley, et al. Global strategy for the diagnosis, management, and prewention of chronic obstructive pulmonary disease. NHLBI/WHO Global Initiative for Chronic Obstructive Lung Disease (GOLD) Workshop summary. Am I Respir Crit Care Med, 2001; 163 (5): 1256-76.

12. Pauwels, R.A. and K.F. Rabe. Burden and clinical features of chronic obstructive pulmonary disease (COPD). Lancet; 2004; 364: 613-620:

13. Sherrill, D., C. Holberg, P. Enright, et all. Longitudinal analysis of the effects of smoking onset and cessation on pulmonary function. Am J Respir Crit Care Med, 1994; 149 (3): 591-597.

14. Soejima, K., K. Yamaguchi. E. Kohda, et al. Longitudinal follow-up study of smoking-induced ltnng density changes by high resolution computed tomography. Am J Respir Crit Care Med, 2000; 161: $1264-1273$.

15. Anthonisen, N.R. J.E. Connett, J.P. Kiley, et al. Effects of smoking intervention and the use of an inhaled anticholinergic bronchodilator on the rate of decline of $N E V 1$. The liang Health Study. JAMA, 1994; 272 (19): 1497-505.

16. Scanlon, P.D. I.E. Connett, L.A. Waller, et al. Smoking cessation and lung function in mild-tow moderate chronic obstructive pulmonary disease: the Lung Health Study. Am. I Respir Crit Care Med, 2000; 161: $381-390$.

17. Buist, A.S., G.J. Sexton, J.M. Nagy, et al. The effect of smoking cessation and modification on lung function. Am Rev Respir Dis, 1976, 114: 115-122.

18. Wise, R.A., R.E. Kanner, P. Lindgren, et al. The effect of smoking on intervention and inhaled bronchodilator on airways reactivity in COPD; the Lung Health Study. Chest, 2003; 124: 449-458.

19. Johnston, L.M., Tobacco smoking and nicotine. Lancet, 1942 ; ii: 742.

20. Action on Smoking and Health, Tobacco explained: 2. Nicotine and addiction (http:/www.ash.org.uk/html/conduct/html/tobexpld2.html).

21. Britton, J., M. Jarvis, A. McNeill, et al. Treating nicotine addiction. Not a medical problem? Am J Respir Crit Care Med, 2001; 164: 13-15.

22. Henningfield, J.E., K. Miyasato, and D.R. Jasinski. Abuse liability and pharmacodynamic characteristics of intravenous and inhaled nicotine. ] Pharmacol Exp Ther, 1985; 234 (1):1-12. 
23. OBrien, C.P. A range of research-based phamacotherapies for addiction. Science, 1997; 278: 6670 .

24. Department of Health and Human Services and Public Health Service, The health conseguences of smoking: nicotine addiction: a teport of the Surgeon General. 1988, Government Printing Office: Washington, D.C.

25. Henningfield, J.E. Drug therapy: nicotine medications for smoking cessation. N Engl J Med, 1995; 333: 1196-1203.

26. Benowitz, WL Nicotine replacement therapy: what has been accomplished - can we do better? Drugs, $_{i, i} 1993 ; 45(2): 157-170$.

27. Diagnostic and statistical manual of mental disorders, 4th ed: DSM-IV. 1994, American Psychiatric. Asoociation: Washington D.C.

28. Rigoti, N.A. Treatment of tobacco use and dependence. N Engl I Med, 2002,346 (7): 506-512.

29. Henningfield, IE and R.M. Keenan. Nicotine delivery kizetics and abuse liability. J Consult Clin Psychol, $1993 ; 61: 18$.

30. Benowitz, N.L. Pharmacokinetics considerations in understanding nicotine dependence, in The biology of nicotine dependence 1990. 1990 , Wiley: Chicester.

31. Zevin, S, S.G. Gourlay, and N.L. Benowitz. Clinical pharmacology of nicotine. Clin Dermatol, 1998; $16: 557-564$

32. Gourlay, S.G. and N.L. Benowitz. Arteriovenous differences in plasma concentration of nicotine and catecholamines and related cardiovascular effects after smoking, nicotine nasal spray, and: intravenous nicotine. Clin Pharmacol Ther, 1997; 62: 453-463.

33. Moxham, J. Nicotine addiction. BMT, 2000; 320 (7232): 391-392.

34. Medici, T.C. S. Umger, and M. Ruegger. Smoking pattern of smokers with and without tobaccosmoke-related lung diseases. Am Rev Respir Dis, 1985; 131: 385-388.

35. Balfour, D.J.K., M.E.M. Benwell, C.E. Birell, et ail. Sensitization of the mesoaccumbens dopamine response to nicotine. Pharmacol Biochem Behav, 1998; 59: 1021 1030.

36. Balfour, D.J.K., A.E. Wright, M.E.M. Benwell, et al. The putative role of extra-synaptic mesolimbic dopamine in the neurobiology of nicotine dependence. Behav Brain Res, 2000; 113: 73-83.

37. Piccioto, M.R., D.H. Brunzell, and B.J. Caldarone. Effect of nicotine and nicotinic receptors on anxiety and depression. Neurorepore, 2002"13 (9): 1097-1106.

38. Breslau, N., E.L. Peterson, L.R. Schultz, et al. Major depression and stages of smoking. A longitudinal investigation. Arch Gen Psychiatry, 1998; 55 (2): 161-166.

39. Covey, L.S., A.H. Glassman, and F. Stetner. Cigarette smoking and major depression. ) Addict Dis, $1998 ; 17(1): 35-46$.

40. Glassman, A.H. J.E. Helzex, L.S. Covey, et al, Smoking, smoking cessation, and major depression. IAMA, 1990; 264 (12): 1546-1549.

41. Glassman, A.H., L.S. Covey, Stetner, et al. Smoking cessation and the course of major depression: al follow-up study. Lancet, 2001; 357: 1929-1932.

42. Glassman, A.H., F. Stetner, B.T. Walsh, et al. Heavy smokers, smoking cessation, and clonidine Results of a double blind, randomized trial. JAMA, 1988; 259 (19): 2863-2866.

43. Pomerleau, O.S. Nicotine as a psychoactive drug: anxiety and paim reduction. Psychopharmacol Bull, 1986; 22: 865-869.

44. Cilbert, D.G., J.H. Robinson, C.L. Chamberlin, et al. Effects of smoking/nicotine on anxiety, heart rate $_{n}$ andl lateralization of EEG during a stressful movie. Psych

45. Van Bde, L., C.J. Yzermans, and H.J. Browwer. Prevalence of depression in patients with chronic obstructive pulmonary disease: a systematic review. Thorax, 1999; 54 (8): 688-692.

46. Brenes, G.A. Anxiety and chronic obstructive pulmonary disease: prevallence, impact, and treatment. Psychosom Med, 2003; 65: 963-970.

47. Lasser, K. I.W. Boyd, S. Woolhandler, et al. Smoking and mental illness; a population-based prevalence study. JAMA, 2000; 284 (20): 2606-2610.

48. Dierker, L.C., S. Avenevoli, M. Stolar, et al. Smoking and depression: an examination of mechanisms of comorbidity. Am J Psychiatry, 2002; 159 (6): $947-953$ 
49. American Psychiatric Association. Diagnostic and statistical manual of mental disorders (4thed., rev.). 1994, Washington D.C.: American Psychiatric Associarion.

50. Fabbri, L.M and S.S. Hurd. Global strategy for the diagnosis, management and prevention of COPD: 2003 update. Eur Respir J, 2003; 22: 1-2.

51. Van Manen, J.G., P.J. Bindels, F.W. Dekker, et al. Risk of depression in patients with chronic obstructive pulmonary disease and its determinants. Thorax, 2002; 57: 412-416.

52. Wagena, EI., W.A. Arrindell, E.F.M. Wouters, et al. Are patients with COPD psychologically distressed? Eur Respir J, 2005; in press.

53: Wagena, E.J., L.G.P.M. van Amelsvoort, I. Kant, et al. Risk of depression and anxiety in employees with chronic bronchitis: the rnodifying effect of cigarette smoking. Psychosom Med, 2004; 66: 729734.

54. Breslau, $\mathbb{N}$. and E.O. Johnson. Predicting smoking cessation and major depression in nicotinedependent smokers. Am J Public Health, 2000, 90 (7): 1122-1127.

55. Killen, J.D. S.P. Formann, H.C. Kraemer, et al. Interactive effects of depression symptoms, nicotine dependence, and weight change on late smoking relapse. I Consult Clin Psychol, 1996; 64 (5): 1060-1067.

56. Kotlyar, M., M. Golding, D.K. Hatsukami, at al. Effect of nonnicotine pharmacotherapy on smoking behavior. Pharmacotherapy, 2001; 21: 1530-1548.

57. Benowitz, N.L. and M.W. Peng. Non-nicotine pharmacotherapy for smoking cessation. CNS Drugs, 2000; 13: 265-285.

58. Hurt, R.D., D.P. Sachs, E.D. Glover, et al, A comparison of sustained-release bupropion and placebo for smoking cessation. N Engl J Med, 1997: 337 (17): 1195-202.

59. Hall, S.M., V.I. Reus, R.F, Munoz, et al. Nortriptyline and cogritive-behavioral therapy in the treatment of cigarette smoking. Arch Gen Psychiatry, 1998; 55 (8): 683-90.

60. Hughes, J.R., L.F. Stead, and T, Lancaster. Antidepressants for smoking cessation, in "The Cochrane Library, Issue 1, 2004, John Wiley \& Sons, Ltd.: Chicester, UK.

61. Silagy, C., T. Lancaster, L. Stead, et al. Nicotine replacement therapy for smoking cessation (Cochrane Review), in The Cochrane Library, Issue 1, 2004, John Wiley \& Sons Ltd: Chicester, UK.

62. Robinson, T.E. and K.C. Berridge. The psychology and neurobiology of addiction: an incentivesensitization view. Addiction, 2000; 95 (Suppl 2): \$91-\$117. 
Psychological distress and depressed mood in employees with asthma, chronic bronchitis or emphysema: A population-based observational study on prevalence and the relationship with smoking cigarettes

Wagena EJ, Kant I], Huibers MJH, van Amelsvoort LGPM, Swaen GMH, Wouters EFM, van Schayck CP

EUROPEAN JOURNAL OF EPIDEMIOLOGY, 2004; 19: 147-153 


\section{Abstract}

\section{OBJECTTVES}

To evaluate if employees with asthma, chronic bronchitis or emphysema can be characterized as a population of parients with a high prevalence of psychological distress and/or depressed mood. Above all, we wanted to examine the influence of smoking status on the relationship between chronic disease and psychological distress/depressed mood.

\section{METHODS}

A postal survey was conducted among 12,103 employees participating in the Maastricht Cohort Study.

\section{RESULTS}

Smoking employees, who reported having asthma, chronic bronchitis or emphysema were more likely to report suffering from depressed mood compared to smokers with no long-lasting disease (prevalence rate, PR: 29.3 and 9.0\%, respectively; OR for depressed mood $=4.04 ; 95 \% \mathrm{CI}: 2.56-6.39$ ) and when compared to smoking employees with a history of heart disease, hypertension or myocardial infarction (PR: 18.1\%; OR: 1.99; 95\% CI: 1.07-3.68), or rheumatoid arthritis (PR: $20.1 \%$; OR: $1.73 ; 95 \%$ CI: $0.96-3.11$ ).

\section{CONCLUSION}

These findings provide health care professionals with additional evidence regarding the importance for including the assessment of psychological distress and depressed mood in the routine evaluation of the patient with asthma, chronic bronchitis or emphysema, especially with regard to smoking cessation. 


\section{Introduction}

Respiratory disease (e.g. asthma and chronic bronchitis or emphysema [also referred to as chronic obstructive pulmonary disease, i.e. COPD]) is an important cause of temporary disability as expressed by sickness absence in both men and women [1]. About 10 years ago almost $9 \%$ of all GP consultations and about $13 \%$ of all absenteeism due to illness was caused by asthma and COPD [2].

In asthma patients, years of clinical observation have led to the perception that cigarette smoke can trigger acute symptoms [3]. For example, in a recent casecontrol study, current smoking was found to increase asthma severity [4]. Also, patients with asthma who continue to smoke cigarettes may well develop COPD. In patients with COPD, smoking cigarettes is the main cause of the disease in $80-90 \%$ of the cases. This disease is rare in lifetime non-smokers. Because the main cause of the disease is exposure to cigarette smoke, COPD is largely preventable. Furthermore, the main preventive measure in reducing the (accelerated) decline in lung function in patients with COPD is smoking cessation (conform guidelines for the management of COPD [5-8]).

Smoking cessation is the single most important way of affecting outcome in patients at all stages of the disease. As a result, temporary disability caused by respiratory disease may well be prevented if employees with asthma or COPD stop smoking. Smoking cessation (and as a result preventing absenteeism) has become a national priority in the US and many other countries. However, the effectiveness of smoking cessation programs can be influenced by the co-existence of depression. Both depression and depressive symptoms are associated with failure to quit smoking and relapse. Smokers with a history of or current major depression have lower quit rates than smokers with either no current or past depression [9]. A likely explanation is that smokers with a history of or current depression experience tobacco withdrawal symptoms more severely [10]. Depression-prone smokers are much less likely to sustain abstinence from smoking, especially because smoking cessation can contribute to the occurrence of depression during the post-cessation period [10].

Many different groups of chronically ill patients exhibit significant elevated scores on depression and/or other psychiatric disorder scales, and hence such elevations might not be a specific feature of patients with asthma or COPD [11, 12]. However, until now it is not clear if psychiatric disorders are more prevalent in patients with asthma or COPD compared to other chronically ill patients. Furthermore, although a positive relationship between psychiatric disorders and cigarette smoking has been well established $[9,13,14]$, it is still not clear how the 
presence of a chronic disease, smoking cigaretres and suffering from a psychiatric disorder are intertwined. For a continuation of the effect of smoking cessation. strategies in patients with asthma or COPD, it is essential to gain more insight in this triad.

The objective of this study is to evaluate if employees with asthma or COPD can be characterized as a population of patients with a high prevalence of psychological distress or depressed mood compared to other chronically ill employees and non-chronically ill employees. Above all, we will examine the influence of cigarette smoking on the relationship between chronic diseases on the one hand and psychological distress and/or depressed mood on the other in a population-based sample of employees.

\section{Methods}

\section{RESPONDENTS}

We used cross-sectional data from the Maastricht Cohort Study, a prospective population-based cohort study described in detail by Kant et al. [15]. A total of 12,140 employees completed and returned the baseline questionnaire (overall response rate $45 \%$ ). Because we restricted the analyses to the employees aged between 18 and 65 years, the data of 12,103 employees were used for the analysis in this study.

\section{DATA COLLECTION PROCEDURES}

To determine the presence of chronic diseases, all participants were asked to complete a questionnaire on 19 diseases that was part of the baseline questionnaire. The assessment of chronic disease was thus self-reported. This procedure does not differ from other epidemiological studies $[4,16]$. Diseases included in the questionnaire have a prevalence of more than $2 \%$ in the general population and are long-lasting by nature. With this questionnaire, respondents were asked whether they were suffering from one or more of the 19 listed diseases at that moment. The diseases were described in a way that was easy to understand for all respondents.

For this study, respondents were selected if they reported suffering from asthma or COPD. Because a strong relationship exists between psychiatric morbidity and smoking cigarettes, the following control groups were selected from the total population of 12,103 employees. We wanted to select employees with a chronic disease in which smoking cigarettes is (one of) the main cause(s) of the disease and employees with a chronic disease to which smoking cigarettes is not causally related. 
As a result, we selected employees suffering from heart disease, hypertension or myocardial infarction and employees suffering from rheumatoid arthritis. To evaluate whether the prevalence of psychological distress or depressed mood is high in employees with a chronic disease, a "healthy" control group is required. The healthy control group in this study consisted of employees who reported not suffering from any of the 19 listed diseases.

\section{MEASURES}

The General Health Questionnaire (GHQ) is the most widely used screening test to detect psychological distress in medical practice and estimate the prevalence of non-psychotic psychiatric disturbances, especially anxiety and depression disorders, within various samples or sub-samples $[17,18]$. The Dutch translation of the 12-item version of the GHQ was used [19], in which each of the 12 items has four answering categories. For analysis the 4 category answer scale was dichotomized, resulting in a score ranging from 0 to 12 . A cut-off score of four was used to discriminate psychological distressed cases (score >4) and non-cases (score $<4)$, which according to a study in which cut-off scores of the GHQ were evaluated, shows a positive and negative predictive value of 71 and $78 \%$ respectively $[20]$. Because the GHQ detects various dimensions of symptomatology and is multidimensional [17], the Departments of Psychiatry and Epidemiology of Maastricht University developed one question to be used in epidemiological research to assess depressed mood: 'Did you feel down during most days of the last 2 weeks?'. Respondents could answer with 'yes' or 'no'. A recently published study showed that a single question can be accurate in assessing depression [21].

We defined respondents as smokers if they gave an affirmative response to the question 'Do you smoke every day?'. In addition, questions on demographic factors (age and gender) were asked.

\section{STATISTICAL METHODS}

Prevalence rates (PRs) of psychological distress and depressed mood were calculated for all groups selected, and for smokers and non-smokers separately by using $2 \times 2$ contingency tables. To compare the prevalence of psychological distress and depressed mood for the different groups, odds ratios (ORs) including 95\% confidence intervals ( $95 \% \mathrm{CIs}$ ) were computed.

The relationship between health status and psychological distress or depressed mood was studied in univariate logistic regression models, with selfreported psychological distress and depressed mood as the dependent variables and health status as independent variables. To determine whether these relationships 
were uniform in both smokers and non-smokers, we conducted stratified analysis. To reduce the initial model (largest model considered, including all covariates) to a final model we used a hierarchical backward elimination approach [22]. The importance of each possible covariate is verified by a comparison of the estimated coefficient for the model including that variable with the coefficient from the model without that variable. Because of validity reasons, we did not assess the importance of possible confounders by statistical testing. If a covariate did not contribute to a more precise estimation of the coefficient (narrower $\mathrm{CI}$ ), the variable was eliminated and a new; smaller model was fit. As a result, all analyses were adjusted for the following potential confounders: age and gender. Results from the logistic regression analyses are presented as ORs (as an estimation of the relative risk) and 95\% CIs. The statistical analyses were carried out using the Statistical Package for the Social Sciences (SPSS for Winclows version 10.0.5).

Dummy variables were created for the following disease pairs: (1) employees with asthma or COPD vs. healthy respondents; (2) Employees with asthma or COPD vs. employees with rheumatoid arthritis, and (3) employees with asthma or COPD vs. employees with a history of heart disease or myocardial infarction.

\section{Results}

The demographic characteristics sex, age and smoking status of the employees who responded to the baseline questionnaire of the Maastricht Cohort Study are presented in Table 1. Employees with asthma or COPD were least likely to be smokers compared to the three reference groups. In Table 2, the PRs of psychological distress and depressed mood are presented for the different groups. The PRs for psychological distress as assessed by the GHQ-12 and depressed mood were higher in the chronically ill groups compared to the healthy group. Compared to the healthy employees, significantly more employees with asthma or COPD reported suffering from psychological distress (GHQ-12: prevalence rate ratio [PRR] $=1.79 ; 95 \% \mathrm{CI}: \mathbb{1 1 . 4 0 - 2 . 2 9}$ ) and depressed mood (PRR $=2.53 ; 95 \% \mathrm{CI}: 1.91-3.35$ ). Compared to the other two groups of employees with a chronic disease, the PRs for the employees with asthma or COPD did not differ significantly. 


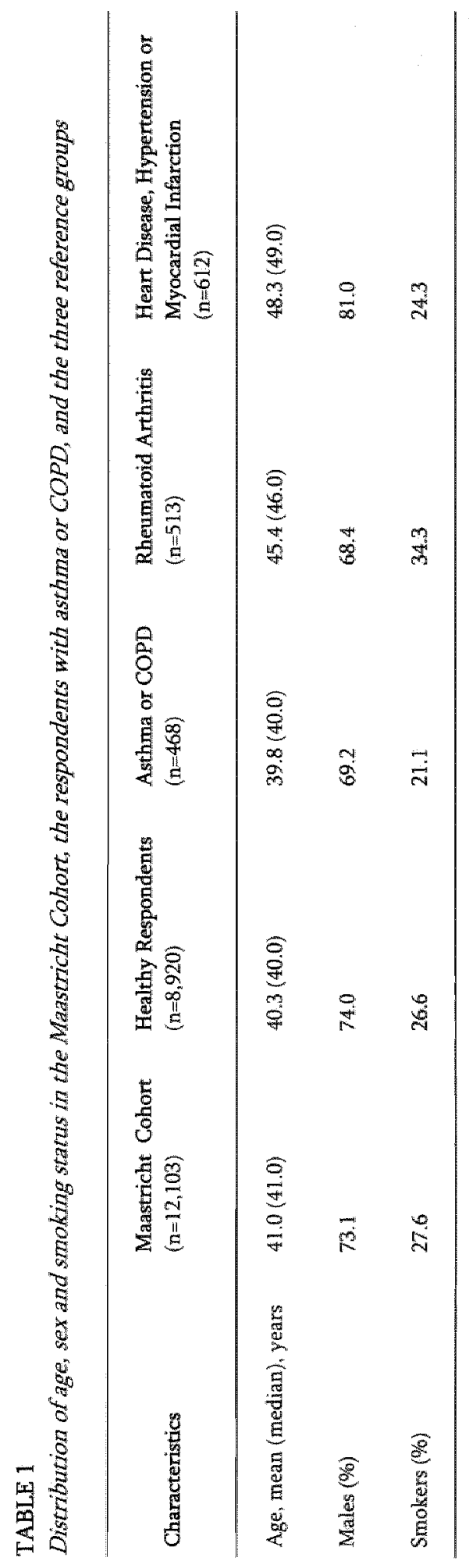




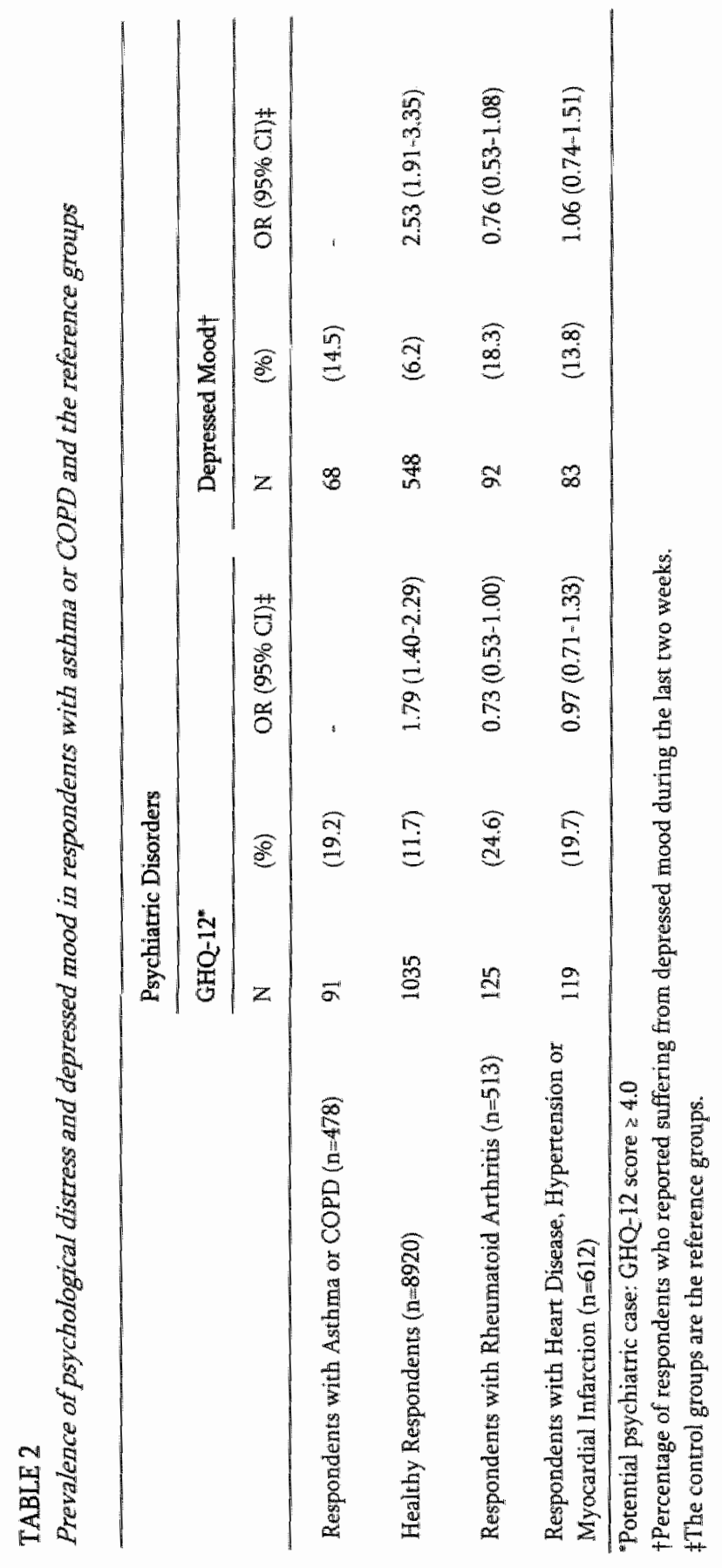


Table 3 shows the PRs for psychological distress and depressed mood for the different groups according to smoking status. Furthermore, the ORs for the comparison of prevalences among smokers and non-smokers are presented. In all groups (healthy controls and chronically ill employees) the PRs for psychological distress and depressed mood were higher for smokers compared to non-smokers. The difference between smokers and non-smokers is statistically significant for all comparisons when the GHQ-12 is used and is biggest in the group of employees with asthma or COPD (OR $=1.95,95 \% \mathrm{CI}: 1.14-3.23)$. However, when the prevalence of depressed mood is assessed, only within the group of healthy respondents (OR $=1.80,95 \% \mathrm{CI}: 1.50-2.15)$ and the employees with asthma or COPD (OR $=3.52,95 \% \mathrm{CI}: 2.04-6.07)$ the difference between smokers and nonsmokers is statistically significant. Table 4 presents evidence regarding the relationship between health status, smoking status and psychological distress or depressed mood. Because the relationships that were studied did not change when we controlled for age and gender, only adjusted ORs are presented. Table 4 shows that compared to employees without a chronic disease, the risk of suffering from psychological distress or depressed mood was higher in smoking employees with asthma or COPD, (OR for psychological distress $=2.39,95 \%$ CI: $1.51-3.76$; OR for depressed $\operatorname{mood}=4.04 ; 95 \% \mathrm{CI}: 2.56-6.39$ ), as well as in the non-smokers group (OR for psychological distress $=1.64 ; 95 \%$ CI: $1.24-2.18$; OR for depressed $\operatorname{mood}=2.13$; 95\% CI: 1.50-3.03). Furthermore, employees with asthma or COPD who smoke seem to be most likely to report suffering from psychological distress and depressed mood.

When using the GHQ-12 it seems that employees with asthma or COPD are not more likely to report suffering from psychological distress compared to employees with heart disease, hypertension or myocardial infarction (OR smokers = $1.07,95 \%$ CI: $0.60-1.91$; OR non-smokers $=1.00,95 \%$ CI: $0.69-1.44$ ) or rheumatoid arthritis (OR smokers $=0.99,95 \% \mathrm{CI}: 0.57-1.94$; OR non-smokers $=0.75,95 \% \mathrm{CI}$ : $0.51-1.10$, respectively). However, the risk of suffering from depressed mood was higher in smoking employees with asthma or COPD compared to smoking employees with heart disease, hypertension or myocardial infarction (OR $=1.99$; 95\% CI: $1.07-3.68)$ and smoking employees with rheumatoid arthritis (OR $=1.73$; 95\% CI: 0.96-3.11). However, the comparison with this last group of employees did not reach significance.

To assess whether the relationship between health status and psychological distress/depressed mood is (statistically) different for smokers and non-smokers, pvalues are presented in Table 4. This relationship did not differ statistically when comparing the smokers and non-smokers on GHQ-12 scores. 


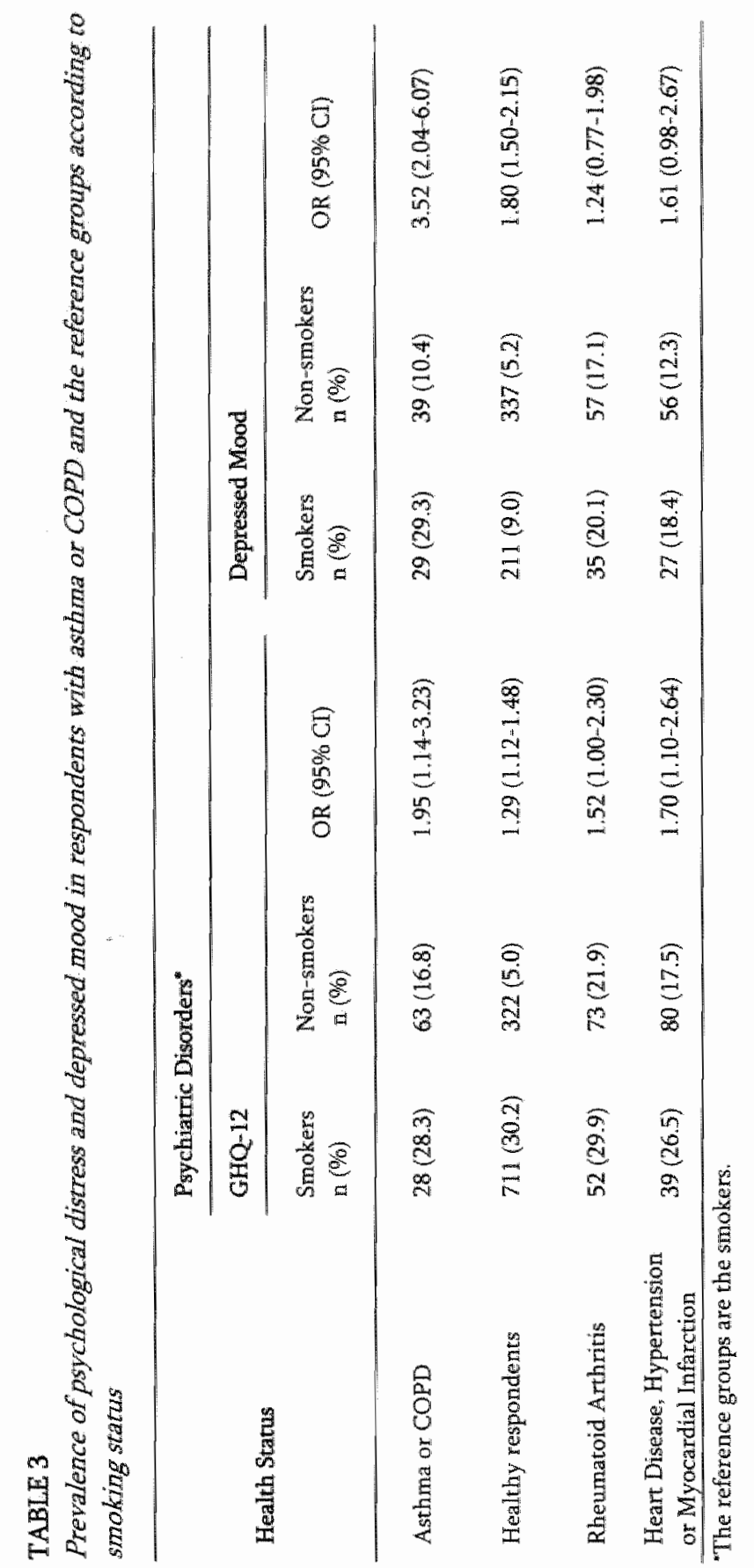




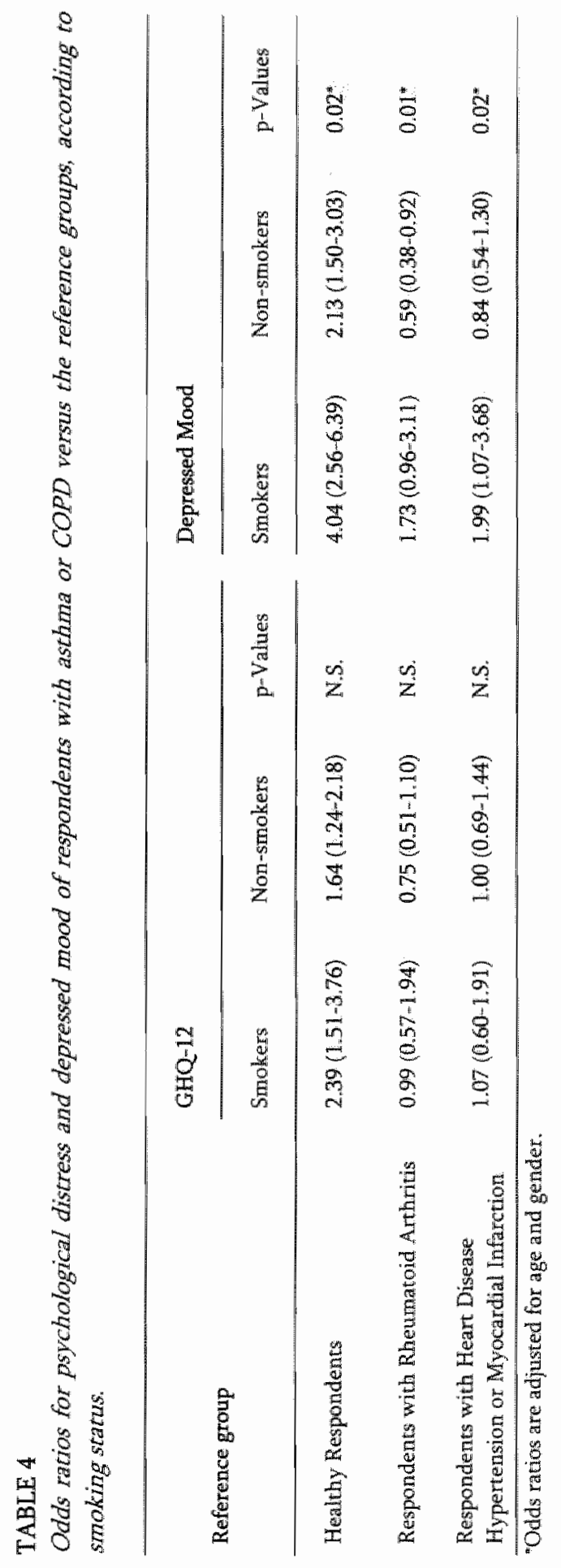




\section{Discussion}

The results found in this population based sample show that employees with asthma or COPD do not have a higher prevalence of psychological distress or depressed mood compared to other chronically ill employees. However, the data indicate that smoking status modifies the relationship between health status and psychological distress or depressed mood. As a result, compared to the smoking employees with heart disease, hypertension or myocardial infarction or rheumatoid arthritis, employees with asthma or COPD who smoke are more likely to suffer from depressed mood. We found that employees with asthma or COPD who smoke were three times more likely to report suffering from depressed mood compared to nonchronically ill smokers ( $\mathrm{OR}=4.04 ; 95 \% \mathrm{CI}: 2.56-6.39$ ), and almost twice as likely when compared to smoking employees with heart disease, hypertension or myocardial infarction (OR $=1.99 ; 95 \% \mathrm{CI}: 1.07-3.68$ ), or rheumatoid arthritis (OR = $1.73 ; 95 \%$ CI: $0.96-3.11$ ).

With regard to the question if employees with asthma or COPD are more likely to suffer from psychological distress or depressed mood compared to healthy employees or employees with a chronic disease, no existing literature is available. Although numerous studies have confirmed the finding that patients with a chronic disease are more likely to suffer from psychiatric disorders (e.g. depressed mood) compared to the general population, the authors could not find a study in which the prevalence of psychological distress or depressed mood in employees with asthma or COPD is compared to other employees with a chronic disease. Furthermore, no study was identified in which the role of smoking cigarettes on the relationship between chronic disease and psychiatric disorders in a working population was assessed. We found two studies in which the prevalence of depression was assessed in subjects with a chronic airway obstruction according to smoking status $[23,24]$. The findings from the study conducted by Van Manen and colleagues support our finding that smokers with COPD or asthma are more likely to report suffering from bad mental health (i.e. depressed mood) compared to non-smoking patients.

Our search of the literature suggests that the results presented in this paper are the first findings to demonstrate that the prevalence of depressed mood is higher in employees with COPD or asthma who smoke compared to other chronically ill employees who smoke and healthy smokers. This study is also the first to show that smoking status modifies the relationship between health status and psychological
distress or depressed mood. 
This study has several limitations. The first issue concerns the non-response in this study. An overall response rate of $45 \%$ at baseline is regarded to be reasonable for a survey in the working population, although results related to selective participation cannot be ruled out. The non-response analysis, however, demonstrated no differences in reported health complaints; demographic characteristics and smoking status between respondents and non-respondents.

Second, by using the baseline assessment of the Maastricht Cohort study, no distinction could be made between patients suffering from COPD or asthma. Although there is an important clinical overlap between asthma on the one hand and COPD patients with a chronic obstruction on the other, we do not know how many employees with asthma also had an (irreversible) airway obstruction. As a result, the relationship between health status, psychological distress or depressed mood and smoking cigarettes could be different for patients with COPD compared to those with asthma.

A third limitation pertains to the assessment of chronic disease. Using a list of multiple chronic diseases, respondents were asked to indicate if and which chronic disease they were suffering from. Because we could not evaluate the presence of any of the chronic diseases by using diagnostic instruments, misclassification of cases could therefore have occurred. If it occurred, it is expected to be non-differential. Therefore, the risk of psychological distress or depressed mood represented by ORs is biased towards unity. Furthermore, several studies have indicated that patients' self-reports of chronic diseases are generally fairly accurate $[25,26]$.

Finally, to detect depressive cases, we used a self-rating scale on which respondents had to answer with 'yes' or 'no'. Although this question was developed in close cooperation with the department of psychiatry, it was not validated in earlier studies. However, one might assume that it is highly correlated with the presence of depressive symptoms and depression.

What could explain the results found in this study? Differences in the prevalence of psychological distress or depressed mood between groups of patients with a 151 chronic disease, or between patients with a chronjic disease and healthy controls could be explained by a difference in severity of somatic symptoms. This might be an explanation for the differences we found in this study. However, because participants were still working, severity probably did not have a major influence on the relationship between chronic diseases, smoking cigarettes and psychiatric disorders. 
The observed role of smoking status on the relationship between chronic disease and psychological distress or depressed mood, and the differences found when assessing depressed mood compared to psychological distress, supports the hypotheses Wagena and colleagues postulated in their editorial [27]. These authors hypothesized about the strong relationship between chronic disease (i.e. COPD), smoking cigarettes and depression as opposed to any other psychiatric disorder [27]. In conclusion, although the limitations mentioned above do not allow firm conclusions about the causality between health status, psychological distress or depressed mood and smoking cigarettes, our findings provide health care professionals with additional evidence regarding the importance of including the assessment of a patient's mental health in the routine evaluation of the patient with asthma or COPD. As was stated before, the attempt to quit smoking and maintaining abstinent from smoking might be hampered by the co-existence of depression or some other psychiatric disorder. Therefore, for a continuation of the effect of inclividual treatments in patients with asthma or COPD, we recommend a holistic approach in which the possible co-existence of multiple problems is being integrated. 


\section{References}

1. Alexopoulos $\mathrm{EC}$. Burdorf A. Prognostic factors for respiratory sickness absence and return to work among blue-collar workers and office personnel. Occup Environ Med 2001; 58: 246-252.

2. Rutten-vara Möken MPMH, Van Doorslaer EKA, Rutten FFH. Economic appraísal of asthma and copd care: A literature review 1980-1991. Soc Sci Med 1992; 35: 161-175.

3. Floreani AA, Rennard SI. The role of cigarette smoke in the pathogenesis of asthrna and as a trigger for acute symptoms. Curr Opin Pulmon Med 1999; 5; 38-46.

4. Godtfredsen NS, Lange P, Prescott $E_{3}$ Osler M, Vestbo I. Changes in smoking habits and risk of astima: A longitudinal population based study. Eur Respir J 2001; 18: $549-554$.

5. American Thoracic Society. Standards for the diagnosis and care of patients with chronic obstructive pulmonary disease. Am J Respir Crit Care Med 1995; 152: 577-S121.

6. BTS guidelines for the management of chronic obstructive pulmonary disease: The COPD Guideline Group of the Standards of Care Committee of the BTS. Thorax 1997; 52(Suppl 5): S1-S28.

7. Pauwels RA, Buist AS, Calverley PM, Jenkins CR. Hurd SS. Global strategy for the diagnosis, management, and prevention of chronic obstructive pulmonary disease. NHLBI/WHO Global Initiative for Chronic Obstructive Lung Disease (GOLD) Workshop summary. Am J Respir Crit Care Med 2001; 163: 1256-1276.

8. Siafakas NM, Vermeire P, Pride NB, et al. Optimal assessment and management of chronic obstructive pulmonary disease (COPD). The European Respiratory Society Task Force. Eur Respir J 1995: 8: $1398-1420$.

9. Glassman AH, Helzer]E, Covey LS, et al. Smoking, smoking cessation, and major depression. JAMA 1990: $264: 1546-1549$.

10. Covey LS. Tobacco cessation among patients with depression. Prinary Care 1999; 26: 691-706.

11. Cassileth BR, Lusk EJ, Strouse TB, et al. Psychosocial status in chronic illness. A comparative analysis of six diagmostic groups. N Engl J Med 1984; 311: 506 -511.

12. Dudley DL, Glaser EM, Jorgenson BN, Logan DL. Psychosocial concomitants to rehabilitation in chronic obstructive pulmonary disease. Part I. Psychosocial and psychological considerations. Chest $1980 ; 77: 413-420$.

13. Glassman AH, Stetner F, Walsh BT, et al. Heavy smokers, smoking cessation, and clonidine. Results of a donble blind, randomized trial. JAMA 1988; 259: 2863-2866.

14. Lasser K, Boyd JW, Woolhandler S, Himmelstein DU, McCormick. D, Bor DH.. Smoking and mental illness: A population-based prevalence study. JAMA 2000; 284: 2606-2610.

15. Kant II, Bültmann U, Schroër CAP. Beurskens AJHM, wan Arnelswoort LGPM, Swaen GMH. An epidemiological approach to study fatigue in the working population: "lhe Matastricht Cohort Study. Occup Environ Med 2003; 60 (Suppl 1): :32-139.

16. Torén $\mathrm{K}$, Brisman /, Jarvholm B. Asthma and asthma like symptoms in adults assessed by questionnaires. Chest 1993; 104: 600-608.

17. Graetz B. Multidimensional properties of the General Health Questionnaire. Soc Psychiatry Psychiatr Lpidemiol 1991;26: 132-138.

18. Goldberg DP, Williams P. A User's Guide to the Genera! Health Questionnaire. Windsor: NFERNelson, 1988.

19. Koeter MW], Ormel J. General Health Questionnaire, handleiding Nederlandse bewerking [General Health Questionnaire, manual Dutch version]. Lisse: Swets \& Zeitlinger, 1991.

20. Van Hemert AM. Den Heijer M, Vorstenbosch M, Bolk TH. Detecting psychiatric disorders in medical practice using the General Health Questionnaire: why do cut-off scores vary? Psychol Med 1995; $25: 165-170$.

21. Watkins C, Daniels $\mathbb{L}_{x}$ Jack $\mathrm{C}$, Dickinson $\mathrm{H}$, wan den Broek. M. Accuracy of a single question in screening for depression in a cohort of patients after stroke: Comparative study. Br Med $12001 ; 323$ : 1159.

22. Klein baum DG. Logistic regression: A self-learning text. New York: Springer-Verlag, 1996. 
23. Van Manen IG, Bindels PJ, Dekker FW, Ifzermans Cj, van der Zee IS, Schadé E. Risk of depression in patients with chronic obstructive pulmonary disease and its determinants. Thorax 2002; 57:412416.

24. Van Manen JG, Bindels PJ, IJermans CJ, wan der Zee IS, Bottema BJ, Schadé E. Prevalence of comorbidity in patients with a chronic airway obstruction and controls over the age of 40.1 Clin Epidemiol 2001; 54:287-293.

25. Haapanen $\mathbb{N}$, Milunpalo S, Pasanen M, Oja P, Vuori I. Agreement between questionnaire data and medical records of chronic diseases in middle-aged and elderly Finnish men and women. Am I Epidemiol 1997; 145: 762-769.

26. Kriegsman DM, Penninx W, van Eijk JT, Boeke AJ, Deeg DJ. Self-reports and general practitioner information on the presence of chronic diseases in community dwelling elderly. A study on the accuracy of patients' self-reports and on determinants of inaccuracy. I Clin Epidemiol 1996; 49: $1407-1.417$.

27. Wagena El, Huibers MJ, van Schayck CP. Antidepressants in the treatment of patients with COPD: Possible associations between smoking cigarettes, COPD and depression. Thorax 2001; 56: 587-588. 
Risk of depression and anxiety in employees with chronic bronchitis:

The modifying effect of cigarette smoking

Wagena EJ, Kant IJ, van Amelsvoort LGPM, Wouters EFM, van Schayck CP, Swaen GMH

PSYCHOSOMATIC MEDICINE, 2004; 66: 729-734 


\section{Abstract}

\section{OBJECTIVE}

The present study evaluates whether smoking status modifies the association between chronic bronchitis and depression or anxiety in a population-based sample. Furthermore, we tested whether these associations are different in people without any respiratory complaints and those with asthma.

\section{METHODS}

For this study, we used cross-sectional data form the Mastricht Cohort Study, a population- based cohort study among Dutch employees.

\section{RESULTS}

In total, 7482 employees completed and returned the questionnaire (92.7\%). In employees with chronic bronchitis, the prevalence of depression and anxiety was significantly higher compared with healthy employees and employees with asthma. Results indicate that the odds of having comorbid depression or anxiety for employees with chronic bronchitis compared with healthy employees is highest in current and past smokers, indicating that smoking status modifies this association.

\section{CONCLUSION}

Chronic bronchitis is strongly associated with depression and anxiety. Because depression and/or anxiety may not only interfere with an attempt to stop smoking but also contribute significantly to experiencing low quality of life, it is important to consider these disorders and chronic bronchitis as different disease entities. Prospective longitudinal studies are needed to elucidate the mechanisms underlying the association among chronic bronchitis, psychiatric disorders, and cigarette smoking. 


\section{Introduction}

Respiratory disease such as chronic bronchitis is an important cause of temporary disability as expressed by sickness absence in both men and women (1). Approximately 10 years ago, almost $9 \%$ of all general practitioner consultations and approximately $13 \%$ of all absenteeism as a result of illness were caused by asthma and chronic bronchitis or emphysema (i.e., chronic obstructive pulmonary disease [COPD] (2)). Chronic bronchitis prevalence, morbidity, and mortality vary across countries and across different groups within countries but are in general directly related to the prevalence of tobacco smoking (3). In the developed world, smoking accounts for at least $75 \%$ of cases with chronic bronchitis $(4,5)$. Because the main cause of the disease is exposure to cigarette smoke, chronic bronchitis is largely preventable. Furthermore, in the treatment of patients who already have been diagnosed with chronic bronchitis, the main preventive measure in reducing the decline in lung function is smoking cessation (as recommended by international guidelines for the management of chronic bronchitis; 3, 6-8). Smoking cessation is the most effective way to reduce the risk of developing chronic bronchitis $(9,10)$. Also, it can prevent or delay the development of aifflow limitation or reduce its progression.

Smoking cessation has become a national priority in the United States and many other countries. However, the effectiveness of smoking cessation programs is influenced by the coexistence of psychiatric disorders such as depression and anxiety. Both depression and depressive symptoms are associated with failure to quit smoking and relapse. Smokers with a history of or current major depression have lower quit rates than smokers with either no current or past depression (11). A likely explanation is that smokers with a history of depression or current depression experience tobacco withdrawal symptoms more severely (12). Furthermore, because depression, depressed mood or anxiety can occur during withdrawal from nicotine and because smoking cessation can contribute to the occurrence of depression during the post cessation period, depression-prone smokers are much less likely to remain abstinent from smoking (12).

Many different groups of chronically ill patients have high prevalence rates of depression or score higher on psychiatric disorder scales (13). Therefore, high prevalence of depression and anxiety might not be specific features of patients with chronic bronchitis $(14,15)$. Although many clinicians and researchers remain. uncertain about the exact status of psychiatric disorders in patients with a chronic disease, the physical illness itself is often considered to be reason enough for patients to be depressed (16). Comorbid psychiatric disorders are therefore often regarded as 
a complication of the physical complaints. As a result, comorbid psychiatric disorders complicating chronic bronchitis are regularly overlooked and often remain undiagnosed and under treated (16).

The objectives of this study are threefold. First, we wanted to evaluate whether people with chronic bronchitis can be characterized as a group of patients with a high prevalence of depression and anxiety compared with people without any respiratory complaints. Second, because patients with asthma also suffer from a chronic inflammatory disorder, but with a different nature of inflammation, $(17,18)$ we wanted to evaluate whether the prevalence of depression and anxiety is different in this group of patients compared with patients with chronic bronchitis. Third, although a positive association among depression, anxiety, and cigarette smoking is well established (see Dierker et al. (19) for an overview; 11, 20, 21) it is still not clear how the presence of chronic bronchitis, smoking cigarettes, and psychiatric disorders are intertwined. Therefore, we examined whether smoking status modifies the association between chronic bronchitis and psychiatric comorbidity and tested whether these associations are different in people without any respiratory complaints and those with asthma.

\section{Methods}

\section{SAMPLE}

We used cross-sectional data from the Maastricht Cohort Study, a prospective population-based cohort study described in detail by Kant et al. (22) In January 2001 we sent a questionnaire on respiratory complaints, depression and anxiety, and smoking to 8070 employees. In total, 7482 employees completed and returned the questionnaire $(92.7 \%)$. Data from 494 respondents $(6.6 \%)$ were excluded from the analyses because they forgot to fill out part of the stem and leaf questions on smoking behavior. Furthermore, 93 respondents (1.2\%) had missing values on any of the other variables used in this study (i.e., dependent, independent, or demographic variables) and were therefore excluded. For this study, we also excluded a) employees who reported suffering simultaneously from chronic bronchitis" and asthma (or asthmatic bronchitis), and b) employees who reported suffering from any of respiratory symptoms, but who did not fulfil the diagnostic criteria for chronic bronchitis or asthma. As a result, another 1267 respondents (16.9\%) were excluded. For this article, we restricted the analyses to the data collected from 5628 employees. 


\section{ASSESSMENT OF CHRONIC BRONCHITIS AND ASTHMA}

To determine the presence of chronic bronchitis and asthma, all participants were asked to complete a self-report questionnaire on respiratory complaints and diagnoses. This procedure has been used in several other epidemiological studies (4, 15). The diagnoses were described in a way that was easy to understand for all respondents.

In clinical terms, chronic bronchitis is usually defined by the presence of chronic or recurrent increases in bronchial secretions sufficient to cause expectoration and cough (23). In this study, chronic bronchitis conforms to the definition and classification of chronic bronchitis for clinical and epidemiological purposes proposed by the Medical Research Council: "the presence of cough and sputum production on most days for a minimum of 3 months per year, in the previous 2 successive years, and cannot be attributed to other pulmonary or cardiac causes" $(24,25)$. Furthermore, respondents were asked whether a clinician or family physician had ever diagnosed asthma.

\section{ASSESSMENT OF DEPRESSION AND ANXIETY}

We used the validated Dutch version of the Hospital. Anxiety and Depression Scale (HADS; 26). The HADS was developed by Zigmond and Snaith (27) originally to identify caseness (possible and probable) of anxiety and depression among patients in nompsychiatric hospital clinics. Spinhoven et al. (26) found that the Dutch version of the HADS was stable across different age groups from the general population and in different clinical samples. It is divided into an anxiety subscale and a depression subscale, each containing seven items. Each question is rated 0 to 3,

giving a possible maximum score for anxiety and depression of 21 . Subjects scoring 11 or more on the depression subscale were classified as being depressed, and subjects scoring 11 or more on the anxiery subscale were classified as being anxious. To prevent bias from somatic disorders on the scores, symptoms of anxiety or depression also relating to a physical disorder, such as dizziness, headaches, insomnia, and fatigue, have never been included in the questionnaire (28).

\section{ASSESSMENT OF SMOKING STATUS}

Questions regarding the smoking habits of employees refer only to cigarette smoking. To assess the smoking status of respondents, we asked them whether they smoked cigarettes on a daily basis, and whether they used to smoke every day in the past. We defined respondents as never smokers if they answered no to both questions. Past smokers were defined as giving an affirmative response only to the second question, and current smokers if they gave an affirmative response to the 
question, "Do you smoke every day?" We also assessed how many cigarettes they smoked or used to smoke on average per day.

\section{STATISTICAL PROCEDURES}

We distinguished 3 subgroups: a) employees with chronic bronchitis, b) employees with asthma, and c) employees without any respiratory symptoms or diagnosis of lung disease. First, the Student $t$ test and Pearson $\chi^{2}$ test were used to determine differences in demographic characteristics between the 3 groups. Next, multivariate logistic regression analyses were performed to calculate odds ratios (ORs; with 95\% confidence intervals [CIs]) for the association between chronic bronchitis, asthma, smoking status, and (individual) potential confounders on the one hand and psychiatric morbidity (i.e., depression and anxiety) on the other, adjusted for all other study variables. Third, logistic regression analyses were conducted to evaluate the association between the presence of respiratory complaints (i.e., the presence of chronic bronchitis or asthma) and depression or anxiety. Results were adjusted for sex, age, educational level, and the presence of one or more chronic disease (as assessed by a list of diseases that have a prevalence of more than $2 \%$ in the general population and are long-lasting by nature). Fourth, prevalence rates of depression and anxiety were calculated for the same groups, and for never-smokers, past smokers, and current smokers separately by using contingency tables. Finally, to determine whether these associations were similar in current smokers, past smokers, and never-smokers, we conducted stratified analysis. The statistical analyses were performed using SAS release 8.02 (SAS Institute Inc., Cary, NC, USA).

\section{Results}

Table 1 shows the demographic characteristics separately for employees with chronic bronchitis $(N=357)$, employees with asthma $(N=373)$, and employees without any respiratory complaints $(N=4898)$. All 3 groups consisted mainly of men (more than $70 \%$ ). Compared with the group of employees with asthma and the group without respiratory complaints, the percentage of smokers in the group of employees with chronic bronchitis was significantly higher $\left(\chi^{2}=113.0 ; d f=2 ; p<\right.$ $.001 ;$ and $\chi^{2}=75.9 ; d f=2 ; p<.001$, respectively), in addition to the percentage of smokers who smoke on average more than 10 cigarettes per day $\left(x^{2}=30.2 ; d f=2 ; p<\right.$ $.001 ;$ and $x^{2}=31.3 ; d f=2 ; p<.001$, respectively). 


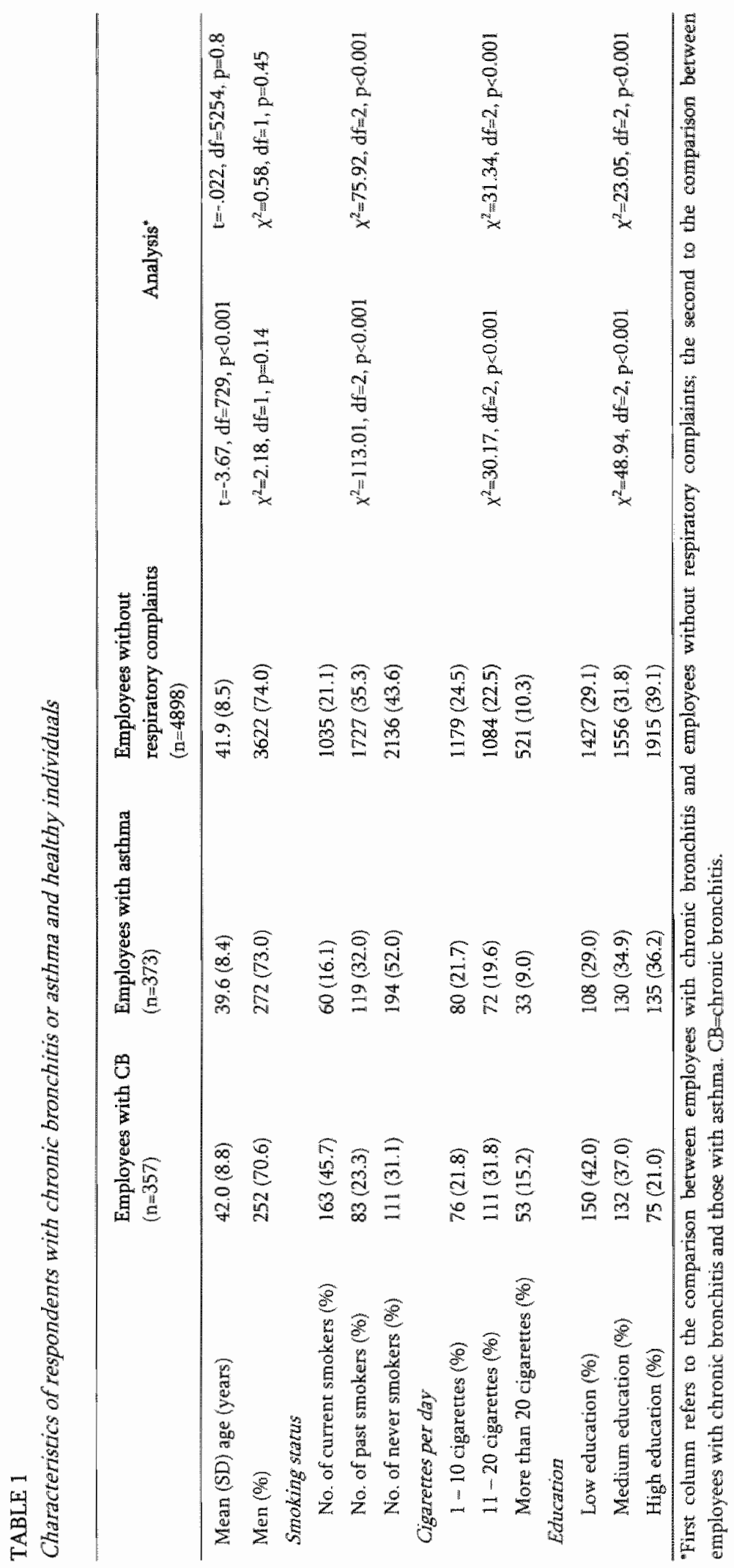




\section{ASSOCIATTON BETWEEN CHRONIC BRONCHITIS AND PSYCHLATRIC}

MORBIDITY

In Table 2, we present the ORs for the association among chronic bronchitis, asthma, smoking status, and potential confounders separately on the one hand and depression and anxiety on the other, adjusted for all other study variables. The results indicate that the presence of chronic bronchitis was associated with a significantly higher likelihood of depression and anxiety compared with healthy employees even when adjusted for smoking status (OR for depression $=2.53,95 \% \mathrm{CI}$ $1.78-3.61$; OR for anxiety $=3.29,95 \%$ Cl $2.40-4.51$ ). Furthermore, being a smoker or former smoker was significantly associated with neither depression (OR current smokers vs. never smokers $=0.80,95 \%$ CI $0.61-1.05$; OR past smokers vs. never smokers $=1.13,95 \% \mathrm{CI} 0.88-1.45)$ nor anxiety (OR current smokers vs. never smokers $=0.89,95 \% \mathrm{CI} 0.66-1.20 \%$ OR past smokers vs. never smokers $=1.16,95 \%$ CI $0.88-1.52$ ).

\section{TABLE 2}

Adjusted odds ratios for the association between individual study variables and psychiatric unorbidity in Dutch employees

\begin{tabular}{|c|c|c|}
\hline & $\begin{array}{l}\text { OR for Depression } \\
(95 \% \mathrm{Cl})\end{array}$ & $\begin{array}{l}\text { OR for Anxiety } \\
(95 \% \text { CI })\end{array}$ \\
\hline Chronic Bronchitis & $2.53(1.78-3.61)$ & $3.29(2.40-4.51)$ \\
\hline Asthmab" & $1.06(0.67-1.67)$ & $1.26(0.84-1.89)$ \\
\hline Current smokerse & $0.80(0.61-1.05)$ & $1.13(0.88-1.45)$ \\
\hline Past smokers & $0.89(0.66-1.20)$ & $1.16(0.88-1.52)$ \\
\hline Men & $1.03(0.79-1.34)$ & $0.66(0.52-0.83)$ \\
\hline Age (per 10 years) & $1.14(0.98-1.31)$ & $1.14(1.00-1.30)$ \\
\hline High educational heved & $0.79(0.60-1.05)$ & $0.85(0.66-1.10)$ \\
\hline Middle educational level & $0.98(0.74-1.30)$ & $0.80(0.62-1.04)$ \\
\hline One or more chronic disease present & $1.87(1.45-2.41)$ & $2.08(1.66-2.62)$ \\
\hline
\end{tabular}

"Odds ratios are adjusted for all other study variables.

The reference group consisted of employees without any respiratory complaints.

"The reference group consisted of employees who had never smoked.

ithe reference group consisted of employees with low educational hevel. 
Table 3 shows that the prevalence rates of depression and anxiety were highest in employees with chronic bronchitis $(12.6 \%, N=45$; and $17.6 \%, N=63$, respectively). Table 3 also shows that the presence of chronic bronchitis was associated with a significantly higher likelihood of depression and anxiety compared with healthy employees (adjusted $\mathrm{OR}$ for depression $=2.55,95 \% \mathrm{CI} 1.80-3.61$; adjusted $O R$ for anxiety $=3.33,95 \%$ CI $2.44-4.55$ ) and compared with employees with asthma (adjusted OR for depression $=2.51,95 \% \mathrm{CI} 1.45-4.35$; adjusted OR for anxiety $=2.73,95 \%$ CI $1.68-4.45)$.

ASSOCIATION BETWEEN CIGARETTE SMOKING, CHRONIC BRONCHITIS, AND PSYCHIATRIC MORBIDITY

Table 4 presents the adjusted ORs for the association between the presence of respiratory complaints (i.e., chronic bronchitis or asthma) and depression or anxiety, stratified for smoking status. Results indicate that compared with employees without any respiratory complaints, employees with chronic bronchitis had an increased prevalence of depression and anxiety, regardless of their smoking status. However, the odds of having depression or anxiety for employees with chronic bronchitis compared with employees without respiratory complaints seem to be highest in the past smokers and smokers groups. 


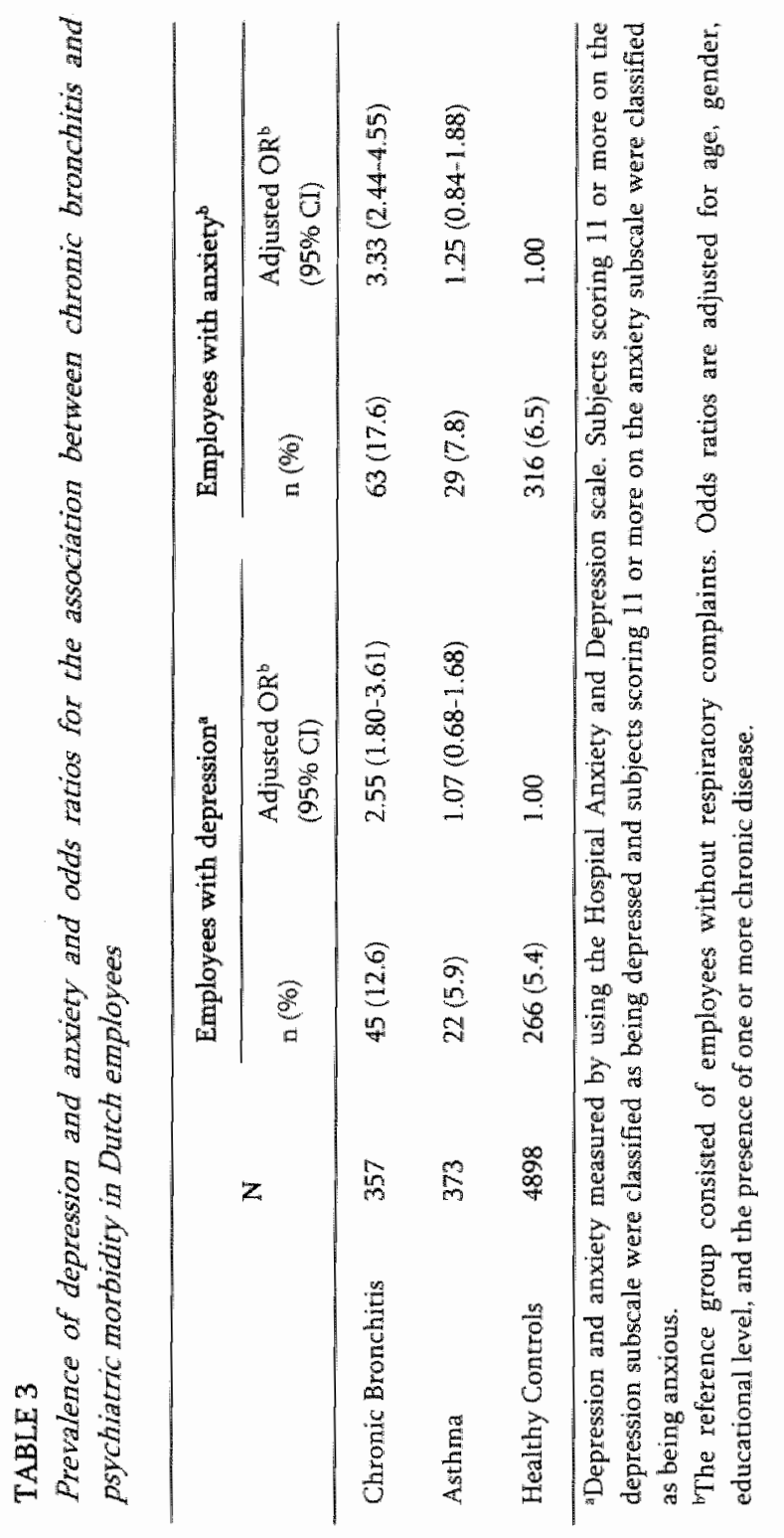




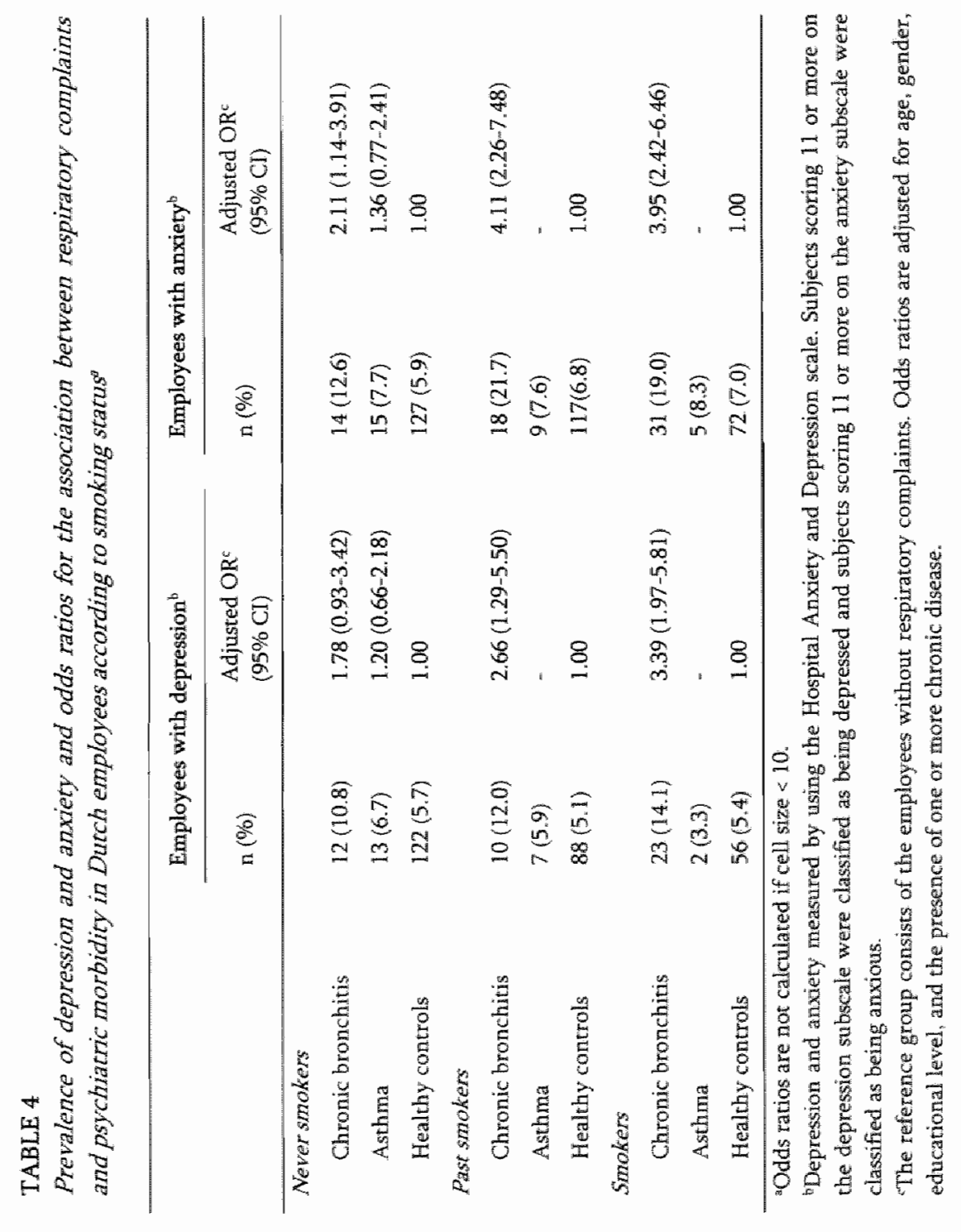




\section{Discussion}

In a population-based sample of Dutch employees (consisting mainly of middle-aged men), we found that the point prevalence of depression and anxiety in parients with chronic bronchitis was $12.6 \%$ and $17.6 \%$, respectively. These data suggest that compared with employees with asthma and employees without any respiratory complaints, the prevalence of depression and anxiety was significantly higher in employees with chronic bronchitis. Of primary interest was the finding that the association between chronic bronchitis and psychiatric morbidity was different for smokers, past smokers, and never smokers, indicating that smoking status modifies this association in a population of Dutch employees. In addition, the odds of having comorbid depression or anxiety were highest in employees with chronic bronchitis who smoke or used to smoke, and were significantly higher in these groups compared with healthy employees.

To our knowledge, the present study is the first to examine the association among the presence of chronic bronchitis, psychiatric morbidity, and cigarette smoking. Although numerous studies have confirmed the finding that patients with a chronic disease are more likely to have depression or anxiety compared with the general population, the authors could not find a study in which the association between chronic bronchitis and psychiatric morbidity was assessed in large population-based sample. Van Ede et al. conducted a systematic review to achieve a more definite answer to the question whether patients with COPD showed a higher than normal prevalence of depression. They concluded that the empirical evidence for a significant risk of depression in these patients remained inconclusive, mainly because of the poor methodological quality of most of the published studies, the absence of a control group, and the lack of studies with an adequate sample size. Recently, Van Manen et al. (29) showed that the risk of depression was significantly increased in patients with a chronic irreversible obstruction and in patients with COPD with severe impaired physical functioning. However, they did not study the role of cigarette smoking. Furthermore, it is expected that most of the patients with COPD did not work any more, because the average age of that group was a little greater than 65 years. Also, although in several studies the presence of anxiety was assessed in patients with COPD, most studies did not include a control group or presented average scores on an anxiety scale. In one study, it was found that patients with asthma or chronic bronchitis had higher mean ratings for anxiety compared with people without these disorders (30). 
Several mechanisms may be responsible for the observed association between chronic bronchitis, depression and anxiety, and cigarette smoking. Although many clinicians and researchers remain uncertain about the exact status of depression and anxiety in patients with a chronic disease (31), the physical illness itself is often considered to be reason enough for patients to feel depressed or anxious. The presence of these psychiatric complaints is therefore often regarded as a complication of the physical complaints (16). The results found in this study could be explained by a difference in severity of somatic symptoms. Because the nature of the inflammation affects the response to pharmacological agents $(17,18)$, which means that the treatment with inhalled corticosteroids is effective against the inflammation in asthma but not in COPD, patients with chronic bronchitis might feel more depressed or anxious when thinking of a future exacerbation. These feelings could even increase further if patients with chronic bronchitis experienced low self-efficacy of symptoms management. A number of studies have shown that the risk of depression and anxiety increases by increasing severity of respiratory complaints (30, 32). Furthermore, McCathie et al. (33) showed that psychological factors like a low sense of personal mastery or efficacy regarding the management of symptoms is associated with higher levels of depression and anxiety. In smokers, the risk of psychiatric comorbidity might increase even further compared with nonsmokers because of a negative self-evaluation when they compared themselves with peers regarding sports and activities of daily living. This is being supported by the finding that during pulmonary rehabilitation, depression and anxiety decreased as the patients' performance of daily living activities increased (34).

This study has several limitations. The first limitation pertains to the assessment of respiratory complaints and psychiatric morbidity. To determine the presence of chronic bronchitis and asthma, all participants were asked to complete a questionnaire on respiratory complaints and diagnoses. The assessment of (chronic) respiratory disease was thus self-reported. We could not evaluate the presence of chronic bronchitis or asthma by using diagnostic instruments. As a result, we may have systematically overrated or underrated the presence of chronic bronchitis or asthma. Misclassification of cases may therefore have occurred. However, if it occurred, it is expected to be non-differential. Misclassification may also have occurred in the diagnosis of depressive disorders. Participants tend to underreport depressive symptoms, which will have resulted in an underestimation of the true point prevalence rates of depression and anxiety. However, because it is expected that the underreporting is not selective, it will not have introduced a major bias in our study. 
Second, because the study population consisted of a relatively healthy population (i.e., employees), it is likely that relatively fewer patients with a severe chronic disease were included because they were still working. This might well have resulted in a lower prevalence of depression and anxiety in the group with chronic bronchitis compared with people with chronic bronchitis in the Dutch general population.

Third, given the cross-sectional design of the study, this study cannot show whether the observed association with depression and anxiety precipitates or results from chronic bronchitis.

In conclusion, in this population-based study, we found a strong association between the presence of chronic bronchitis and depression and anxiety. We also found that smoking cigarettes modifies this association, resulting in an increased risk for depression and anxiety in employees with chronic bronchitis who smoke or used to smoke. As depression and anxiety remain easily undiagnosed because of underpresentation and because the symptoms are not very specific, it is important to consider the presence of these disorders in employees with chronic bronchitis. Depression and/or anxiety might not only interfere with an attempt to stop smoking but also contribute significantly to experiencing low quality of life. The quality of life of patients with chronic bronchitis may be particularly complicated by a concurrent psychiatric disorder, which may bring the patient into a vicious circle (35): the presence of a psychiatric disorder lowers the force needed to cope with the chronic disease, the physical symptoms become less tolerable, and the psychosocially debilitating effect of the disease may be enforced by feeling depressed or anxious. To elucidate further the mechanisms underlying the association between chronic bronchitis, depression and anxiety, and cigarette smoking, prospective longitudinal studies are needed.

\section{Funding/Support}

The Maastricht Cohort Study is part of the Netherlands concerted research action on Fatigue at Work, granted by The Netherlands Organization for Scientific Research. The work presented in this paper was supported by the Dutch Asthma Foundation (NAF grant no. 3.2.00.21) and the Health Research and Development Council (ZorgOnderzoek Nederland grant no. 2200.0111), The Netherlands. 


\section{References}

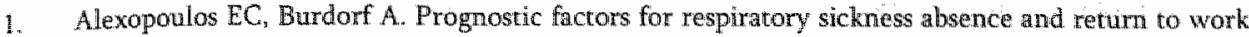
annong blue-collar workers and office personnel. Occup Enwiron Med 2001; 58: 246-252.

2. Rutten-van Mölken MPMH, Van Doorslaer EKA, Rutten FFH. Economic appraisal of asthma and COPD care: a literature review 1980-1991. Soc Sci Med 1992; 35: 161-175.

3. Pauwels RA, Buist AS, Calverley PM, Jenkins CR, Hurd SS. Global strategy for the diagnosis, management, and prevention of chronic obstructive pulmonary disease. NHLBB/WWHO Global Initiative for Chronic Obstructive Lung Disease (GOLD) Workshop surmary. Am I Respir Crit Care Med 2001; 163" 1256-1276.

4. Roche $\mathrm{N}$, Huchon $\mathrm{G}$ ]. Current issues in the management of chronic obstructive pulmonary disease. Respirology 1,997; 2: 215-229.

5. US Department of Health and Human Services The health consecuences of smoking: chronic obstructive lung disease. Rockwille, MD: Office on Smoking and Health, Department of Health and Human Services; 1984.

6. American Thoracic Society. Standards for the diagnosis and care of patients with chronic obstructive pulmonary disease. An J Respir Crit Care Med 1995; 52: S77-S121.

7. BTS guidelines for the management of chronic obstructive pulmonary disease: the COPD Guideline Group of the Standards of Care Committee of the BTS. Thorax 1997; 52 (Suppl 5): S1-S28.

8. Siafakas NM, Vermeire P, Pride NB, Paoletti P, Gibson J. Howard P, Yernault JC, Decramer M, Higenbottam T, Postma DS. Optimal assessment and management of chronic obstructive pulmonary disease (COPD). The European Respiratory Society Task Force. Eur Respir ) 1995; 8; $1398-1420$.

9. Anthonisen NR, Connett JE, Kiley JP, Alose MD, Bailey WC Buist AS, Conway WA Jr, Enright PI, Kanner RE, O'Hara P, Scanlon PO, Tashkin DP, Wise RA. Effects of smoking intervention and the use of an inhaled anticholinergic bronchodilator on the rate of decline of FEV1. The Lung Health Study. JAMA 1994; 272: 1497-1505.

10. Xu X, Dockery DW, Ware JH, Speizer FE, Ferris BG. Effects of cigarette smoking on rate of loss of pulmonary function in adults: a longitudinal assessment. Am Rev Respir Dis 1992; 146: 1345-1348.

11. Glassman AH, Helzer JE, Covey LS, Cottler LB, Stetner F, "Tipp JE, Johnson J. Smoking, smoking cessation, and major depression. IAM.A 1990; 264: 1546-1549.

12. Covey LS. Tobacco cessation among patients with depression. Primary Care 1999; 26: 691-706.

13. Franssen PML, Bu"Itmann U, Kant 1, wan Amelswoort LGPM. The association between chronic diseases and fatigue in the working population. J Psychosom Res 2003; $54: 339-344$

14. Cassileth BR, Lusk EI, Strouse TB, Miller DS, Brown LL, Cross PA, Tenaglia AN. Psychosocial status in chronic illness: a comparative analysis of six diagnostic groups. N Engl I) Med 1984:311:506-511.

15. Dudley DL, Glaser EM, Jorgenson BN, Logan DL. Psychosocial concomitants to rehabilitation is chronic obstructive pulmonary disease, part I: psychosocial and psychological considerations. Chest 1980; $77: 413-420$.

16. Peveler $\mathrm{R}$, Carson A, Rodin G. ABC of psychological medicine: depression in medical patients. BMJ 2002; 325: 1.49-152.

17. Buist A.S. Similarities and differences between asthma and chronic obstructive pulmonary disease: treatment and early outcomes. Eur Respir 1 2003; 21: \$30-\$35.

18. Barnes PJ. Mechanisms in COPD: differences from asthma. Chest 2000; 117: S10-\$14.

19. Dierker LC, Avenevoli S, Stolar M. Merikangas KR. Smoking and depression: an examination of mechanisms of comorbidity. Am / Psychiatry 2002; 159: 947-953.

20. Glassman AH, Stetner F, Walsh BT, Raizman PS, Fleiss /L, Cooper TB, Covey LS. Heavy smokers, smoking cessation, and clonidine: results of a double blind, randomized trial. JAMA 1988: 259: $2863-2866$.

21. Lasser K, Boyd JW, Woolhandler S, Himmelstein DU, McCormick D, Bor DH. Smoking and mental illness: a population-based prevalence study. JAMA 2000;284: 2606-2610. 
22. Kant 1. Bültmann U, Schroèr CAP, Beurskens AJHM, van Amelswoort LGPM, Swaen GMH. An epidemiological approach to study fatigue in the working population: the Maastricht Cohort Study. Occup Environ Med 2003; 60: 132-i39.

23. Barnes PI. Chronic obstructive pulmonary disease. N Engl J Med 2000; 343: 269-280.

24. Medical Research Council. Definition and classification of chronic bronchitis for clinical and epidemiological purposes: a report to the Medical Research Council by their committee on the etiology of chronic bronchitis. Lancet 1965; i: 775-779.

25. Fletcher C, Pride NB. Definitions of emphysema, chronic bronchitis, asthma, and airflow obstruction: 25 years on from the Ciba symposium. Thorax 1984; 39:81-85.

26. Spinhoven P, Ormel I, Sloekers PP, Kempen GIM, Speckens AEM, Van Hemert AM. A validation study of the Hospital Anxiety and Depression Scale (HLADS) in different groups of Dutch subjects. Psychol Med 1997; 27: 363-370.

27. Zigmond AS, Snaith RP. The hospital anxiety and depression scale. Acta Psychiatr Scand 1983; 67: $361-370$.

28. Bjelland I, Dahl AA. Tangen Haug T, Neckelmann D. The validity of the Hospital Anxiety and Depression Scale: an updaced review. J Psychosom Res 2002; 52: 69-77.

29. Van Manen JG, Bindels PJ, Dekker FW, IJzermans CJ, wan der Zee JS, Schadé E. Risk of depression in patients with chronic obstructive pulmonary disease and its determinants. Thorax 2002; $57: 412$ 416.

30. Oswald NC, Waller $\mathbb{R E}$, Drinkwater J. Relationship between breathlessness and anxiety in asthma and bronchitis: a comparative study. Br Med J 1970; 2: 14-17.

31. Wagena EJ, Huibers MI, wan Schayck CP. Antidepressants in the treatment of patients with COPD: possible associations between smoking cigarettes, COPD and depression. Thorax 2001; 56:587-588.

32. Dahlén I, Janson C. Anxiety and depression are related to the outcome of emergency treatment in patients with obstructive pulmonary disease. Chest $2002 ; 122: 1633-1637$.

33. McCathie HCF, Spence SH, Tate RL. Adjustment to chronic obstructive pulmonary disease: the importance of psychological factors. Eur Respir $\pi$ 2002; 19:47-53.

34. Dekhuijzen PNR, Beek MML, Folgering HWM, Van Herwaarden CLA. Psychological changes during pulmonary rehabilitation and target-flow inspiratory muscle training in COPD patients with a ventilatory limitation during exercise. Int I Rehabil Res 1990; 13: 109-117.

35. Van Ede L, Yzemans CJ, Brouwer HJ. Prevalence of depression in patients with chronic obstrucrive pulmonary disease: as systematic review. Thorax 1999; 54: 688-692. 


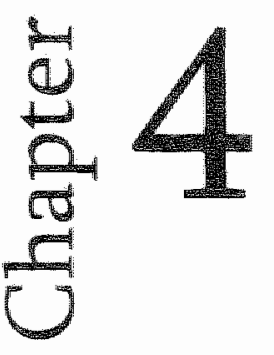

Chronic bronchitis, cigarette smoking and the subsequent onset of depression and anxiety: Results from a prospective population-based cohort study

Wagena EJ, van Amelsvoort LGPM, Kant IJ, Wouters EFM

PSYCHOSOMATIC MEDICINE, 2005; in press 


\section{Abstract}

\section{OBJECTTVE}

In the present study the authors used data from a prospective, populationbased cohort study to examine: 1) whether the presence of chronic bronchitis predicts the subsequent onset of depression or anxiety, and 2) if the incidence of depressed or anxious cases was different for smokers compared to non-smokers.

\section{METHODS}

For studying the relation between chronic bronchitis and anxiety or depression we used data from respectively 4468 and 4520 respondents.

\section{RESULTS}

The number of incident anxious $(19.1 \%, \mathrm{n}=17)$ and depressed $(14.0 \%, \mathrm{n}=13)$ cases was highest in employees with chronic bronchitis compared to employees without respiratory complaints ( $4.3 \%, \mathrm{n}=189$ and $3.3 \%, \mathrm{n}=145$ respectively). The presence of chronic bronchitis was associated with a significant increase in anxious and depressed cases (OR for anxiety $=5.09$, 95\% CI 2.91, 8.89; OR for depression $=4.38,95 \%$ Cl $2.35,8.16)$. The incidence of anxiety as well as depression was strongest in the smokers group (OR for anxiety $=8.94,95 \%$ CI $4.08,19.59$ \% OR for depression $=7.56,95 \%$ CI $3.37,16.96)$.

\section{CONCLUSIONS}

This prospective study shows significant higher levels of anxiety as well as depression in employees with chronic bronchitis. Results also seem to indicate that smoking cigarettes modifies this association, resulting in an increased risk of depression and anxiety in employees with chronic bronchitis who smoke. 


\section{Introduction}

Patients with chronic bronchitis or emphysema (i.e, chronic obstuctive pulmonary disease [COPD]) have repeatedly been characterized being at increased risk of developing psychiatric disorders such as depression and anxiety. However, until recently, the empirical evidence for a significant risk of depression in patients with COPD remained inconclusive.[1] Based on their systematic review, Van Ede and colleagues concluded that most studies were of poor methodological quality, did not use a control group, and used small sample sizes.[1] Since the publication of the review conducted by Van Ede et al.[1], the number of studies addressing the relation between psychiatric morbidity and COPD has increased. Patients with COPD not only seem to be at increased risk of depression (e.g. [2-6]), the prevalence of anxiety disorders, particularly generalized anxiety disorder and panic disorder, also seems to be higher in patients with COPD compared to that in the general public (see Brenes[7] for an overview, and Wagena et al. $[5,6]$ ).

To our knowledge, all studies addressing the relation between psychiatric disorders and COPD have been of cross-sectional design (e.g., [2-4, 8-14]). However, this design is known to be prone to bias as cause and effect cannot be separated. Therefore, in the present study we used data from a prospective, population-based cohort study to extend the investigation of the psychiatric consequences of COPD. Since most studies on this topic used cross-sectional data we wanted to examine whether the presence of COPD predicts the subsequent onset of depression or anxiety. Furthermore, because recent research has shown that associations between smoking cigarettes and psychiatric disorders are due, at least in part, to the role of smoking in predicting the onset of psychiatric disorders[15, 16], we examined whether the incidence of depressed or anxious cases was different in subjects with COPD compared to that in healthy subjects, stratified by smoking status.

\section{Materials and Method}

\section{SAMPLE}

Since COPD is defined as a disease state characterised by airflow limitation that is not fully reversible and usually progressive (especially if a person continues to smoke)(17), and we wanted to investigate the psychiatric consequences mainly in subjects with mild or moderate COPD, we used data from a cohort study among. employees. This study, the Maastricht Cohort Study was set up as a prospective 
population-based cohort study among Dutch emplayees and is described in detail by Kant et al.(18). Although this cohort was established in 1999 the first data on COPD were available from January 2001. In January 2001 we sent a questionnaire on respiratory complaints, depression, anxiety, and smoking to 8070 employees. In total, 7483 employees completed and returned the questionnaire (92.7\%). All employees who returned this questionnaire received a second questionnaire in June 2002, containing the same set of variables. 5542 employees completed and returned the second questionnaire (74.1\%). When we studied the relation between chronic bronchitis and anxiety, we excluded the data from respondents who fulfilled the criteria for anxiety caseness and doubtful caseness at the first assessment (i.e. anxiety score $>7$ ); respondents who had a missing value on the anxiety scale of the HADS on one or both assessments, and respondents who were classified differently on both assessments with regard to chronic bronchitis as well as those respondents who could not be classified as having chronic bronchitis or not, resulting in a sample size of 4468 . When we studied the relation between chronic bronchitis and depression, we excluded the data from respondents who fulfilled the criteria for depression caseness and doubtful caseness at the first assessment (i.e. depression score $>7$ ); respondents who had a missing value on the depression scale of the HADS on one or both assessments, and respondents who were classified differently on both assessments with regard to chronic bronchitis as well as those respondents who could not be classified as having chronic bronchitis or not. This resulted in using data from 4520 respondents.

\section{ASSESSMENT OF CHRONIC BRONCHITIS}

In clinical terms, chronic bronchitis is usually defined by the presence of chronic or recurrent increases in bronchial secretions sufficient to cause expectoration and cough. [19] In this study chronic bronchitis is defined conform the definition and classification of chronic bronchitis for clinical and epidemiological purposes, as proposed by the Medical Research Council: "the presence of cough and sputum production on most days for a minimum of 3 months per year, in the previous 2 successive years, and cannot be attributed to other puimonary or cardiac causes". $[20,21]$ This procedure has been used in several other epidemiological studies. $[22,23]$ The diagnoses were described in a way that was easy to understand for all respondents.

\section{ASSESSMENT OF DEPRESSION AND ANXIETY}

We used the validated Dutch version of the Hospital Anxiety and Depression Scale (HADS). $[24,25]$ The HADS was developed by Zigmond and Snaith, [26] originally to identify caseness (possible and probable) of anxiety and depression 
among patients in nonpsychiatric hospital clinics. Spinhoven et al. found that the Dutch version of the HADS was stable across different age groups from the general population and in different clinical samples.[24] It is divided in an anxiety subscale (HADS-A) and a depression subscale (HADS-D) both containing seven items. Each question is rated $0-3$, giving a possible maximum score for anxiety as well as depression of 21. Subjects scoring 11 or more on the depression subscale were classified as being depressed and subjects scoring 11 or more on the anxiety subscale were classified as being anxious. Subjects who scored between 7 and 11 were classified as doubtful case.

\section{ASSESSMENT OF SMOKING STATUS}

Questions regarding the smoking habits of employees refer only to cigarette smoking. In order to assess the smoking status of respondents we asked them if they smoked cigarettes on a daily basis, and if they used to smoke every day in the past. We defined respondents as never smokers if they answered "no" to both questions. "Past smokers" were defined as giving an affirmative response only to the second question, and "current smokers" if they gave an affirmative response to the question "Do you smoke every day?" We also assessed how many cigarettes they (used to) smoke on average per day.

\section{STATISTICAL PROCEDURES}

First, $t$ test for two independent samples and chi-squared test were used to test the differences in demographic and smoking characteristics between employees with chronic bronchitis and healthy employees. Next, multivariate logistic regression analyses were performed to calculate, for sex, age, educational level, and smoking status adjusted, odds ratios (OR) with $95 \%$ confidence intervals (CI) for the association between chronic bronchitis (assessed in January 2001), and the subsequent onset of psychiatric disorders (assessed in June 2002). The analyses were conducted separately for anxiety and depression. Third, the multivariate logistic regression analyses were repeated but now stratified for smoking status. The statistical analyses were carried out using SAS release 8.02 (SAS Institute Inc., Cary, NC, USA). 


\section{Results}

Table la and 1b show the demographic and smoking characteristics of the samples used to study the relation between chronic bronchitis and anxiety, and chronic bronchitis and depression, respectively.

\section{TABLE IA}

Characteristics of employees with chronic bronchitis and healthy individuals at first assessuenc (ankiety)

\begin{tabular}{|c|c|c|c|}
\hline & $\begin{array}{l}\text { Emplloyees with } \\
\text { chronic bronchitis } \\
(n=89)\end{array}$ & $\begin{array}{l}\text { Employres without } \\
\text { respiratory complaints } \\
(n=4379)\end{array}$ & Statistics \\
\hline Mean (SD) age (years) & $42.5(8.6)$ & $41.7(8.3)$ & $t=-0.1, d f=4466, p=0.38$ \\
\hline Men $(0 \%)$ & $59(66.3)$ & $3237(73.9)$ & $x^{2}=2.6, \mathrm{df}=1, \mathrm{p}=0.11$ \\
\hline \multicolumn{4}{|l|}{ Smoking statuss } \\
\hline No. of smokers (\%) & $40(44.9)$ & $861(19.7)$ & \multirow{2}{*}{$x^{2}=34.5, d f=1, p<0.001$} \\
\hline No. of non-smokers (\%) & $49(55.1)$ & $3510(80.3)^{*}$ & \\
\hline \multicolumn{4}{|l|}{ Cigarettes per day } \\
\hline $1-10$ cigarettes $(\%)$ & $17(19.8)$ & $1005(23.4)$ & \multirow{3}{*}{$x^{2}=5.3, d f=2, p=0.07$} \\
\hline $11-20$ cigaretres $(\%)$ & $31(36.1)$ & $922(21.5)$ & \\
\hline$>20$ cigaretres $(\%)$ & $10(11.6)$ & $422(9.8)$ & \\
\hline \multicolumn{4}{|l|}{ Education } \\
\hline Low education (\%) & $32(36.4)$ & $1.152(26.8)$ & \multirow{3}{*}{$x^{2}=5.2, \mathrm{df}=2, \mathrm{p}=0.07$} \\
\hline Medium education (\%) & $29(33.0)$ & $1387(32.2)$ & \\
\hline High education (\%) & $27(30.7)^{* *}$ & $1764(41.0)+$ & \\
\hline
\end{tabular}

Both samples (as well as the groups of employees with chronic bronchitis and those without respiratory complaints) consisted mainly of men (approximately $70 \%$ ). In both samples, the percentage of smokers in the group of employees with chronic bronchitis was significantly higher $(\mathrm{p}<0.001)$. In addition, the percentage of smokers who smoke more than 10 cigarettes per day is higher in the group of employees with chronic bronchitis compared to employees without respiratory complaints. At the first assessment, 634 respondents were classified as anxious (score $\geq 11$ on the anxiety subscale; $8.5 \%$ ), and 504 as depressed (score $\geq 11$ on the depression subscale; $6.7 \%$ ). 


\section{TABLE $1 B$}

Characteristics of employees with chronic bronchitis and healthy individuals at first assessment (depression)

\begin{tabular}{|c|c|c|c|}
\hline & $\begin{array}{l}\text { Employees with } \\
\text { chronic bronchitis } \\
(n=89)\end{array}$ & $\begin{array}{l}\text { Employees without } \\
\text { respiratory complaints } \\
\text { (n=4379) }\end{array}$ & Statistics \\
\hline Mean (SD) age (years) & $42.7(8.5)$ & $41.7 \overline{(8.3)}$ & $\mathrm{t}=-1.09, \mathrm{df}=4518, \mathrm{p}=0.27$ \\
\hline $\operatorname{Men}(\%)$ & $65(69.9)$ & $3243(73.3)$ & $\chi^{2}=0.5, \mathrm{df}=1, \mathrm{p}=0.47$ \\
\hline \multicolumn{4}{|l|}{ Smoking status } \\
\hline No. of smokers $\%$ & $43(46.2)$ & $884(20.0)$ & \multirow{2}{*}{$x^{2}=38.4, d f=1, p<0,001$} \\
\hline No. of non-smokers $(\%)$ & $50(53.8)$ & $3536(80.0)^{*}$ & \\
\hline \multicolumn{4}{|l|}{ Gigarettes per day } \\
\hline $1-10$ cigarettes $(\%)$ & $18(20.2)$ & $1025(23.6)$ & \multirow{3}{*}{$x^{2}=5.6, \mathrm{df}=2, \mathrm{p}=0.06$} \\
\hline $11-20$ cigarettes $(\%)$ & $32(36.0)$ & $939(21.6)$ & \\
\hline More than 20 cigarettes (\%) & $14(15.7)$ & $427(9.8)$ & \\
\hline \multicolumn{4}{|l|}{ Education } \\
\hline Low education $(\%)$ & $36(39.6)$ & $1167(26.9)$ & \multirow{3}{*}{$x^{2}=8.0, d f=2, p=0.02$} \\
\hline Medium education (\%) & $28(30.8)$ & $1397(32.2)$ & \\
\hline High education (\%) & $27(29.7)^{* *}$ & $1770(40.8) \uparrow$ & \\
\hline
\end{tabular}

7 missing values; 193 missing values" $* 2$ missing value

Table $2 \mathrm{a}$ and $2 \mathrm{~b}$ show that the number of incident anxious $(19.1 \%, \mathrm{n}=17)$ and depressed (14.0\%, $\mathrm{n}=13$ ) cases is highest in employees with chronic bronchitis compared to employees without respiratory complaints (4.3\%, $\mathrm{n}=189$ and $3.3 \%$, $\mathrm{n}=145$ respectively). The presence of chronic bronchitis was associated with a significant increase in anxious and depressed cases during the 18-month follow up period (adjusted OR for anxiety $=5.09$, 95\% CI 2.91, 8.89; adjusted OR for depression $=4.38,95 \%$ GI 2.35, 8.16). Furthermore, although also in non-smokers the risk of developing anxiety or depression is increased in employees with chronic bronchitis (OR for anxiety in non-smokers $=2.93,95 \%$ CI $1.22,7.03$; OR for depression in non-smokers $=2.01,95 \%$ Cl $0.61,6.57$ ), this risk is highest in smokers (OR for anxiety in smokers $=8.94,95 \%$ CI $4.08,19.59$; OR for depression in smokers $=7.56,95 \%$ CI $3.37,16.96)$. When controlling for age, gender, education and the presence of chronic bronchitis, smoking status does not seem to be significantly related to the development of anxiery (OR=1.01, 95\% CI $0.71,1.44$ ), although the risk of developing depression is slightly increased in smokers (OR $=1.44,95 \%$ CI 1.00 , 2.08). The number of employees who picked up smoking as well as those who quit during follow-up was too low to assess whether these employees were at increased risk for developing anxiety and/or depression. 
TABLE 2A

Incident anxious cases and odds ratios for the association between chronic bronchits and psychiatric morbidity in Dutch employees stratifed for smoking status

\begin{tabular}{|c|c|c|c|}
\hline & $\mathbf{N}$ & $\begin{array}{l}\text { Anxious cases } \\
\mathrm{n}(\%)\end{array}$ & $\begin{array}{l}\text { Adjusted OR } \\
(95 \% \mathrm{Cl})\end{array}$ \\
\hline \multicolumn{4}{|l|}{ Total group } \\
\hline Chromic bronchicis & 89 & $17(19.1)$ & $5.09(2.91,8.89)^{*}$ \\
\hline Healthy controls & 4379 & $189(4.3)$ & 1.00 \\
\hline \multicolumn{4}{|l|}{ Snokers } \\
\hline Chronic bronchitis & 40 & $\mathbb{1 1}(27.5)$ & $8.94(4.08,19.59)^{* * *}$ \\
\hline Healthy controls & 861 & $36(4.2)$ & 1.00 \\
\hline \multicolumn{4}{|l|}{ Non-smakers } \\
\hline Chronic bronchitis & 49 & $6(12.2)$ & $2.93(1.22,7.03)^{\omega *}$ \\
\hline Healthy controlls: & 3510 & $152(4.3)$ & 1.00 \\
\hline
\end{tabular}

*Odds ratios adjusted for sex, age, educational levell and smoking status.

"Odds ratios adjusted for sex, age and educational level.

\section{TABLE 2B}

Incident depressed cases and odds ratios for the association between chronic bronchitis and psychiattic morbidity in Dutch employees stratified for smoking status

\begin{tabular}{|c|c|c|c|}
\hline & N & $\begin{array}{l}\text { Depressed cases } \\
\mathrm{n}(\%)\end{array}$ & $\begin{array}{l}\text { Adjusted OR } \\
(95 \% \mathrm{Cl})\end{array}$ \\
\hline \multicolumn{4}{|l|}{ Total group } \\
\hline Chronic bronchitis & 93 & $13(14.0)$ & $4.38(2.35,8.16)^{*}$ \\
\hline Healthy controis & 4427 & $145(3.3)$ & 1.00 \\
\hline \multicolumn{4}{|l|}{ Smakersy } \\
\hline Chronic bronchitis & 43 & $1.0(23.3)$ & $7.56(3.37,16.96)^{* *}$ \\
\hline Healthy concrols & 884 & $37(4.2)$ & 1.00 \\
\hline \multicolumn{4}{|l|}{ Non-sinokers } \\
\hline Chronic bronchitis & 50 & $3(6.0)$ & $2.01(0.61,6.57)^{* * *}$ \\
\hline Healthy controls & 3536 & $107(3.0)$ & 1.00 \\
\hline
\end{tabular}

- Odds ratios adjusted for sex, age, edacational level and smoking status.

*Odids ratios adjusted for sex, age and educational level. 


\section{Discussion}

Results from this population-based sample rewealed that the presence of chronic bronchitis was associated with an increased risk of developing anxiety as well as depression compared to employees without respiratory complaints. Results also seem to indicate that smoking cigarettes modifies this association, resulting in an increased risk of depression and anxiety in smoking employees with chronic bronchitis.

As we already stated in the introduction, all studies addressing the relation between chronic bronchitis and psychiatric morbidity have been of cross-sectional design, and as a result are more likely to be prone to bias compared to prospective studies. The present study is therefore an important extension of the existing knowledge on psychiatric morbidity in patients with COPD. However, one limitation of this study needs to be mentioned. To determine the presence of chronic bronchitis, all participants were asked to complete a questionnaire on respiratory complaints and diagnoses. The assessment of chronic bronchitis was thus self-reported. We could not evaluate the presence of chronic bronchitis by using spirometry. As a result, we may have systematically over-or underestimated the presence of chronic bronchitis. Misclassification of cases may therefore have occurred. However, if it occurred, it is expected to be non-differential.

Several mechanisms may be responsible for the observed association between chronic bronchitis and depression or anxiety. The physical illness itself is often considered to be reason enough for patients to feel anxious or depressed. The presence of these psychiatric complaints is therefore in many cases regarded as a complication of the physical complaints.(27) Conform earlier studies $(5,6,9,28)$, the results found in this study could be explained by a difference in severity of the respiratory complaints. Patients with chronic bronchitis might feel more depressed. and/or anxious when thinking about their health status and the future. However, since the sample consisted mainly of middle-aged employees (a generally healthy sample), it is unlikely that the group of employees with chronic bronchitis consisted of patients with severe complaints. Furthermore, the follow up time of 18 months is rather short for someone's lung function to decrease significantly. However, mild or moderate complaints might also cause these subjects to feel anxious or depressed, since in an earlier study we failed to find a significant increase in psychiatric complaints in patients with severe or very severe COPD compared to patients with mild or moderate COPD.(6) Our finding that smokers are at increased risk for developing psychiatric complaints like anxiety and depression is not surprising. The complexity of nicotine addiction is often accompanied by co-morbid depression or 
depressive symptoms.(29-31) Contending explanations include a causal influence of smoking on psychiatric complaints based on the possible effects of long-term nicotine exposure on neurobiological systems implicated in the aetiology of these complaints,(32) and the effects of shared environmental or genetic factors that predispose to both smoking and depression.(32) In smokers, the risk of psychiatric morbidity might be increased compared to non-smokers because of a negative selfevaluation when they compare themselves with peers regarding sports and activities of dailly living.

In conclusion, this prospective study shows a significant higher incidence of anxiety as well as depression in employees with chronic bronchitis. We also found that smoking cigarettes seems to modify this association, resulting in an increased risk for depression and anxiety in smoking employees with chronic bronchitis. As depression and anxiety remain easily undiagnosed due to under presentation and because the symptoms are not very specific, it is important to consider the presence of these disorders in primary and secondary care settings. Furthermore, because we could not assess the severity of chronic bronchitis, future research should assess whether smokers with severe chronic bronchitis are at increased risk for becoming anxious or depressed compared to smokers with less severe chronic bronchitis. 


\section{References}

1. Van Ede $\mathbb{L}$, Yzermans $\mathbb{C}$, Brouwer Hij. Prewalence of depression in patients with chronic obstructive pulmonary disease: a systematic review. Thorax 1999; 54: 688-692.

2. Van Manen JG, Bindels PJ, Dekker FW, IJermans CJ, van der Zee IS, Schade E. Risk of depression in patients with chronic obstructive pulmonary disease and its determinants. Thorax 2002: $57: 412-$ 4116.

3. Peruzza S, Sergi G, Vianello A, Pisent C, Tiozzo F, Manzan A, Coin A, Inelmen EM, Enzi G. Chronic obstructive pulmonary disease (COPD) in elderly subjects: impact on functional status and quality of life. Respir Med 2003; 97:612-617.

4. Aghanwa HS, Erhabor GE. Specific psychiatric morbidity among patients with chronic obstructive pulmonary disease in a Nigerian general hospital. J Psychosom Res 2001; 50: 179-183.

5. Wagena EJ, van Amelswoort LGPM, Kant I, Wouters EFM, wan Schayck CP, Swaen GMH, Risk of depression and anxiety in employees with chronic bronchitis: the modifying effect of cigarette smoking. Psychosom Med 2004; 66: 729-734.

6. Wagena EJ, Arrindell WA, Wouters EFM, wan Schayck CP. Are parients with COPD psychologically distressed? Eur Respir $\mathrm{I}$ 2005; in press.

7. Brenes GA. Anxiety and chronic obstructive pulmonary disease: prevalence, impact, and treatment. Psychosom Med 2003; 65: 963-970.

8. Lacasse Y, Rousseau L, Maltais F. Prevalence of depressive symptoms and depression in patients with severe oxygen-dependent chronic obstructive pulmonary disease. I Cardiopulm Rehabil 2001; 20: $80-86$.

9. Dahlén I, Janson C. Anxiety and depression are related to the outcome of emergency treatment in patients with obstructive pulmonary disease. Chest 2002; 122: 1633-1637.

10. Yohannes AM. Baldwin RC, Connolly MJ. Depression and anxiety in elderly outpatients with chronic obstructive pulmonary disease: prevalence, and validation of the BASDEC screening questionnaire. Int J Geriatr Psychiatry 2000; 15: 1090-1096.

11. Yohannes AM, Baldwin RC, Connolly MJ. Prevalence of sub-threshold depression in elderly patients with chronic obstructive pulmonary disease. Int J Geriatr Psychiatry 2003; 18:412-416.

12. Stage $\mathrm{KB}$, Middelboe $\mathrm{T}$, Pisinger $\mathrm{C}$. Measurement of depression in patients with chronic obstructive pulmonary disease (COPD). Niord J Psychiatry 2003:57:297 301.

13. Aydin IO, Ulusahin A. Depression, anxiety comorbidity, and disability in tuberculosis and chronic obstructive pulmonary disease patients: applicability of GHQ-12. Gen Hosp Psychiatry 201; 23: 77 83.

14. Dowson $C$, Laing R, Barraclough $R$, Town $I$. Mulder $R$, Norris $K$, Drennan $C$, The use of the Hopsital Anxiery and Depression Scale (HADS) in patients with chronic obstructive pulmonary disease: a pilor stady. NZ Med I 2001; 11.4: 447-449.

15. Dierker LC, Avenevoli S, Stolar M, Merikangas KR. Smoking and depression: an examination of mechanisms of comorbidity. Am I Psychiatry 2002; 159:947-953.

16. Breslau N, Nowak SP, Kessler RC. Daily smoking and the subsequent onset of psychiatric disorders. Psychol Med 2004; 34: 323-333.

17. Pauwels RA. Buist AS, Ma P. Jenkins CR, Hurd SS. Global strategy for the diagnosis, management, and prevention of chronic obstructive pulmonary disease. NHLBU/WHO Global lnitiative for Chronic Obstructive Lung Disease (GOLD) Workshop summary. Am I Respir Crit Care Med 2001; 163: $1256-1276$.

18. Kant II, Bülltmann U, Schröer CAP, Beurskens AJHM, van Amelsvoort LGPM, Swaen GMH. An epidemiological approach to study fatigue in the working population: the Mastricht Cohort Sudy. Occup Environ Med 2003; 60: i32-i39.

19. Barnes PJ. Chronic obstructive pulmonary disease. N Engl I Med 2000; 343: 269-280.

20. Medical Research Council. Definition and classification of chronic bronchitis for clinical and. epidemiological purposes: a report to the Medical Research Council by their committee on the etiology of chronic bronchitis. Lancet 1965 ; i: 775-779. 
21. Fleteher $C_{x}$ Pride $N B$. Definitions of emphysema, chronic bronchitis, asthma, and anflow obstruction: 25 years on from the Ciba symposium. Thorax 1984; 39: 81-85.

22. Torén $K_{\mathrm{w}}$ Brisman J, Jarvholm B. Asthma and asthma-like symptoms in adults assessed by questionnaires. Chest 1993; 104:600-608.

23. Codtredisen NS, Lange P, Prescott E, Osler M, Vestbo J. Changes in smoking habits and risk of asthma: a longitudinal population based study. Eur Respir ] 2001; 18: 549-554.

24. Spinhoven P, Ormel J, Sloekers PP, Kempen GIM, Speckens AEM, Van Hemert AM. A validation study of the Hospital Anxiety and Depression Scale (HADS) in different groups of Dutch subjects. Psychol Med 1997; 27: 363-370.

25. Bjelland I, Dahl AA, Tangen Haug $T$. Neckelmann D. The validity of the Hospital Anxiety and Depression Scale: an updated review. I Psychoson Res 2002; 52:69-77.

26. Zigmond AS, Snaith RP. The hospital anxsety and depression scale. Acta Psychiatr Scand 1983; 67: $361-370$.

27. Peveler $\mathbb{R}_{\mathrm{t}}$ Carson $\mathrm{A}_{\mathrm{s}}$ Rodin $\mathrm{G} . \mathrm{ABC}$ of psychological medicine. Depression in medical patients. Brit. Med I 2002; 325: 149-152.

28. Oswald $\mathrm{NC}$, Waller RE, Drinkwater J. Relationship between breathlessness and anxiety in asthma and bronchitis: a comparative study. Brit Med J 1970: 2: 14-17.

29. Breslau $\mathbb{N}$, Johnson $\mathbb{E O}$. Predicting smoking cessation and major depression in nicotine-dependent smokers. Am J Public Health 2000; 90; 1.122-1127.

30. Killen JD, Fortmann SP, Kraemer HC. Varady A, Newman B. Who will relapse? Symptons of nicotine dependence predict long-term relapse after smoking cessation. J Consult Clin Psychol 1992; 60: 797-801.

31. Killen ID, Formann SP, Kraemer HC, Varady AN, Davis L, Newman B. Interactive effects of depression symptoms, nicotine dependence, and weight change on late smoking relapse. J Consult Clin Psychol 1996: 64: 1060-1067.

32. Kendler KS, Neale MC, MacLean CI, Heath AC, Eaves LJ, Kessler RC. Smoking and major depression. A calusal analysis. Arch Gen Psychiatry 1993; 50: 36-43. 
Depression in patients with COPD: Are somatic symptoms more indicative of depression compared with cognitive and affective symptoms?

Wagena EJ, Arrindell WA, Wouters EFM

SUBMITTED FOR PUBLICATION 


\section{Abstract}

We studied which symproms (somatic or cognitive/affective) are indicative of depression in patients with COPD. A total of 197 subjects with a wide range in severity of COPD participated. Results showed that patients with severe COPD scored significantly higher on the somatic subscale of the BDI when compared with patients with mild or moderate COPD and subjects without an irreversible limiration in airflow. We did not find any systematic between-group differences on the cognitive/affective subscale. In patients with COPD, the presence and severity of depressive complaints is mainly caused by the presence and severity of somatic symptoms. 


\section{Introduction}

Chronic obstructive pulmonary disease (COPD) is a highly incapacitating health problem and can disturb various aspects of a patient's life. The ability to function in day-to-day life, as well as the quality of life of a patient with COPD, may be further complicated by psychological complaints. Since the publication of the review of Van Ede et al.[1], further studies (e.g. Lacasse et al.[2], Dahlén and Janson[3], Peruzza et al.[4], Yohannes et al.[5], Yohannes et al. [6], Dowson et al.[7], Stage et al.[8], Van Manen et al.[9], Aydin and Uluşahin[10], and Aghanwa and Erhabor[11]) have addressed the prevalence of depression in patients with COPD. In general, these studies showed significantly higher levels of psychological distress in patients with COPD compared with the general population as well as with other chronically ill people. However, in patients with a physical illness, psychological problems are regularly overlooked, often remain undiagnosed and are rarely treated.[12, 13] Many health-care professionals often regard the presence of what really are depressive complaints, as symptoms of the physical illness.[12] This is not surprising because, according to the $4^{\text {th }}$ edition of the Diagnostic and Statistical Manual of Mental Disorders (DSM-IV-TR ${ }^{\mathrm{TM}}$ )[14], next to cognitive/affective symptoms, a depressive disorder can be characterized by the presence of somatic symptoms like fatigue or loss of energy, insomnia, and somatic preoccupation. Symptoms which are expected to occur more frequently in patients with severe COPD, compared with patients with less severe COPD and subjects without a chronic airflow limitation.

To our knowledge, no study has so far investigated, which symptoms (somatic or cognitive/affective) are indicative of depression in patients with severe or very severe COPD (stages III and IV according to the Global Initiative for Chronic Obstructive Lung Disease (GOLD) [15, 16], as compared with the symptoms reported by patients with mild or moderate COPD (stages I and II) and subjects at risk for COPD (stage 0). We used the Beck Depression Inventory[17-19], designed to measure the severity of depression, because it has a well-developed subset of cognitive/affective and somatic items of symptoms descriptive of depression, is selfadministered, and is easily used for screening for depression in the medically ill. Our secondary objective was to assess whether female subjects score higher on the subscales of the BDI compared to males. In a number of studies the relation between the BDI and gender has been evaluated (see Beck et al.[17], for an overview). Although the overall pattern of findings is not conclusive, several studies reported that women have higher BDI mean scores than men.[17] 


\section{Materials and Methods}

\section{SUBJECTS}

Subjects were recruited from patients with COPD who responded to newspaper and radio announcements between March 2002, and August 2003. All participants lived in the same province in the south of The Netherlands. The diagnosis of COPD was based on the definition provided by the Global Initiative for Chronic Obstructive Lung Disease (GOLD) [15, 16], using postbronchodilator spirometric results. The FEV w was expressed as percentage of the predicted value using ECCS equations.[20] All participants had to have a smoking history of at least 10 years. The study protocol was approved by the ethics committee of Maastricht University/university hospital Maastricht, and informed consent was obtained from all participants.

\section{MEASUREMENTS}

The Beck Depression Inventory (BDI) was used to assess the presence and severity of depressive disorder.[17, 19] The BDI is based on clinical observations, which were consolidated systematically into 21 symptoms and attitudes that can be rated from 0 to 3 in terms of intensity. [17] We used a cut-off score for the BDI of 15 in order to separate the patients with no or mild depression (BDI<15) from the patients with moderate to severe depression (BDI $\geq 15)$. [17] We also assessed age, body mass index (BMI) and smoking status. BMI was calculated as weight height ${ }^{-2}$ $\left(\mathrm{kg} \cdot \mathrm{m}^{-2}\right)$.

\section{STATISTICAL ANALYSIS}

All analyses were performed using the Statistical Package for Social Sciences (SPSS) for Windows, release 12.01. The critical value for $\alpha$ was set at $5 \%$.

Three subgroups were distinguished: 1) patients with severe or very severe COPD (stage III and IV; FEV $/$ FVC $<0.7, \mathrm{FEV}_{1}<50 \%$ predicted), 2) patients with mild or moderate COPD (stage I and II FEV $/ F V C<0.7$, and $F E V_{1} \geq 50 \%$ predicted), and 3) subjects at risk for COPD (stage $0 ; \mathrm{FEV}_{1} / \mathrm{FVC}>0.7$ combined with the presence of cough, sputum production or dyspnea). We computed descriptive statistics for demographic and clinical characteristics of included subjects. Data for contimuous variables are presented as mean scores \pm standard deviation (SD). Each item of the BDI was scored as follows: a zero indicated that the symptom was not present, while increasing severity was graded with 1,2 , or 3 . The BDI was divided into two subscales, one scale containing the cognitive/affective items and the other the somatic items. $[19,21]$ The cognitive/affective scale consists of the first 14 items 
of the BDI ( $A$ to $\mathrm{N}_{\text {; }}$ see table 1 ). The items $\mathrm{O}$ to $\mathrm{U}$ are best described as somatic symptoms of depression.

To compare the frequency of reporting depressive symptoms by the three study groups, non-parametric chi-square tests were performed. Our main interest was to determine whether more or less patients with severe or very severe COPD reported a specific symptom compared with COPD patients with mild or moderate COPD and subjects classified as at risk for COPD, and if there was a significant difference between men and women. Multivariate Analysis of Variance (MANOVA) was conducted for comparing means on the BDI and both subscales, using COPD staging as independent variable. The overall multivariate F-test (performed across all three groups for each dependent variable) was used to detect significant differences between the groups. Next, using the subprogram ONEWAY Analysis of Variance in SPSS, pairwise, a posteriori contrasts were carried out (using Scheffés test) in order to determine just which groups differed from one another on a specific dependent variable.

The internal consistency of the BDI and both subscales was assessed by calculating Gronbach's coefficient $\alpha$. [22] The size of Cronbach's coefficient $\alpha$ reflects the reliability of the scale. Alpha-values $<0.70$ were considered (unacceptably) low, $\alpha$-values of $0.70-0.79$ reasonable, and $\alpha$-values $\approx 0.80$ good to excellent.[23] Furthermore, we assessed the homogeneity of the subscales by calculating the mean inter-item correlation for the BDI and both subscales. Homogeneity refers to the statistical coherence of the scale items and is assumed to be optimal if the mean. inter-item correlation lies between 0.20 and 0.40 .[24] High mean inter-item correlations $(s 0.70)$ could indicate redundancy of (some of the) items. 


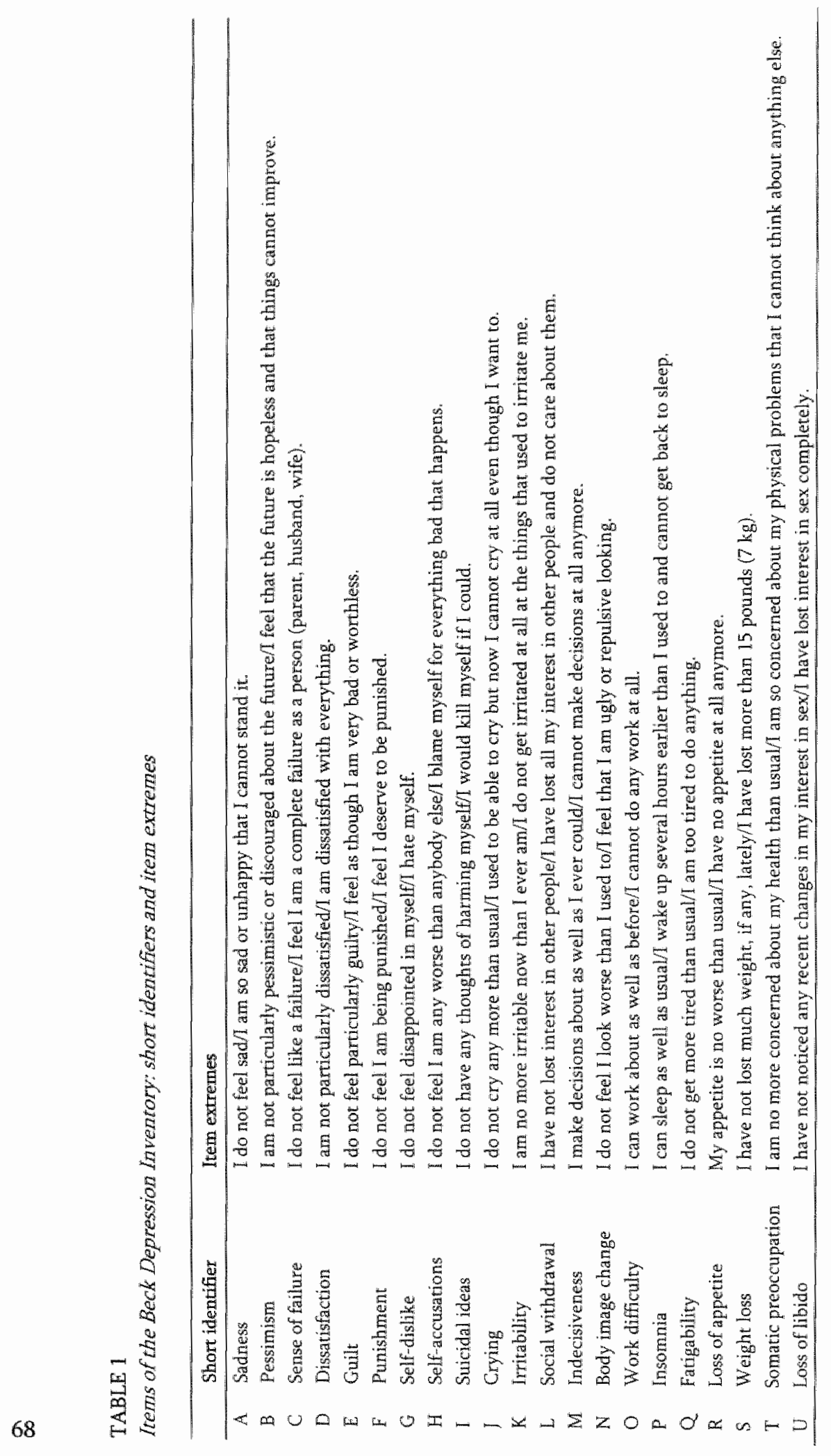




\section{Results}

\section{PARTICIPANT CHARACTERISTICS}

A total of 197 subjects gave oral consent to participate in this study. Because one subject missed more than 3 items of the BDI, his data were excluded from the analysis. Demographic and respiratory function characteristics of the included subjects are shown in table 2. Results indicate that almost $36 \%(n=23)$ of the patients with severe or very severe COPD had a score of $z 15$ on the BDI, indicating moderate to severe depression, compared to $20 \%(n=14)$ of the patients with mild or moderate COPD and $23 \%(n=15)$ of the subjects at risk for COPD. However, the difference between groups was not statistically significant $\left(\chi^{2}=4.45, \mathrm{df}=2, \mathrm{NS}\right)$. Although more women had a score of $\geq 15$ on the BDI indicating moderate to severe depression ( $\mathrm{n}=31,31.6 \%)$ compared to men $(\mathrm{n}=21,21.4 \%)$, this difference also failed to reach statistical significance $\left(\chi^{2}=2.62, \mathrm{df}=1, \mathrm{NS}\right)$. It should be pointed out that there was no systematic difference in the distribution of gender across the three groups $\left(\chi^{2}=3.34, \mathrm{df}=2, \mathrm{NS}\right)$.

\section{PSYCHOMETRIC CHARACTERISTICS OF THE BDI}

The internal consistency of the BDI and the cognitive/affective subscale was good to excellent ( $\alpha=0.88$ and $\alpha=0.82$, respectively). The internal consistency of the somatic subscale was rather low $(\alpha=0.68)$. However, the mean inter-item correlations of the BDI and both subscales varied between 0.26 and 0.31 , indicating appropriate item homogeneity of the BDI and its subscales.

\section{SYMPTOMS INDICATIVE OF DEPRESSION IN COPD}

Table 3 shows the frequency with which BDI items were reported by the patients with COPD and the subjects at risk for COPD. Compared to patients with mild or moderate COPD, patients with severe or very severe COPD reported two cognitive/affective items ("pessimism" and "dissatisfaction") and two somatic symptoms ("work difficulty" and "weight loss") more often (with a difference in frequency of reporting of more than 10\%), while the latter reported one cognitive/affective symptom ("self-dislike") and no somatic symproms less often. Chi-squared tests showed that the comparisons regarding "pessimism", "work difficulty" and "weight loss" were statistically significant $(P<0.01, P<0.05$ and $P<0.05$, respectively). 


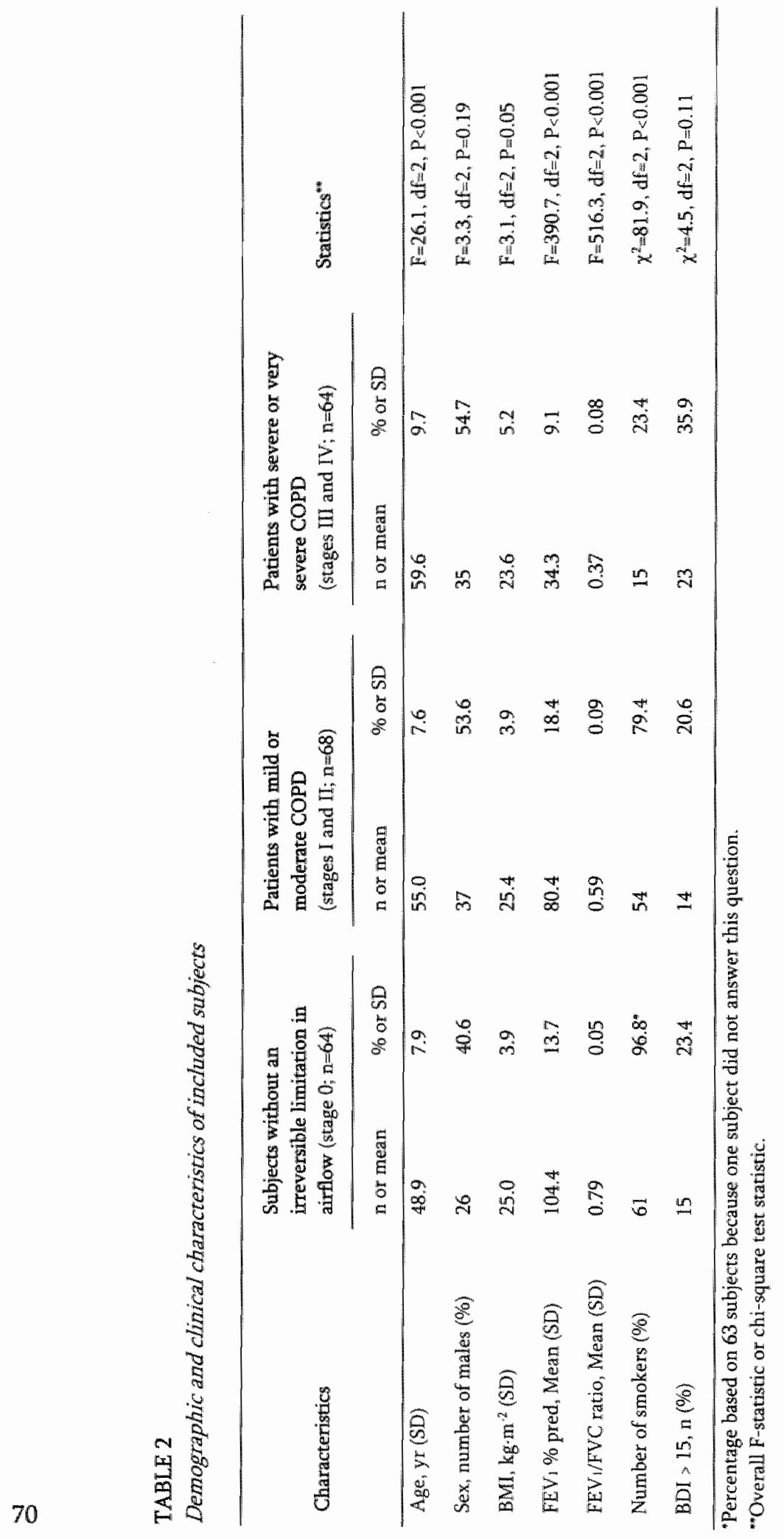




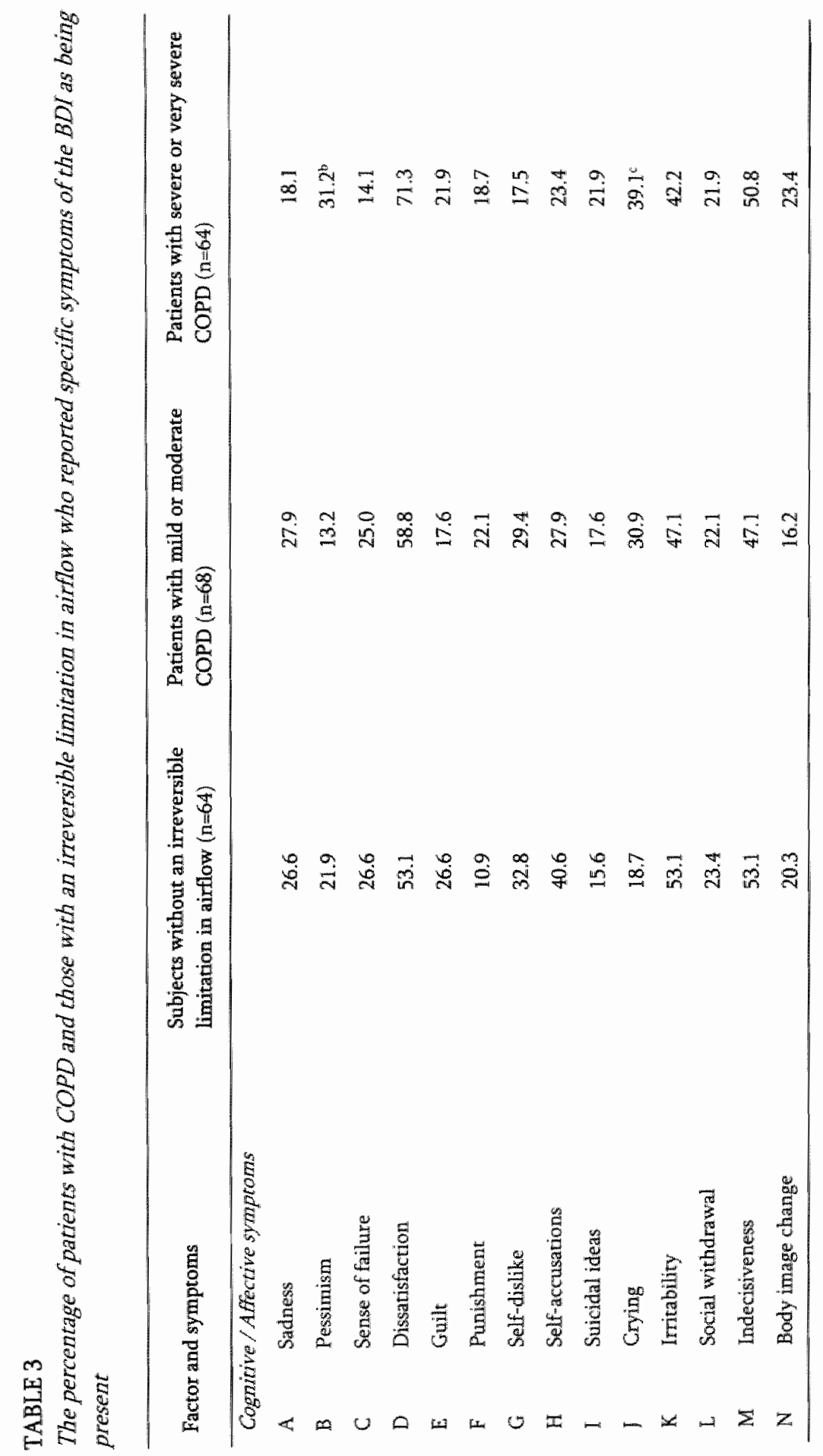




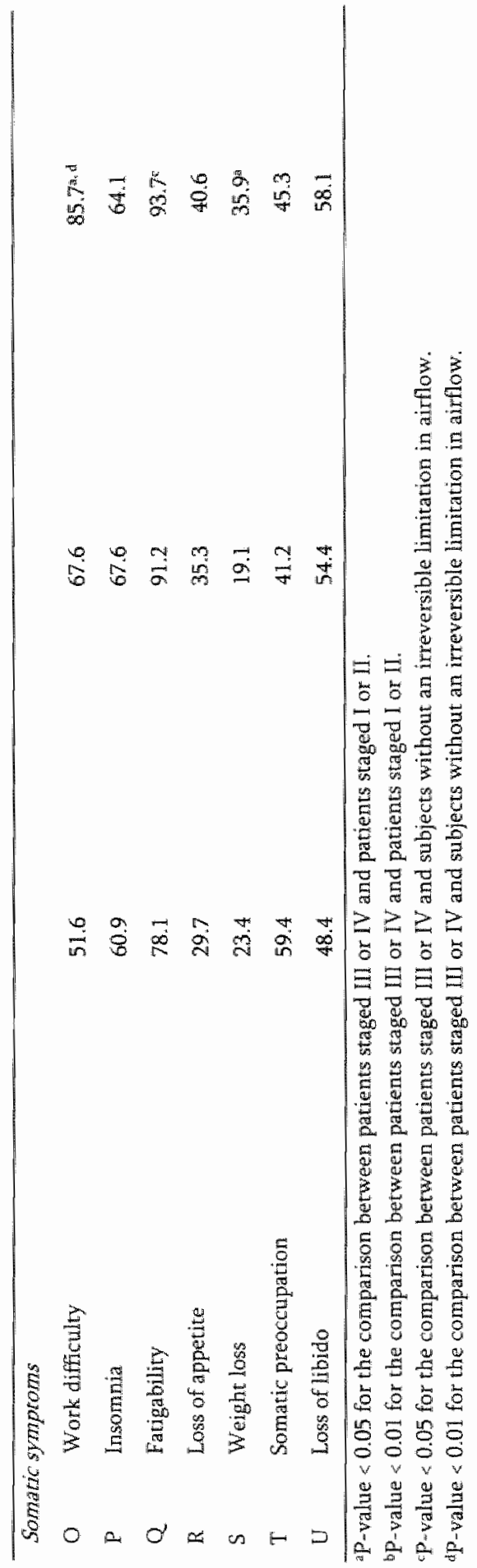


Compared to subjects without an irreversible limitation in airflow, three cognitive/affective symptoms ("pessimism", "dissatisfaction" and "crying") and five somatic symptoms ("work difficulty", "fatigability", "loss of appetite", "weight loss" and "loss of libido") were reported at least $10 \%$ more often by the patients with severe or very severe COPD. The difference in frequency of reporting was statistically significant for two cognitive/affective items ("dissatisfaction" and "crying" $[\mathrm{P}<0.05$ and $\mathrm{P}<0.01$ respectively]) and two somatic items ("work difficulty" and "fatigability" $[\mathrm{P}<0.01])$. The same group of patients reported four cognitive/affective symptoms ("sense of failure", "self-dislike", "self-accusations", and "irritability") and one somatic symptom ("somatic preoccupation") at least 10\% less often, although none of the comparisons resulted in a statistically significant difference. Thus, in spite of a large number of tests having been carried out, the number of significant findings obtained (7) exceeded the number, which one would have obtained on the basis of chance alone, namely 2 ( $5 \%$ of 42 ).

\section{MEAN SCORES ON THE BDI, THE SOMATIC SUBSCALE AND THE COGNITIVE/AFFECTIVE SUBSCALE}

Figure 1 depicts the mean scores on the BDI, the somatic subscale, and the cognitive/affective subscale for the three study groups separately. Multivariate Analysis of Variance showed that there were systematic between-group differences on the dependent variables (Wilks"s Lambda $=0.87, F=4.56, \mathrm{df}=6$ and $382, \mathbb{P}<0.001$ ). Further analysis specified that these differences could be located on one dependent variable. Thus, the mean scores on the somatic subscale differed significantly between the groups (overall $F_{\text {toral score on the } \mathrm{BDI}}=2.93, \mathrm{df}=2, \mathrm{P}=0.06$; overall $\mathrm{F}_{\text {somatic subscale }}$ $=9.41, \mathrm{df}=2, \mathrm{P}<0.001$, and overall Fcognitive/ffective subscale $=0.47, \mathrm{df}=2, \mathrm{NS})$. Next, ONEWAY Analyses of Variance indicated that patients with severe or very severe COPD scored significantly higher on the somatic subscales of the BDI when compared with patients with mild or moderate COPD (mean difference=1.85, $\mathrm{P}<0.01$ ) and subjects wirhout an irreversible limitation in airflow (mean difference $=2.41, P<0.001$ ). These results indicate that in patients with (severe or very severe) COPD, the presence and severity of depressive complaints is mainly caused by the presence and severity of somatic symptoms. Since the mean score on the somatic subscale increased with increasing severity of the disease, the presence of somatic symptoms seems most indicative of depression in patients with severe or very severe COPD. After all, there were no systematic between-group differences on the cognitive/affective subscale. This was confirmed by the finding that the standardized differences in mean somatic scores (i.e., Cohen's effect size d)[25]

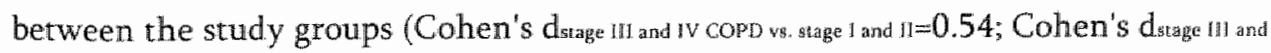
w COPD vs. sabbjers withour airflow limitation $=0.68$ ) were higher than the standardized difference for 
the cognitive/affective subscale (Cohen's dotage In and w copp ws. stage I and a $=0.10$; Cohen's

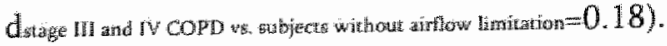

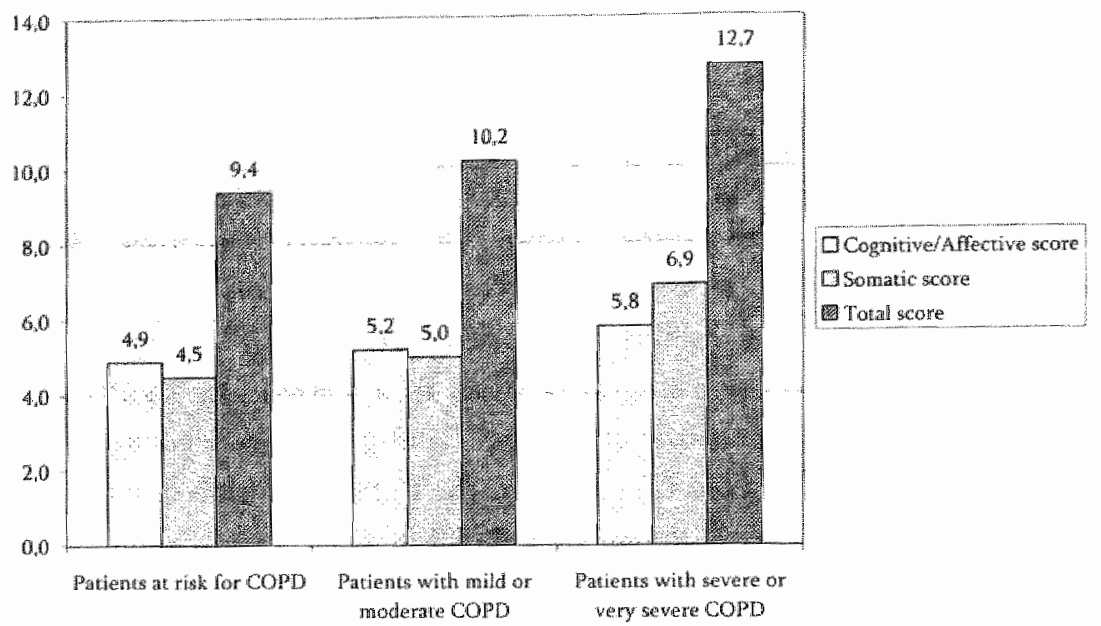

FIGURE 1 Mean scores and standard deviations on the BDI and both subscales for the three study groups

Furthermore, when we take into account that the maximum score on the cognitive/affective subscale is 42 and the maximum score on the somatic subscale is 21. the relative contribution of the somatic subscale to the total score on the BDI was higher in all study groups (the somatic score and the cognitive/affective score relate to each other in the proportion 1.8 to 1 in the subjects without an irreversible limitation in airflow, 1.9 to 1 in patients with mild to moderate COPD and 2.4 to 1 in patients with severe or very severe COPD).

Figure 2 shows the mean scores on the BDI and both subscales for the three study groups stratified by gender. When controlling for COPD stage, women scored significantly higher on the cognitive/affective subscale compared to men (overall $F=6.10, \mathrm{~d} f=1, P=0.02$ ). Women also had a significantly higher score on the total scale compared to men (overall $F=4.66, \mathrm{~d} f=1, \mathrm{P}=0.03$ ). The results seem to indicate that the mean difference berween females and males on the BDI is mainly caused by a difference in scores on the cognitive/affective subscale. 


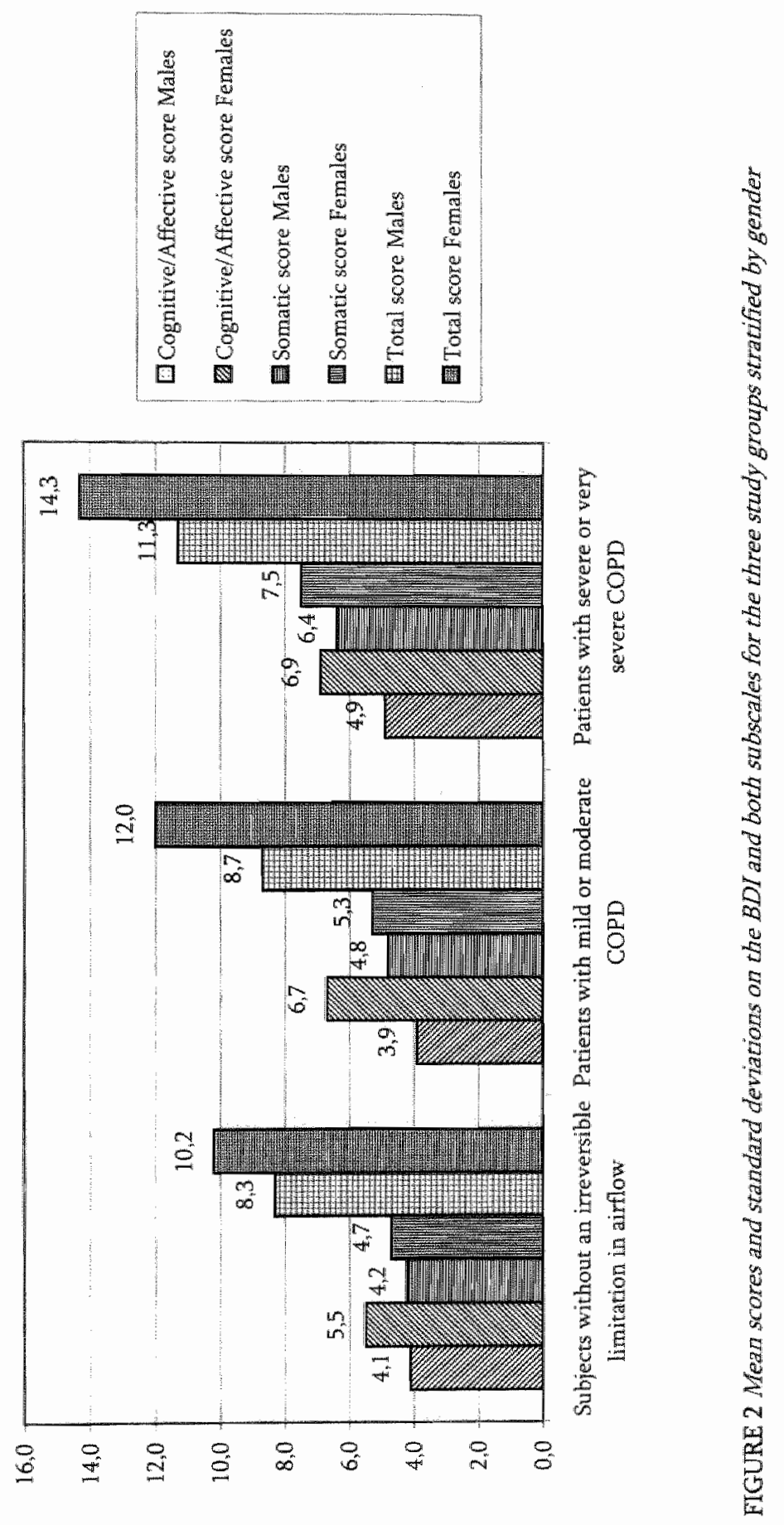




\section{Discussion}

The results of this observational study showed that the presence and severiry of depressive complaints (as assessed with the BDI) in patients with severe or very severe COPD was mainly caused by the presence and severity of somatic symptoms. Although this was also the case in patients with mild or moderate COPD and subjects at risk for $C O P D$, the mean score on the somatic subscale was significantly higher in patients with severe or very severe $\mathrm{COPD}(\mathrm{M}=6.9[\mathrm{SD}=4.1])$, compared to the mean scores of patients with mild or moderate $\operatorname{COPD}(\mathrm{M}=5.0[\mathrm{SD}=2.8])$, and of subjects at risk for COPD $(M=4.5[S D=2.9])$. Significantly more patients with severe or very severe COPD experienced difficulties with work (compared to patients with mild or moderate COPD and subjects at risk for COPD), felt tired and had lost weight (both compared to subjects at risk for COPD).

Since Beck et al.,[17] described a number of studies in which the relation between the BDI and gender has been evaluated, we also wanted to assess whether female subjects would score higher on the (subscales of) the BDI compared to males. Although the overall pattern of findings reported by Beck et al.,[17] was not conclusive, several studies reported that women have higher BDI mean scores than men. Oliver and Simmons for example, found that men scored about two points lower than women in a random sample of 298 adults. Our results are in accordance with these earlier studies indicating that females scored higher on the BDI compared to men. This study also showed that the mean difference on the BDI between females and males was mainly caused by a difference in scores on the cognitive/affective subscale.

Although this study indicates that the severity of depressive complaints seems to increase with increasing severity of the pulmonary disease (i.e., chronic limitation in airflow), we need to interpret these findings with care. Since the increase in depressive complaints was mainly caused by the presence and severity of somatic symptoms, we need to make sure that the somatic complaints are (also) related to mood and not (only) to a general medical condition before concluding that a person is indeed depressed. The use of somatic items could inflate the total score on the BDI by complaints, which are unrelated to mood. One could question whether the presence of difficulties with work, feeling tired and weight loss should be used to diagnose depression in these patients. Because COPD is an invalidating disorder, the disease is an important cause of disability. The reduced ability to perform activities of daily life with comfort is usually attributed to dyspnea and breathlessness resulting from patients' reduced capacity to breathe and exchange gas. Also, muscle weakness is now gemerally considered as an important factor limiting exercise 
performance in COPD patients.[26, 27] Furthermore, feeling tired (i.e., the perception of fatigue), may be a precursor of, may coexist with, or may occur in response to symptoms not related to mood experienced by patients with COPD. Patients with COPD have a higher prevalence of insomnia than the general population[28], with close to $50 \%$ of patients reporting significant disturbance in sleep quality. Sleep disturbance probably contributes to the non-specific daytime symptoms of fatigue described by these patients. $[29,30]$ Lastly, weight loss is also considered to be a systemic consequence of the disease.[31] Weight loss in these patients can be the result of an energy imbalance, preferentially manifested by a loss of fat mass or be the consequence of muscle wasting as manifestation of the presence of systemic inflammation as part of the disease process. These changes in body composition are highly prevalent in COPD.[32]

Is the total score on the BDI found in this study inflated by somatic complaints, which are unrelated to mood? Two arguments suggest this might be the case to some extent. First of all, important features of depression, such as 'work difficulty', 'weight loss', and 'fatigability' are frequently found in patients with (severe or very severe) COPD, even in the absence of depressed mood. Second, with regard to depression, these symptoms are judged to be of clinical significance when they interfere with normal activities and persist for at least two weeks.[12] Once a patient with COPD reports suffering from one (or more) of these symptoms, it is unlikely that the symptoms will disappear within those two weeks, in which case a diagnosis of a depressive illness or disorder may be made. Whether these symptoms overestimate the severity of the depressive complaints, and if they do to what extent, needs however, to be studied in future research.

This study has two limitations that need to be mentioned. First, because we used a cross-sectional design, only associations can be assessed and causal inferences cannot be drawn. This means that we could not establish whether the physical illness itself caused the occurrence and severity of the psychological complaints. The second limitation pertains to the external validity of our results. Ideally, our group of COPD patients and the subjects without an irreversible limitation in airflow should be random samples of the corresponding Dutch groups. Although the inclusion of subjects was balanced for disease severity, we do not know whether this sample is representative for the Dutch population of COPD patients at large. The patients who participated in this study lived in the same southern province of The Netherlands, called Limburg.

In conclusion, although self-report screening instruments, such as the Beck Depression Inventory, cannot replace systematic clinical assessment, they are useful in drawing attention to depression and other psychological problems in clinical settings where mood is not routinely assessed. However, doctors must be aware that 
symptoms simultaneously attributable to both medical illness and psychiatric problems may confound measurement of depression, and that there is no distinct boundary between normal and abnormal symptoms in patients with COPD.

\section{Funding/support}

This study was funded by grants from the Dutch Asthma Foundation (NAF grant no. 3.2.00.21), the Health Research and Development Council (ZorgOnderzoek Nederland, grant no. 2200.0111), The Nerherlands, and a personal grant from GlaxoSmithKline to E.F.M. Wouters. 


\section{References}

1. Wan Ede, L.. C.J. Yzermans, and H.J. Brouwer, Prevalence of depression in patients with chronic obstructive pulmonary disease: a systematic review, "Thorax, 1999; 54 (8): 688-692.

2. Lacasse, Y., L. Rousseau, and F. Maltais, Prevalence of depressive symptoms and depression in patients with severe oxygen-dependent chronic obstructive pulmonary disease. I Cardiopulm Rehabil, $2001 ; 20: 80-86$.

3. Dahlén, L and C. Janson, Anxiety and depression are related to the outcome of emergency treatment in patients with obstructive pulmonary disease. Chest, 2002; 122; 1633-1637.

4. Peruzza, S., G. Sergi, A. Vianello, et al. Chronic obstructive pulmonary disease (COPD) in elderly subjects: impact on functional status and quality of life. Respir Med, 2003; 97:612-617.

5. Yohannes, A.M. R.C. Baldwin, and M.J. Connolly, Depression and anxiety in elderly outpatients with chronic obstructive pulmonary disease: prevalence, and validation of the BASDEC screening questionmaire. Int J Geriatr Psychiatry, 2000; 15: 1090-1096.

6. Yohannes, A.M., R.C. Baldwin, and M.J. Connolly, Prevalence of sub-threshold depression in elderly patients with chronic obstructive pulmonary disease. Int J Geriatr Psychiatry, 2003; 18: $412-416$.

7. Dowson, C., R. Laing, R. Barraclough, et al., The use of the Hopsital Anxiety and Depression Scale (HADS) in patients with chronic obstructive pulmonary disease: a pilot study. NZ Med J, 2001; 114: $447-449$.

8. Stage, K.B., T. Middelboe, and C. Pisinger, Measurement of depression in patients with chronic obstructive pulmonary disease (COPD). Nord I Psychiatry, 2003; 57(4): 297-301.

9. Van Manen, J.G. P.I. Bindels, F.W. Dekker, et al., Risk of depression in patients with chronic obstructive pulmonary disease and its determinants. Thorax, 2002; 57: 412 416.

10. Aydin, 1.O. and A. Ulusahin, Depression, anxiety conorbidity, and disability in tuberculosis and. chronic obstructive pulmonary disease patients: applicability of GHQ-12. Gen Hosp Psychiatry. 2001; $23: 77-83$.

11. Aghanwa, H.S. and G.E. Erhabor, Specific psychiatric morbidity among patients with chronic obstructive pulmonary disease in a Nigerian general hospital. J Psychosom Res, 2001; 50: 179-183.

12. Peveler, R., A. Carson, and G. Rodin, ABC of psychological medicine. Depression in medical patients. Brit med J, 2002; 325: 149-152.

13. Spitzer, R.L., J.B.W. Williams, K. Kroenke, et al., Utility of a new procedure for diagnosing mental disorders in primary care. JAMA. 1994; 272: 1749-1756.

14. American Psychiatric Association, Diagnostic and statistical manual of mental disorders (4th ed., rev.). 1994, Washington D.C.: American Psychiatric Association.

15. Pauwels, R.A., A.S. Buist, P.M. Calverley, et al., Global strategy for the diagnosis, management, and prevention of chronic obstructive pulmonary disease. NHLBL/WHO Global Initiative for Chronic Obstructive Lung Disease (GOLD) Workshop summary. Am I Respir Crit Care Med, 2001; 163 (5): 1256-1.276.

16. Fabbri, L.M. and S.S. Hurd, Global strategy for the diagnosis, management and prevention of COPD: 2003 update. Eur Respir J، 2003; $22: 1-2$.

17. Beck, A.T., R.A. Steer, and M.G. Garbin, Psychometric properties of the Beck Depression Inventory: Twenty-five years of evaluation. Clinical Psychology Review, 1988; 8(1): 77-100.

18. Gift, A.G. and S.H. McCrone, Depression in patients with COPD. Heart Lung, 1993; 22 (4): 289 297.

19. Beck, A.T., C.H. Ward, M. Mendelson, et al., An inwentory for measuring depression. Arch Gen. Psychiatry, 1961: 4: 561-571.

20. Quanjer, P., G.J. Tammeling, J.E. Cotes, et al., Standardized lung function testing Eur Respir J. $1993 ; 6: 5-40$.

21. Cavanaugh, S., D.C. Clark, and R.D. Gibbons, Diagnosing depression in the hospitalized medically iil. Psychosom, 1983; 24 (9): 809-815. 
22. Cronbach, L., Coefficient alpha and the internal structure of tests. Psychometrika, 1951; 16: 297. 334.

23. Cicchetti, D.V., Guidelines, criteria, and rules of thumb for evaluating normed and standardized assessment instruments in psychology. Psychological Assessment, 1994; 6: 284-290.

24. Briggs S.R. and I.M. Cheek, The role of factor analysis in the development and evaluarion of personality scaless. Journal of Personality, 1986; 54: 106-148.

25. Cohen, 1., Statistical power andysis for the behavioural sciences. 2nd ed. 1988, Hillsdale, N!: Lawrence Earllbaum Associates.

26. Killian, K.J. Limitation to muscular actiwity in chronic obstructive pulmonary disease. Eur Respir . $2004 ; 24(1): 6-7$.

27. Gogker, H.R., E.F. Wouters, G.I. van der Vusse, et all, Skeletal muscle dysfunction in chronic obstructive pulmonary disease and chronic heart failure: underlying mechanisms and therapy perspectives. Am J Clin Nutr, 2000; 71 (5): 1033-1047.

28. Klink $\mathrm{M}$. and $\mathrm{S}$. Quan, Prevalence of reported sleep disturbances in a general population and their relationship to obstructive airways diseases. Chest, $1987 ; 91: 5,40-546$.

29. Cormick, W., L.G. Olson, M.J. Hensley, et al, Noctumal hypoxaemia and quality of sleep in patients with chronic obstructive lung disease. Thorax $1986_{*}^{*} 41: 846-854$.

30. Breslin, E., C. van der Schans, S. Breukink, et al, Perception of fatigue and quality of life in patients with COPD. Chest, 1998; 114 (4): 958-964.

31. Schols, A.M.W.J. and E.F.M. Wouters, Nutritional abnormalities and supplementation in chronic obstructive pulmonary disease. Clin Chest Med, 2000; 21 (4): 753-762.

32. Schols, A.M., P.B. Soeters, A.M. Dingemans, et al., Prevalence and characteristics of nutritional depletion in patients with stable COPD eligible for pulmonary rehabilitation. Am Rev Respir Dis, $1993 ; 147(5): 1151 \cdots 1156$ 
The efficacy of bupropion for smoking cessation in relation to pharmaceutical industry sponsorship and methodological quality:

A systematic review and meta-analysis

Wagena E], Knipschild P

TOBACCO CONTROL, accepted pending revision 


\section{Abstract}

\section{OBTECTIVES}

The objective of this review was to evaluate the efficacy of bupropion for smoking cessation in relation to pharmaceutical industry sponsorship and methodological quality.

\section{DATA SOURCES}

Randomized trials were identified by: 1) searching electronic databases; 2) checking online publicly accessible registers of clinical trials; 3) searching references of identified studies and screening abstract books of conferences and symposia, and 4 ) personal communication with the first authors of identified papers.

\section{REVIEW METHODS}

We included randomized trials in which $300 \mathrm{mg} /$ day sustained-release bupropion was compared to placebo. The main clinical outcome measure was at least 6 months prolonged abstinence, confirmed with a biochemical test. To assess the methodological quality of selected trials, we used the Delphi list and the criteria of Jadad.

\section{RESULTS}

Sixteen placebo-controlled trials of bupropion for smoking cessation, comprising 6092 smokers, met the inclusion criteria. Random effects meta-analysis shows that the trials sponsored by the manufacturer as well as those supported by other organizations seem to favor treatment with bupropion compared to placebo (relative risk $[\mathrm{RR}]=1.9,95 \%$ confidence interval $[\mathrm{CI}] 1.5,2.5 ; \mathrm{RR}=1.3,95 \% \mathrm{CI} 0.9$, 1.7 respectively). However, the efficacy of bupropion was significantly lower in the trials that were not sponsored by the manufacturer (relative risk ratio $=1.5,95 \% \mathrm{CI}$ $1.0,2.3)$. We did not find any major differences in methodological quality between both types of trials.

\section{CONCLUSION}

Our review indicates that although bupropion is efficacious in helping smokers to quit, the studies sponsored by the manufacturer of bupropion resulted in higher prolonged abstinence rates compared to the trials sponsored by other organizations. Whether the efficacy of bupropion is overestimated in the studies sponsored by the manufacturer needs to be investigated. 


\section{Introduction}

There is a long-standing history of collaboration between pharmaceutical manufacturers and medical researchers. ${ }^{12}$ The proportion of clinical trials funded by the pharmaceutical industry is still increasing. ${ }^{3}$ 'This results in widespread financial relationships between industry, scientific investigators, and academic institutions. Empirical evidence shows that conclusions of randomized trials as well as reviews are more positive toward experimental interventions if they are funded by the pharmaceutical industry. ${ }^{48}$ One explanation for this finding could be a difference in the methodological quality of studies. Is the research funded by industry more likely to result in false positive outcomes because they are subject to biases in design, outcome, and reporting compared to studies that are not funded by the industry? 10 One example of repeated collaboration between the pharmaceutical industry and individual researchers and research institutes concerns the evaluation of sustainedrelease bupropion (trade name Zyban) for smoking cessation. Linda Ferry, a specialist in preventive medicine heard from a psychiatrist colleague that some patients who were treated for depression with bupropion were reporting a reduction in their desire to smoke. ${ }^{11}$ She followed this up with a pilot study ${ }^{12}$ and a randomized clinical trial..$^{13}$ Although the trial did not detect a statistically significant beneficial effect of bupropion compared to placebo, these studies ultimately led to the development of the medication as an aid to smoking cessation. Recently, the manufacturer, GlaxoSmithKline, financially supported many trials that evaluated the efficacy of bupropion. Since its approval, both authors of this review have questioned whether bupropion is as efficacious as is often stated. Our skepticism arose because so many reviews on bupropion for smoking cessation appeared, highlly recommending the use of this drug, and a number of them included only a selection of the randomized trials published so far (e.g. Ferry and Johnston ${ }^{14}$ and MartinezRaga et al. ${ }^{15}$ ). Furthermore, other reviews on bupropion were initiated or financially supported by the manufacturer of the drug (e.g. Perruchoud et al., ${ }^{16}$ and Jorenby ${ }^{17}$ ). Most importantly however, in many trials on bupropion, continuous or prolonged abstinence from smoking for a relatively short period of time (e.g. 7 weeks) was used as primary efficacy measure. Although short-term health effects of smoking cessation are clinically very important ${ }^{18}{ }^{19}$, these outcome measures are neither appropriate for assessing the long-term health effects of smoking cessation, nor to evaluate the maintenance effect of an intervention. We therefore evaluated whether the results of trials that were financially supported by the manufacturer of bupropion are different from the results of trials that were not sponsored by the 
manufacturer. Furthermore, we explored whether the quality of the methods in trials sponsored by the manufacturer of bupropion was different from that in the other trials.

\section{Methods}

\section{SELECTION OF RANDOMISED TRIALS}

We selected randomized trials in which $300 \mathrm{mg} /$ day sustained-release bupropion, the recommended dose for the indication smoking cessation, was compared to placebo. We used prolonged abstinence or continuous abstinence from smoking until 6 or 12 months after the target quitting date (TQD) as outcome measure ${ }^{20}$, although 12 months prolonged abstinence rates were prefered over 6 months abstinence rates. Since not all studies reported cessation rates at exactly these intervals, we allowed a time window of 6 weeks at each follow-up point. Selfreported abstinence needed to be confirmed with a biochemical test (e.g. expired air CO, urinary cotinine) ${ }^{21}$

\section{LITERATURE SEARCH}

Electronic databases and Internet registers of clinical trials

Randomised trials were identified by a computer-aided search of Medline (1966 to March Week 1 2004), Embase (1989 to March Week 1 2004), PsycINFO (1872 to March Week 1 2004), CINAHL (1982 to March Week 1 2004) and the Cochrane Central Register of Controlled Trials using the drug name "bupropion" and 'smoking' as free text terms. We also searched publicly accessible registers of clinical. trials ${ }^{22}$ : ClinicalTrials gov ${ }^{23}$, TrialsCentral.org ${ }^{24}$, Controlled-Trials.com, the National Research Register (NRR), Issue 3, 2003, and the most recent version of the Clinical Trials Register of GlaxoSmithKhine (i.e. version. 1.0, rellease date 27/09/1999).

\section{Reference tracking}

The reference lists of all selected trials were inspected for additional published reports and citations of unpublished research. Since bupropion was registered for the indication smoking cessation in 1999, we screened abstract books of relevant conferences and symposia from 1999 until March 2004 (e.g. annual meetings of the Society for Research on Nicotine and Tobacco). 


\section{Personal communication}

We visited the Director Medical Affairs of Europe and the Medical Affairs Manager of GlaxoSmithKline in Greenford, United Kingdom, to discuss the methodology of our review and find out whether we missed any randomised trials.

\section{DATA EXTRACTION}

Both authors checked all references that were retrieved by our literature search for relevance. For each trial we extracted the following data: (1) first author, year of publication and country; (2) methods (randomisation and length of followup); (3) number of smokers randomised; (4) type of intervention; (5) number of dropouts, and (6) definition of abstinence, validation method used and (prolonged) abstinence rates. We extracted the sources of (financial) support from the text, statements of sources of support, authors' affiliations, and acknowledgements. Based on the sources of support, we classified all trials into the following two groups: (1) trials financially supported by the manufacturer of bupropion or for which the manufacturer provided manpower (authorship, statistical analysis, and/or other assistance), and (2) trials which did not receive any financial support from the manufacturer. Trials, for which the manufacturer of bupropion provided study medication only, were grouped with the studies that were not financially supported by the manufacturer.

\section{METHODOLOGICAL QUALITY ASSESSMENT}

Both reviewers assessed the methodological quallity of the trials independently by using full text versions of the studies. We did not assess the methodological quality if only an abstract or poster was available. The reviewers were not blinded for authors, institution and journal title. In a consensus meeting, disagreements were discussed and resolved.

To assess the methodological quality of selected trials, we used items from the Delphi list ${ }^{25}$ in combination with the criteria of Jadad ${ }^{26}$. We assigned a score for reported compliance with each of the following quality criteria: method of randomisation described (use of random [unpredictable] assignment sequence), treatment allocation concealed (assignment generated by an independent person not responsible for determining the eligibility of the patients), specification of eligibility criteria, comparability regarding prognostic indicators (level of nicotine dependence, number of cigarettes smoked per day, use of aids for smoking cessation in the past), (attempt to) patient blinding, (attempt to) blinding of therapist, (attempt to) blinding of assessor, success of blinding checked, loss to follow up. less than $20 \%$, intentionto-treat analysis performed, and reasons given for withdrawals. All criteria were 
scored as "yes', 'no' or 'unclear". The use of placebo medication is considered to be an attempt to blind the patient.

The first author or principal investigator of identified papers and unpublished trial reports was contacted through dissemination of a standard e-mail. It explained the purposes of the review and, if necessary, specified the additional data that we required.

\section{QUANTITATTVE DATA SYNTHESIS}

\section{Measures of effect}

We used Review Manager $4.2 .2^{27}$ to estimate the summary statistics (risk differences (RD), relative risks (RR) and corresponding $95 \%$ confidence intervals (95\% CI)). In order to compare RRs, we calculated relative risks ratios (RRR). The risk difference will be calculated because it reflects the absolute change in risk with the intervention. Heterogeneity refers to variability or differences between studies in the estimates of effects. ${ }^{28}$ A distinction is being made between "statistical heterogeneity' (differences in the reported effects), 'methodological heterogeneity" (differences in study design) and 'clinical heterogeneity' (differences between studies in key characteristics of the participants, interwentions or outcome measures). Where there is no evidence of statistical heterogeneity (as assessed by the natural approximate chi-square test), a fixed effect model will be used in the first instance to combine data. This statistical model stipulates that the units under analysis (e.g. people in a study in a meta-analysis) are the ones of interest, and thus constitute the entire population of units. Only within-study variation is taken to influence the uncertainty of results of a meta-analysis, as reflected in the confidence interval, using a fixed effect model. Variation between the estimates of effect from each study does not affect the confidence interval in a fixed effect model. Where there is evidence of statistical heterogeneity, results will be calculated using a random effects model. In this statistical model both within-study sampling error (variance) and between-studies variation are included in the assessment of the uncertainty of the results of a meta-analysis. A formal test for statistical heterogeneity, the natural approximate chi-square test, was conducted to assess whether the observed variability in study results was greater than that expected to occur by chance. Funnel plots were constructed to investigate the possibility of publication bias. ${ }^{29} 30$ 


\section{Results}

\section{IDENTIFICATION OF ELIGIBLE TRIALS}

The combined searches resulted in 39 potential studies of which five were not published yet (neither as full paper nor as abstract) and three were ongoing ${ }^{31-33}$. The Director Medical Affairs of Europe of GlaxoSmithKline provided us with the reports of the five trials that were not published yet (study codes: AK1A4008, ZYB30008, ZYB40028, ZYB40036, and ZYB40044; no references available). We retained 16 trials for analysis. The other 23 were excluded for the following reasons: (1) two trials evaluated bupropion for relapse prevention instead of smoking cessation ${ }^{34}$ 35; $^{3}$ (2) of six trials we could not retrieve 6 or 12 months prolonged abstinence data (study ZYB40044 and 36-40); (3) one trial evaluated bupropion for smoking reduction ${ }^{41}$; (4) six trials did not include a placebo bupropion group ${ }^{42-47}$; (5) one trial used a dosage of $150 \mathrm{mg} /$ day instead of $300 \mathrm{mg} /$ day $^{48} ;(6)$ one trial only measured point prevalence abstinence from smoking ${ }^{49}$; (7) three trials did not randomize study participants (study codes ZYB30008, ZYB40028, ZYB40036; no references available), and (8) three trials were still ongoing. ${ }^{31-33}$

\section{TRIAL CHARACTERISTICS}

Table 1 gives the characteristics of the trials included in the analysis. Sixteen placebo-controlled trials of bupropion for smoking cessation, comprising 6092 smokers, met the inclusion criteria and contributed to our meta-analysis. ${ }^{12} 13$ 50-63 The results of six of these trials were available only from abstracts of conference presentations or posters. ${ }^{12135760-62}$

Because Ferry and colleagues ${ }^{12}$ did not present 12 months prolonged abstinence data and she did not respond to our e-mails, we used the data presented by Hughes et al. ${ }^{64}$ However, what the exact abstinence rates were remains unclear because Hughes and colleagues stated that 45 smokers participated in that study while Ferry et al. ${ }^{12}$ mention the inclusion of only 42 . The multi-centre trial conducted by Hurt and colleagues evaluated sustained release bupropion in doses of $100 \mathrm{mg} /$ day, $150 \mathrm{mg} /$ day or $300 \mathrm{mg} /$ day against placebo for seven weeks. ${ }^{50}$ For this review we used the data from the comparison between bupropion $300 \mathrm{mg} / \mathrm{day}$ and placebo. In another multi centre trial a combined treatment of bupropion 300 $\mathrm{mg} /$ day and nicotine transdermal patch was compared to bupropion alone and patch alone and to placebo in a factorial design..$^{51}$ We extracted the abstinence data from the comparison between bupropion $300 \mathrm{mg} / \mathrm{day}$ alone versus placebo. In the trial conducted by Gonzales et al., ${ }^{52}$ the smokers who participated were all familiar with bupropion. The authors only recruited smokers who had previously failed to quit 
smoking using bupropion for at least two weeks. ${ }^{52}$ Lerman and colleagues reported outcomes only for a subgroup of trial participants who were Caucasian of European descent. ${ }^{63}$ Although we contacted the principal investigator and asked for the abstinence data from the total group enrolled, they did not provide us with the missing data. Hall and colleagues used a factorial design to compare bupropion, nortriptyline and placebo crossed with two different behavioural programs. ${ }^{56} \mathrm{We}$ combined the data from the bupropion groups and compared the abstinence rate in this group to the combined rates of the placebo groups. One unpublished trial conducted by Simon et al., ${ }^{57}$ compared bupropion with placebo as an adjunct to a behavioural program combined with nicotine replacement therapy (NRT) using the nicotine patch.

All but one trial were conducted in the USA $A^{12130-5763}$ or Europe ${ }^{5860-62}$ In one multi centre trial, European smokers as well as smokers from Australia were included. ${ }^{65}$ The follow-up period ranged from 6 to 12 months. Five trials reported

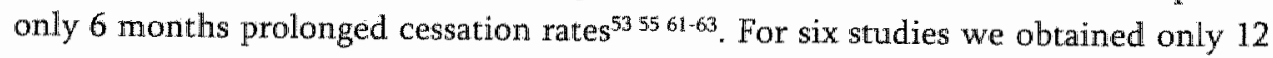
months prolonged abstinence data 121350515660 , and for five studies we obtained both 6 and 12 months prolonged abstinence rates. ${ }^{52} 5457-59$ All participants also took part in a behavioural program that consisted of individual (face-to-face or telephone) and/or group counselling. The number of face-to-face (individual or group) sessions ranged from 4 to 13, and the telephone counselling sessions from 0 to 11 . The period, during which the participants attended these sessions, ranged from 4 weeks to 12 months. 


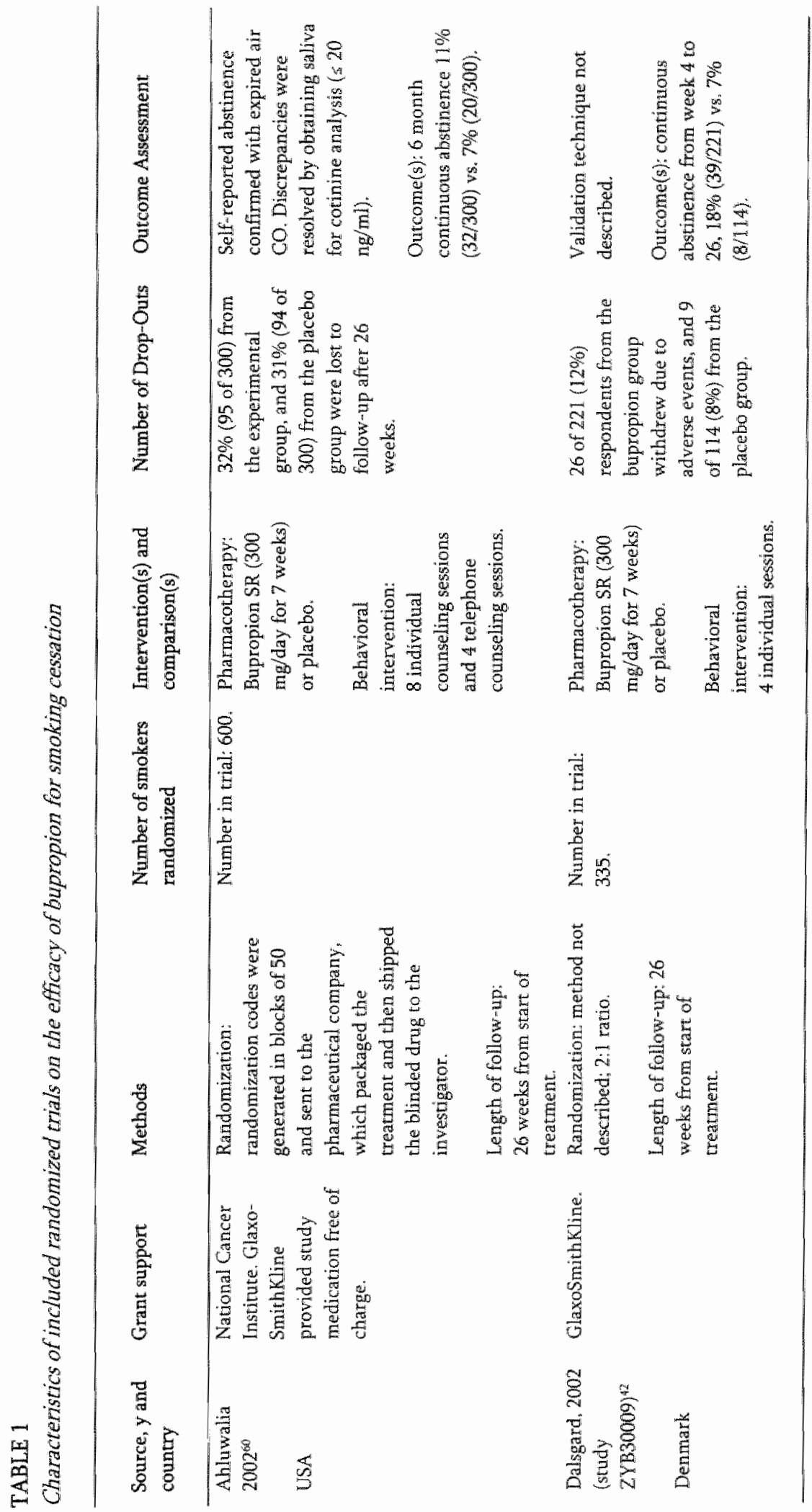




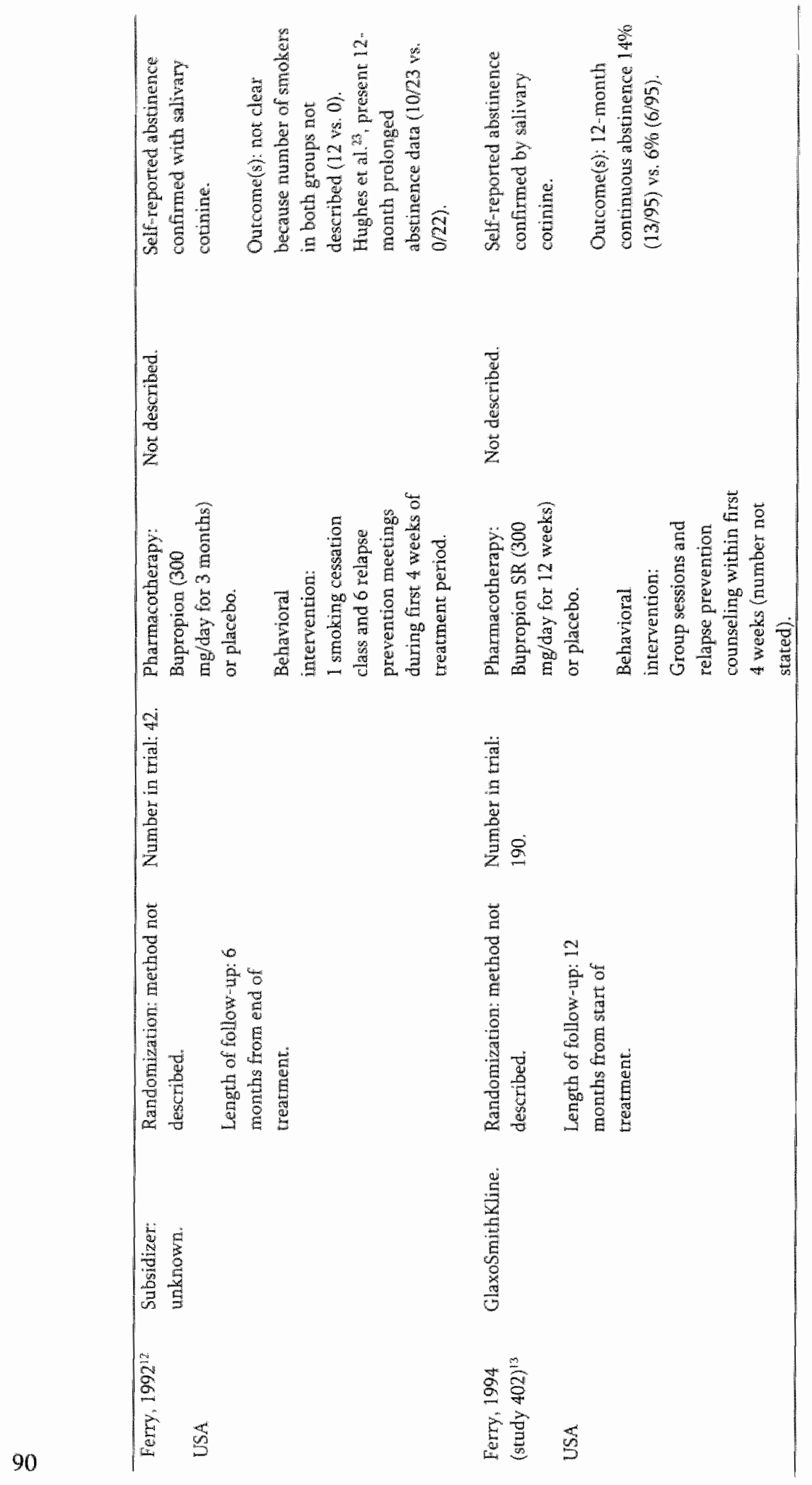




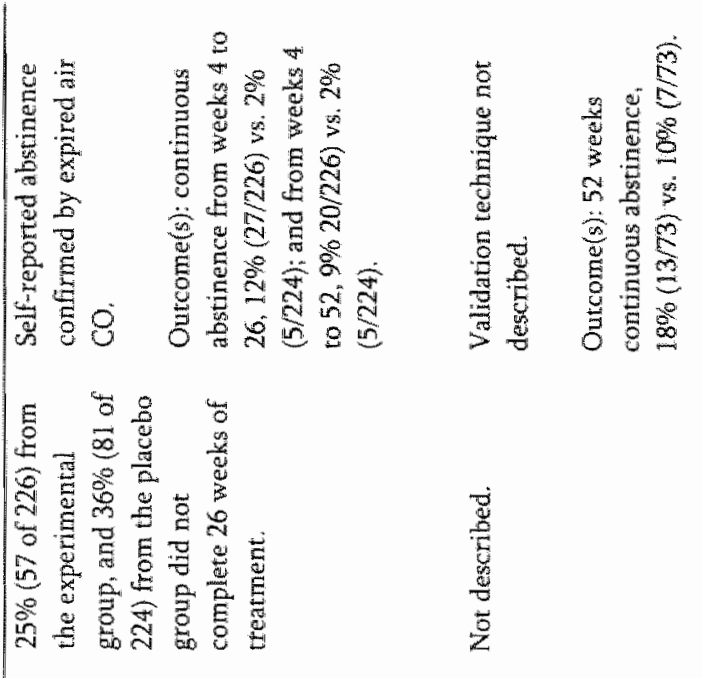

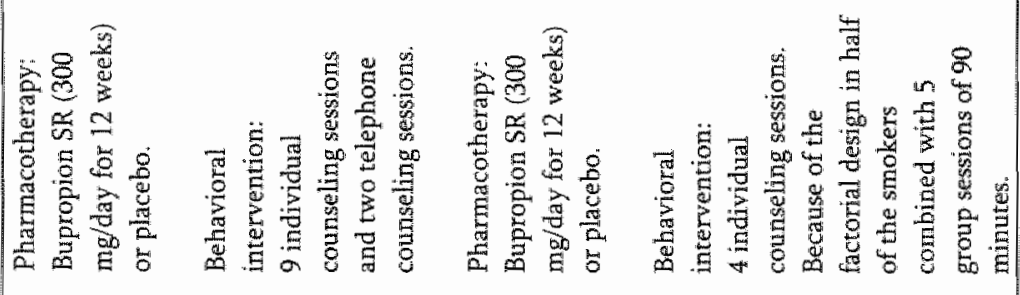

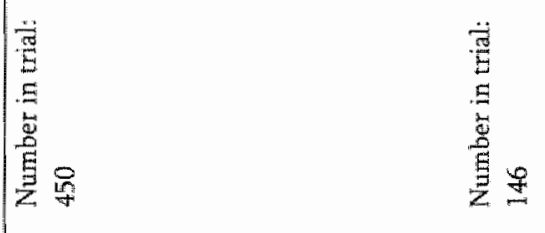

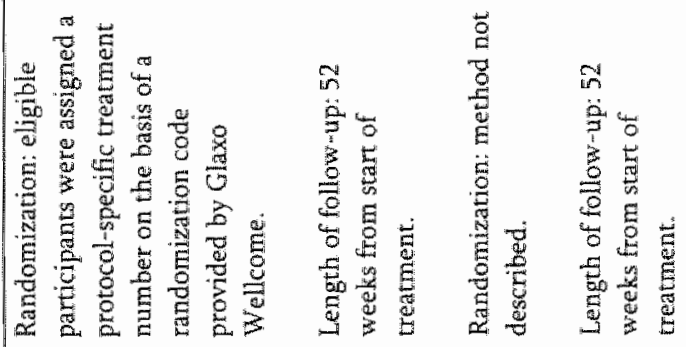

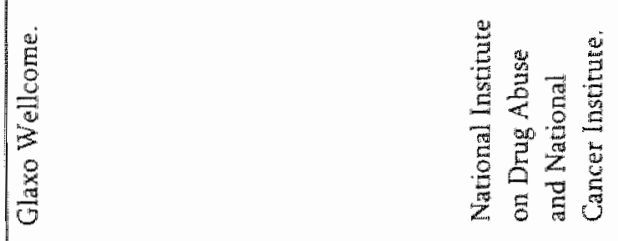

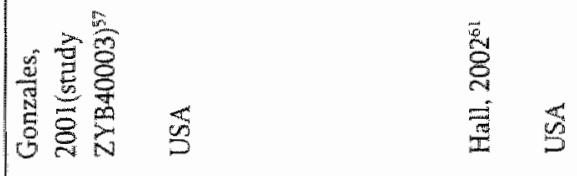




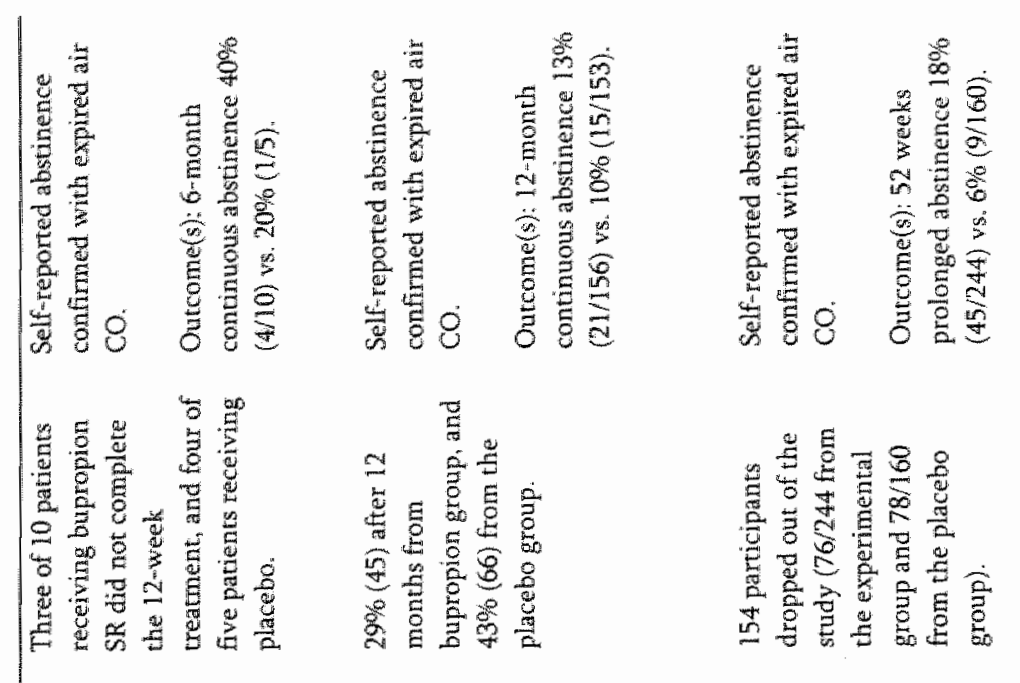

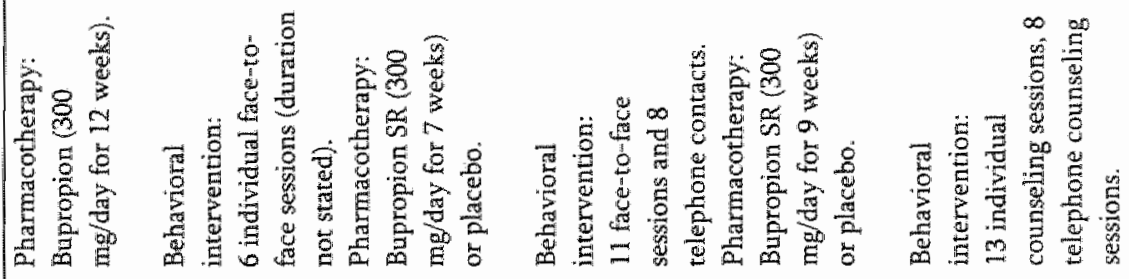

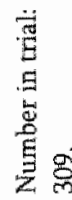

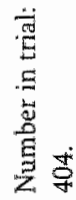

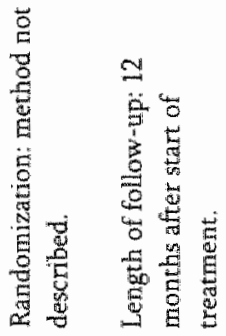

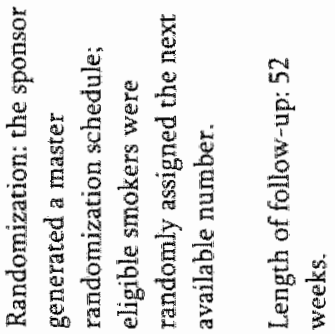

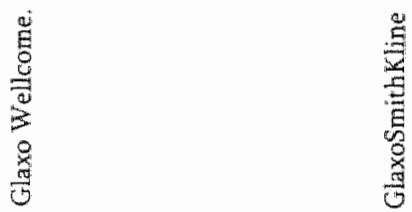

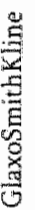

察鲸

量瓷

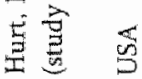

喜高弯 


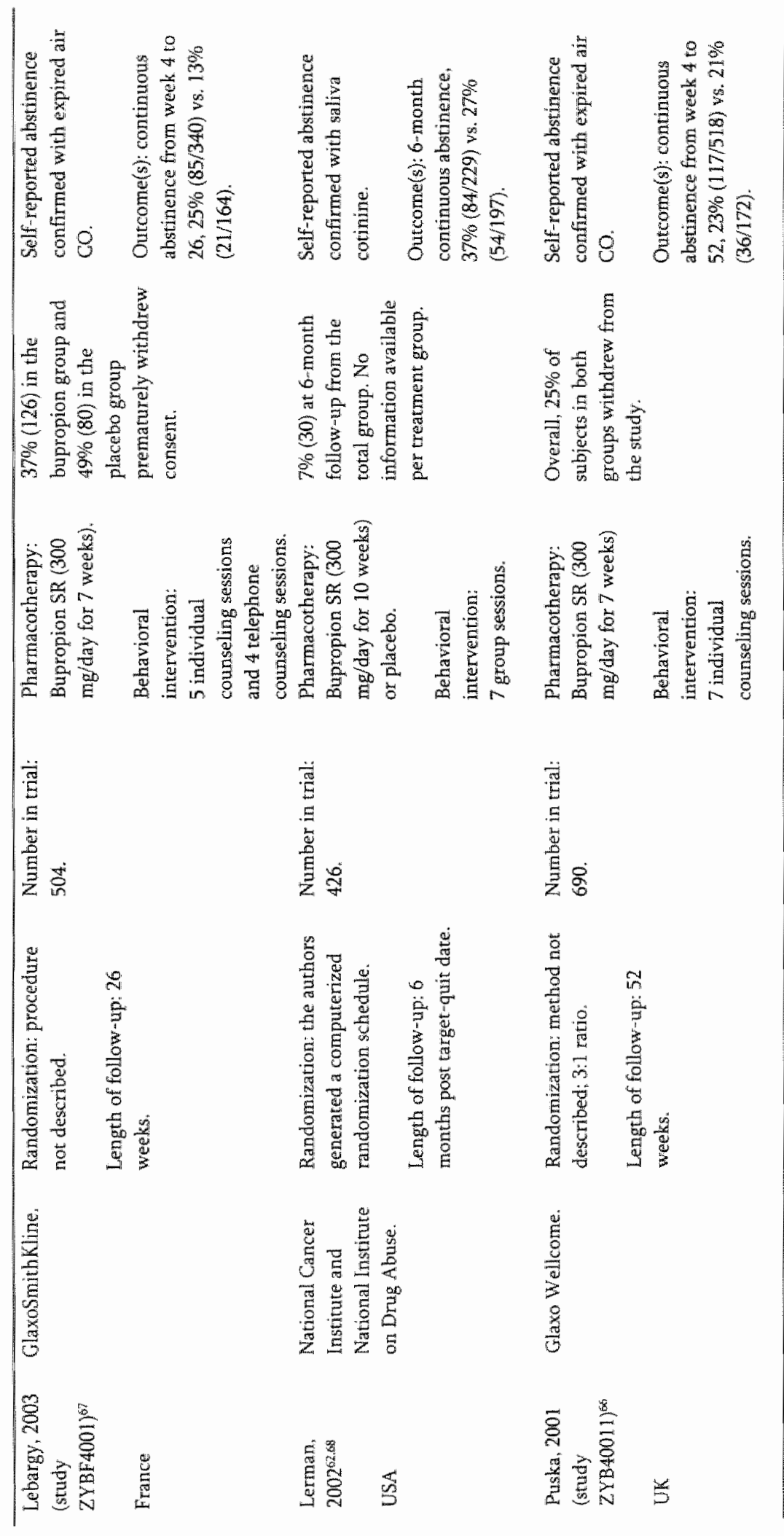




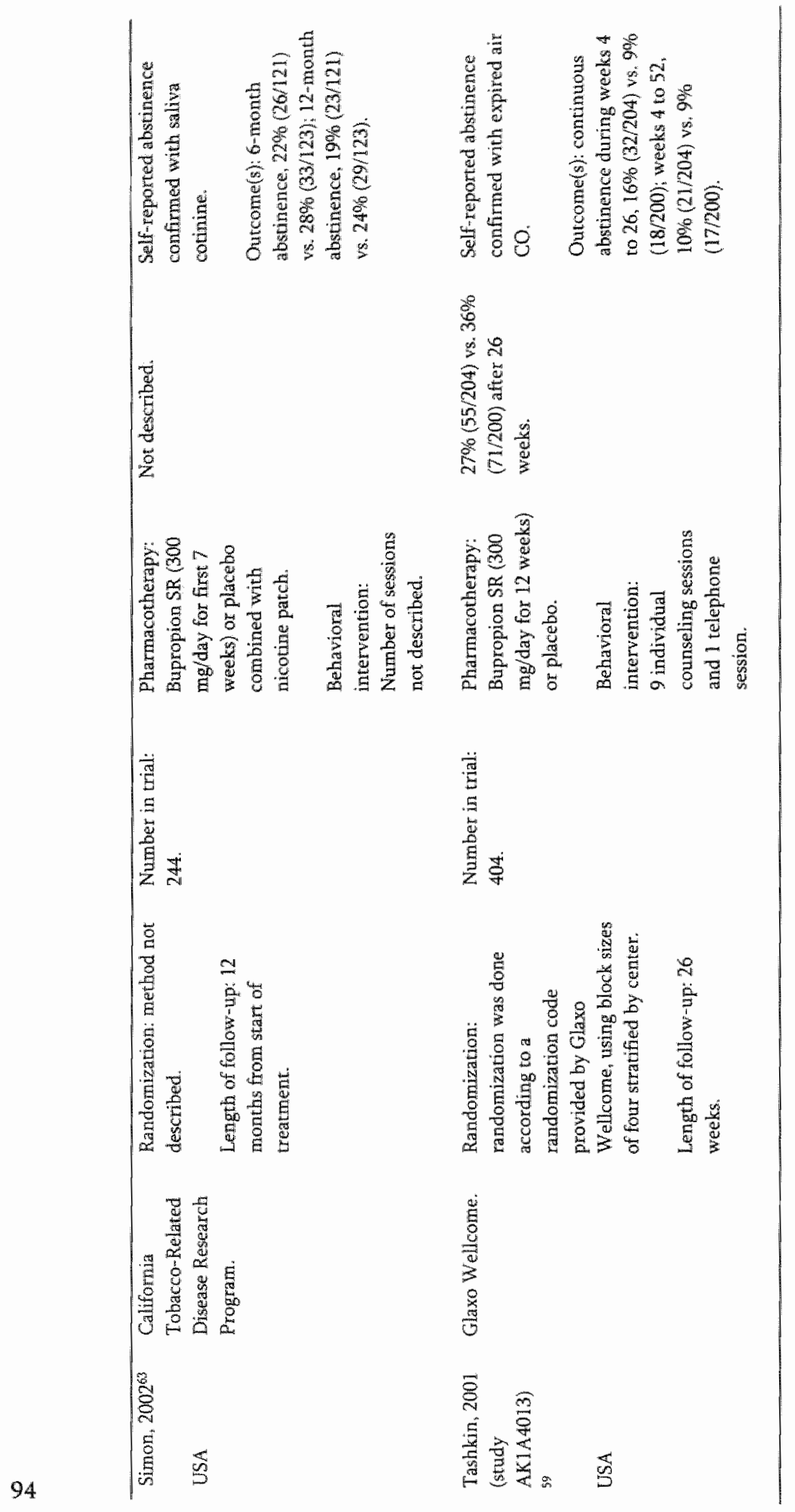




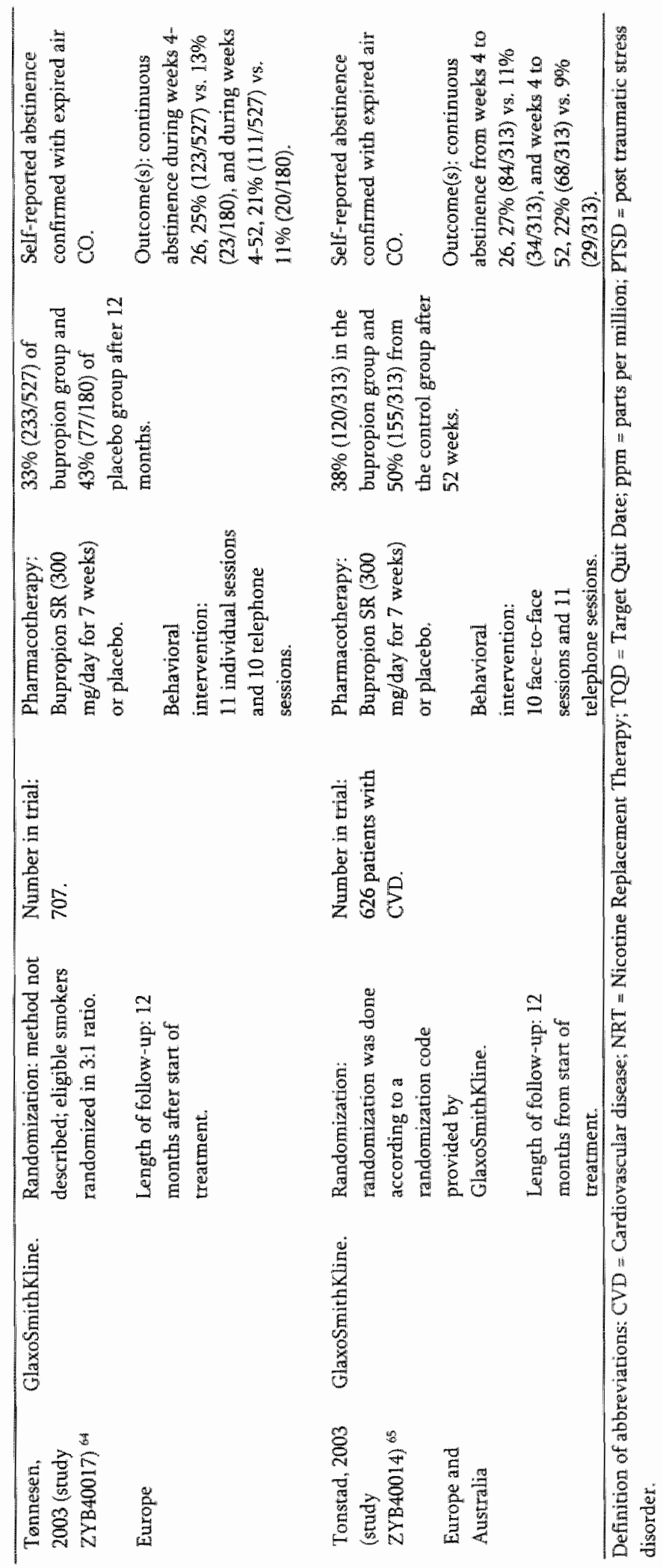




\section{FINANCIAL SUPPORT AND EFFECT ESTIMATION}

We considered 12 trials $(75 \%)$ to be financially supported by the manufacturer of bupropion ${ }^{12} 130.5458 .62$ and four by other organizations $s^{55} 565763$. Of one of the trials ${ }^{i 2}$ we could not retrieve the sponsor from the abstract. We sent several e-mails to the principal investigator, Linda Ferry, but did not get a response. Since Linda Ferry has been involved in the development and registration of bupropion from the beginning, we chose to treat this trial as financially supported by the manufacturer.

Since we found evidence of statistical heterogeneity (chi-square $=36.8, \mathrm{df}=15$, $\mathrm{P}=0.001$ ), we used a random effects model to estimate the RRs and RDs. When the results of all included trials are combined bupropion resulted in higher prolonged abstinence rates compared to placebo $(19.7 \%$ and $11.3 \%, \mathrm{RR}=1.7 ; 95 \% \mathrm{CI} 1.4,2.1)$. Results indicate that using bupropion for smoking cessation increases the absolute chance of reaching at least 6 months prolonged abstinence by $8 \%(\mathrm{RD}=0.08 ; 95 \% \mathrm{CI}$ 0.05-0.11). Figure 1 shows the forest plots with prolonged abstinence rates and pooled relative risks and risk differences for bupropion compared with placebo stratified by source of financial support. Random effects meta-analysis shows that the trials sponsored by the manufacturer favor treatment with bupropion compared to placebo ( $\mathrm{RR}=1.9,95 \%$ CI $1.5,2.5 ; \mathrm{RD}=0.09,95 \% \mathrm{CI} 0.06,0.12$ ). Although the trials that were financially supported by other organizations than the manufacturer also favor treatment with bupropion compared to placebo, the difference with placebo just failed to reach statistical significance ( $R R=1.3,95 \% \mathrm{CI} 0.9,1.7 ; \mathrm{RD}=0.04$, $95 \% \mathrm{Cl}-0.01,0.09)$. The pooled RR was significantly lower for these trials compared to the ones that were financially supported by the manufacturer $(R R R=1.5,95 \%$ CI $1.0,2.3)$. 
STUDES SPONSORED BY THE MANUFACTURER OF BUPROPION

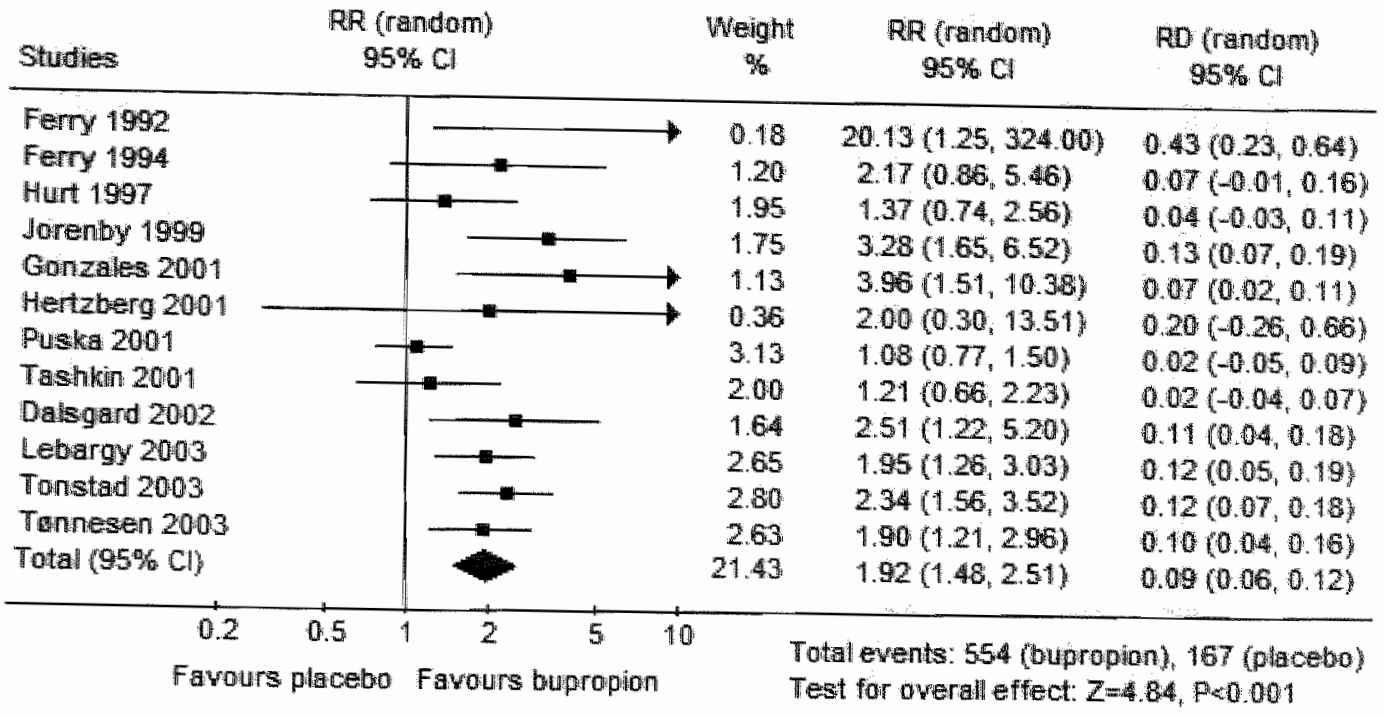

STUDVES SPONSORED EY OTHER ORGANLATIONS

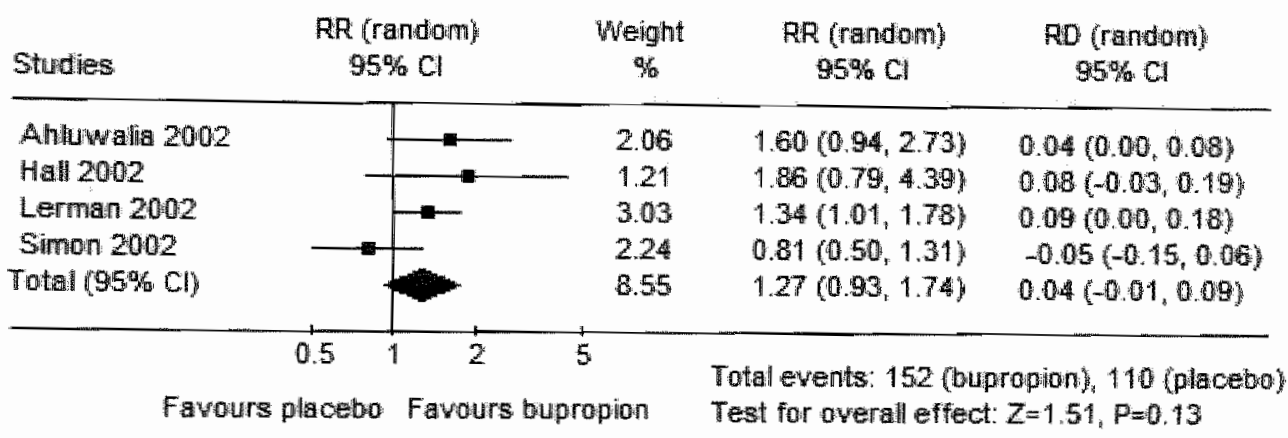

FIGURE 1 Efficacy of bupropion compared with placebo for at least 6 month prolonged abstinence from smoking stratified by source of financial support: forest plots with study werghts, pooled relative risks and pooled risk differences

In order to assess whether the difference between trials sponsored by the manufacturer of bupropion compared with trials that were financially supported by other organizations is caused by the inclusion of mostly 6 months prolonged abstinence rates, we present the 6 and 12 months prolonged abstinence rates for trials financially supported by the manufacturer of bupropion in figure 2 . The results indicate that the efficacy of bupropion compared with placebo declines in time (RRo montas prolonged abstinemee $=2.2,95 \%$ CI $1.8,2.7$ and RR 12 months prolonged alstintenes $=1.9,95 \%$ CI 1.4 , 2.7). 


\section{FUNDING AND METHODOLOGICAL QUALITY}

Table 2 shows the results of our methodological quality assessment. Of the 10 trials published in full, the manufacturer financially supported seven trials. ${ }^{50-54}$.5\% All trials were described as randomized, but four trials did not describe the method of allocation. ${ }^{50535658}$ Also, all trials reported that patients were blinded, but only two evaluated whether blinding was successful by asking the participants which treatment they thought they were given. ${ }^{55}{ }^{56}$ Only three of the 10 trials reported to have blinded the therapist as well as the assessor ${ }^{51}{ }^{52}{ }^{59}$, and only two trials (both supported by other organizations than the manufacturer) succeeded in following up more than 80 percent of the randomized participants. ${ }^{56.63}$ These results do not reveal any (major) differences in methodological quality between trials supported financially by the manufacturer and other trials.

\section{PUBLICATION BIAS}

In figure $3 \mathrm{a}$ and $3 \mathrm{~b}$ we presented funnel plots to investigate the possibility that our review is subject to publication bias. Figure 3a shows the funnel plot, which is based on all trials included in this review. The funnel plot is not symmetrical, which is mainly caused by one small study ${ }^{12}$. This may indicate publication bias, although there are other possible explanations. The results of the study conducted by Ferry and colleagues were presented only as abstract. Even though we contacted Dr Ferry for additional information by e-mail and in person at the World Conference on Tobacco or Health in Helsinki, Finland, she did not provide any. This study may be of lesser quality, and poor quality studies, especially those failing to conceal allocation, often result in exaggerated treatment effect sizes. In looking at this plot, we can only report that there may be publication bias. When we take a closer look at the top half of this plot, excluding the two smallest studies conducted by Ferry et al. ${ }^{12}$ and Hertzberg et al. ${ }^{53}$, it appears that the smaller, less precise studies are (much) more positive than the larger, more precise studies, and there are no smaller studies to the left side of the graph (Figure 3b). This asymmetry in our funnel plot suggests the likelihood of bias towards smaller-sized trials reporting more positive results in favor of bupropion. 
GHONTHS PROLONGED ABSTMENCE RATES

\begin{tabular}{|c|c|c|c|c|}
\hline Study & $\begin{array}{l}\text { andomy } \\
\mathrm{Cl}\end{array}$ & $\begin{array}{c}\text { Weight } \\
\%\end{array}$ & $\begin{array}{c}\text { RR (randam) } \\
95 \% \mathrm{Cl}\end{array}$ & $\begin{array}{c}\text { RO rendom } \\
\text { genc c }\end{array}$ \\
\hline Gonzales 2001 & $\longrightarrow$ & 3.74 & $5.35,(2.10,13.65)$ & $0.10\{0.05,0.47$ \\
\hline Hertzkerg 2001 & $\longrightarrow$ & 1.12 & $2.00(0.30,13.51)$ & $0.20(-0.25,0.65$ \\
\hline Tashoin 2001 & 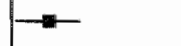 & 7.15 & $1.05(1.06,321)$ & 0.070 .01 .0 .139 \\
\hline Dalsgard 2002 & $\longrightarrow$ & 5.28 & $2.51(1.22,520)$ & $0.11\{0.04,0.18\}$ \\
\hline Lebargy 2003 & - & 876 & $1.95(1.26,3.03)$ & $0.12(0.05,0.19$ \\
\hline Tonstad 2003 & - & 9.91 & $2.47(1.71,3.56)$ & $0,16(0,10,0,22)$ \\
\hline Tonnesen 2003 & - & 9.19 & $1.83(1.21,2.76)$ & $0.11(0.04,17)$ \\
\hline Total $95 \%$ Cl) & & 45.14 & $2.18(1.79,267)$ & $0,110,09,13)$ \\
\hline
\end{tabular}

12 MONTHS PROLONGED ABSTINENCE RATES

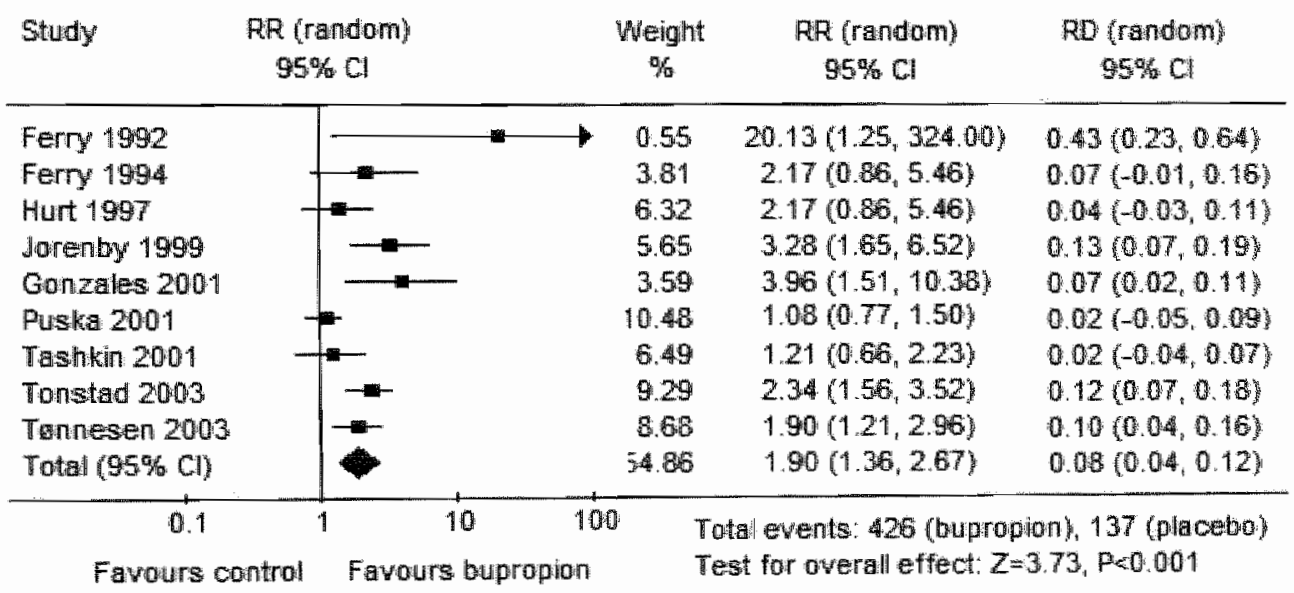

FIGURE 2 Six and 12 months prolonged abstinence from smoking for trials financially supported by the manufacturer of bupropion: forest plor with study weights pooled relative risks and pooled risk differences 


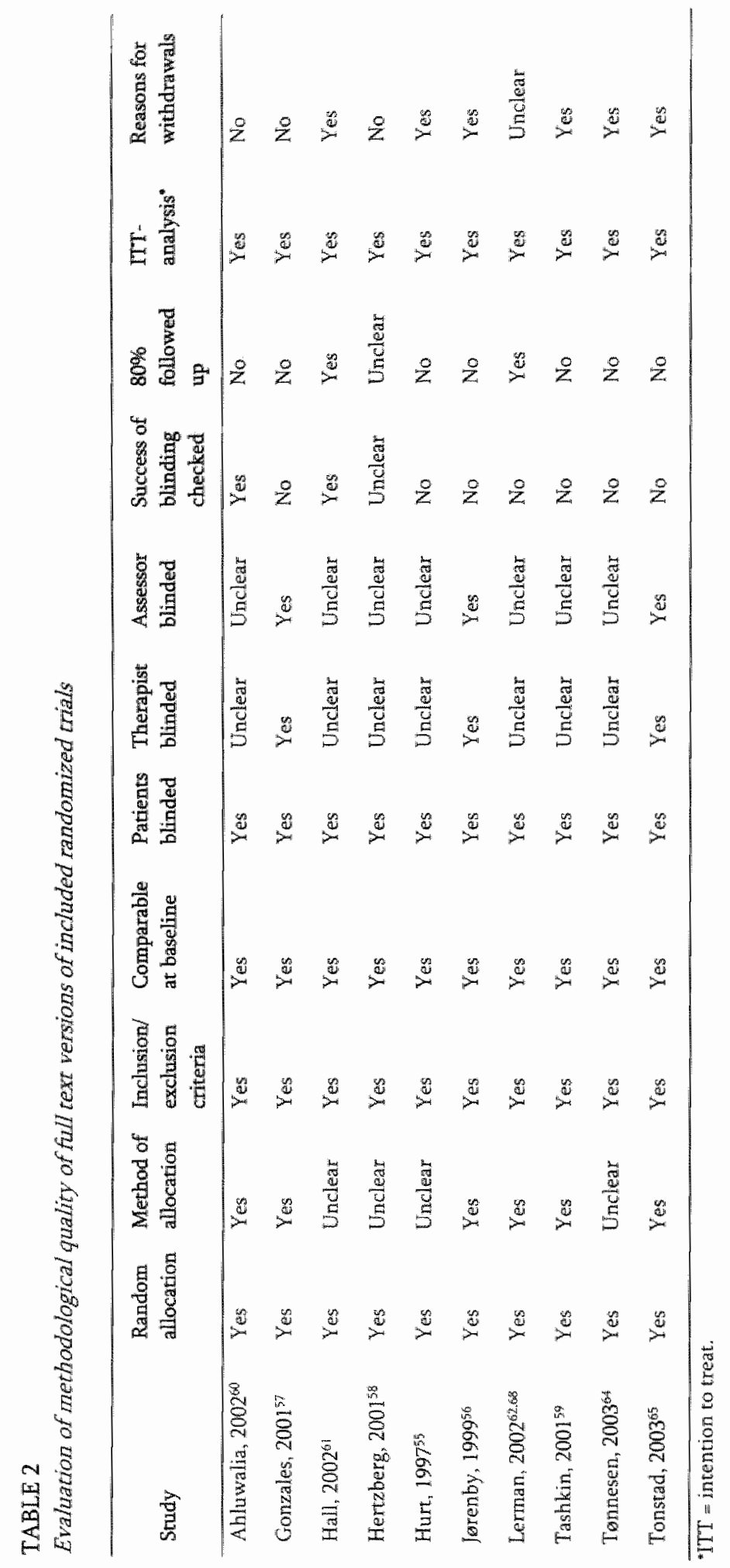




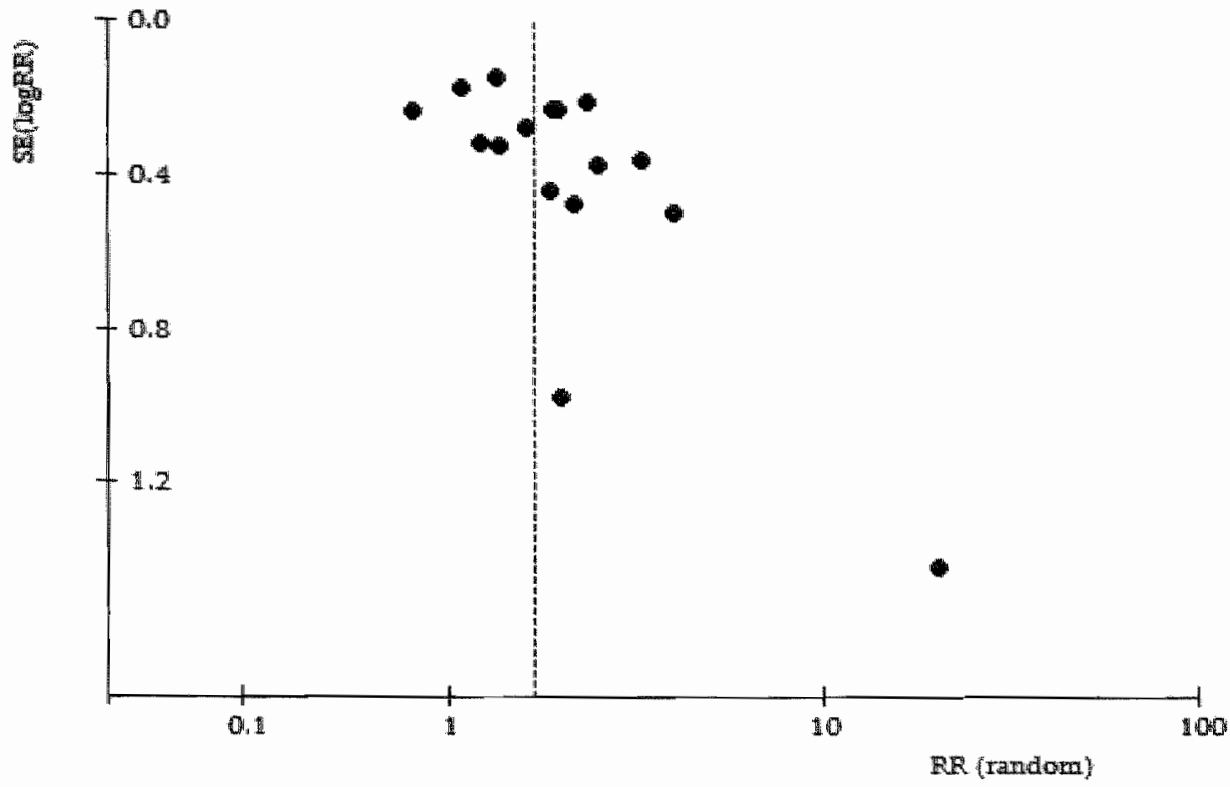

FIGURE 3a Funnel plot of trials evaluating the efficacy of bupropion for smoking cessation

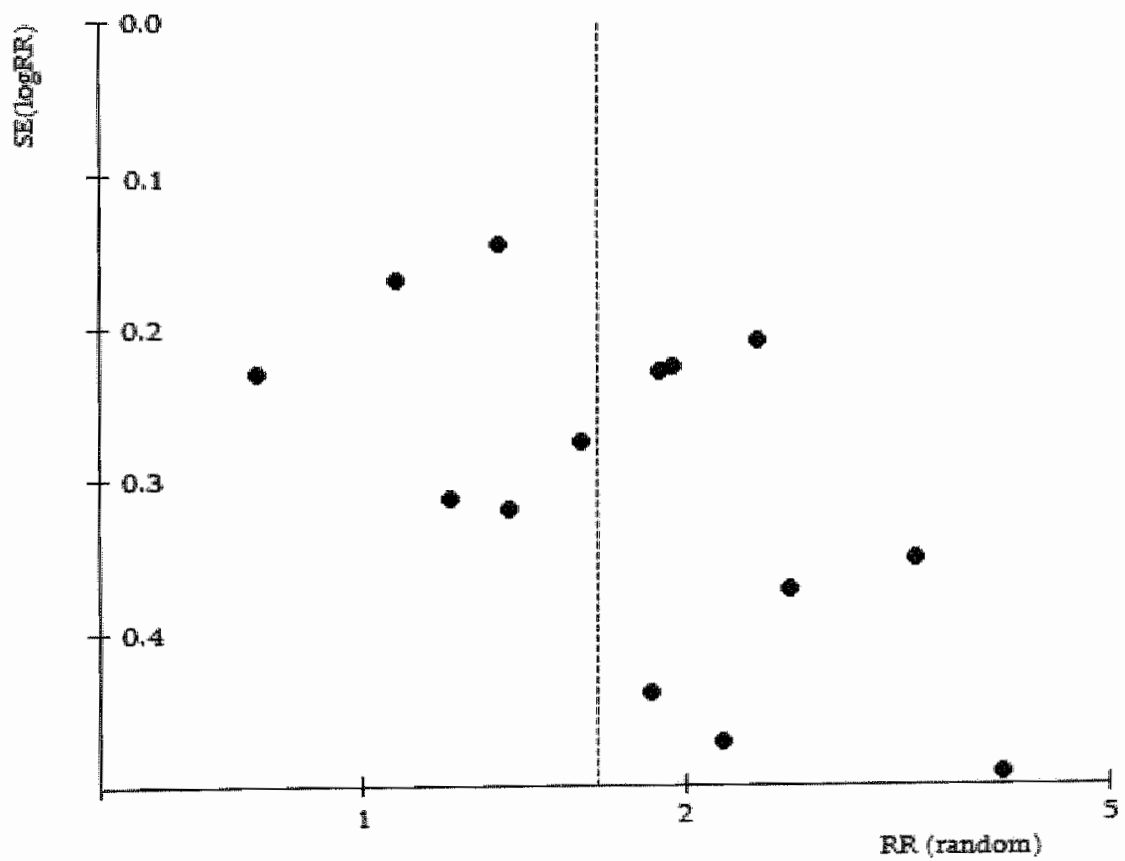

FIGURE $3 \mathrm{~b}$ Funnel plot of trials evaluating the efficacy of bupropion for smoking cessation excluding the two smallest studies 


\section{Discussion}

This systematic review and meta-analysis shows that the use of bupropion for smoking cessation results in higher prolonged abstinence rates compared with placebo treatment. However, the efficacy of the drug seems to depend in part on the source of funding. Placebo-controlled randomised trials that were financially supported by the manufacturer of bupropion found higher prolonged abstinence rates compared to trials sponsored by other organizations. This difference in prolonged abstinence rates does not seem to be caused by a difference in methodological quality. Our results do not reveal any major differences in methodological quality between trials supported financially by the manufacturer of bupropion and the trials supported by other organizations. However, the reader should remember that our quality assessment was based on written reports. Results, however, could still have been influenced by factors that were left out, such as the conduct or reporting of the studies. ${ }^{66}{ }^{67}$ For reviewers it is impossible to evaluate whether trials were conducted exactly as they were reported as journal articles. ${ }^{67}$ Huwiler-Müntener and colleagues have shown that discrepancies might occur between the conduct and reporting of trials. ${ }^{68}$ The same authors concluded that similar quality of reporting may exist despite differences in methodological quality ${ }^{68}$ Furthermore, the inability to critically evaluate the methodology in abstracts is another possible source of bias.

Evidence exists that manufacturers have attempted to prevent studies that were unfavorable to their products from being published. ${ }^{6970}$ Although we did our best to retrieve all placebo-controlled trials evaluating the efficacy of bupropion for smoking cessation, publication bias might have influenced our findings. The asymmetry in our funnel plot caused by a lack of smaller, less precise studies with less positive (or negative) findings, suggests the likelihood of bias towards smallersized trials reporting more positive results in favor of bupropion. Even though the director Medical. Affairs and the Medical Affairs Manager of GlaxoSmithKline gave us the impression that we had not missed any trials sponsored by the manufacturer. When we asked them for additional information regarding unpublished trials, they were very cooperative and willing to disclose relevant information of trials we had not found. On the other hand, at the same meeting they told us that the researchers themselves are sometimes not very eager to publish their results. Could it be that researchers lose interest in publishing their results when it turns out that their trial is just one of many trials comparing the efficacy of bupropion with placebo treatment and the results are not very positive? Whatever the answer may be, we can only speculate how this might have influenced our findings. 
Although we cannot give a clear explanation for our findings, the results of this review are in accordance with the existing literature on research and sponsoring by the industry. The growing body of evidence that sponsoring by the industry is associated with more favorable outcomes was synthesized in two systematic reviews published in $2003 .^{37}$ These reviews included studies across a wide range of disease states, drugs, and drug classes. Lexchin and colleagues found that research financially supported by the (pharmaceutical) industry was more likely to produce results that favored the product made by the company who sponsored the research compared to trials supported by other sources. ${ }^{3}$ Furthermore, they also found no evidence that trials supported financially by the pharmaceutical industry had a worse methodological quality. ${ }^{3}$

What do these findings mean for the clinician who uses the results of published trials to guide their (pharmacotherapeutic) decision-naking? Should the results of trials sponsored by the pharmaceutical industry be discarded? The answer is no. Our review indicates that bupropion is efficacious in helping smokers achieve prolonged abstinence from smoking, even though it leaves much room for improvement. The actual efficacy of the smoking cessation trials we included in our review is estimated to be lower than 9 per 100 smokers who will quit smoking and remain abstinent for at least 6 months as a result of using bupropion compared to placebo treatment. But even if the difference is small, it most likely is large enough to warrant use on a population basis, where small improvements in outcome could lead to potentially large benefits.

\section{Acknowledgements}

The authors would like to thank Pieter Leffers and lain Chalmers for their comments on earlier drafts of this manuscript. 


\section{References}

1. Rawlins MD. Doctors and the drug makers. Lancet 1984; 2 (8406): 814.

2. Relman AS. Dealing with conflicts of interest. New Eng J Med 1984; 310: 1182-1183.

3. Lexchim J, Bero LA, Djulbegovic B, Clark O. Pharmaceutical industry sponsorship and research outcome and quality: systematic review. BM] 2003; 326: 1167 1170.

4. Als-Nielsen B, Chen W. Gluud C, Kjaergard LL. Association of funding and conclusions in randomized drug trials. A zeflection of treatment effect or adverse events? JAMA 2003; 290 (7): $921-928$.

5. Kjaergard LL, As-Nielsen B. Association between competing interests and authors" conclusions: epidemiological study of randomised clinical trials published in the BMJ. BM) 2002; 325 (7358): 249 .

6. Djulbegovic B, Lacevic M, Cantor A, Fields KK, Bennett CL, Adams JR, et al. The uncertainty principle and industry-sponsored research. Lancet 2000; 356: 635-638.

7. Bekelman $\mathrm{IE}, \mathrm{Li} Y$, Gross $\mathrm{CP}$. Scope and impact of financial conflicts of interest in biomedical research. JA.MA 2003; 289 (4): 454-465.

8. Barnes $D E^{*}$, Bero $L A$. Why review articles on the health effects of passive smoking reach different conclusions. JAMA 1998; 279 (19): 1566-11570.

9. Dieppe P, Chard I, Tallon D, Egger M. Funding clinical research. Lancet 1999; 353: 1626.

10. Easterbrook P], Berlin 1, Gopolan R, Matthews DR. Publication bias in clinical research. Lancet $1991 ; 337: 867-872$.

11. West R. Bupropion SR for smoking cessation. Expert Opin Pharmacother 2003; 4 (4): 533-540.

12. lerry HH, Robbins AS, Scariati PD, et al. Enhancement of smoking cessation using the antidepressant bupropion hydrochloride. Circulation 1992; 86 (Suppl. 1): I-671.

13. Ferry LH, Burchette RJ. Efficacy of bupropion for smoking cessation in non-depressed smokers. Journal of Addictive Diseases 1994; 13 (4): 249.

14. Ferry L, Johniston. JA. Efficacy andl safecy of bupropion SR for smoking cessation: data from clinical trials and five years of postmarketing experience. Int I Clin Pract 2003; 57 (3): 224 230.

15. Martinez-Raga J, Keaney $F$, Sutherland G, Perez-Galvez B, Strang J. Trearment of nicotine dependence with bupropion SR: review of its efficacy, safety and pharmacological profile. Addiction Biology 2003; 8: 13-21.

16. Perruchoud AP, Townsend J, Lorand D. The efficacy of bupropion hydrochloride sustained release (SR) for smoking cessation is consistent in placebo-controlled studies. Eur Respir) 2002; 20 (Suppl. 38): 579 .

17. Jorenby D. Clinical efficacy of bupropion in the management of smoking cessation. Drtugs 2002;62 (Suppl. 2): 25 32 .

18. Moller AM, Villebro $N$. Pederson $T$. Tennesen $H$. Effect of preoperative smoking intervention on postoperative complications" a randomised clinical trial. Lancet 2002; 359: 114-117.

19. Nakagawa $M$, Tanaka $H$, Tsukami $H$, Kishi $Y$. Relationship between the duration of the preoperative smoke-free period and the incidence of postoperative pulmonary complications after pulnonary surgery. Chest 2001; 120 (3): 705-710.

20. Pierce JP, Gilpin EA. A minimum 6-month prolonged abstimence should be required for evaluating. smoking cessation trials. Nicotine Tob Res 2003; 5: 151-153.

21. SRNT Subcommittee on Biochemical Verification. Biocheraical verification of tobacco use and cessation. Nicatine snd Tobacco Research 2002; 4: 149-159.

22. Manheimer $\mathbb{E}$, Anderson D. Survey of public information about ongoing clinical trials funded by industry: evaluation of completeness and accessibility. BMI 2002; 325: 528-531.

23. McCray AT. Betten access to information about clinical trals. Ann Tntern Med 2000; 133: 609-614.

24. Anderson D. Costa I. Dickersin $\mathrm{K}$. TrialsCentral, an online register of clinical trials registers. Control Clin Trials 2001; 22: 40S-41S. 
25. Verhagen AP, de Vet HC, de Bie RA, Kessels AG, Boers M, Bouter LM, et all The Delphi list: a criteria list for quality assessment of randomized clinical trials for conducting systematic reviews developed by Delphi consensus. IClin Epidemiol 1998; 51 (12): 1235-1241.

26. Jadad AR, Moore RA. Carroll D, Jenkinson C, Reynollds DI, Gavaghan DJ, et al. Assessing the quality of reports of randomized clinical trials: is blinding necessary? Control Clin Trialls 1996; 17 (1): $1-12$

27. Review Manager 4.2.2 [program]. The Cochrane Collaboration. 2003.

28. Sutton AI, Abrams KR. Jones DR. An illustrated guide to the methods of meta analysis. J Eval Glin Pract $2001: 7(2): 135-148$.

29. Egger M, Davey Smith G, Schneider M, Minder C. Bias in meta-analysis detected by a simple, graphical test. BMJ 1997; 315:629-634.

30. Sterne JAC, Egger M. Funnel plots for detecting bias in meta-analysis: Guidelines on choice of action. J Clin Epidemiol 2001; 54: 1046-1055.

31. Levine M. Bupropion and wreight control. for smoking cessation. ClinicalTrials gov (service of the National Institutes of Health) 2004 (Accessed: March. 9, 2004).

32. Kalman D, Engler P. Mont P. Preliminary findings from a pilot treatment study of smokers in early alcohol recovery. 10th Annual Meeting of the Society for Research on Nicotine and Tobacco, February 18-21 2004; Scottsdale, Arizona (USA).

33. Grant K, Romberger D, Sinclair S, Nevole S, Meyer J, Agrawal $S_{\text {t }}$ et al. Preliminary results from the ongoing study: Bupropion SR as a smoking cessation aid in alcoholics. 10th Annual Meeting of the Society for Research on Nicotine and Tobacco, February 18-21 2004; Scotrsdale, Arizona (USA).

34. Hays IT, Hurt RD, Rigotri NA, Niaura R, Gonzales D. Durcan MI, et al. Sustained-release bupropion for pharmacologic relapse prevention after smoking cessation. A. tandomized, controlled trial. Ann Intern Med 2001; 135 (6): 423-33.

35. Hurt RD, Croghan GH, Sloan JA, Krook JE, Silberstein PT. Bupropion for relapse prevention after nicotine patch therapy (PA 5B abstract). Society for Research on Nicotine and Tobacco 7th Annual Meeting March 20-23 2001; Seattle, Washington.

36. McCarthy DE, Piasecki "TM, Lawrence DL, Fiore MC. Baker TB. Efficacy of bupropion SR and individual counseling among adults attempting to quit smoking. 10th Annual Meeting of the Society for Research on Nicotine and Tobacco, February 18-21 2004; Scottsdalle, Arixona (USA).

37. Piper ME, Belle Federman $\mathbb{E}$, Smith SS, Fiore MC, Eaker TB. Efficacy of bupropion SR alone and combined with 4-mg nicotine gum. 10th Annual Meeting of the Society for Research on Nicotine and Tobacco, February 18-21 2004; Scottsdale, Arizona (USA).

38. Hurt RD, Krook JE, Croghan IT, Lopringi CL, Sloan JA, Novotny PJ. et al. Nicotine patch therapy based on smoking rate followed. by bupropion for prevention of relapse to smoking. I Clin Oncol $2003 ; 21: 914-920$.

39. Selby P, Brosky G, Baker R, Lertzman M, Dakin P. Roberts J Zyban is effective in the retreatment of relapsed adult smokers [poster no. 14]. 3rd European Conference of the Society for Reseurch on Nicotine and Tobacco, Paris 2001.

40. Schmitz IM, Stotts AL, Hokanson PS, Sayre SL, DeLaune K. Bupropion and cognitiwe-behavioural therapy for smoking cessation in women. 9th Annual Meeting of the Society for Research on Nicotine and Tabacco, February 19-22, 2003, New Orleans, Louisiana (USA).

41. Hatsukami DK, Rennard S, PateL MK, Kotlyar M, Malcolm R, Nides MA, et al. Effects of sustainedrelease bupropion among persons interested in reducing but not quitting smoking. Am I Med 2004; 116: $151-157$.

42. Strayer SM, Flusche A, Hodge J, Martindale IR. Effectiveness trial of Zyban for smoking cessation in the outpatient setting. 10th Annual Meeting of the Society for Research on Nicotine and Tobacco, February 18-21 2004; Scotbdale, Arizona (USA).

43. Gratziou C, Rovina $N$, Athanassa Z, Francis $K$, Evangelou E, Chiotis $D$, et al. Evaluation of prolonged bupropion treatment as an aid in smoking cessation. Eur Respir J 2002; 20 (Suppl. 38): 611 s. 
44. Ponciano $G_{3}$ Moralles $A$, Rivero $O$. Behavioral intervention increased efficacy of buppopion in group of Mexican heavy smokers. 12 th World Conference on Tobacco or Health (wetoh), August 3$\mathbb{8}, 2003$; Helsinkt, Finland.

45. Swan GE, McAfee T, Curry S, Jack LM, Javitz H. Dacey S, er al. Effectiveness of bupropion SR for smoking cessation in a health care setting: a randonized trial. Arch Intern Med 2003; 163 (19): $2337-2344$.

46. Sweeney A.K, Buaron, et al. A multicenter, parallel, randomized, open-label, 1-year evaluation of the effects of Zyban (bupropion hydrochloride sustained release tablets) and Niconette DS (nicotine polacrilex double strengthy as aids to smoking cessation in adult chronic cigarette smokers. Glaxo Welicome (internal report AK1 A4008) 2000.

47. Swanson NA, Burroughs CC, Long MA. Lee RW. Controlled trial for smoking cessation in a nawy shipboard population using nicotine patch, sustained-release bupropion, or both. Milltary Medicine 2003; 168 (10): 830-833.

48. Evins AE, Mays VK, Rigoti NA., Tisdale T, Cather C, Goff DC. A pilot trial of bupropion added to cognitive behavioral therapy for smoking cessation in schizophrenia. Nicotine and Tobacco Research $2001 ; 3: 397-403$.

49. George "TP, Vessicchio IC, Termine A, Bregartmer TA, Feingold A, Rounsaville BJ, et al. A phacebo controlled trial of bupropion for smoking cessation in schizophrenia. Biol Psychiatry 2002; 52 : 53 61.

50. Hurt RD, Sachs DP, Glover ED, Offord KP. Johnston JA, Dale LC, et all, A comparison of sustainedrelease bupropion and placebo for smoking cessation. N Engl J Med 1997: 337 (17): 1195-202.

51. Jorenby DE, Leischow SI. Nides MA. Rennard SI, Johnston IA, Hughes AR, et al. A controlled trial of sustained-release bupropion, a nicotine patch, or both for smoking cessation. N Engl I Med 1999; $340(9): 685-691$.

52. Gonzales DH, Nides MA, Ferty LH, Kustra RP, Jamerson BD, Segall N, et al. Bupropion SR as an aid to moking cessation in smokers treated previously with bupropion: a randomized placebocontrolled study. Clin Pharmacol Ther 2001; 69:438-444.

53. Hertzberg MA, Moore SD, Feldman ME, Becklham JC. A preliminary study of bupropion sustainedrelease for smoking cessation in patients with chronic postrraumatic stress disorder lournal of Clincal Psychopharmacology 2001; 21: 94-98.

54. Tashkin DP, Kanner R, Balley W, Buist S, Anderson PI. Nides MA, et al. Smoking cessation in patients with chronic obstructive pulmonary disease: a double-blind, placebo-controlled, randomised triall. Lancet 2001; 357 (9268): 1571-1575.

55. Ahluwalia JS, Harris KJ, Calley D, Okuyemi KS, Mayo MS Sustained-release bupropion for smoking cessation in African Americans. JAMA 2002; $288(4): 468-474$.

56. Hall SM, Humfleet GL, Reus VI, Munoz RF, Harz DT, Maude-Griffin R Psychological interwention and antidepressant treatment in smoking cessation. Arch Gen Psychiatry 2002; 59 : 930-936.

57. Simon JA. Duncan C, Carmody TP, Hudes ES. Bupropion for smoking cessation: a randomized trial. National Conference on Tobacco or Health, Novernber 19-22 2002.

58. Tonnesen P. Tonstad $S$, Hjalmarson $A_{\text {. }}$ Lebargy $F$, van Spiegel PI, Hider $A$, et al. A multicentre, randomised, double blind, placebo-controlled, 1-year study of bupropion SR for smoking cessation. J Intern Med 2003; 254 (2): 184- 192.

59. Tonstad S, Farsang $C$. Klatene G, Lewis $K$, Manolis A. Pernuchoud AP, et al. Bupropion SR for smoking cessation in smokers with cardiowascular disease: a multicentre, randomised study. European Heart J 2003: 24 (10): 946-955.

60. Puska PMI. Brath H, Astbury C, Hider AE. Zyban is an effective and well-tolerated aid to smoking cessation in a thealthcare professionals population: a multi-country study [poster no. 22]. 3rd European Conference of the Sociery for Research on Nicotine and Tobacco, September 19-22, 2001: Pariss France. 
61. Lebargy F, Aubin HI, Lagrue G, Bidaut-Mazel C, Chemali-Hudry I. Poulain L. A placebocontrolled, double-blind study of Zyban LP: an effective and well-tolerated aid to smoking cessation. 12th World Conference on Tobacco or Health (WCToH), August 3-8, 2003; Helsinki. Finland.

62. Dalsgard OI, Vestbo I. A multicenter, randomised, double blind, placebo-controlled 6-month trial to evaluate efficacy and tolerability of bupropion hydrochloride sustaned release (SR) tablets as treatment for nicotine dependency in healchcare workers and as an aid to smoking cessation (2YB30009). Eur Respir J 2002: 20 (Suppl 38): 611s.

63. Lerman $C_{y}$ Roth $D$, Kaufmann V, Audrain J, Hawk L, Liu As ee al. Mediating mechanisms for the impact of bupropion in smoking cessation treatment. Drug and Alcohol Dependence 2002; 67: 219223.

64. Hughes JR, Stead LF, Lancaster T. Antidepressants for smoking cessation. The Cochrane Library, Issue 1. Chicester, UK: John Wiley \& Sons, Ltd., 2004.

65. Tonstad S Aaserud E, Halmarson A, Peiffer G, Van der Molen T, Hider Ax et al. Bupropion hydrochloride (Zyban) is effective and well tolerated as an aid to smoking cessation: a multicountry study [poster no. 24]. 3rd European Conference of the Society for Research on Nicotine and Tobacco 2001; Paris, France.

66. Gatzsche P. Methodology and owert and hidden bias in reports of 196 double-blind trials of nonsteroidal anti-inflammatory drugs in theumatoid arthritis. Control Clin Trials 1989; 10:31-56.

67. Kripschild PG. The false positive therapeutic triall J Clin Epidemiol 2002; 55 (12): 1191-1195.

68. IHuwiler-Müntener $K$, Jüni $P_{\text {, Junker }} C_{s} \mathbb{E}$ gger $M$. Quality of reporting of randomized trials as a measure of methodologic quality. IAMA 2002; 287:2801-2804.

69. Rennie D. Thyroid storm. JAMA 1997; 277; 1238-1243.

70. McCarthey M. Company sought to block paper's publication. Lancet 2000; 356: 1659.

71. Bouvy ML, Buurma H, Egberts ACG. Determinants for successful smoking cessation with bupropion in daily practice. Pharm World Sci 2003; $25(5): 207-211$. 
Should nortriptyline be used as a firstline aid to help smokers quit?

A systematic review and metaanalysis

Wagena EJ, Knipschild P, Zeegers MPA

ADDICTION 2005; 100: 317-326 


\section{Abstract}

\section{OBIECTIVES}

The objective of this article is to evaluate the efficacy of nortriptyline for smoking cessation compared to placebo and bupropion sustained release.

\section{DATA SOURCES}

Randomized trials were identified by (1) checking electronic and (2) online publicly accessible registers of clinical trials, (3) searching references of identified studies and screening abstract books of conferences and symposia, and (4) personal communication with the first authors of identified papers.

\section{REVIEW METHODS}

We included randomized trials in which nortriptyline was compared to placebo or bupropion hydrochloride SR. The main clinical outcome measure was (at least) 6-month prolonged abstinence, confirmed with a biochemical test. To investigate the efficacy of nortriptyline in time, we calculated the percentage of smokers who relapsed in time.

\section{RESULTS}

We identified five randomized trials, including 861 smokers. Compared to placebo medication, nortriptyline resulced in significantly higher prolonged abstinence rates after at least 6 months $(R R=2.4,95 \% \mathrm{CI} 1.7-3.6 ; \mathrm{RD}=0.11,95 \% \mathrm{CI}$ 0.07-0.15). The difference in efficacy between nortriptyline and placebo was highest in the first months after the target quit date. However, the number of people who remained abstinent decreased substantially and significantly faster over time in the nortriptyline group. Although bupropion resulted in higher abstinence rates compared with nortriptyline, the difference was not statistically significant $(R R=1.7$, $95 \%$ CI $0.7-4.1$ ).

\section{CONCLUSION}

This systematic review and meta-analysis shows that the use of nortriptyline for smoking cessation resulted in higher prolonged abstinence rates after at least 6 months compared to placebo treatment. Furthermore, the use of nortriptyline for smoking cessation is well tolerated and safe. As a result, we believe health care professionals should be recommended to prescribe nortriptyline as a first-line therapy for smoking cessation, also because of the much lower cost of nortriptyline compared to bupropion SR. 


\section{Introduction}

Research of the association between smoking, smoking cessation and depression has led to the evaluation of antidepressants as aids for smoking cessation [1]. Bupropion hydrochloride sustained release was the first medication for smoking cessation without nicotine that was approved by the Food and Drug Administration (FDA) forthis use. In the last decade, the manufacturer of bupropion SR funded many (controlled and uncontrolled) trials in order to evaluate the efficacy and safety of this antidepressant. One year after the first study of bupropion SR for smoking cessation was published [2], Hall and colleagues presented their results of a randomized trial evaluating the efficacy of nortriptyline for smoking cessation [3]. The authors concluded that nortriptyline was a promising adjunct for smoking cessation, but much less attention has been paid to this drug compared to bupropion. Nortriptyline is a generic (tricyclic) antidepressant and therefore far less costly than bupropion, so it is worthwhile to assess whether nortriptyline can assist smokers successfully in their quit attempt. This is all the more relevant because bupropion might not be as efficacious as expected [4].

The objective of this article is to evaluate the efficacy of nortriptyline for smoking cessation. Is nortriptyline efficacious in helping smokers to quit and reach long-term abstinence, or is it only efficacious in the short term? Secondary objectives are to determine the efficacy of nortriptyline compared to bupropion, explore the methodological quality of included trials and assess the adverse effects profile.

\section{Methods}

\section{SELECTION OF STUDIES FOR INCLUSION}

We selected randomized trials in which nortriptyline alone, or as part of a combination therapy with (individual or group) counselling, was compared to placebo or bupropion in smokers who were motivated to quit smoking.

To assess the efficacy of nortriptyline, we used shortterm (end-of-treatment), intermediate-term (6 months) and long-term (at least 12 months) abstinence rates [5]. Because not all studies reported cessation rates at exactly these intervals after the target quit date, we allowed a time window of 7 weeks so that the results of the individual studies could be pooled. The main clinical outcome measure was (at least) 
6-month prolonged abstinence, confirmed with a biochemical test (e.g. breach carbon monoxide, urinary cotinine). Point prevalence abstinence rates were used only if prolonged abstinence rates were lacking. Subjects who were lost to follow-up or had dropped out were regarded as being smokers.

\section{SEARCH STRATEGY}

\section{Electronic Databases}

Relevant trials that met our selection criteria were identified by a computeraided search of Medline (1966 to March week 1, 2004), Embase (1989 to March week 1, 2004), PsycINFO (1872 to March week 1, 2004), CINAHL (1982 to March week 1, 2004) and the Cochrane Central Register of Controlled Trials using the drug name "nortriptyline' and. 'smoking' as free text terms.

\section{Internet Databases}

We searched the following online publicly accessible registers of clinical trials [6]: ClinicalTrials.gov [7], Trials-Central.org [8], Controlled-Trials.com and the National Research Register (NRR), Issue 3, 2003.

\section{Reference Tracking}

The reference lists of all selected studies and relevant reviews were inspected for additional published reports and citations of unpublished research. In addition, we screened abstract books of relevant conferences and symposia from 1999 until March 2004 (European Respiratory Society, American Thoracic Society, British Thoracic Society, annual meetings of the European and American Society for Research on Nicotine and Tobacco, and the World Conference on Tobacco or Health).

\section{Personal Communications}

The first authors or principal investigators of identified papers and unpublished trial reports were contacted through dissemination of a standard e-mail. It explained the purposes of the review and specified what data we required additionally. We sent them a list of the references and studies we had retrieved and asked them if we had missed trials that were conducted but never published, or trials that were still ongoing. Every first author or principal investigator was contacted at least three times (by email, telephone or in person) in order to obtain additional information. 


\section{DATA EXTRACTION}

One author (E.J.W.) checked all references that were retrieved by our literature search for relevance. For each trial we extracted the following data: (1) first author, year of publication and country: (2) methods (randomization and length of follow-up); (3) number of smokers randomized; (4) intervention; (5) number of dropouts and (6) definition of abstinence, validation method used and (prolonged) abstinence rates. Two authors (E.J.W. and P.K.) extracted the data using a standardized form. Finally, we described which adverse effects participants from the nortriptyline and control groups experienced.

\section{METHODOLOGICAL QUALITY ASSESSMENT}

Both reviewers assessed the methodological quality of the trials independently, by using full text versions of the studies. We did not assess the methodological quality if only an abstract or poster was available. The reviewers were not blinded for authors, institution and journal title. In a consensus meeting disagreements were discussed and resolved. There was no restriction by country of origin, language or date of publication. If an article did not contain enough information on methodological criteria, i.e. if one or more criteria were scored 'unclear', the authors were contacted for additional information.

To assess the methodological quality of selected trials, we used items from the Delphi list [9] in combination with the criteria of Jadad [10]. The authors assigned a score for reported compliance with each of the following quality criteria: method of randomization described [use of random (unpredictable) assignment sequence], treatment allocation concealed. (assignment generated by an independent person who was not responsible for determining the eligibility of the patients), specification of eligibility criteria, comparability regarding prognostic indicators (level of nicotine dependence, number of cigarettes smoked per day and use of smoking cessation aids in the past), (attempt to) patient blinding, (attempt to) blinding of therapists responsible for the behavioural intervention, (attempt to) blinding of assessor of smoking status, success of blinding checked, loss to follow-up less than $20 \%$, intention-to-treat analysis performed and reasons given for withdrawals. All criteria were scored as 'yes' ( 1 point) 'no' or 'unclear' (both 0 points). A total score for the methodological quality of each study was calculated by summing up the number of positive criteria (range 0-11), higher scores indicating a lower likelihood of bias. If the blinding of the therapist or assessor was not explicitly described, we scored it as "unclear". The use of placebo medication was considered to be an attempt to blind the patient. 


\section{QUANTITATIVE DATA SYNTHESIS}

We pooled the results if at least two trials reported data on a particular outcome of a clinically comparable intervention and with a comparable follow-up period. We used Review Manager 4.2.2 [11] to estimate the summary statistics [risk differences (RD), relative risks (RR) and corresponding 95\% confidence intervals $(95 \% \mathrm{CI})]$. We included the risk difference, which reflects the absolute change in risk with the intervention. A formal test for statistical heterogeneity, the natural approximate $\chi^{2}$ test, was conducted to assess whether the observed variability in study results (effect sizes) was greater than that expected to occur by chance. We used this test to decide which statistical model to use [12]. If we found no evidence of statistical heterogeneity, a fixed effect model was used to combine data. If there was evidence of statistical heterogeneity, results were calculated using a random effects model. Heterogeneity statistics refer to calculation of the RRs.

To investigate the efficacy of nortriptyline in time, we calculated the abstinence percentage (AP) in the different groups for each study at each measured follow-up timepoint. The AP in the nortriptyline groups was compared to the AP in the placebo and/or bupropion groups, respectively. For each contrast we plotted AP against the follow-up time. These contrasts were evaluated further in weighted linear regression analysis, conditional on study status. This assures that the abservations are independent across studies but not necessarily independent within studies. We have used the total number of participants in each experimental group as weight.

Differences in AP at baseline and increase in AP over time has been estimated and tested for statistical significance by evaluating the $F$-change after including the experimental group alone or as a product term with follow-time as additional covariates in the univariate model, respectively.

\section{Results}

\section{IDENTIFICATION AND DESCRIPTION OF ELIGIBLE TRIALS}

We identified six randomized trials of nortriptyline for smoking cessation. All six were eligible for inclusion, although five trials contributed to our meta-analysis. Of one trial, conducted by Hall and colleagues, and presented at the 8 th annual meeting of the Society for Research on Nicotine and Tobacco (SRNT) in Savannah, Georgia, we could not retrieve the number of participants in each treatment group. Four trials were published as full papers $[3,13-15]$ and one trial (conducted by Prochazka and colleagues) was presented in 2001 at the $7^{\text {th }}$ annual meeting of the SRNT in Seattle, Washington. In total, 861 smokers participated in the nortriptyline 
and control groups. The characteristics of the trial participants and design of all six trials are described in Table 1.

Hall and colleagues conducted two trials in which they used a factorial design. In their first trial, medication was crossed with different behavioural treatments and major depressive disorder (i.e. $2 \times 2 \times 2$ design) [3]. In their second trial $(3 \times 2$ design) they studied the efficacy of nortriptyline compared with bupropion and placebo, as well as the efficacy of intensive psychological treatment [15]. In these trials, nortriptyline drug dose was titrated to therapeutic levels for depression, resulting in a modal dose of $100 \mathrm{mg} /$ day. In the other three trials, including the trial presented at the 7th SRNT meeting, nortriptyline drug dose was increased from $25 \mathrm{mg} /$ day to $75 \mathrm{mg} /$ day $[13,14]$. The treatment duration with nortriptyline or placebo ranged from 6 to 14 weeks. Four trials were conducted in the United States (the trial presented at the 7 th SRNT meeting, and $[3,13,15]$ ) and one in Brazil [14]. The follow-up period ranged from 26 to 64 weeks. Three trials reported 26 weeks' prolonged cessation rates (the trial presented at the 7 th SRNT meeting, and the trials conducted by Prochazka et al. [13] and Da Costa et al. [14]), one trial reported 52 weeks' abstinence data [15] and one trial 64 weeks' [3]. In four of the five trials, self-reported abstinence from smoking was validated with a biochemical test (i.e. expired air CO or cotinine) (the trial presented at the 7th SRNT meeting, and $[3,13,15])$. In all five trials included, all subjects participated in some behavioural programme consisting of individual face-to-face counselling and/or group counselling. We could not retrieve information on the behavioural programme that was used in the study conducted by Prochazka and colleagues (presented at the 7th SRNT meeting). In the other four trials $[3,13-15]$, the number of face-to-face (individual or group) sessions ranged from 4 to 14 . The period during which the participants attended these sessions ranged from 5 to 11 weeks. In the study conducted by Prochazka and colleagues (presented at the 7th SRNT meeting), all participants received transdermal nicotine (patches) for 8 weeks. 


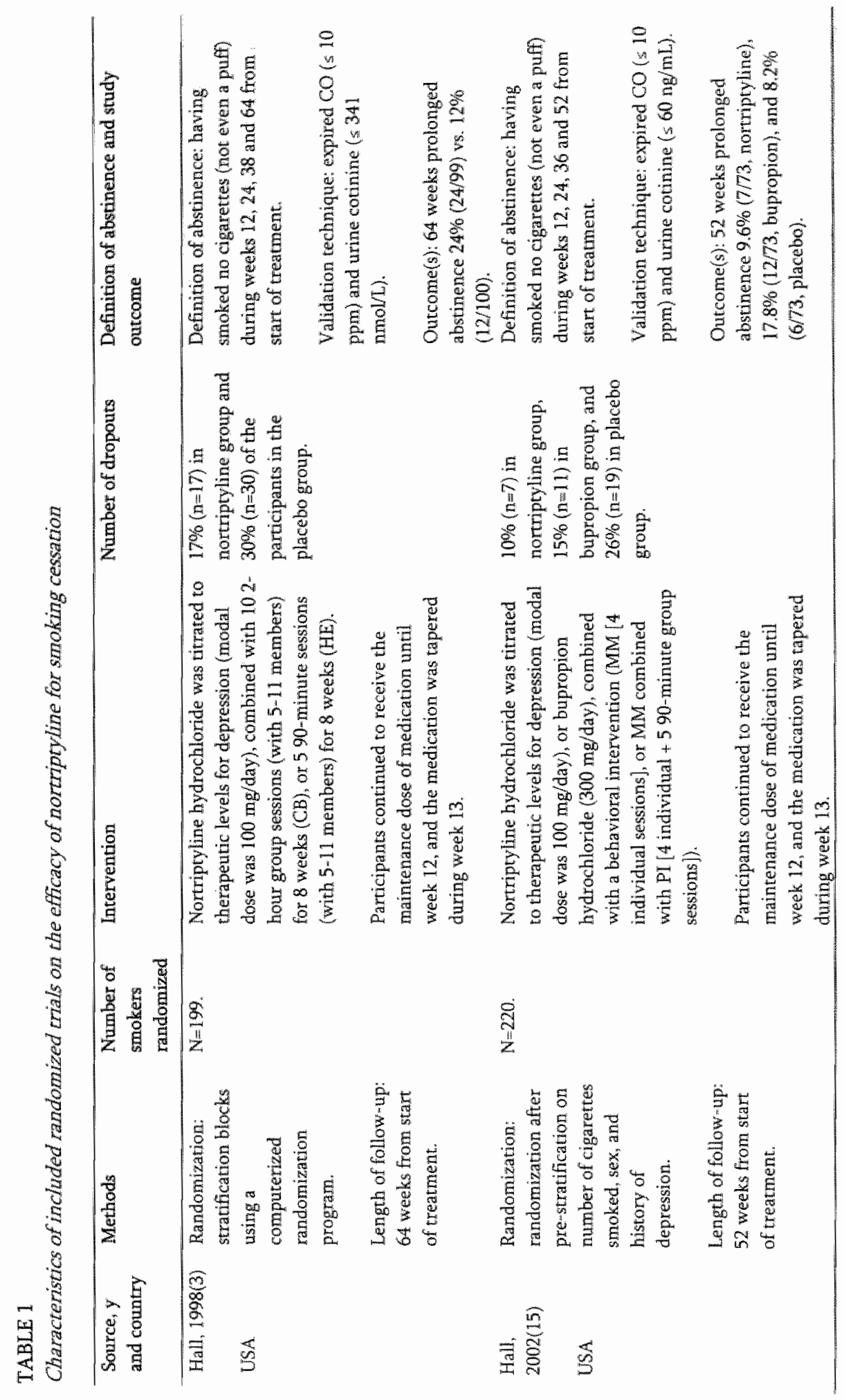




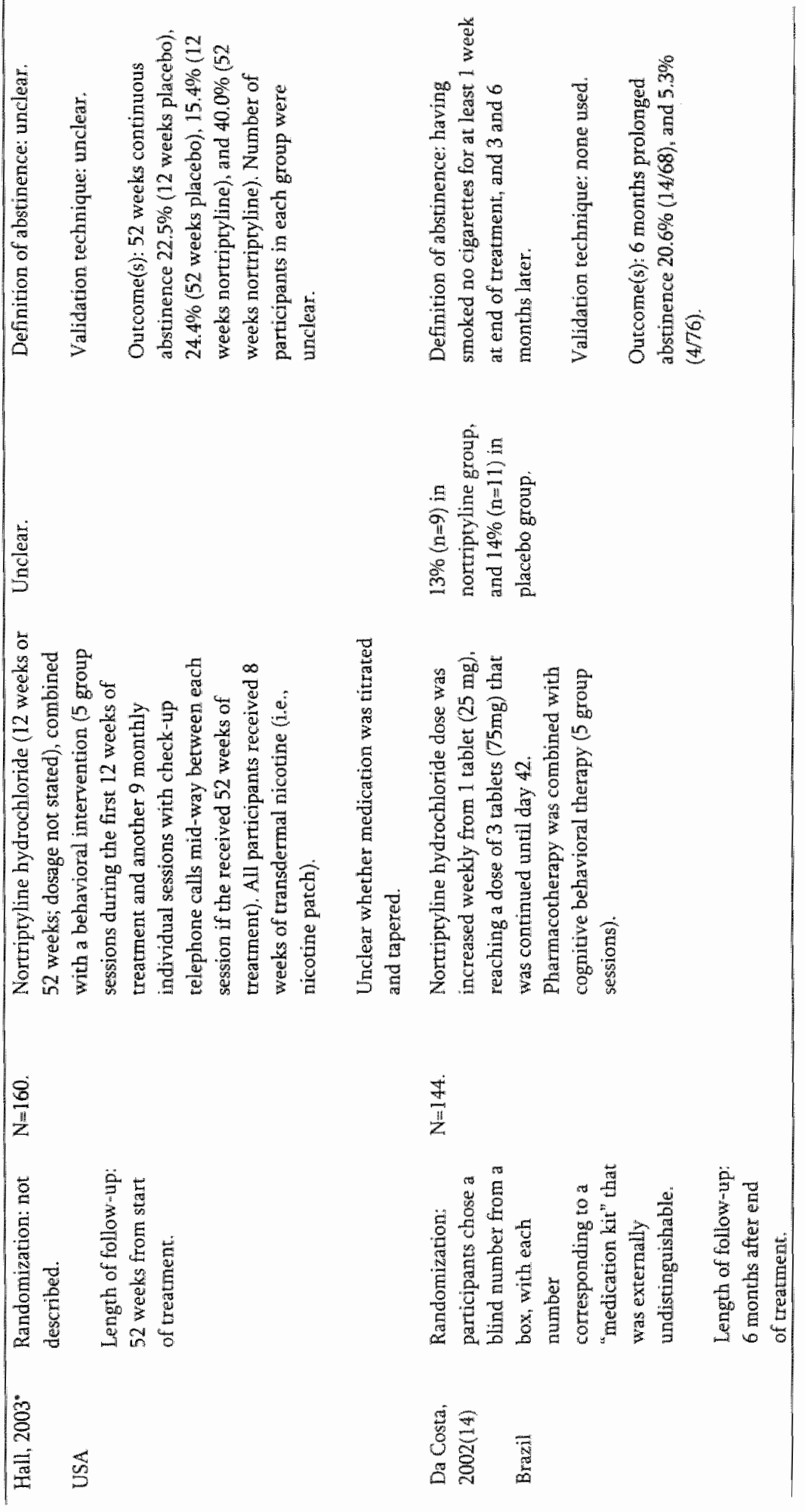




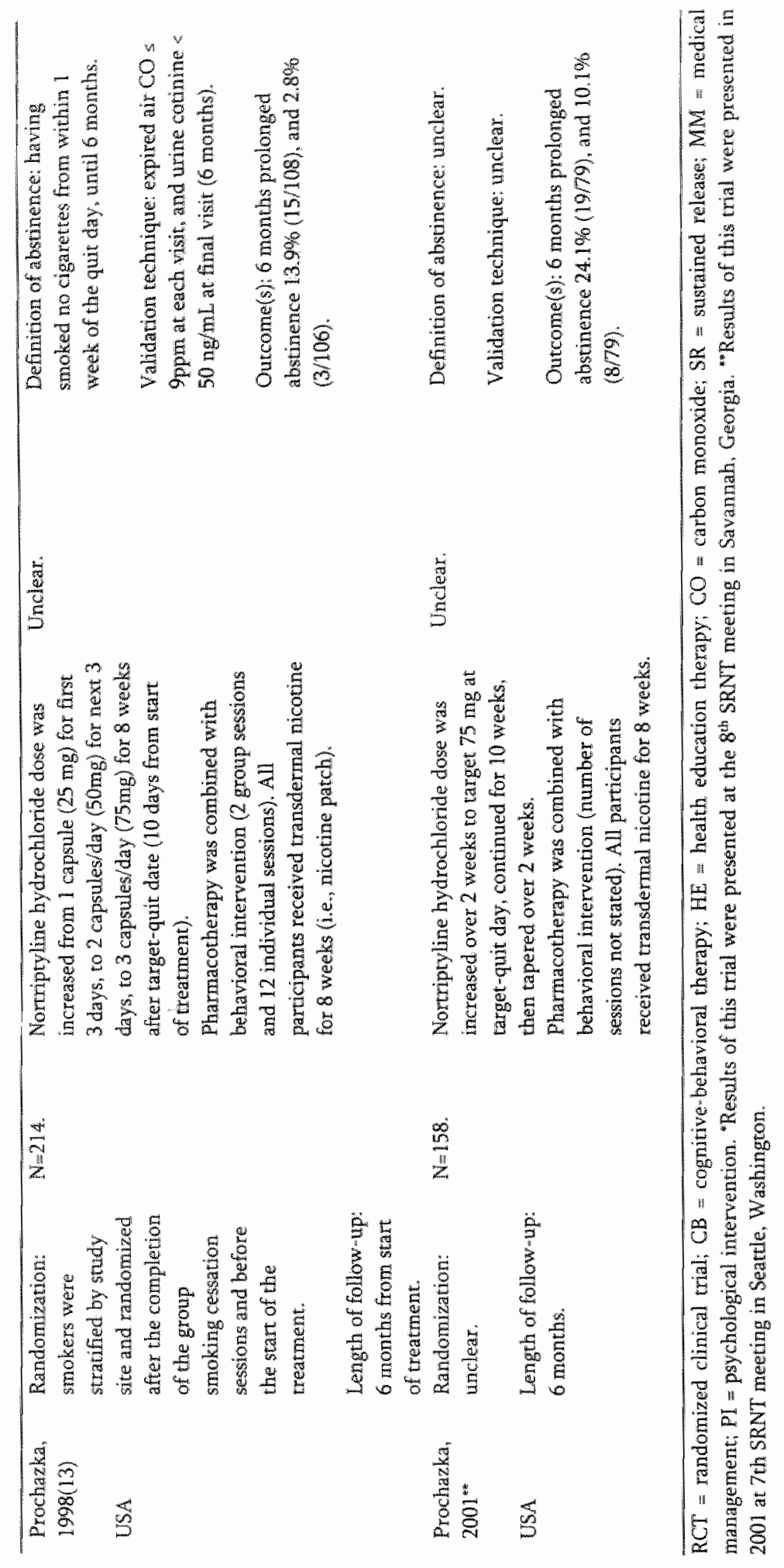




\section{EFFICACY OF NORTRIPTYLINE}

As the natural approximate $x^{2}$ showed no evidence of statistical heterogeneity $\left(x^{2}=4.3, \mathrm{df}=4, P=0.37\right)$, we used a fixed effect model to combine the data. Results indicate that nortriptyline resulted in significantly higher prolonged abstinence rates after at least 6 months compared to placebo ( $R R=2.4,95 \% \mathrm{CI} 1.7-3.6 ; \mathrm{RD}=0.11,95 \%$ CI $0.07-0.15$ ) (see Fig. 1). Because the inclusion of studies that relied only on selfreported abstinence rates could have overestimated the real effect of nortriptyline, we also pooled the data excluding the results of the study conducted by Da Costa and colleagues [14]. This resulted, however, in only a minor change in pooled effect estimates ( $R R=2.2,95 \%$ CI $1.5-3.4 ; R D=0.10,95 \%$ CI $0.05-0.15$ ). The contrast between nortriptyline and placebo in time has been investigated by using the results of the four trials published as full papers [3,13-15], generating 10 followtime specific APs.

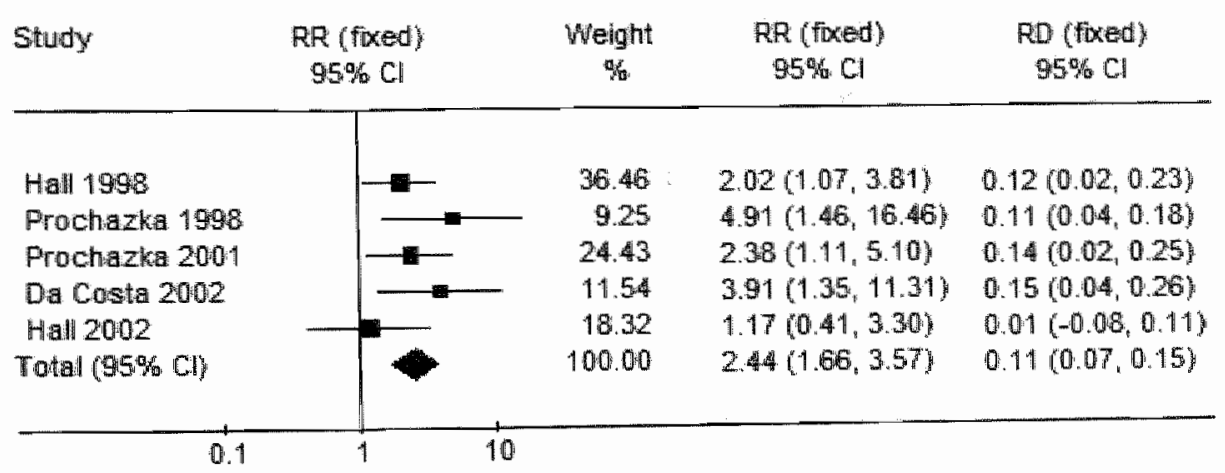

Favaurs placebo Favours nortriptyline

Total events: 79 (Nortriptyline), 33 (Placebo)

Test for overall effect $Z=4.58(\mathrm{P}<0.00001)$

Test for heterogeneity: $C_{\mathrm{C}} \mathrm{P}=4.31, \mathrm{df}=4(\mathrm{P}=0.37), \mathrm{F}=7.2 \%$

FIGURE 1 Efficacy of nortriptyline compared with placebo after at least 6-month prolonged abstinence from smoking: forest plot with study weights, pooled relative risks and pooled risk differences

Both Fig. 2 and regression analysis showed that the A.P at baseline in the nortriptyline group (44.1\%) was substantially higher than in the placebo group (19.2\%). However, the AP decreased substantially and significantly $\left(P_{<} 0.01\right)$ faster over time in the nortriptyline group ( $-1.5 \%$ per month) than in the placebo group ($0.2 \%$ per month). 


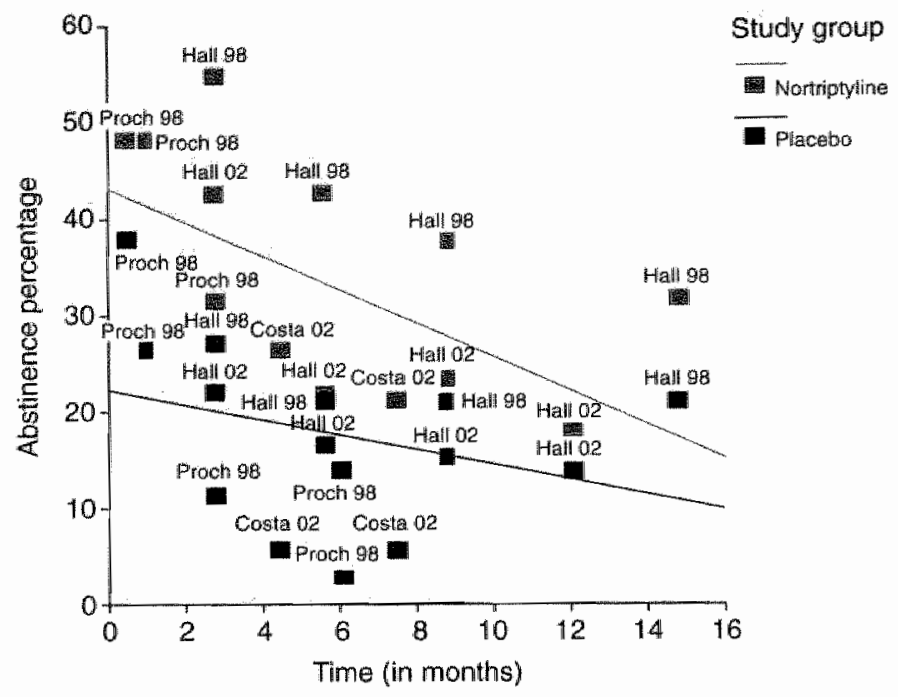

FIGURE 2 Abstinence percentages in the nortriptyline and placebo groups plotted against follow-up time

The difference in efficacy between nortriptyline and bupropion was investigated in only one trial, with four different follow-up time-points ranging from 12 to 52 weeks (Fig. 3) [15]. Although statistically significant $(P<0.01)$, the differences in AP between the nortriptyline (43.1\%) and bupropion groups (45.2\%) were small. The AP increased $-2.3 \%$ per month in the nortriptyline group and $-1.9 \%$ per month in the bupropion group $(P<0.01)$. At the end of the study, after 12-month follow-up, no significant difference was found in efficacy between bupropion SR and nortriptyline ( $\mathrm{RR}=1.7,95 \% \mathrm{CI} 0.7-4.1$ ), even though bupropion resulted in higher prolonged abstinence rates. Twelve participants from the bupropion group were prolonged abstinent (16.4\%), compared to seven from the nortriptyline group ( $9.9 \%$ ). 


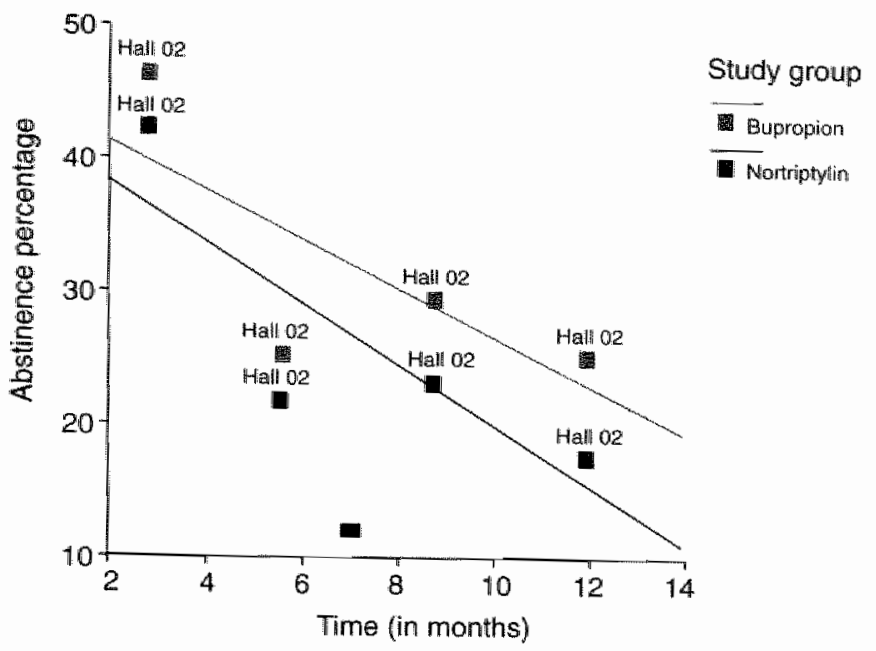

FIGURE 3 Abstinence percentages in the nortriptyline and bupropion groups plotted against follow-up time

\section{METHODOLOGICAL QUALITY}

Table 2 shows the results of the methodological quality assessment of full text papers. In general, the scores varied between seven and 11 points. The four trials that were published as full text papers [3,13-15] were all described as randomized, although in two trials $[13,15]$ the method of allocation was not described. Also, all. trials reported to have used blinded placebo medication, but only two trials $[13,15]$ evaluated whether blinding had been successful by asking the participants which treatment they thought they had been given. Three of the four trials reported to have blinded the health professionals who delivered the behavioural intervention $[3,14,15]$, and none reported to have blinded the assessor. From two papers it was clear that at least $80 \%$ of the smokers who were randomized were also followed-up $\left[3_{n} 15\right]$. Because we could include only four trials and all four scored in the same range with regard to methodological quality, we could not test whether the quality of the methods used was associated with outcome. 


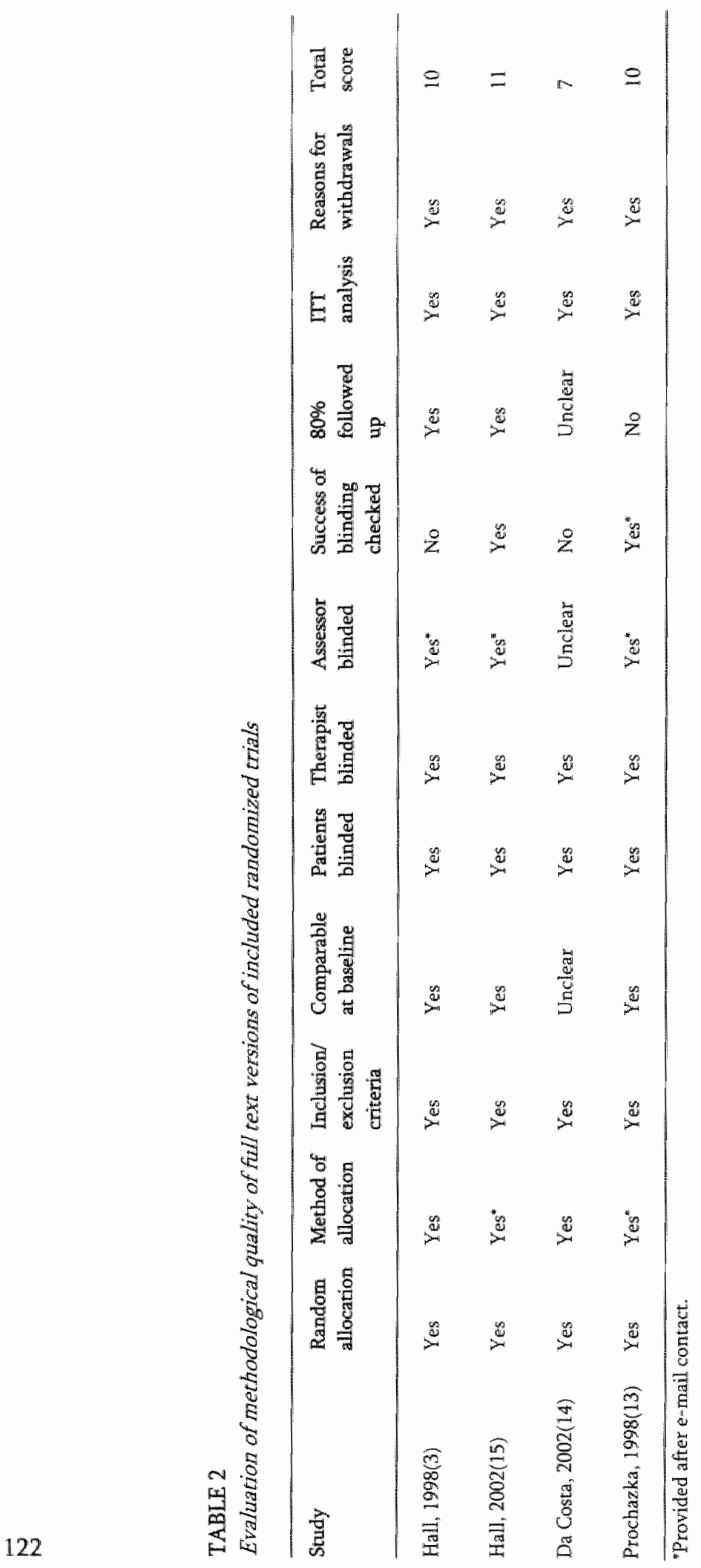




\section{ADVERSE EFFECTS}

Table 3 presents the occurrence of adverse effects in both nortriptyline and placebo groups. The abstract of the study conducted by Prochazka et al. (the trial presented at the 7th SRNT meeting) did not contain information on the occurrence of adverse effects. Hall and colleagues $[3,15]$ used a structured (precoded) checklist in both studies. It was administered at baseline and at weeks $1-4$ and 6 to determine the occurrence of adverse effects. In their papers they presented only those adverse effects that were reported significantly more often in one of the treatment groups. The participants in the study conducted by Da Costa et al. [14] were asked to note and report any adverse effects they experienced. In the study conducted by Prochazka et al. [13], the study nurse assessed the occurrence of adverse effects at each visit. Results indicate that significantly more participants in the nortriptyline group reported adverse effects compared to the placebo group. The most common adverse effects were dry mouth and constipation/gastrointestinal upset. In the four trials that presented information on adverse effects, more participants from the nortriptyline groups reported to have experienced dry mouth. In three of the four trials [13-15], more participants from the nortriptyline groups had experienced constipation or gastrointestinal upset compared to placebo. However, compared to smokers who were given placebo, fewer smokers who used nortriptyline to quit smoking experienced insomnia or sleep disruption, felt irritated, showed lack of attention and felt anxious, although not all studies supported these findings. Although Hall and colleagues [15] did not compare directly the incidence of adverse events in the nortriptyline and bupropion groups, their findings seem to indicate that the use of nortriptyline results in more reports of dry mouth and constipation compared to the use of bupropion.

\section{PUBLICATION BIAS}

Because we only included five randomized trials, we did not construct a funnel plot. 


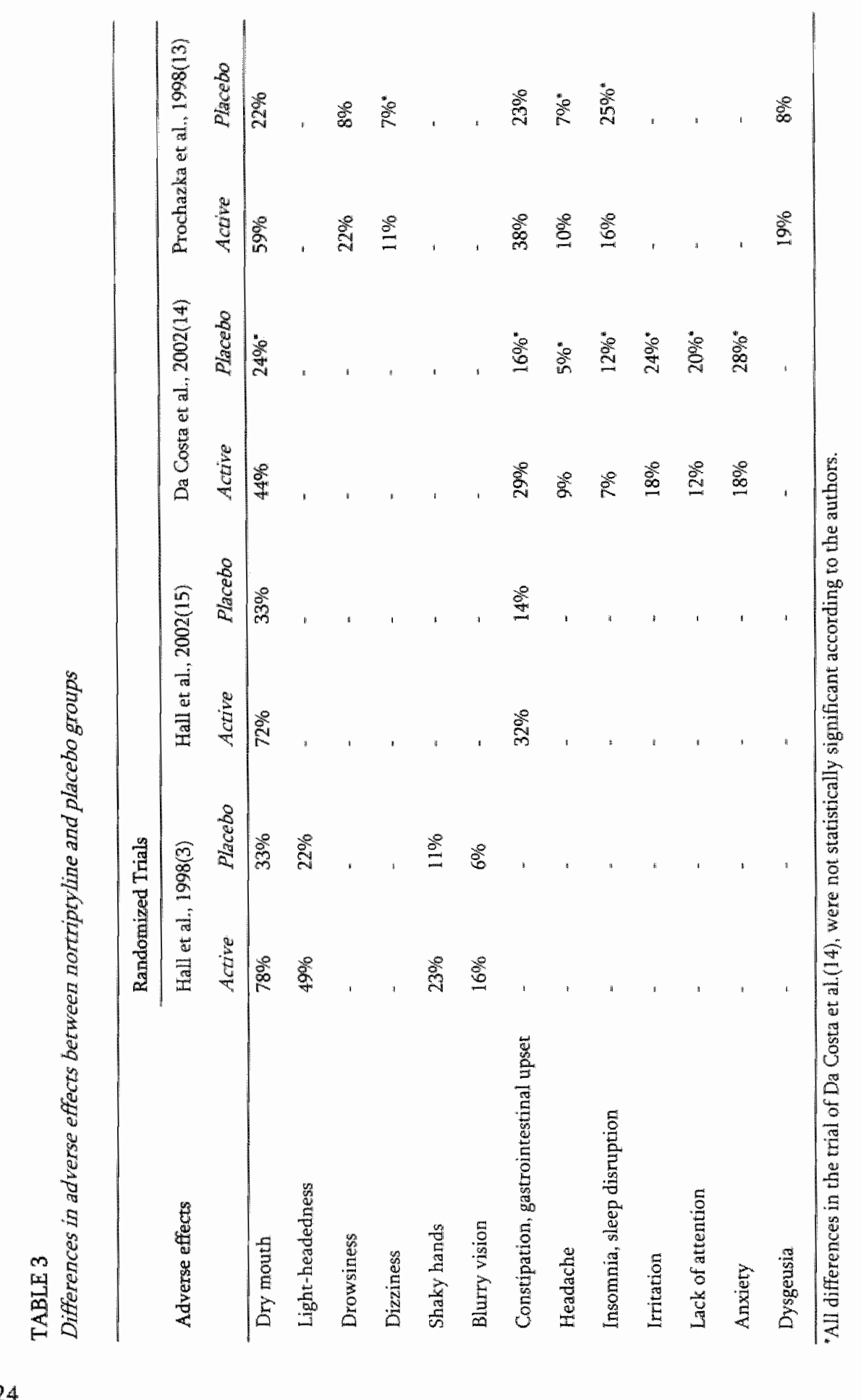




\section{Discussion and Conclusion}

This systematic review and meta-analysis shows that the use of nortriptyline for smoking cessation resulted in higher prolonged abstinence rates after at least 6 months compared to placebo treatment. Nortriptyline resulted in prolonged abstinence rates that were more than twice as high compared to placebo treatment. The number of smokers who will benefit from using nortriptyline, i.e. who will achieve prolonged abstinence from smoking, is estimated to be between seven per 100 and 15 per 100 smokers. The difference in efficacy between nortriptyline and bupropion has only been investigated in one trial [15]. Even though bupropion resulted in higher prolonged abstinence rates after 12 months, this difference was not statistically significant. Future studies are needed to give a decisive answer about the relative efficacy of nortriptyline and bupropion and their associated adverse event profile.

The results of the included trials suggest that the use of nortriptyline for smoking cessation is well tolerated. The most common reported adverse events were comparable to the ones found with the use of bupropion: dry mouth and constipation or gastrointestinal upset. Furthermore, compared to smokers who were given placebo, smokers who used nortriptyline to quit smoking seemed to have lower chances to experience insomnia or sleep disruption, feel irritated, show lack of attention and feel anxious.

To investigate the efficacy of nortriptyline in time, we calculated the relapse percentage (RP) in the different groups for each study at each measured follow-up timepoint. Results indicate that the efficacy of nortriptyline was highest in the first months after the target quit date. The number of people, who relapsed, increased substantially and significantly faster over time in the nortriptyline group than in the placebo group. The same effect occurred in the group of smokers treated with bupropion (although the relapse percentage increased significantly faster in time in the nortriptyline group). These results could indicate that currently available nonnicotine pharmacological interventions for smoking cessation, which (are expected to) act on sites in the central nervous system (CNS) to reduce withdrawal symptoms [16], such as bupropion and nortriptyline, will probably provide only relief of associated symptoms, and in the long term (more than 1 year) will most probably be of limited efficacy. These drugs probably do not attenuate or block the reinforcing effects of nicotine.

So far, bupropion is the only non-nicotine drug licensed for use in smoking cessation in many countries. The clinical practice guideline on the treatment of tobacco use and dependence, prepared by the US Department of Health and Human Services, recommends clinicians to encourage all patients initiating a quit attempt to use one or a combination of efficacious pharmacotherapies [17]. It recommends that nortriptyline, which is classified as second-line therapy, can be used only on a caseby-case basis after first-line treatments, such as bupropion, have been used or 
considered. Nortriptyline is considered to be a second-line medication because: (1) there are more concerns about potential side effects than with first-line medications, and (2) the FDA has not approved it for a tobacco dependence treatment indication. The recommendations in the clinical practice guidelines regarding the use of nortriptyline have been based on only two trials [3,13]. The results of our systematic review show that the safety profile is acceptable and comparable to that of bupropion. As a result, this argument seems therefore to be outdated. The question remains as to whether we should really wait with recommending health-care professionals to prescribe nortriptyline as a first-line therapy for smoking cessation until it has been licensed for that indication. We think that we should not. The approval of bupropion for the indication smoking cessation was based on three randomized trials (see http:/www.fda.gov/cder/foi/nda/97/020711_zyban_toc.htm for the medical reviews), and as our meta-analysis included five randomized trials on nortriptyline, the scientific criteria for a possible approval seem to have been met.

Based on the available literature, which shows that nortriptyline is significantly more effective in helping smokers achieve prolonged abstinence compared to placebo, there seems to be no reason for health-care professionals not to prescribe this drug. Nortriptyline might be a useful alternative to bupropion for smokers who want to quit. First, bupropion does not seem to be significantly more efficacious compared with nortriptyline. Secondly, nortriptyline is well tolerated and safe. Thirdly, nortriptyline is much cheaper compared to bupropion. For instance, in the Netherlands, 1 month of treatment with bupropion ( $300 \mathrm{mg} / \mathrm{day})$ costs 671.48 , and nortriptyline ( $75 \mathrm{mg} /$ day) $€ 12.22$. However, sufficient evidence on the efficacy of nortriptyline for smoking cessation without an intensive behavioural programme is lacking. Because it is unlikely that smokers will receive the same degree of additional support in daily practice, we should be aware of the possibility that the efficacy of nortriptyline as well as bupropion might be lower.

\section{Acknowledgements}

The authors thank S. Hall and A. Prochazka for providing additional information.

\section{Declaration of interest}

Wagena received study medication (nortriptyline) from the manufacturer for a randomized trial assessing the efficacy of nortriptyline and bupropion for smoking cessation in patients with COPD. 


\section{References}

1. Hughes JR, Stead LF, Lancaster T. Antidepressants for smoking cessation. In: The Cochrane Library, Issue 2. Chicester, UK: John Wiley \& Sons, Ltd; 2003.

2. Hurt RD, Sachs DP, Glover ED, Offord KP, Johnston JA, Dale LC, et al. A comparison of sustainedrelease bupropion and placebo for smoking cessation. N Engl I Med 1997; 337 (17): 1195-202.

3. Hall SM, Reus VI, Munoz RF, Sees KL. Humfleet G, Hartz DT, et al. Nortriptyline and cognitivebehavioral therapy in the treatment of cigarette smoking. Arch Gen Psychiatry 1998; 55 (8):68390.

4. Wagena EJ, Knipschild PG. The efficacy of bupropion in relation to competing interests and methodological quality. Eur Respir ) 2003; 22 (Suppl 45): 165s.

5. Velicer WF, Prochaska 10, Rossi JS, Snow MG. Assessing outcome in smoking cessation studies. Psychologicall Bulletin 1992; 111 (1): 23-41.

6. Manheimer $E_{x}$ Anderson $D$. Survey of public information about ongoing clinical trials funded by industry: evaluation of completeness and accessibility. BM] 2002; 325:528-531.

7. McCray AT. Better access to information about climical trials. Ann Intern Med 2000; 133:609-614.

8. Anderson $\mathbb{D}$, Costa 1 , Dickersin $\mathbb{K}$. TrialsCentral, an online register of clinical trials registers. Control Clin Trials 2001; 22: 40S-41S.

9. Verhagen AP, de Vet HC, de Bie RA, Kessels AG, Boers M, Bouter LM, et al. The Delphi list: a criteria list for quality assessment of randomized clinicall trials for conducting systematic reviews developed by Delphi consensus. J Clin Epidemiol 1998; 51 (12): 1235-1241.

10. Jadad AR, Moore RA, Carroll D, Jenkinson C, Reynolds DJ, Gavaghan DJ, et al. Assessing the quality of reports of randomized clinical trials: is blinding necessary? Control Clin Trials 1996; 17 (1): $1-12$.

11. Wintertree Software Inc. Review Manager 4.2.2. In: The Cochrane Collaboration; 2003.

12. Sutton AI, Abrams KR, Jones. DR. An illustrated guide to the methods of meta-analysis. I Fival Clin Pract 2001; 7 (2): 135-148.

13. Prochazka AV, Weaver M), Keller RT, Fryer GE, Licari PA, Lofaso D. A randomized trial of nortriptyline for smoking cessation. Arch Intern Med 1998; 158 (18): 2035-9.

14. Da Costa CL, Younes RN, Cruz Lourenço MT. Stopping smoking. A prospective, randlomized, double-blind study comparing nortriptyline to placebo. Chest 2002; 122 (2): 403-408.

15. Hall SM, Humfleet GL, Reus VI, Munoz RF, Hartz DT, Mande-Griffin R. Psychological. intervention and antidepressant treatment in smoking cessation. Arch Gen Psychiatry 2002; 59: 930-936.

16. Balfour DJK. The pharmacology underlying pharmacotherapy for tobacco dependence: focus on bupropion. Int I Clin Pract 2001; 55: 53-57.

17. Fiore MC, Bailey WC, Cohen SI. Dorfnan SF, Goldstein MG, Gritz ER, er al Treating tobacco use and dependence. A clinical practice guideline. Rockville, MD: US Department of Health and Human Services. Public Health Service; 2000. 
The efficacy of smoking cessation strategies in patients with chronic obstructive pulmonary disease: A systematic review

Wagena EJ, van der Meer RM, Ostelo RJWG, Jacobs JE, van Schayck CP

RESPIRATORY MEDICINE 2004; 98(9): 805-815 


\section{Abstract}

Smoking cessation is the most effective way to reduce the risk of developing chronic obstructive pulmonary disease (COPD). It prevents or delays the development of airflow limitation and also reduces its progression. The objective of this study was to systematically review the effects of interventions for smoking cessation in people with COPD. Comprehensive searches of electronic and Internet databases were carried out from 1966 to March 2002, using the Cochrane Airways Group search strategy. The reference lists of all selected randomized trials and relevant reviews were inspected for additional published reports and citations of unpublished research. We evaluated the efficacy of behavioural interventions (e.g. counselling), pharmacotherapy (nicotine replacement therapy and non-nicotime therapy such as bupropion), and combinations of both. The main clinical outcome measure was prolonged abstinence after at least 6 months, confirmed by a biochemical tesit. Five trials comprising 6491 patients with COPD were included. Results of the Lung Health Study show that, by using an intensive behavioural (relapse prevention) programme combined with nicotine replacement therapy, prolonged abstinence rates are not only significantly higher compared with no intervention, but the difference in efficacy was sustained for over 5 years. A 12week treatment course with bupropion sustained release combined with individual counsellling, however, did not result in significantly higher prolonged abstinence rates after 12 months. Present evidence suggests that the most effective intervention for prolonged smoking cessation in patients with COPD is the combination of nicotine replacement therapy, coupled with an intensive, prolonged relapse prevention programme. 


\section{Introduction}

Chronic obstructive pulmonary disease (COPD) is a leading cause of morbidity and mortality worldwide, and results in an economic and social burden that is both substantial and increasing.(1) COPD prevalence, morbidity and mortality vary across countries and across different groups within countries, but are in general directly related to the prevalence of tobacco smoking.(1) In the developed world, smoking accounts for at least $75 \%$ of COPD cases. (2,3) Furthermore, smoking cigarettes accelerates the rate of decline in pulmonary function beyond that usually seen with aging.(4-10) Fletcher et al.(6) for instance, showed that, in non-smokers, the mean decline in forced expiratory volume in $1 \mathrm{~s}$ (FEV1) due to normal aging is about $30 \mathrm{ml}$ per year in adults, whereas it averages more than $50 \mathrm{ml}$ per year in susceptible smokers. Other studies have also observed increased rates of decline, although the rates vary. $(4,11)$

Smoking cessation is the most effective way to reduce the risk of developing COPD. $(9,12)$ It can prevent or delay the development of airflow limitation and also reduce its progression. Up until now, smoking cessation is the only intervention that has shown to reduce the rate of FEV1 decline for both men and women. $(4,5,9,13,14)$ Several studies have examined the time frame during which benefits of smoking cessation may be observed. In general, results indicate that the onset of the reduction in rate of loss of FEV1 occurs early after cessation. In the study conducted by Burchfiel et al.(4) rate of FEV1 decline was not associated significantly with the length of time since quitting, indicating that smoking cessation may lead to a rapid return to the usual age-related decline seen in people who have never smoked. $(4,9)$ These observations support the hypothesis of a bronchoconstrictive or inflammatory effect of smoking that could be reversible to some degree soon after exposure ceases. $(4,5,8,9)$

Although smoking cessation is widely mentioned as the most important measure in patients with COPD, little is known about the effectiveness of existing smoking cessation interventions specifically in these patients. The objective of this study was to systematically review the effects of interventions for smoking cessation in patients with COPD. We evaluated the efficacy of behavioural interventions, pharmacological interventions and combinations of both. 


\section{Methods}

\section{SELECTION OF STUDIES FOR INCLUSION}

\section{Study design}

Only randomized trials were included in this systematic review. We included studies on smoking cessation that were part of a broader experiment (i.e. use of a factorial design) only if it was possible to extract data on the effects of the smoking cessation component specifically, and if the nature of the experimental and control intervention(s) was explicitly stated.

\section{Population}

Because COPD is defined on the basis of airflow limitation, we included studies in which the study population consisted of smokers with largely irreversible airflow obstruction. The presence of COPD had to be assessed according to guidelines for the diagnosis of COPD (e.g. guidelines from the American Thoracic Society [ATS](15), the British Thoracic Society(16), the European Respiratory Society(17) and the Global Initiative for Chronic Obstructive Lung Disease(1) or by a respiratory clinician.

\section{Interventions}

We included trials that studied the effects of an intervention to assist smokers in making a quit attempt and helping them avoid relapse. The experimental and control intervention(s) could include any behavioural intervention (i.e. self-help interventions [the use of a pamphlet, audiotape, videotape, mailed information or a computer programme], individual counselling, group counselling, or (proactive) telephone counselling, with or without the use of pharmacotherapy (nicotine replacement therapy, non-nicotine therapy such as bupropion, or both).

\section{Types of outcome measures}

The main clinical outcome measure was prolonged abstinence after at least 6 months, confirmed by a biochemical test (e.g. breath carbon monoxide, urinary cotinine). Point prevalence abstinence rates were used if prolonged abstinence rates were not assessed and could not be retrieved. Participants who were lost to followup, or had dropped out, were regarded as being smokers. 


\section{SEARCH STRATEGY}

\section{Electronic databases}

The Cochrane review provides a more detailed description of the search terms used and the electronic databases that were searched.(18)

\section{Reference tracking}

We inspected the reference lists of all selected studies and relevant reviews(19-21) for additional published reports and citations of unpublished research. In addition, we screened abstract books of relevant conferences and symposia from 1999 until November 2003 (European Respiratory Society, ATS and the annual meetings of the European and American Society for Research on Nicotine and Tobacco).

\section{Internet databases}

We also searched the following online publicly accessible registers of clinical trials(22): Clinical-Trials.gov(23), TrialsCentral.org(24), Controlled-Trials.com and the National Research Register, Issue 3, 2003.

\section{Personal communications}

The first author or principal investigator of identified papers was contacted through dissemination of a standard e-mail or letter. It explained the purposes of the review and specified the additional data that we required.

\section{DATA EXTRACTION}

Two reviewers (RvdM, EJW) independently checked for relevance all references that were retrieved by our literature search, and selected the studies to be included in the systematic review. The same authors extracted data independently using a standardized form. A consensus method was used to resolve disagreements concerning selection and inclusion of trials, and a third reviewer (RO) was consulted if disagreements persisted. The data extraction form was pre-tested using two randomized trials on smoking cessation in smokers without a chronic disease. For each trial, two reviewers (RvdM and EJW) extracted the following data using a standardized form: 1) first author and year of publication; 2) comparisons studied; 3) study methods (setting, randomization, length of follow-up); 4) study population (number randomized and diagnostic criteria used); 5) intervention(s); and 6) definition of abstinence (including vallidation technique used). 


\section{METHODOLOGICAL QUALITY ASSESSMENT}

To assess the methodological quality of selected trials, we used the internal validity criteria from the Delphi list.(25) Two reviewers (RvdM and EIW) assigned a score for reported compliance with each of the following criteria: method of randomization described (use of random [unpredictable] assignment sequence), treatment allocation concealed (assignment generated by an independent person not responsible for determining the eligibility of the patients), specification of eligibility criteria, comparability regarding prognostic indicators (e.g. level of nicotine dependence, number of cigarettes smoked per day), (attempt to) patient blinding, (attempt to) blinding of therapist, (attempt to) blinding of outcome assessor, presentation of point estimates and measures of variability for primary outcome measures, and intention-to-treat analysis performed. The items were scored as "yes" (1 point), "no" or "unclear" (both 0 points). A total score for the methodological quality of each study was calculated by summing up the number of positive criteria (range 0-9), higher scores indicating a lower likelihood of bias.(26)

For studies published in languages other than English, German or Dutch, the help of a translator of the Cochrane Airways Group was obtained (see acknowledgements). If an article did not contain enough information on methodological criteria (i.e. if one or more criteria were scored "unclear"), the authors were contacted for additional information.

\section{QUANTITATIVE DATA SYNTHESIS}

\section{Measures of effect}

We used Review Manager 4.2.2(26) to estimate the summary statistics (relative risks $[R R]$, risk differences $[R D \rrbracket$ and corresponding $95 \%$ confidence intervals $[95 \% \mathrm{CI}]$ ). We included the RD because it reflects the absolute change in risk with the intervention. Abstinence rates were calculated on the basis of the number of participants randomized to an intervention.

\section{Results}

\section{IDENTIFICATION AND DESCRIPTION OF ELIGIBLE TRIALS}

We retrieved 30 papers out of 365 references. The first selection was based on ticles, keywords and abstracts, and resulted in both reviewers including 13 studies. Checking the reference lists of identified studies and relevant reviews resulted in the inclusion of another 17 studies. The final selection was based on full papers (30 papers, 29 studies), and resulted in exclusion of 24 papers that seemed relevant but 
did not meet all inclusion criteria, and inclusion of six papers that met the inclusion criteria and contributed to the review. They referred to five different trials, comprising 6491 patients with COPD (5887 of these patients participated in the Lung Health Study), conducted in the USA, Canada and Denmark between 1991 and 2001.(12,27-30) The characteristics of the trials are described in Table 1.

\section{QUANTITATIVE DATA SYNTHESIS}

Because studies were clinically heterogeneous with regard to study population (severity of the obstruction) and types of interventions, abstinence rates were not pooled.

\section{COMPARISON OF BEHAVIOURAL INTERVENTIONS}

We found three trials comparing different behavioural interventions.(27-29) Figure 1 shows the forest plots with (point prevalence and prolonged) abstinence rates, RR and RD for the comparisons studied. Brandt et al.(28) evaluated whether use of the words "smoker's lung" instead of traditional terminology when talking to patients with COPD changed their smoking habits. Although use of the words "smoker's lung" increased abstinence from smoking, the effect did not reach statistical significance ( $\mathrm{RD}=0.16,95 \% \mathrm{CI}-0.07$ to $+0.38 ; \mathrm{RR}=1.98,95 \% \mathrm{CI} 0.74$ to 5.31). The trial conducted by Pederson et al.(29) showed that individual counselling responsive to the patients' needs and questions combined with the use of a self-help smoking cessation manual was not significantly more effective compared with physician advice to quit smoking $(\mathrm{RD}=0.11,95 \% \mathrm{CI}-0.08$ to $+0.29 ; \mathrm{RR}=1.67,95 \%$ $\mathrm{CI} 0.68$ to 4.11 ). Crowley et al.(27) compared the efficacy of different behavioural reinforcement schedules. Contingent reinforcement with lottery tickets for reduced breath carbon monoxide increased quit rates compared with only reimbursing patients when they came in for their planned visits, although the difference was not statistically significant $(\mathrm{RD}=0.10,95 \% \mathrm{Cl}-0.11$ to $+0.31 ; \mathrm{RR}=2.50,95 \% \mathrm{Cl} 0.29$ to 21.61). The trial also failed to find a statistically significant difference in prolonged abstinence rates between contingent reinforcement with lottery rickets for reduced breath carbon monoxide compared with contingent reinforcement for self-report of reduced smoking (also with lottery tickets) $(\mathrm{RD}=-0.08,95 \% \mathrm{CI}-0.36$ to $+0.19 ; \mathrm{RR}=$ $0.67,95 \%$ CI 0.18 to 2.54 ) (Fig. 1). 


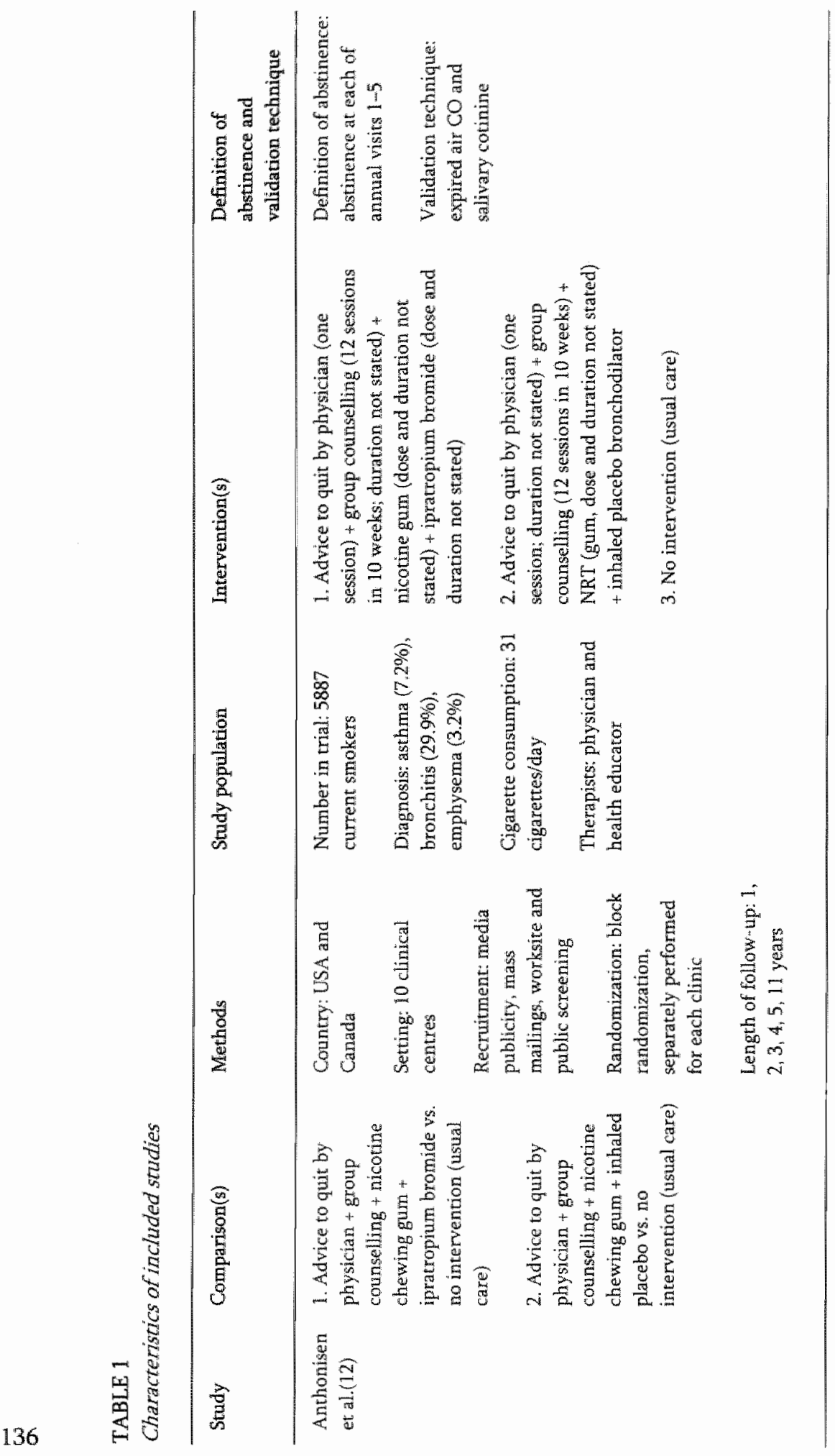




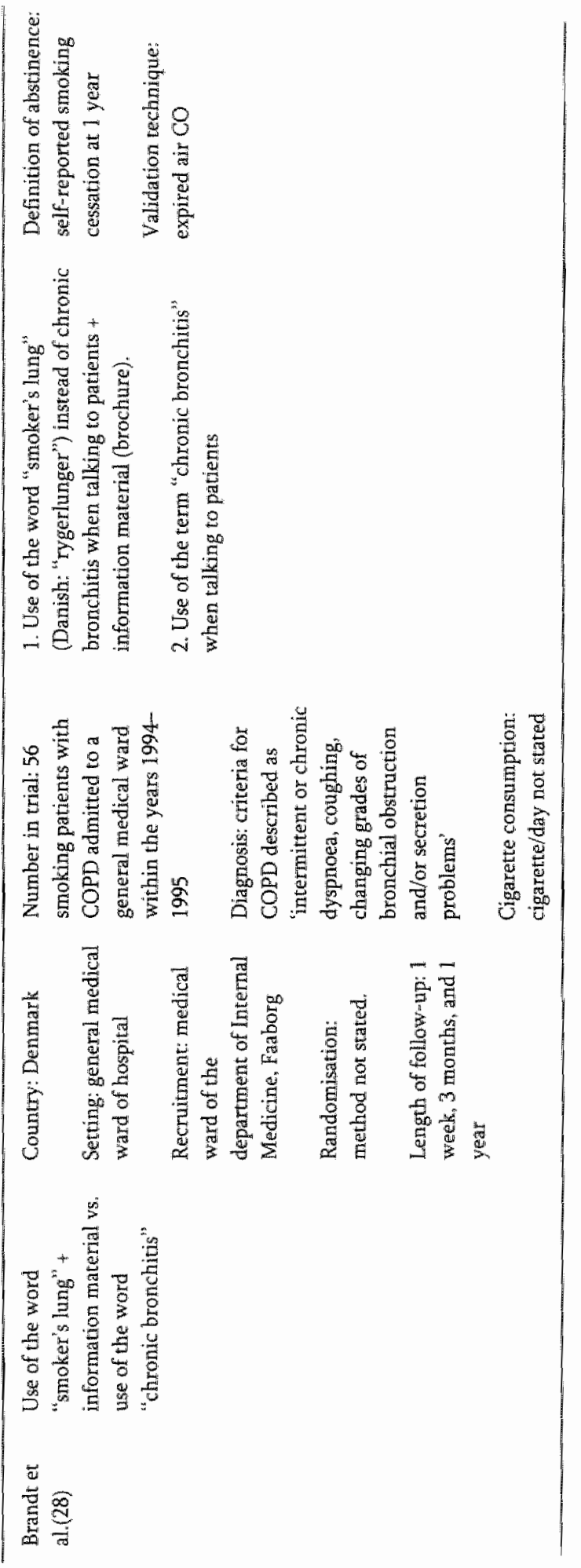




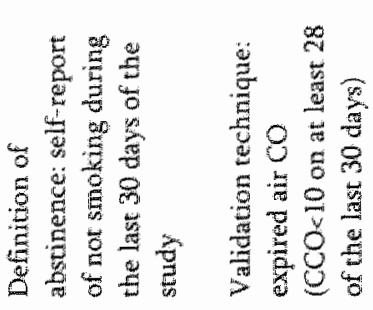

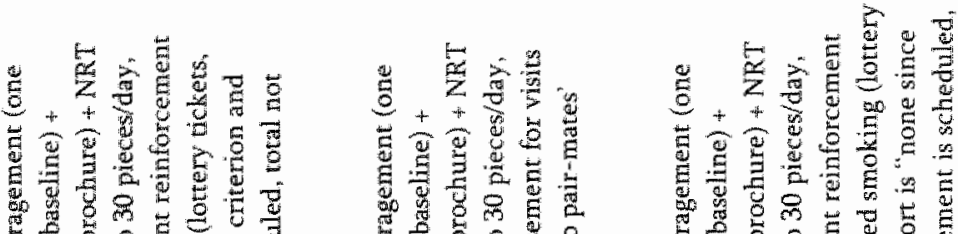

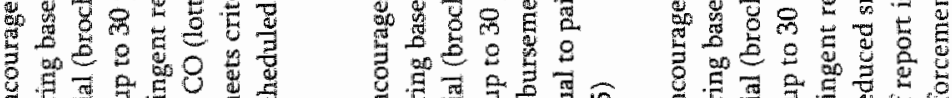

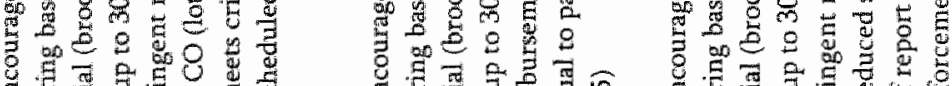

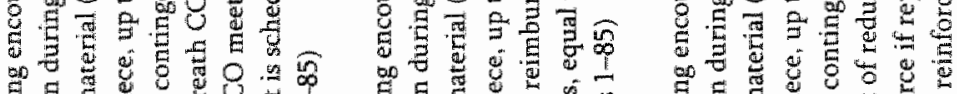

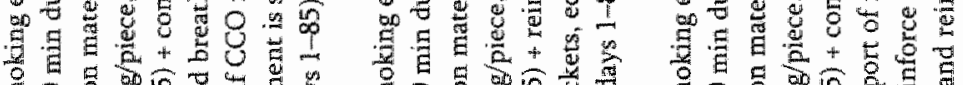

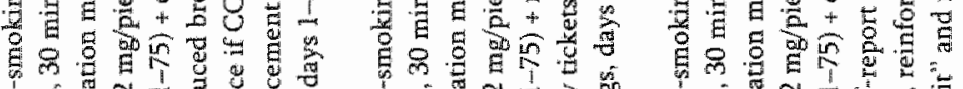

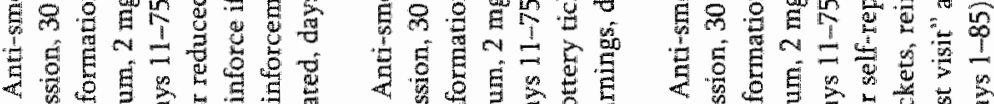

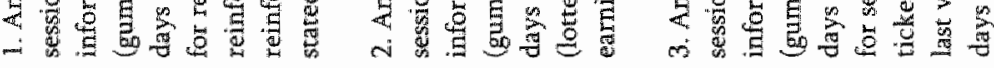

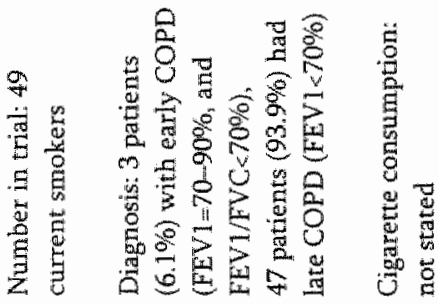

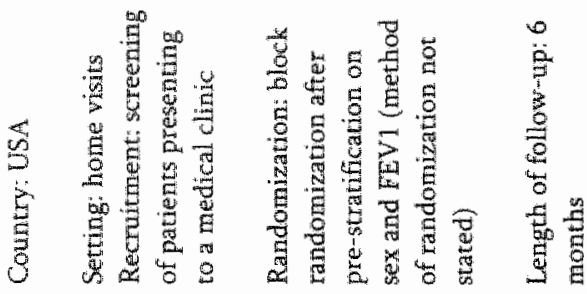

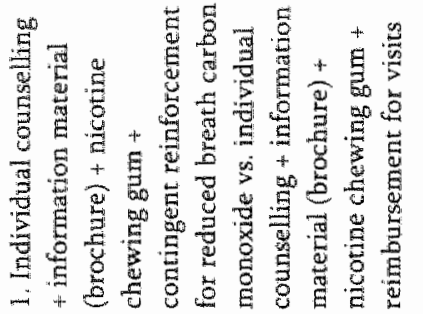

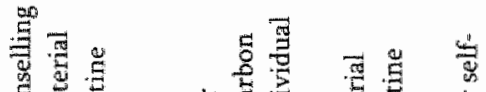

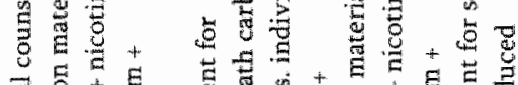

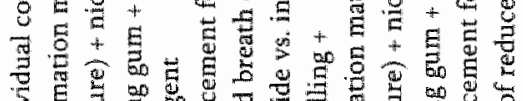

莎

$\underbrace{\frac{8}{3}}_{0}$ 


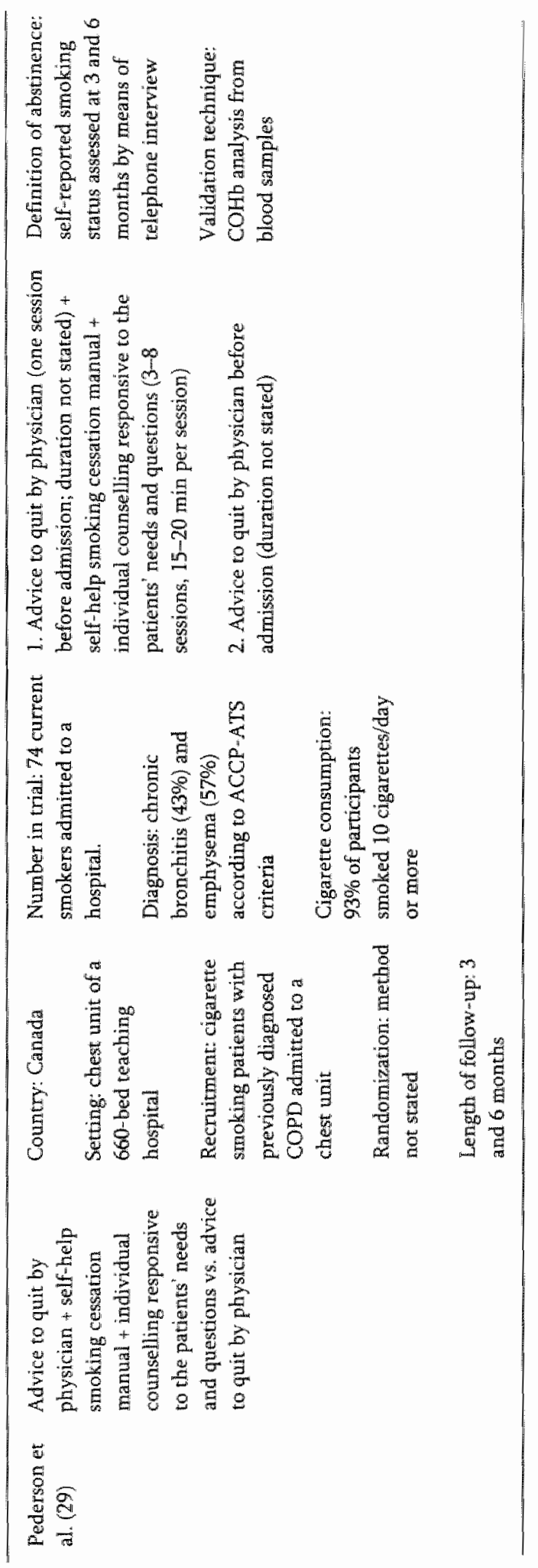




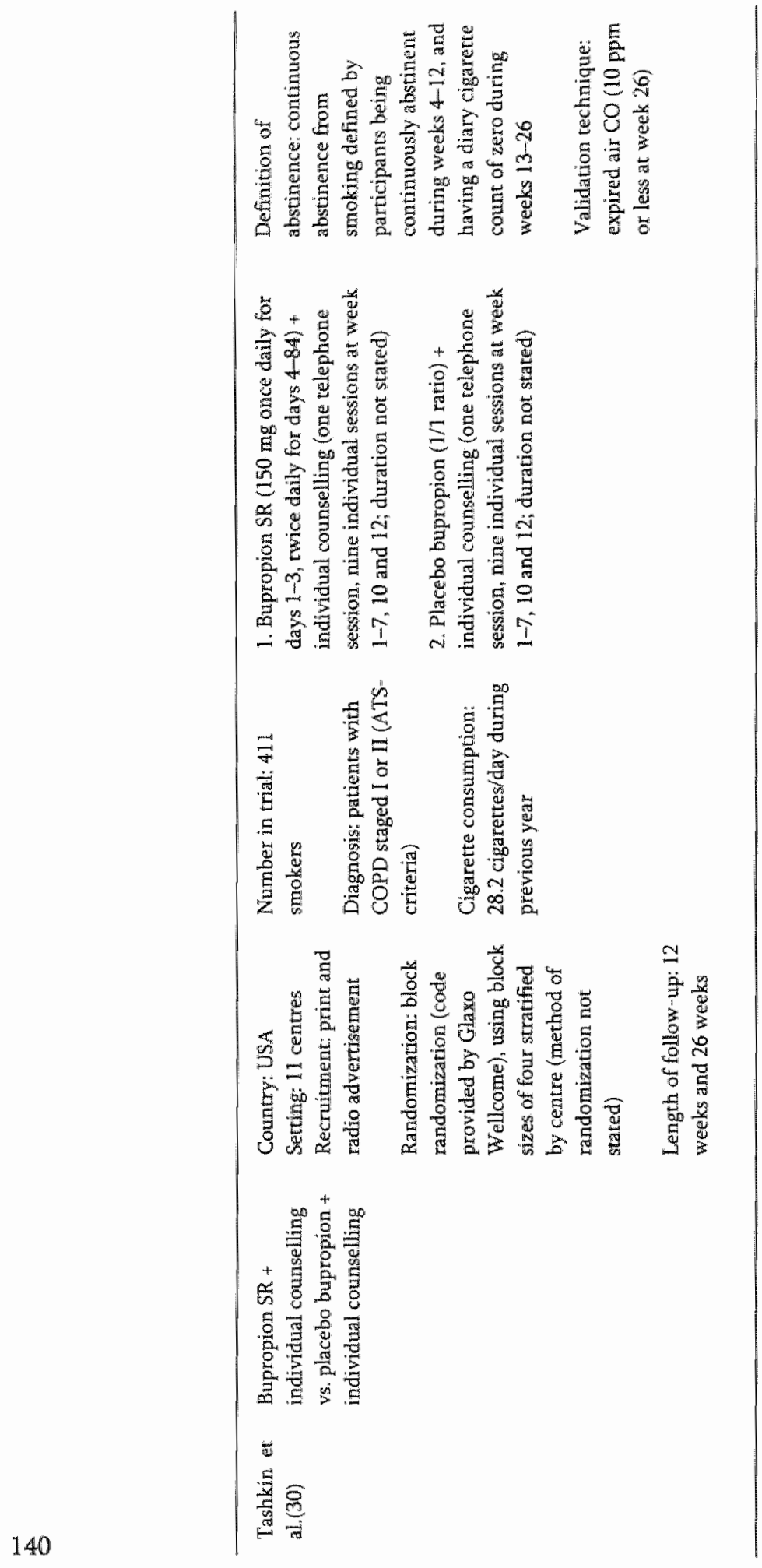




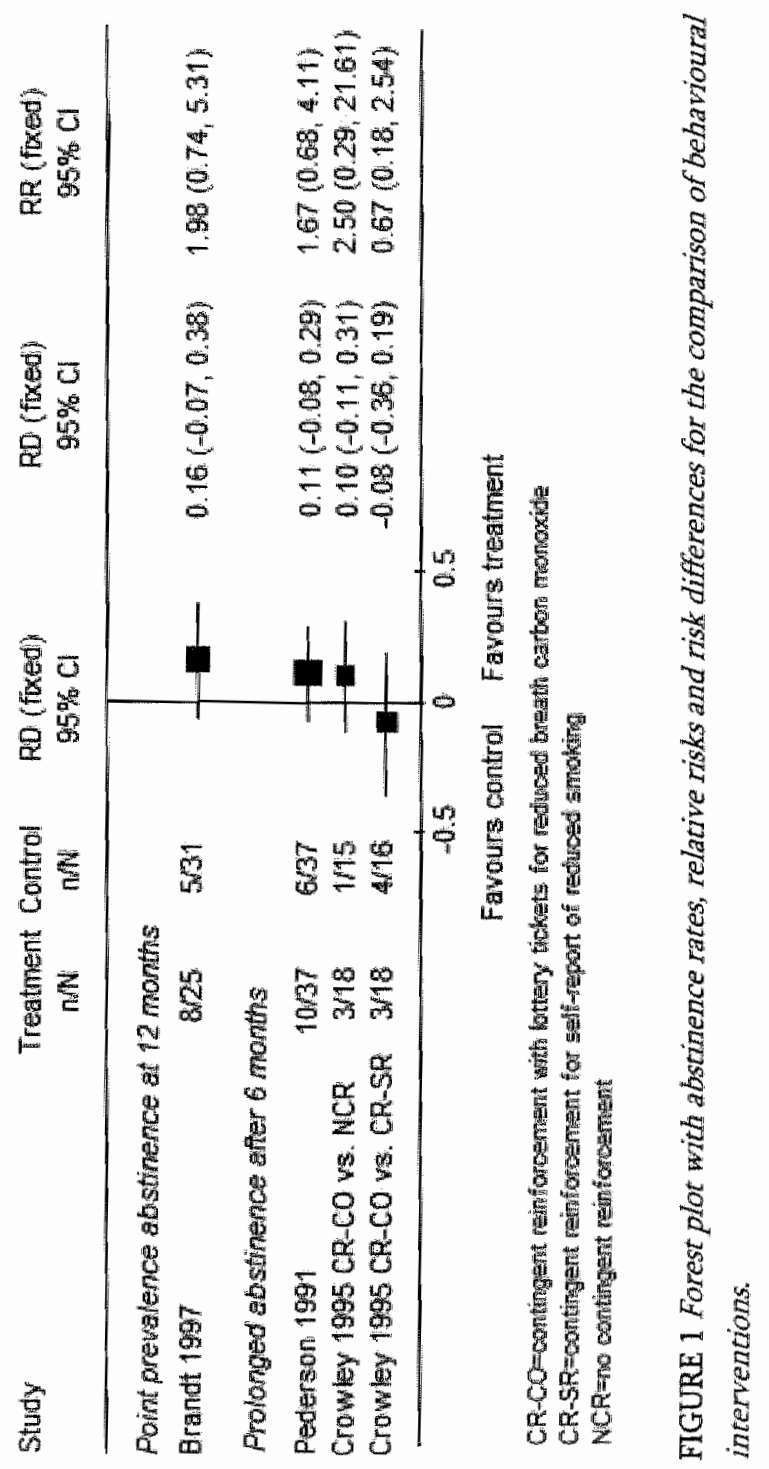



THERAPY COMPARED WITH NO INTERVENTION

The Lung Health Study(12) evaluated the effect of an intensive smoking cessation intervention (combined with either the inhaled bronchodilator ipratropium bromide or placebo) on the rate of decline in FEV1. The comparison group, termed "usual care" by the authors, received no definitive smoking intervention. The smoking intervention consisted of: 1) 12 group sessions in the first 10 weeks of the study (the frequency of meetings starting at four per week and gradually declining); 2) nicotine gum provided at no cost (the authors did not describe the prescribed dose and duration); and 3) a maintenance programme for people who quit smoking aimed at preventing relapse by teaching coping skills for problems such as stress and increases in body weight. Relapses were individually treated as soon as they occurred if the participant was willing. Smokers thought to be at high risk for COPD as indicated by the presence of mild airways obstruction, which the Lung Health Study Research Group defined as a (prebronchodilator) ratio of FEV1 to forced vital capacity (FVC) of $70 \%$ or less, were eligible for participation. Smokers were excluded if they regularly used physician-prescribed bronchodilators.

In Fig. 2, point prevalence and prolonged abstinence smoking cessation rates from the Lung Health Study are presented.(12) Results indicate that the use of an intensive smoking cessation programme (combined with ipratropium bromide) is significantly more effective after 12 months' follow-up than no intervention in helping smokers to quit $(\mathrm{RD}=0.26,95 \% \mathrm{CI} 0.23$ to 0.28 ; $\mathrm{RR}=3.85,95 \% \mathrm{CI} 3.30$ to 4.48). This difference remained statistically significant throughout the 5 -year follow-up ( $\mathrm{RD}=0.16,95 \%$ CI 0.14 to 0.18 ; $\mathrm{RR}=4.01,95 \%$ CI 3.25 to 4.93 ). The combination of the smoking intervention with a placebo bronchodilator yielded almost identical outcomes compared with no intervention (after 12 months: $\mathrm{RD}=$ $0.25,95 \% \mathrm{CI} 0.23$ to 0.28 ; $\mathrm{RR}=3.81,95 \% \mathrm{CI} 3.27$ to 4.44 ; after 5 years $\mathrm{RD}=0.17$. $95 \% \mathrm{Cl} 0.15$ to $0.19 ; \mathrm{RR}=4.19,95 \% \mathrm{Cr} 3.41$ to 5.16 ). Murray et al.(31) have recently shown that the benefit in reducing FEV1 decline between the smoking intervention programme and no intervention (referred to by the authors as "usual care") persisted 11 years after the start of the Lung Health Study.(12) 


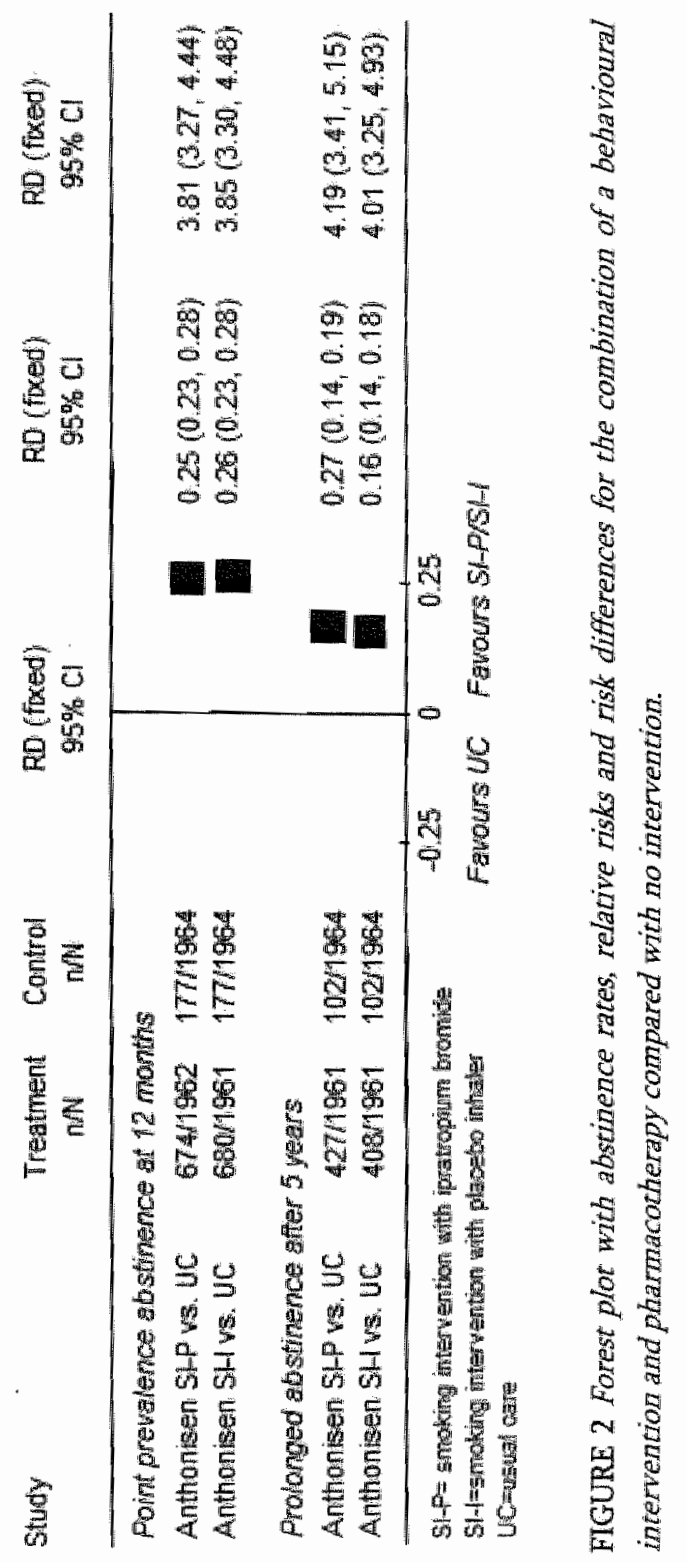




\section{BUPROPION COMPARED WITH PLACEBO MEDICATION}

Tashkin et al.(30) reported on the efficacy of bupropion sustained release (SR) for smoking cessation. The study population consisted of current smokers with a ratio of FEV1 to FVC of $70 \%$ or less and presence of clinically defined COPD. They defined severity of COPD according to COPD-staging guidelines from the ATS (ATS; stage I = FEV1 $\geq 50 \%$ predicted, and stage II $=$ FEV1 between $35 \%$ and $50 \%$ of predicted). Figure 3 indicates that the combination of bupropion SR $300 \mathrm{mg} /$ day for 12 weeks and 10 individual counselling sessions resulted in significantly higher prolonged abstinence rates after 26 weeks compared with placebo combined with the same behavioural intervention $(\mathrm{RD}=0.07,95 \% \mathrm{CI} 0.00$ to $0.13 ; \mathrm{RR}=1.74,95 \%$ CI 1.01 to 3.00 ). However, data from the same study (although not presented in their publication) showed that, after 12 months, the difference between bupropion and control group disappeared. After 12 months, 21 smokers (10\%) from the bupropion group were still abstinent from smoking, compared with $17(8 \%)$ smokers from the control group ( $\mathrm{RD}=0.02,95 \% \mathrm{CI}-0.04$ to $0.07 ; \mathrm{RR}=1.21,95 \% \mathrm{Cl} 0.66$ to 2.23$)$. (20)

\section{METHODOLOGICAL QUALITY}

Table 2 shows the results of the methodological quality assessment. In general, the scores for methodological quality varied between 2 and 9 points. Although one study(30) hadl a maximum score of nine, indicating a low likelihood of bias, the scores of the other four studies varied between 2 and 5 points. Two of the five studies had an acceptable quality score ( 25 points). The most prevalent methodological flaws were associated with inadequate allocation concealment, and the blinding of the outcome assessor, the therapist and the patient. Although four studies reported that a method of randomization was carried out, only one study(30) reported the randomization procedure in sufficient detail to determine whether a satisfactory attempt to control selection bias had been made. All trials used some form of validation of self-reported smoking cessation. Validation of abstinence was carried out by blinded methods (measurement of metabolites in body fluids) in two trials, $(12,29)$ although, in one trial, biochemical verification was sought in a random sample of quitters.(29) The other three trials measured carbon monoxide in expired air. $(27,28,30)$ 


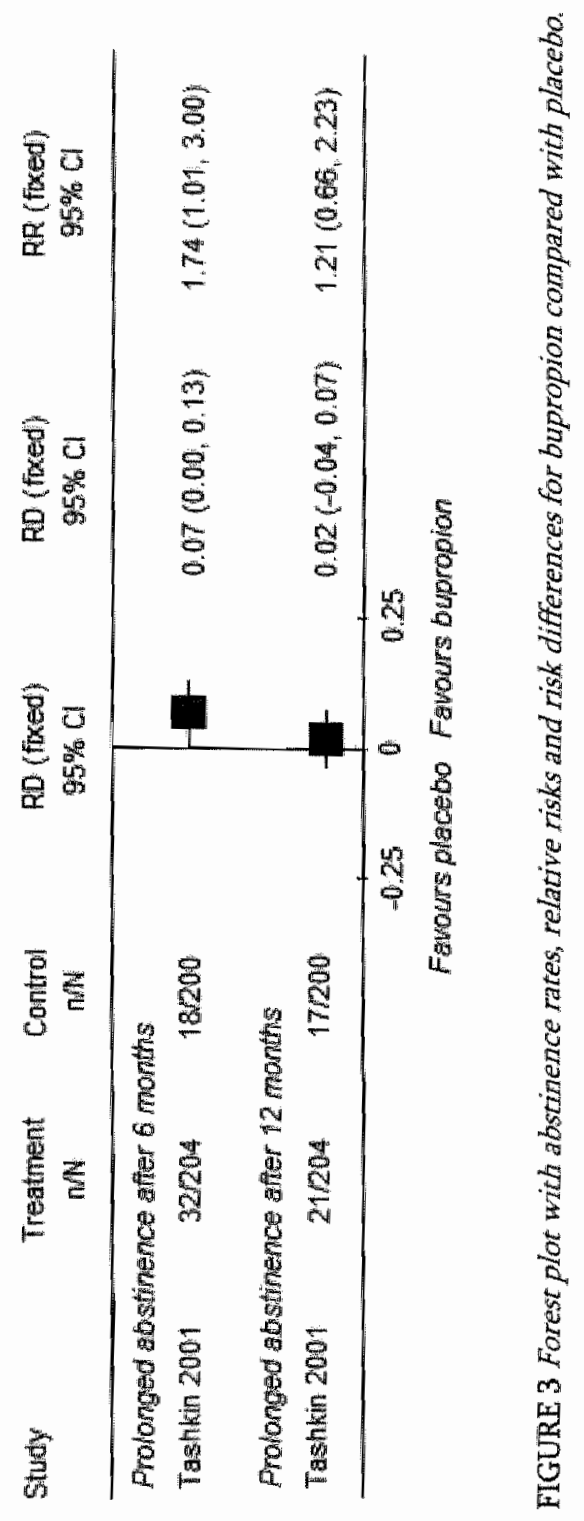




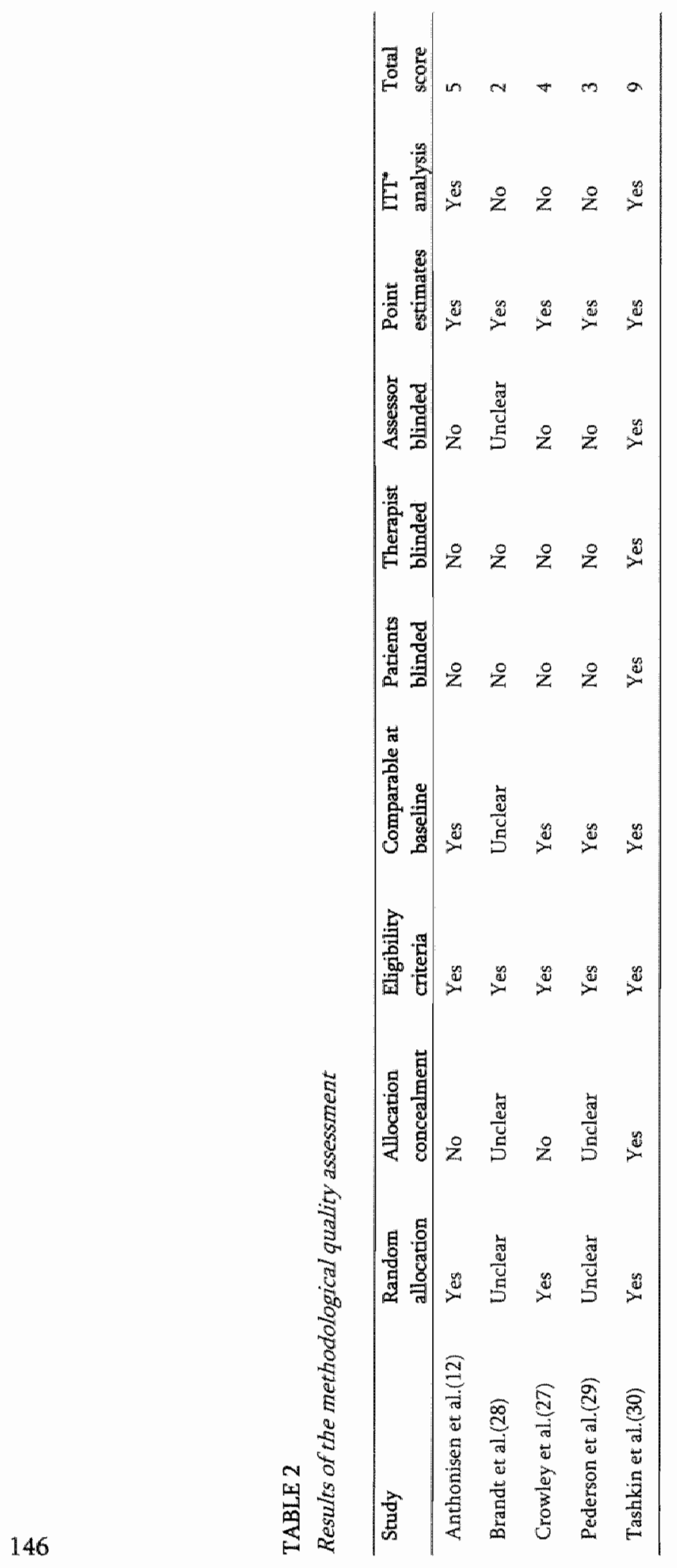




\section{Discussion}

This systematic review shows that, until now, only five randomized trials, comprising 6491 patients with COPD, have evaluated the efficacy of smoking cessation interventions directed specifically at patients with COPD. Because the included trials were clinically heterogeneous with regard to study population (severity of the obstruction) and the type of intervention that was studied, pooling of data was impossible. In three trials, the efficacy of different behavioural interventions for smoking cessation was assessed.(27-29) The three trials, namely, use of the words "smoker"s lung" instead of traditional terminology when talking to patients with $C O P D,(28)$ contingent reinforcement for smoking cessation(27) and individual support and encouragement responsive to the patients' needs and questions,(29) all failed to find a statistically significant difference in efficacy, even though each showed a trend in favour of the intervention. The number of patients in each trial was small, however, and the $\mathrm{CI}$ wide, so it remains possible that a clinically useful effect might have been missed.

In the Lung Health Study,(12) 5887 smokers who were thought to be at high risk for COPD (pre-bronchodilator FEV1 to FVC ratio of $70 \%$ or less) participated and tried to quit smoking. Eligible smokers were not recruited through healthcare professionals but by using media publicity, mass mailings and worksite and public screening. As a result, most participants did not have a history of physiciandiagnosed bronchitis or emphysema. Results of the Lung Health Study(12) showed that the combination of nicotine chewing gum and intensive individual counselling for a sustained period ( 5 years) significantly increased smoking cessation. Results from the Cochrane review on nicotine replacement therapy for smoking cessation(32) indicate that there is strong evidence for the efficacy of nicotine gum as part of a strategy to promote smoking cessation in smokers in general. Also, the absolute probability of not smoking at 6-12 months was greater in trials that provided intensive additional support, particularly with nicotine gum, although the result was not statistically significant.(32)

As the experimental intervention in the Lung Health Study resulted in high prolonged abstinence rates (even after 5 years), the question arises whether it is feasible to implement this intervention in daily practice. We think it is not, for two reasons. Many of the patients had mild or asymptomatic airways disease, and had not necessarily presented to a health professional outside the context of this study. Secondly, the intervention is very resource intensive. Smoking cessation programmes would need to be established in which healthcare professionals had the time and resources to implement an intensive intervention (i.e. 12 sessions during 
the first 10 weeks, combined with visits at 4-month intervals for the remainder of the 5 years), and retain the ability to respond rapidly to relapses.

On the basis of the medium-term results of the study conducted by Tashkin et al.(30) (i.e. after 26 weeks), one would conclude that bupropion is an effective aid in smoking cessation for patients with mild-to-moderate COPD. However, when the results of this study were evaluated after 12 months, the efficacy of bupropion compared with placebo could not be sustained.(20) The number of participants who relapsed increased significantly faster over time in the bupropion group than in the placebo group. The prolonged abstinence rates declined from week 26 to 52 by $6 \%$ in the bupropion group (from 16\% at week 26 to $10 \%$ at week 52) compared with only $1 \%$ in the placebo group (from 9\% after week 26 to $8 \%$ after week 52), 20,30

Bupropion has now been licensed for use in smoking cessation in the USA and many countries of the European Union. In a recent Cochrane review update, Hughes et al.(19) identified 16 randomized trials in which the efficacy of bupropion was compared with placebo medication (including the study conducted by Tashkin et al.(30)). In only half of the 16 trials did bupropion result in significantly higher prolonged abstinence rates after at least 6 months, compared with placebo medication.(19) Bupropion acts on sites in the central nervous system to reduce withdrawal symptoms.(33) This drug probably does not attenuate or block the reinforcing effects of nicotine. The results of the systematic review by Hughes et al.(19) raise the possibility that bupropion will provide relief of associated smoking cessation symptoms and, in the long term, will most likely be of limited efficacy. In this respect, it would be interesting to evaluate the efficacy of bupropion without (intensive) behavioural support, as the follow-up time during which bupropion is significantly more effective compared with placebo treatment could well be extended by prolonged behavioural treatment.

\section{Conclusion}

"To summarize, the results of this systematic review indicate that, with the exception of the combined use of pharmacotherapy to reduce craving and withdrawal, with intensive individual counselling for a sustained period, the success of other smoking cessation interventions in patients with COPD is low. This is consistent with the commonly held assumption that continued smoking in the presence of established COPD and aggravating symptoms is an indication that these patients are particularly addicted to nicotine,(34) and would already have quit smoking if they could. Tashkin et al.(30) evaluated whether bupropion SR resulted. 
in higher abstinence rates in patients with stage I COPD (FEV1 $z 50 \%$ predicted) compared with patients with stage II COPD (FEV1 between $35 \%$ and $50 \%$ of predicted). Prolonged abstinence rates after 26 weeks were lower in patients with more severe COPD, although this difference was not statistically significant. Published studies on smoking cessation show that about $70-80 \%$ of the motivated (non-chronically ill) smokers relapse within the first 12 months.(35-37) Whether quit rates are lower in patients with severe COPD compared with healthy smokers or smokers with mild COPD remains unknown.

Future research might address the short, intermediate and long-term effects of a range of cost-effective strategies for smoking cessation in patients with COPD, and also whether the effects of smoking cessation interventions in "healthy" smokers can be extrapolated to smokers with COPD. This would involve trials in which the efficacy of smoking cessation strategies in smokers without a chronic illness is compared with the efficacy in smokers with COPD.

\section{Acknowledgements}

We would like to thank Steve Milan, Karen Blackhall and Toby Lasserson of the Cochrane Airways Group for their assistance in searching relevant randomized trials. We thank Jane Dennis for translating a Danish paper, Maurice Zeegers for his assistance with the quantitative data synthesis, and Phillippa Poole for her editorial comments.

\section{Funding/Support}

The work presented in this paper was supported by the Dutch Asthma Foundation (NAF grant no. 3.2.00.21) and the Health Research and Development Council (ZorgOnderzoek. Nederland), The Netherlands (grant no. 2200.0111). 


\section{References}

1. Pauwels RA, Buist AS, Calverley PM. Jenkins CR, Hurd SS. Global strategy for the diagnosis, management, and prevention of chronic obstructive pulmonary disease. NHLBI/WHO global initiative for clinonic obstructive lung disease (GOLD) Workshop summary. Am I Respir Crit Care Med 2001; 163: 1256-1276.

2. Roche N, Huchon G. Currertit issues in the management of chronic obstructive pulmonary disease. Respirology 1997; 2: 215-229.

3. Us Department of Health and Human Services. The health consequences of smoking: chronic obstructive lung disease. Rockwille, MD: Office on Smoking and Health, Department of Health and Hus rian Services; 1984. Report No. (CDC) 8.416.

4. Burchfiel $\mathbb{C}_{9}$ Marcus $E$, Curb J, Maclean $C$, et al. Effects of smoking and smoking cessation on longitudinal decline in pulmonary function. Am J Respir Crit Care Med 1995; 151: 1778-1785.

5. Camilli AE, Burrows $B$, Knudson Rf, Lyle SK, Lebowitz MD. Longitudinal changes in forced expiratory volume in one second in adults. Am Rev Respir Dis. 1987; 135: 794-799.

6. Fletcher CM, Peto $R$, Tinker CM, Speizer FE. The natural history of chronic bronchitis and emphysema, Oxford: Oxford Uniwersity Press; 1976.

7. Muers MF: Quitting smoking and lungs. Lancet 1999; 354: 177-178.

8. Pelkonen $\mathbb{M}_{*}$ Notkola $\mathrm{I}-\mathrm{L}$, Tukiainen $\mathrm{H}$, Tervahauta $M$, Tuomilehto J, Nissinen A. Smoking. cessation, decline in pulmonary function and total mortality: a 30 year follow up study among the Finnish cohorts of the seven countries study. Thorax 2001; 56: 703-7.

9. Xu X, Dockery DW, Ware JH, Speizer FE, Ferris BG. Effects of cigarette smoking on rate of loss of pulmonary function in adults: a longitudinal assessment. Am Rev Respir Dis 1992; 146: 1345-1348.

10. Tashkin DP. Deress R, Simmons M, Liu, et al. The UCLA population studies of chronic obstructive respiratory disease: XI. Impact of air pollution and smoking on annual change in forced expiratory wolume in one second. Am J Respir Crit Care Med 1994; 149; 1209-1217.

11. Tager IB, Segal MR, Speizer FE, Weiss ST. The natural history of forced expiratory volumes: effect of cigarette smoking and respiratory symptoms. Am Rev Respir Dis 1988; 138: 837-849.

12. Anthonisen NR, Comnett JE, Kiley JP, et al. Effects of smoking intervention and the use of an inhaled anticholinergic bronchodilator on the rate of decline of $\mathbb{E E V} 1$. The Lung Health Study. IAMA 1994: 272:1497-1505.

13. Sherrill D, Holberg C, Enright P, Lebowitz M, Burrows B. Longitudinal analysis of the effects of smoking anset and cessation on pulmonary function. Am J Respir Crit Care Med 1994; 149: 591597.

14. Soejima K, Yamaguchi $\mathrm{K}$, Kohda E, et al. Longitudinal follow w study of smokingwinduced lung density changes by high resolution computed tomography. Am I Respir Crit Care Med 2000; 161: $1264-1273$.

15. American Thoracic Society. Standards for the diagnosis and care of parients with chronic obstructiwe pulmonary disease. Am J Respir Crit Care Med 1995; 152: S77-S121.

16. BTS guidelines for the management of chronic obstructive pulmonary disease: the COPD guideline grotup of the standards of care committee of the BTS. Thorax 1997; 52 (Suppl. 5): S1-S28.

17. Siafakas NM. Vermeire P. Pride NB, et al. Optimal assessment and management of chronic obsuructive pulmonary disease (COPD). The European Respiratory Society Task Force. Eur Respir I 1995; 8: 1398-1420.

18. Van der Meer R, Wagena EJ, Ostelo R, lacobs J, Van Schayck C.P. Smoking cessation for people with chronic obstructive pulmonary disease (Cochrane review). In: The Cochrane Library, Issue 2. Oxford: Update Software; 2003.

19. Hughes JR. Stead LF, Lancaster T. Antidepressants for smoking cessation (Cochrane review). In: The Cochrane Library, Issue 2. Oxford: Update Software; 2002. 
20. Jarvis MT, Powell SR, Marsh HS, Browning D, Aristides M, Brown A. A meta-analysis of clinical studies confirms the effectiveness of bupropion SR (Zyban) in smoking cessation. Poster Presentation at the Sth Annual Meeting of the Sociey for Research on Nicotine and Tobacco, Savannah, Georgia, February 20-23, 2002.

21. Perruchoud AP, Townsend I, Lorand D. The efficacy of bupropion hydrochloride sustained release (SR) for smoking cessation is consistent in placebo-controlled studies. Eur Respir ) 2002; 20(5uppl. 38): $579 \mathrm{~s}$.

22. Manheimer E, Anderson D. Survey of public information about ongoing clinical trials funded by industry: evaluation of completeness and accessibility. BMI 2002; 325: 528-531.

23. McCray AT. Better access to information about climical trials. Ann Intern Med 2000; 133: 609-614.

24. Anderson $D$, Costa $I$, Dickersin $K$. TrialsCentral, an online register of clinical trials registers. Control Clin Trials 2001; 22: S40.

25. Verhagen A.P, de Vet HC, de Bie RA, et al.. The Delphi list: a criteria list for quality assessment of randomjzed clinical trials for conducting systematic reviews developed by Delphi consensus. / Chin Epidemiol 1998; 51: 1235-1241.

26. Wintertree Software Inc. Review Manager 4,2.2. In: The Cochrane Collaboration; 2003.

27. Crowley TI, Macdonald MI, Walter MI. Behavioral antismoking trial in chronic obstructive pulmonary disease patients. Psychopharmacology 1995; 119: 193--204.

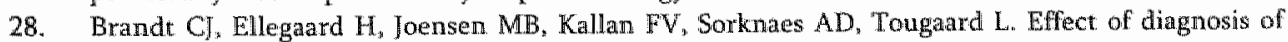
"smoker"s lung". Lancet 1997; 349: 253.

29. Pederson LL. Wanklin JM, Lefcoe NM. The effects of counseling on smoking cessation among patients hospitalized with chronic obstructive pulmonary disease: a randomized clinical trial. Int J Addiction 1991; 26: 107-119.

30. Tashkin DP, Kanner R. Bailey W, et al. Smoking cessation in patients with chronic obstructive pulmonary disease: a double-blind, placebo-controlled, randonised trial. Lancet 2001; 357: $1571-$ 1575.

31. Murray RP. Connett JE, Rand CS, Pan W, Anthonisen NR. Persistence of the effect of the fung health study (LHS) smoking intervention over eleven years. Prev Med 2002; 35: 314-319.

32. Silagy C, Lancaster T, Stead L, Mant D, Fowler G. Nicotine replacement therapy for smoking cessation (Cochrane review). In: The Cochrane Library, Issue 2. Oxford: Update Software; 2002.

33. Balfour DJK. The pharmacology underlying pharmacotherapy for tobacco dependence: focus on bupropion. Int I Clin Pract 2001; 55: 53-57.

34. Scanlon PD, Connet JE, Waller LA, Altose MD, Bailey WC, Buist AS. Smoking cessation: effects on symptoms, spirometry and future trends in COPD. Thorax 2001; 56 (Suppl. II): iit-ij10.

35. Lancaster T, Stead L, Silagy C, Sowden A. Effectiveness of interventions to help people stop smoking: findings from the Cochrane library. BMJ 2000; 321: 355-358.

36. Covey LS, Sullivan MA, Johnston JA, Glassman AH, Robinson MD, Adams DP. Advances in non nicotine pharmacotherapy for smoking cessation. Drugs 2000; 59: 17-31.

37. Hughes JR. Distinguishing nicotine dependence from smoking. Why it matters to tobacco control and psychiatry. Arch Gen Psychiatry 2001;58: 817-818. 
The efficacy of bupropion and nortriptyline for smoking cessation among people who are at risk for or have chronic obstructive pulmonary disease: A randomized, placebocontrolled trial

Wagena EJ, Knipschild P, Huibers MJH, Wouters EFM, van Schayck CP

SUBMITTED FOR PUBLICATION 


\section{Abstract}

\section{CONTEXT}

The observation that: 1) (especially) smoking patients with COPD seem to be at increased risk of depression, 2) nicotine addiction is often accompanied by comorbid depression or depressive symptoms, and 3) nicotine may have antidepressant effects and regulate mood, provides a rationale for the use of antidepressant drugs for smoking cessation in patients with COPD. No clinical trial has yet studied the efficacy of bupropion and nortriptyline for smoking cessation in this patient population.

\section{DESIGN, PATIENTS AND INTERVENTION}

In a randomized, double-dummy, placebo-controlled trial, 255 adults at risk for or with existing COPD were assigned bupropion SR (150 $\mathrm{mg}$ twice daily), or nortriptyline (75 mg once daily) for 12 weeks. All patients received smoking cessation counseling.

\section{MAIN OUTCOME MEASURE}

The primary outcome measure was prolonged abstinence from smoking from week 4 to week 26 after the target quitting date. Analysis was by intention to treat.

\section{RESULTS}

The use of bupropion $\mathrm{SR}$ as well as nortriptyline resulted in higher prolonged abstinence rates compared to placebo, although only the difference between bupropion SR and placebo was statistically significant (difference between bupropion SR and placebo, $18.9 \%, 95 \%$ PI, 3.6, 34.2, and between nortriptyline and placebo, $13.4 \% ; 95 \% \mathrm{PI},-0.3,27.2)$. In participants at risk for COPD, no statistically significant differences in prolonged abstinence rates with placebo were found. Cox regression analysis showed that the estimated risk of relapse occurring in participants with existing COPD was more than $30 \%$ higher compared to that in participants at risk for COPD (Hazard Ratio, $1.3 ; 95 \%$ PI, 1.0, 1.7).

\section{CONCLUSION}

Bupropion SR is an efficacious aid to smoking cessation in patients with existing COPD. Nortriptyline seems to be a useful alternative. 


\section{Introduction}

Smoking and pulmonary diseases such as chronic bronchitis or emphysema (i.e. chronic obstructive pulmonary disease [COPD]) are causally related. 'However, it was not until 1964 that the US Surgeon General's report warned about a potential causal relation between smoking and emphysema.' Since then numerous studies have shown that cigarette smoking accelerates the rate of decline in pulmonary function. ${ }^{2-8}$ Smoking cessation is not only the most effective way to reduce the risk of developing COPD. In smokers who already have a decreased pulmonary function, smoking cessation is the only intervention which has shown to reduce the rate of decline in forced expiratory volume (FEV $)^{2,3,79-11}$ Furthermore, it improves longterm prognosis ${ }^{12}$ and reduces the symptoms of cough and sputum production, ${ }^{13}$, as well as airways reactivity. ${ }^{14}$

The observation that: 1) (especially) smoking patients with COPD seem to be at increased risk of depression, ${ }^{15-17}$ 2) nicotine addiction is often accompanied by comorbid depression or depressive symptoms, ${ }^{18,19}$ and 3) nicotine may have antidepressant effects, ${ }^{20,2 \rrbracket}$ provides a rationale for the use of antidepressant drugs for smoking cessation in patients with COPD. ${ }^{22,23}$ Despite all this evidence, only one randomized trial has so far evaluated the efficacy of an antidepressant (bupropion sustained release [SR]) for smoking cessation in patients with COPD. ${ }^{24} \mathrm{We}$ conducted an independent randomized trial to assess the efficacy of bupropion SR and nortriptyline for smoking cessation among smokers with existing COPD and at risk for COPD. Furthermore, we wanted to assess whether the time to relapse is different across the treatment groups. Patients with COPD are expected to experience additional barriers for success in smoking cessation, such as higher nicotine addiction scores ${ }^{25}$ and a higher prevalence of psychiatric disorders like depression. ${ }^{16,17}$ The second objective of this trial was therefore to explore the efficacy of bupropion SR and nortriptyline in smokers with existing COPD compared with smokers at risk for COPD. On the basis of the existing literature, ${ }^{26,27}$ we deemed differences between bupropion SR and nortriptyline unlikely. We therefore did not predict differences between these two groups. 


\section{Methods}

\section{PARTICIPANTS, SCREENING, RANDOMIZATION}

The study population consisted of current daily smokers with existing COPD or at risk for COPD. All participants were aged between 30 and 70 years, had to have a smoking history of at least 5 years, smoked on average at least 10 cigarettes per day during the last year, and were motivated to stop smoking. We screened subjects by means of a telephone interview to measure demographic and smoking variables. Next, potential participants were invited for a baseline assessment including standlardized spirometric tests to assess airflow limitation. We defined the severity of COPD according to the definition provided by the Global Initiative for Chronic Obstructive Lung Disease (GOLD) ${ }^{28}$ : Stage D (at risk), FEV /FVC>0.7 combined with the presence of cough, sputum production or dyspnea (as assessed by the Clinical COPD Questionnaire ${ }^{29}$ ); Stage I (mild COPD), FEV $/$ FVC $<0.7$, and $\mathrm{FEV}_{1} 800 \%$ of predicted; Stage II (moderate COPD), FEV $/$ FVC $<0.7, \mathrm{FEV}_{\Perp}$ between $50 \%$ and $80 \%$ of predicted; Stage III (severe COPD), FEV $1 / F^{2} C<0.7, F_{1} V_{1}$ between $30 \%$ and $50 \%$ of predicted. Patients with stage $1, I I$ and III COPD were combined for analysis. We excluded people who reported having used or were still using bupropion SR or nortriptyline, people who were using nicotine replacement therapy and/or psychoactive medication at the time of assessment, and patients who had any serious or unstable medical disorders that might affect lung function or for which bupropion SR or nortriptyline was contraindicated.

Participants were randomized between March 1, 2002, and August 27, 2003, with a last 6-month follow-up session before March 2004. Of the 611. people who were screened, 255 met the screening criteria and all these participated in the study (Figure 1). Randomization was done according to a randomization code provided by the pharmacist of the Radboud University Nijmegen Medical Centre, stratified for COPD severity. Patients were stratified based on the definition provided by the European Respiratory Society. ${ }^{30}$ However, since the GOLD guideline was published in $2001,{ }^{31}$ and has been implemented worldwide since then, ${ }^{28}$ we decided to present the results of this trial stratified for COPD severity according to the GOLD classification. ${ }^{28}$ As a result, participants in each of the strata (at risk for COPD, mild COPD, moderate and severe COPD) were not evenly distributed over the three treatment groups. Within each of the strata, we used blocks of 33 . The pharmacist in Nijmegen and one senior investigator in Mastricht knew the randomization codes. No patient, research nurse, counselor, investigator, or any other staff member was aware of the treatment assignments for the duration of the study. The pharmacist was instructed to break the code for a medical emergency, which happened once. 


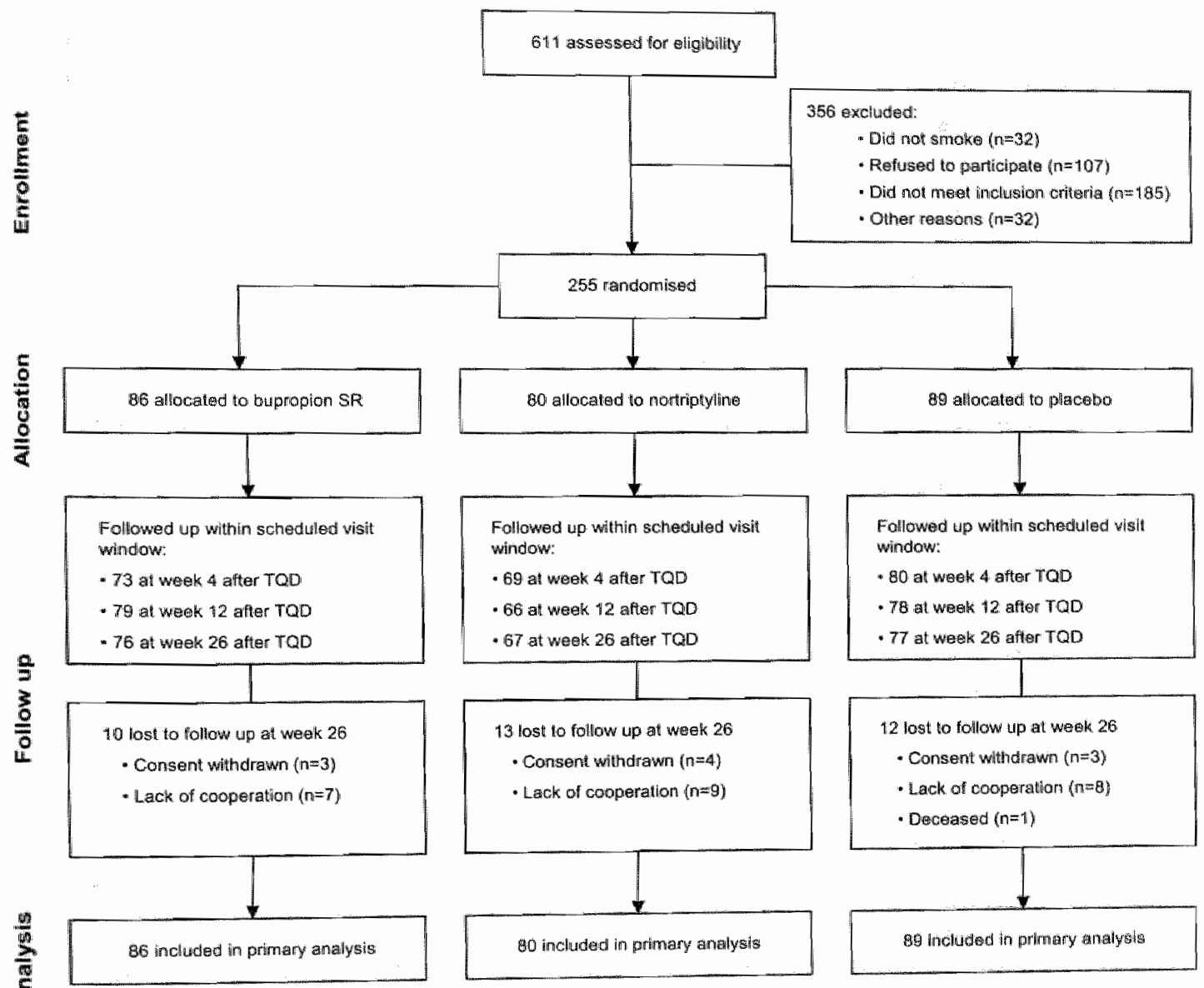

FIGURE 1 Study fowchart 


\section{STUDY DESIGN, MEDICATION AND BLINDING}

Our study was a blinded, placebo-controlled, double-dummy, independent randomized trial conducted at Maastricht University in the Netherlands. Participants provided written informed consent during the first visit. The medical ethics committee of the University Hospital Maastricht/Maastricht University approved the trial.

Eligible individuals were randomly assigned to receive bupropion SR $150 \mathrm{mg}$ once daily for days 1-6, followed by $150 \mathrm{mg}$ twice daily for days $7-84$, nortriptyline $25 \mathrm{mg}$ once daily for days $1-3$, followed by $50 \mathrm{mg}$ once daily for days $3-7$, and $75 \mathrm{mg}$ once daily for days 8-84, or placebo in a $1 / 1$ ratio. Bupropion SR (Zyban) was purchased from GlaxoSmithKline. Pharmacin B.V. produced placebo bupropion and film-coated these tablets as well as the bupropion SR tablets to maintain the patency of the bupropion formulation and to provide (in appearance) identical drugs. Pharmacin B.V. tested whether the film coating influenced the dissolution characteristics of the tablets, which it did not. Nortriptyline tablets were provided free of charge by Lundbeck B.V. Tablets were crushed and reformulated as capsules. Matching placebo capsules of nortriptyline were produced by Pharmacin B.V. At the baseline visit the target quitting date (TQD) was set for the second week, usually at day 11 from the start of the medication. Participants were told not to attempt to stop before this date.

Participants were assessed at baseline and 1,3,12 and 26 weeks after the TQD. At the first three assessments, participants also attended an individual face-toface counseling session (duration approximately 10-20 minutes). The provider was one of three master's-level counselors, trained in counseling smokers who want to quit. In general, participants received counseling from the same person at all 3 sessions. The counselors interacted with every individual smoker in a confronting and directive manner by using spirometric results, focusing on the (advanced) stage of the disease and the health consequences of continuing smoking. They tried to make the participants aware of potential cognitive biases or beliefs that might have been elicited to justify their smoking behavior. Participants also received supportive telephone calls from a counselor on the TQD, and $2,3,6,8$, and 11 weeks after the TQD, to prevent relapse. During the follow-up period (weeks 13-26), we did not provide any relapse-prevention counseling.

Participants were reminded to attend a visit by letter, which was sent at least 2 weeks before the visit. Participants who missed appointments were called at least 3 times to reschedule their visit within the scheduled visit window. Scheduled visit windows were 2 days before to 7 days after week 4 , and 7 days before to 14 days after week 12 and week 26 . At the end of the 26-weeks follow-up, the study staff tried to contact all participants who were lost to follow-up, in order to collect data 
regarding their smoking status that were missing. The database was completed with the collected information.

The primary outcome measure for the study was prolonged abstinence from smoking from week 4 to week 26 after the TQD. Prolonged abstinence was defined as a participant's report of zero cigarettes per day (not even a puff) during weeks 4 26, confirmed by urinary cotinine values of $60 \mathrm{ng} / \mathrm{ml}$ or less ${ }^{32}$ at weeks 4,12 and 26 after the TQD. Participants were allowed to miss one in-person visit, but not the last one, 26 weeks after the TQD. Secondary outcome measures included prolonged abstinence during weeks 4-12, and 7-day point prevalence abstinence (defined as having smoked no cigarettes, not even a puff, for the previous 7 days) at weeks 4,12 and 26 , confirmed by urinary cotinine levels of $60 \mathrm{ng} / \mathrm{ml}$ or less. ${ }^{32}$

The baseline assessment included demographic, smoking, and clinical. characteristics. Nicotine dependence was assessed with the Fagerström Test for Nicotine Dependence (FTND). ${ }^{33}$ Scores of 6 or higher indicate greater levels of nicotine dependence. ${ }^{33}$ The Beck Depression Inventory (BDI) was used to assess the presence and severity of depressive disorder. ${ }^{34,35}$ We used a cut-off score for the BDI of 15 in order to separate the participants with no or mild depression $(B D I<15)$ from the participants with moderate to severe depression (BDI 15 ) ${ }^{34}$ Nicotine dependence and depression were reassessed at weeks 12 and 26 after the TQD.

\section{STATISTICAL ANALYSIS}

The sample size was determined a priori assuming a type 1 error of 0.05 double-sided, a power of $80 \%$, and a 26 -weeks biochemically verified quit rate of $10 \%$ in the placebo and $25 \%$ in the treatment groups. Under these assumptions approximately 100 smokers were to be randomly assigned to each of the three groups (bupropion SR, nortriptyline and placebo). However, even though we extended our planned recruitment period of 12 months to 18 months, we stucceeded in recruiting 255 smokers.

We performed both intention-to-treat and per protocol analysis. All statistical analyses were done with blinding maintained. The $\chi^{2}$ test was used to compare both active treatments (bupropion SR and nortriptyline) with placebo on primary and secondary outcomes. Participants lost to follow-up were considered to be smokers in the intention-to-treat analysis.

We conducted Cox regression analysis ${ }^{36}$ to compare time to relapse across treatment groups using failure to achieve abstinence from smoking as criterion. Survival probabilities were calculated (using the Kaplan-Meier method ${ }^{37}$ ) and presented for the three treatment groups separately. Differences between bupropion SR and placebo, and between nortriptyline and placebo, were calculated with corresponding $95 \%$ precision intervals (PI). To assess the relapse probability at the 
TQD, we used self-report measures by calling participants at the end of this day. Cox regression analysis ${ }^{36}$ was used for quantifying the effects of COPD on time to relapse.

To assess side effects, we asked participants at every study visit and each corisult by telephone to describe any adverse events they experienced. We did not prepare a checklist of possible symptoms. For each patient we kept a record of events on a special form. Frequencies and percentages were used to summarize adverse events in relation to medication over the entire treatment period.

\section{Results}

\section{BLINDING}

A panel of three judges, not including the main investigator EJW, concluded that placebo bupropion and placebo nortriptyline matched the active formulation perfectly in: a) shape, b) size, c) surface color, and d) surface texture. Furthermore, placebo bupropion matched the active drug closely for: a) taste on licking, b) internal color c) internal texture, and d) smell. However, based on the taste on chewing, the authors correctly distinguished bupropion SR from the placebo formulation. Although placebo and active nortriptyline matched on taste on licking, the internal color and smell, the judges could distinguish both formulations based on a difference in taste on chewing, and internal texture.

Blinding of participants was checked one week after the TQD (in 108 participants) and at the end of treatment (in 195 participants). Participants receiving active drug compared with those receiving placebo were one week after the TQD more likely to guess that they had received bupropion SR or nortriptyline $(72 \%[51 / 71]$ vs. $\left.43 \%[16 / 37] ; \chi^{2}=8.44, \mathrm{df}=107, P<0.01\right)$ as well as at the end of treatment $(62 \%[79 / 128]$ vs. $\left.37 \%[25 / 67] ; \chi^{2}=10.52, \mathrm{df}=194, P=0.001\right)$. Of the participants who were able to correctly guess their assignment to active drug, one week after the TQD, 68\% (28/41) of the participants who received bupropion SR and 77\% (23/30) of the participants who received nortriptyline, correctly guessed they received active drug $\left(\chi^{2}=0.60, \mathrm{~d} f=70\right.$, $P=0.44)$. At the end of treatment, $49 \%(34 / 70)$ of the participants who received bupropion and $78 \%$ (45/58) of the participants who received nortriptyline, correctly guessed they had received active drug $\left(\chi^{2}=11.30, \mathrm{df}=127, P<0.001\right)$. At both time points, participants could not distinguish between bupropion SR and nortriptyline. Blinding of study staff (study nurses, counselors, main investigator and outcome assessor) was not evaluated. 


\section{MEDICATION COMPLIANCE}

We assessed medication compliance by counting the number of pills allotted minus returned. At baseline, participants were asked to retain empty blisters and return them on the next visit. At the end of the treatment period, we asked all participants to return the pills they had not used, as well as the remainder of the empty blisters. Of 73 participants $(28 \%)$, medication compliance could not be assessed. Of all other participants, 82 participants ( $45 \%$ ) used more than $80 \%$ of the study medication, 33 (18\%) used between 50 and $80 \%$, and $67(37 \%)$ used less than $50 \%$ of the medication they were intended to use. Medication compliance did not significantly differ between the three groups $\left(x^{2}=7.52, \mathrm{df}=6, \quad P=0.28\right)$, although relatively more participants receiving nortriptyline used less than $50 \%$ of study medication ( $48 \%$ versus $34 \%$ of bupropion SR group and $28 \%$ of placebo group). Compared to participants who used more than $80 \%$ of study medication and those using between 50 and $80 \%$, abstinence rates were lowest among the participants who used less than $50 \%$ of the study medication (27\% and $24 \%$ compared to $16 \%$, respectively). However, prolonged abstinence rates did not differ significantly between these groups $\left(\chi^{2}=2.36, \mathrm{df}=2, P=0.31\right)$. Although more patients with existing COPD used less than $50 \%$ of the study medication $\{42 \%$ vs. $25 \%$ in the at risk group, respectively), no statistically significant difference in compliance between these two groups was found $\left(\chi^{2}=4.25, \mathrm{df}=2, P=0.12\right)$.

\section{PARTICIPANT CHARACTERISTICS}

Table 1 presents the baseline characteristics of the study participants. The average age of the participants was 51 years $(S D=8.5)$, and $51 \%$ were women. The bupropion SR group consisted of relatively more women (61\%) compared with the nortriptyline (45\%) and placebo (48\%) group. On average, participants smoked 23 cigarettes per day $(\mathrm{SD}=8.7)$, and in the past had tried 2.4 times to quit smoking ( $S D=1.8$ ). Compared to the bupropion $S R$ and nortriptyline group, more participants in the placebo group reported to have used nicotine gum in the past. When using the GOLD guideline ${ }^{2 s}$ to classify participants, the nortriptyline group consisted of relatively fewer participants at risk for COPD (Stage 0;35\%) compared with the bupropion SR (49\%) and placebo group (46\%). Lastly, the number of participants scoring 15 or higher on the BDI was highest in the bupropion SR group (27\%) and lowest in the nortriptyline group (13\%). 


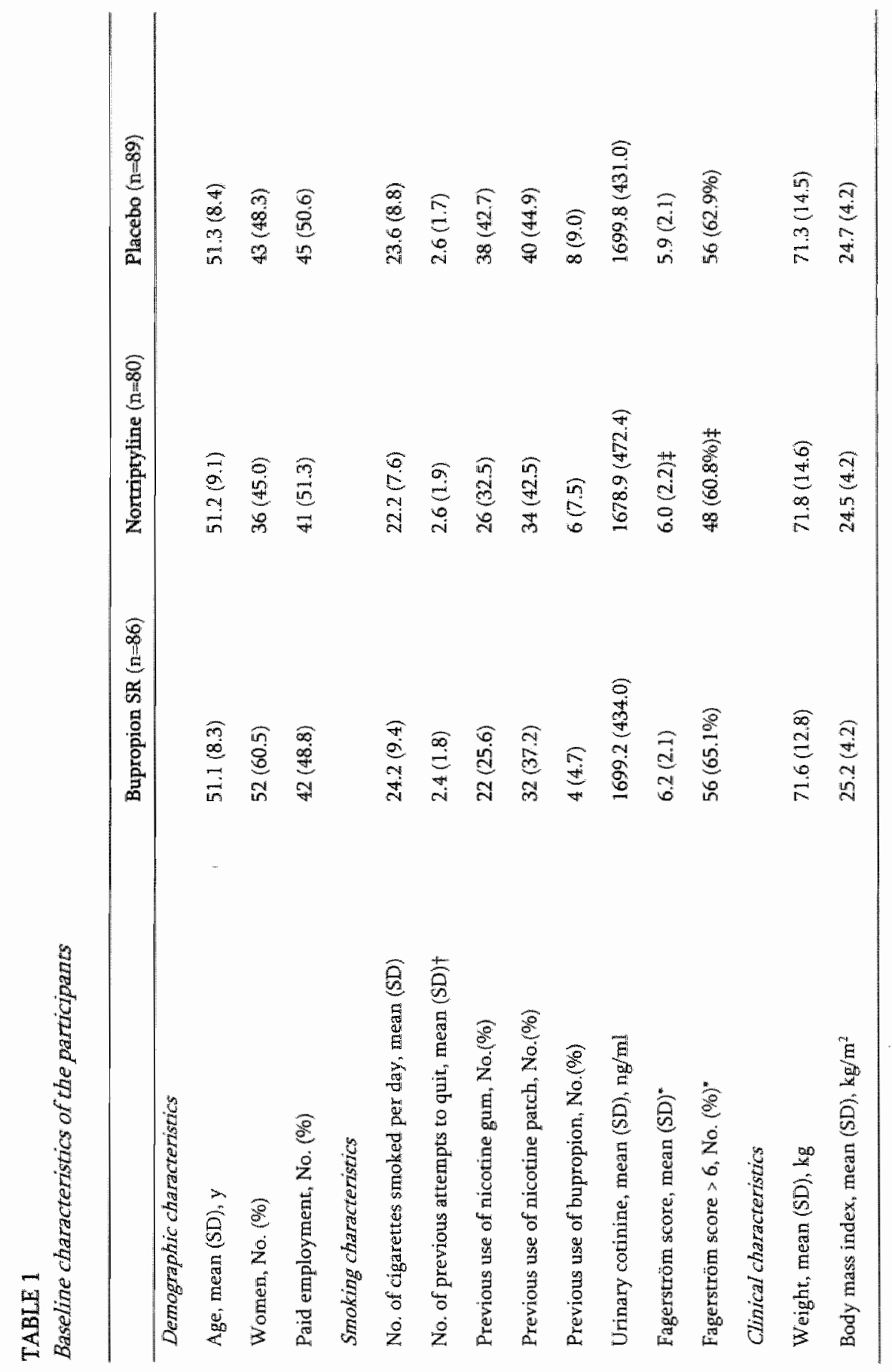




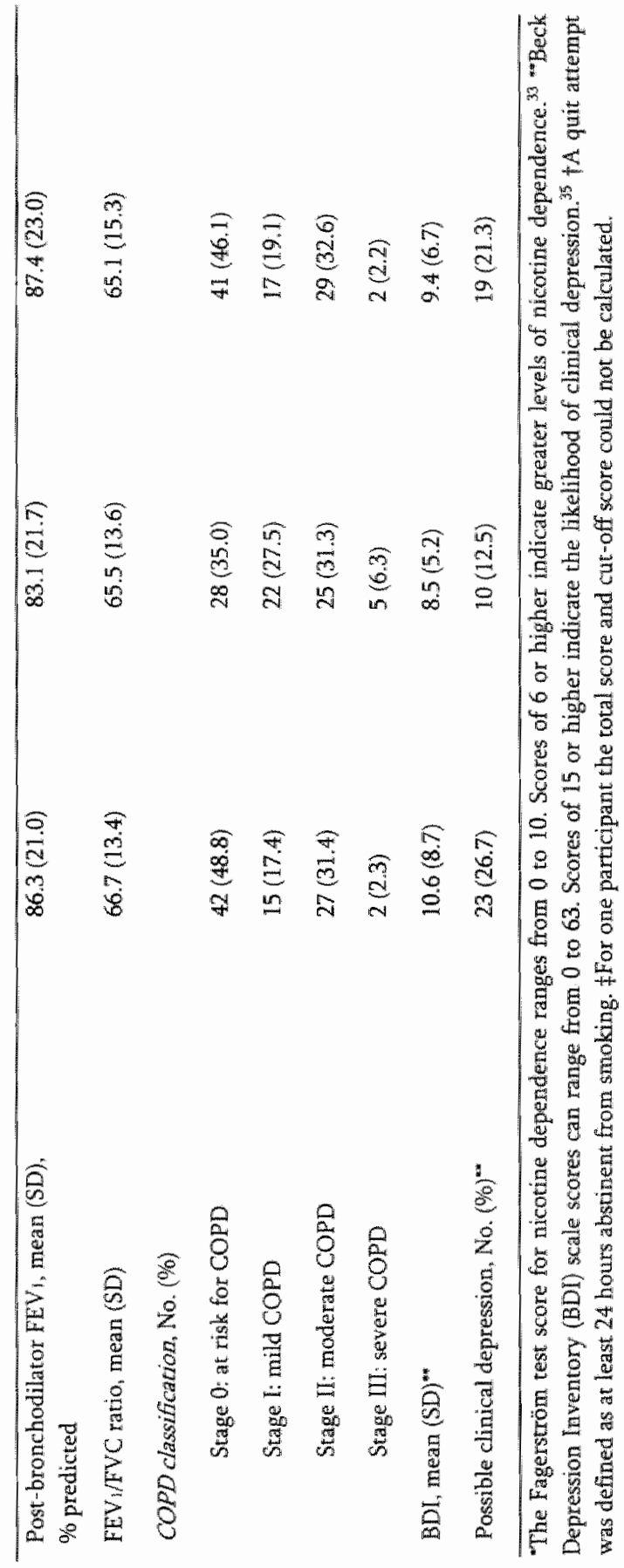




\section{ABSTINENCE}

Prolonged abstinence rates from smoking from week 4 to the end of week 26 after the TQD were higher in the bupropion SR and nortriptyline groups compared to the placebo group, although only the difference between bupropion SR and placebo was statistically significant (Table 2). Of 86 participants receiving bupropion SR, $24(28 \%)$ remained abstinent, compared to 20 (25\%) of 80 participants receiving nortriptyline and $13(15 \%)$ of the 89 participants receiving placebo. When we restricted the analysis to those subjects who were assessed at the different time points, treating those lost to follow-up as missing, the results turned out to be comparable. As we had expected beforehand, significant differences between bupropion SR and nortriptyline were not found. When missing data are considered indicative of smoking, $30 \%$ of the participants in the bupropion SR group were abstinent 26 weeks after the TQD, 29\% in the nortriptyline group and $19 \%$ in the placebo group. Complete-case analyses resulted in $29 \%, 27 \%$ and $17 \%$, respectively being abstinent.

Figure 2 shows estimated survival curves for the probability of relapse. The log rank test showed that the time until participants relapsed differed between the bupropion SR and the placebo group (Log Rank statistic, 6.0, $\mathrm{df}=1, P=0.01$ ), and also between the nortriptyline and placebo group, although mot statistically significant (Log Rank statistic, 2.7, $\mathrm{df}=1, P=0.10$ ). In patients with $\mathrm{COPD}$, bupropion $\mathrm{SR}$ was more efficacious than placebo in achieving prolonged abstinence form week 4 to week 12 (difference, 21.2\%; 95\% PI, 5.6, 36.8; $P<0.01$ ), as well as from week 4 to week 26 (difference, $18.9 \% ; 95 \%$ PI, 3.6, 34.2; $P$-0.02)(Table 3). In the same patient population, nortriptyline also resulted in higher prolonged abstinence rates, although these differences just failed to reach statistical significance (difference from week 4 to $12,16.7 \% ; 95 \%$ PI, $2.5,30.8 ; P=0.07$; difference from week 4 to $26,13.4 \%$; $95 \% \mathrm{PI},-0.3,27.2 ; P=0.07)$. In participants at risk for COPD, we found much smaller differences in prolonged abstinence rates. Prolonged abstinence rates in men did not differ from those in women (difference, $1.3 \%, 95 \%$ PI $-10.3,13.0 ; P=0.70$ ), and participants who had previously used nicotine gum, were less likely to achieve 26weeks prolonged abstinence from smoking (difference, $12.7 \%$; $95 \%$ PI 2.8, 22.6; $P=0.02$ ).

We performed ancillary analyses to explore the efficacy of bupropion SR and nortriptyline in smokers classified as depressed. In these participants ( $\mathrm{n}=52[20 \%]$ ), rates of prolonged abstinence from smoking from week 4 to 26 were significantly higher in participants who received bupropion SR, compared to participants who received placebo (Table 3)(difference, $24.3 \% ; 95 \%$ PI 0.3, 48.1; $P=0.05$ ). 


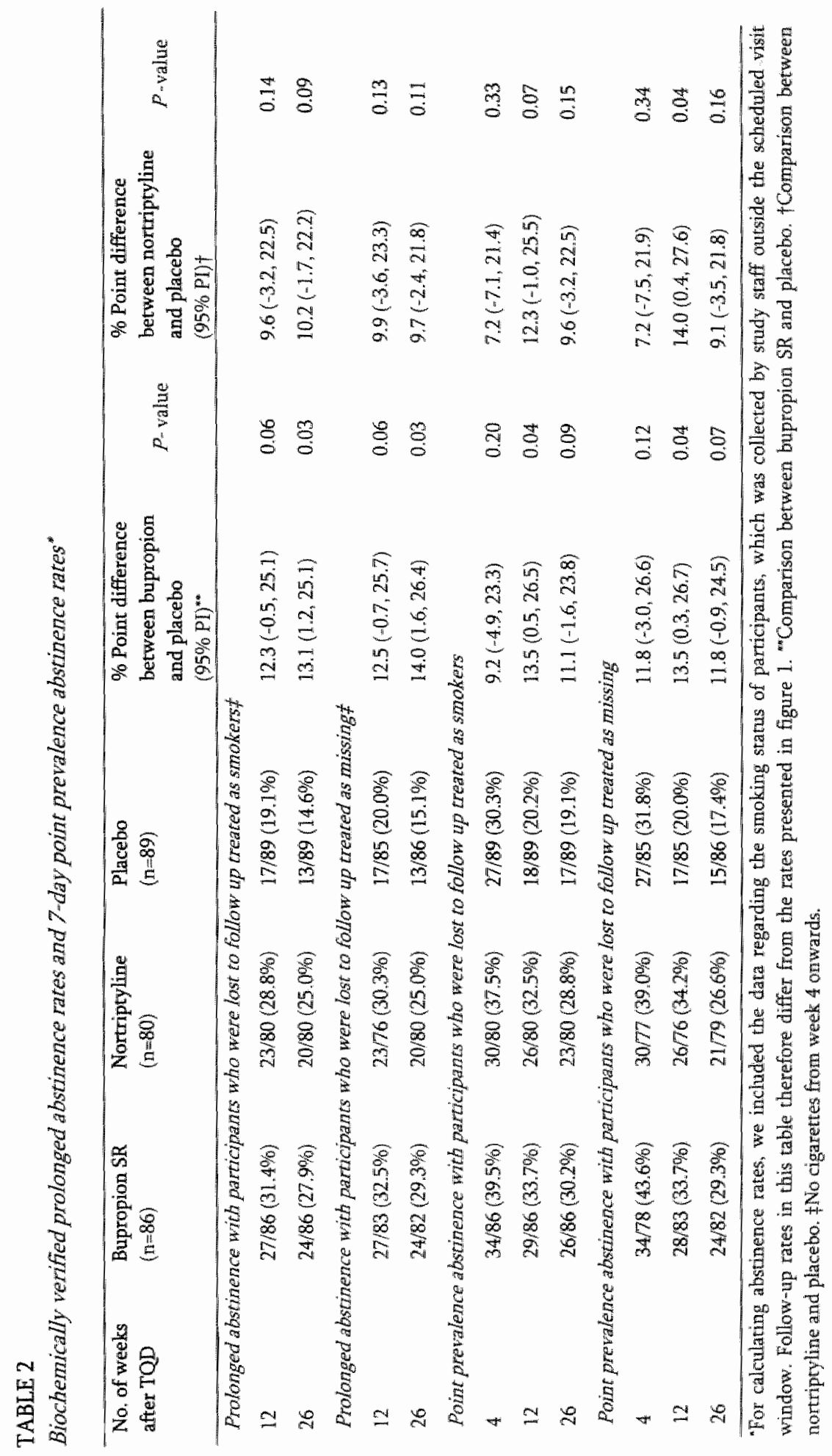




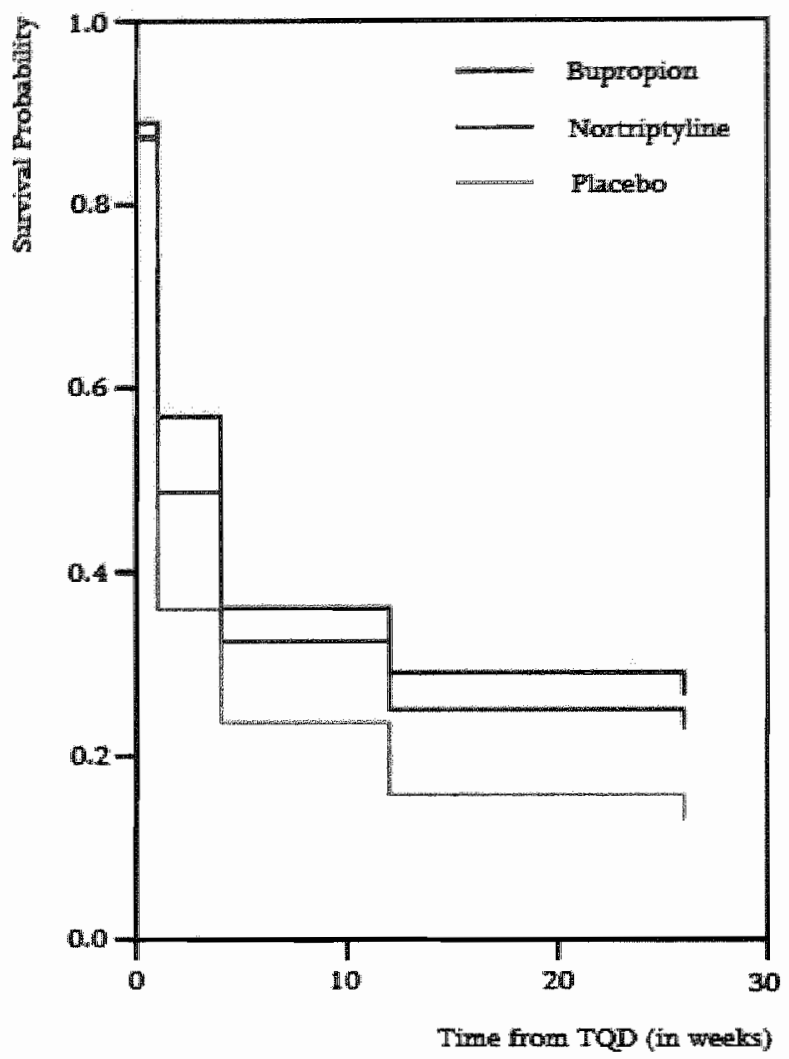

FIGURE 2 Survival curves showing the probability of relapse after smoking cessation

Cox regression analysis with treatment group, depression and previous use of nicotine gum entered as covariates, showed that the estimated risk of relapse occurring in participants with existing COPD, was more than $30 \%$ higher compared to that in participants at risk for COPD (Hazard Ratio, 1.3; 95\% PI, 1.0, 1.7; $P=0.03$ )(see figure 3 ).

\section{ADVERSE EVENTS}

A total of 40 participants ( $16 \%$ ) discontinued medication because of adverse events: $8(9 \%)$ in the placebo group, $13(15 \%)$ in the bupropion SR group, and 19 (24\%) in the nortriptyline group. The rate of discontinuation of treatment was statistically significantly higher among those receiving nortriptyline $(P<0.01)$ compared with the participants receiving placebo. Insomnia, dry mouth and diarrhea/constipation were the most commonly reported adverse events by participants in the bupropion SR and nortriptyline groups (see table 4). Participants 
receiving bupropion SR were significantly more likely to report headache, while participants who received nortriptyline were significantly more likely to report dry mouth, diarrhea/constipation and fatigue. No seizures were reported in any group. One participant (on placebo) reported being hospitalized during the treatment phase because of dermatological reactions. She died two months later.

\section{TABLE 3}

Biochemically verified prolonged abstinence rates stratified for COPD, and depression

\begin{tabular}{|c|c|c|c|}
\hline Subgroup & $\begin{array}{l}\text { Bupropion SR } \\
(\mathrm{n}=86)\end{array}$ & $\begin{array}{l}\text { Nortriptyline } \\
(\mathrm{n}=\mathrm{80})\end{array}$ & $\begin{array}{l}\text { Placebo } \\
(n=89)\end{array}$ \\
\hline \multicolumn{4}{|c|}{ Prolonged abstinence from week 4 to week 12} \\
\hline \multicolumn{4}{|l|}{ COPD Stage } \\
\hline Stage 0 & $14 / 42(33.3 \%)$ & $10 / 28(35.70 \%)$ & $12 / 41(29.3 \%)$ \\
\hline Stage I. II and III & $13 / 44(29.5 \%)$ & $13 / 52(25.0 \%)$ & $4 / 48(8.3 \%)$ \\
\hline \multicolumn{4}{|l|}{ Depressed* } \\
\hline Yes & $8 / 23(34.8 \%)$ & $1 / 10(10.0 \%)$ & $4 / 19(21.10 \%)$ \\
\hline No & $19 / 63(30.2 \%)$ & $22 / 70(31.4 \%)$ & $13 / 70(18.6 \%)$ \\
\hline \multicolumn{4}{|c|}{ Prolonged abstinence fron week 4 to week 26} \\
\hline \multicolumn{4}{|c|}{ COPD Stage } \\
\hline Stage 0 & $12 / 42(28.6 \%)$ & $9 / 28(32.1 \%)$ & $9 / 41(22.0 \%)$ \\
\hline Stage I, II and III & $12 / 4.4(27.3 \%)$ & $11 / 52(21.2 \%)$ & $4 / 48(8.3 \%)$ \\
\hline \multicolumn{4}{|l|}{ Depressed ${ }^{*}$} \\
\hline Yes & $8 / 23(34.8 \%)$ & $1 / 10(10.0 \%)$ & $2 / 19(10.5 \%)$ \\
\hline No & $16 / 63(25.4 \%)$ & $19 / 70(27.1 \%)$ & $11 / 70(15.7 \%)$ \\
\hline
\end{tabular}

We used a cut-off score for the BDI of 15 in order to separate the participants with no or mild depression (BDI $<15$ ) from the participants with moderate to severe depression (BDIæ15). ${ }^{34}$

\section{Comment}

As we had expected, participants with existing COPD had more problems quitting and remaining abstinent from smoking compared to participants at risk for COPD. The most striking finding was, however, that bupropion SR was significantly more efficacious in achieving prolonged abstinence compared to placebo, especially among participants with existing COPD. Although nortriptyline also resulted in higher prolonged abstinence rates compared to placebo, this difference was not statistically significant. The finding that the nortriptyline group consisted of relatively fewer participants at risk for COPD might have influenced study results. 
The difference in prolonged abstinence rates between bupropion $S R$ and nortriptyline on the one hand and placebo on the other, were rather small and not statistically significant in the participants at risk for COPD.

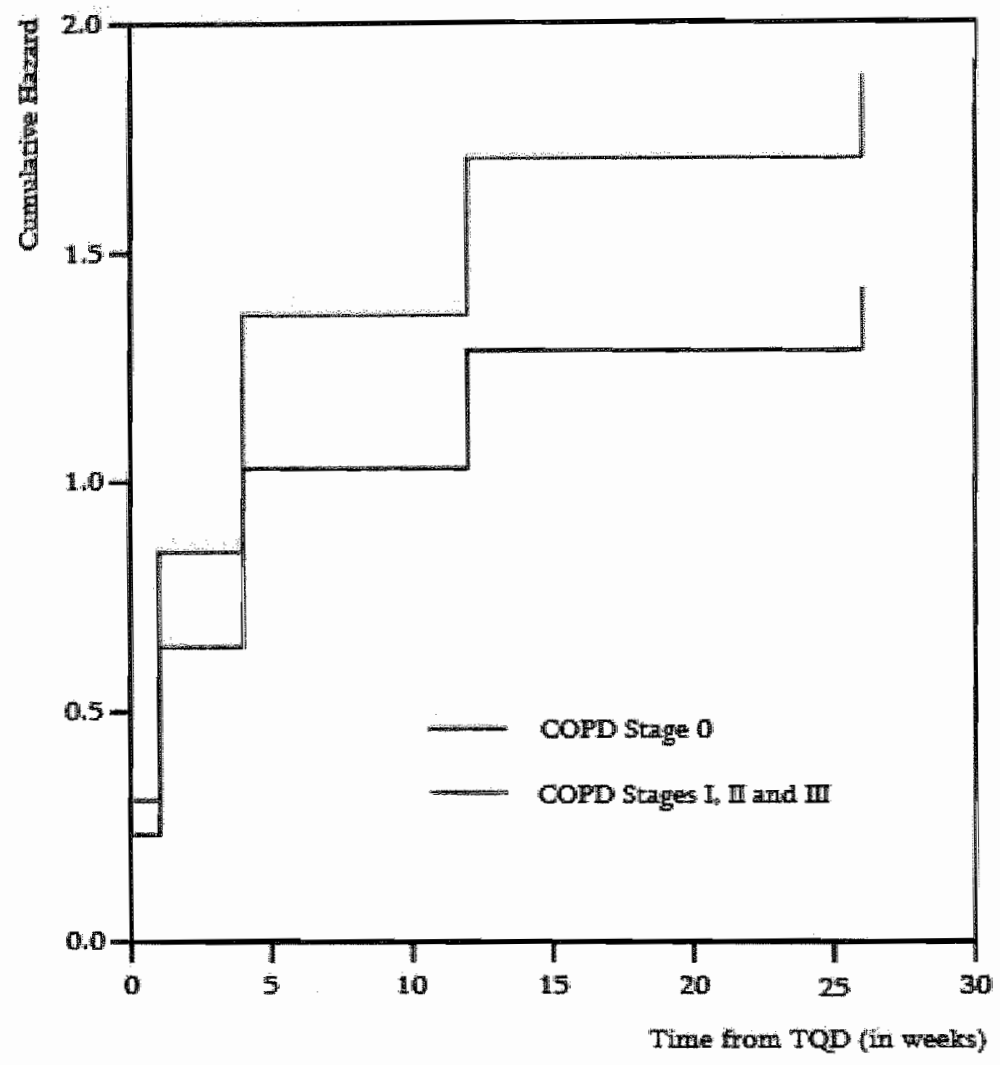

FIGURE 3 Survival curves showing relapse hazards after smoking cessation stratified for COPD stage

Since smoking patients with COPD seem to be at increased risk of depression ${ }^{15-17}$, and nicotine addiction is often accompanied by co-morbid depression or depressive symptoms ${ }^{18.19}$, we performed ancillary analyses to explore the efficacy of bupropion SR and nortriptyline in smokers classified as depressed. Results seem to indicate that bupropion SR is efficacious in helping smokers who are classified as depressed in achieving prolonged abstinence from smoking throughout the 26 -week period. The number of depressed participants from the nortriptyline group was considered too low to study this relation. 


\section{TABLE 4}

Number and percentage of participants reporting adverse evencs at any toune point"

\begin{tabular}{|c|c|c|c|}
\hline Aiverse event & $\begin{array}{l}\text { Bupropion (n-86) } \\
\text { No. }(0)\end{array}$ & $\begin{array}{l}\text { Nortripty line }(n=80) \\
\text { No. }(\%)\end{array}$ & $\begin{array}{l}\text { Placebo }(\text { of }=9) \\
\text { No. (\%) }\end{array}$ \\
\hline Insomnia & $29(33.7)$ & $23(28.8)$ & $28(236)$ \\
\hline Dry mouth & $24(27.9)$ & $49(61.3)^{4 * 4}$ & $18(20.2)$ \\
\hline Binarry vision & $6(7.0)$ & $8(10.0)$ & $2(22)$ \\
\hline Headache & $12(14.0) \dagger$ & $4(5.0)$ & $7(7.9)$ \\
\hline Dizziness & $13(15.1)$ & $16 \cdot(20.0)$ & $15(16.9)$ \\
\hline Nervousness & $13(15.1)$ & $9(12.5)$ & $779)$ \\
\hline Dysphoria & $11(12.8)$ & $6(7.5)$ & $7(7.9)$ \\
\hline Diarrhea/constipation & $29(33.7)$ & 38. $(47.5)+1$ & $23(25.8)$ \\
\hline Mouth ulcer & $10(11.6)$ & $11(13.8)$ & $6(6.7)$ \\
\hline Allergic reactions & $11(12.8)$ & $6(7.5)$ & $5(5.6)$ \\
\hline Sweating & $12(14.0)$ & $7(8.8)$ & $8(9.0)$ \\
\hline Fatigue & $7(8.1)$ & $16(20.0) *$ & $8(9.0)$ \\
\hline
\end{tabular}

\footnotetext{
"Adverse events were reports of symptoms that began affer or were exacerbated by treament. Only adverse reactions that were reported by at least 10 percent of the participants in any of the groups are listed. "P<0.001 for the comparison with placebo and bupropion $S R$, $+P=0.05$ for the comparison with nortriptyline. $I P<0.01$ for the comparison with placebo, $f P_{<0} 0.05$ for the comparison with placebo and bupropion $\mathrm{SR}$.
}

Only one randomized trial thus far has evaluated the efficacy of an antidepressant for smoking cessation in patients with COPD. Tashkin and colleagues studied the effects of bupropion SR in patients with existing COPD. ${ }^{24}$ The authors included 343 smokers with mild to moderate COPD (FEV between 50 and $80 \%$ of predicted according to COPD-staging guidelines from the American Thoracic Society) and 61 with severe COPD (FEV between 35 and $50 \%$ of predicted). They also found a significant effect of bupropion SR compared to placebo (prolonged abstinence rates from week 4 to $26,16 \%$ versus $9 \%$ respectively), although smaller than the difference that we found $(13 \%)$. Both studies used the same recruitment methods, assigned participants to bupropion SR or placebo for 12 weeks, and participants were comparable with regard to age, number of cigarettes smoked per day, and Fagerström Test for Nicotine Dependence score. Hall and colleagues conducted a clinical trial in which they studied the effects of bupropion SR as well as nortriptyline for smoking cessation. ${ }^{38}$ Comparison of the results of their study with ours is not only problematic because they did not specify eligibility criteria 
based on spirometric results, but also because they only presented prolonged abstinence rates through week 52 ( $18 \%$ of bupropion SR group, $10 \%$ of nortriptyline group, and $8 \%$ of the placebo group achieved prolonged abstinence).

There are some limitations to our findings. The first limitation is related to the blinding of participants. Because, 1) a panel of three judges correctly distinguished bupropion SR as well as nortriptyline from the placebo formulation, 2) participants receiving active drug were more likely to guess that they had received active drug than placebo participants were to believe they were receiving active drug (even if assessed before the success of the intervention was determined ${ }^{39}$ ), and 3 ) differences in adverse event profile between bupropion SR or nortriptyline and placebo, blinding of participants was not completely successful. Even though tests of blindness in participants might actually be tests of hunches for adverse events or efficacy ${ }^{40.41}$, our finding that active preparations and placebo were identical in appearance, but differed in taste on chewing and/or internal texture, might have introduced bias. Since this is a common problem in medication trials, we were surprised to see that, to our knowledge, in none of the earlier studies on bupropion SR and nortriptyline, an independent panel of judges tested the active preparations and placebo. Furthermore, in only three of the earlier trials on bupropion SR and/or nortriptyline for smoking cessation, the blinding of participants was evaluated. ${ }^{38,42,43}$ Second, even though medication compliance did not significantly differ between the three study groups in our trial, compliance in general was poor, with approximately $55 \%$ of participants using less than $80 \%$ of the pills they were asked to take. Poor compliance may have resulted in lower overall abstinence rates in our study population. Whether the differences in adverse events between bupropion SR, nortriptyline and placebo resulted in differences in prolonged abstinence rates could not be assessed. Some of the other studies on bupropion SR or nortriptyline reported the number of participants who completed the treatment (e.g., Hall et al.. ${ }^{36,44}$ Jorenby et al., $\left.{ }^{45}\right)$, but we could not find one other study in which medication compliance was presented. Third, smokers in cessation clinical trials are a selfselected group who are motivated to quit, which limits the generalization of our findings. On the other hand, it represents the group of smokers for whom pharmacotherapy might be most appropriate. Because of the relatively small number of participants with existing COPD, we could not evaluate whether the efficacy of bupropion $\mathrm{SR}$ and nortriptyline is different in the different disease groups (i.e., mild, moderate and severe COPD).

There are a number of strengths of this study. This clinical trial extends the existing knowledge on the efficacy of bupropion SR as well as nortriptyline for smoking cessation among participants with existing COPD and at risk for COPD. Furthermore, we did not get any grants from GlaxoSmithKline (the manufacturer of 
bupropion SR), or Lundbeck B.V. (manufacturer of nortriptyline). Finally, we were successful in following up study participants. Less than $5 \%$ of the participants who entered the study, were lost to follow-up at 26 weeks. Of the earlier studies on bupropion SR or nortriptyline, published as full papers, only three succeeded in following up more than $80 \%$ of participants. ${ }^{38,44,46}$ In the study conducted by Tashkin and colleagues ${ }^{24}$ (in which the efficacy of bupropion SR for smoking cessation in patients with COPD was studied) more than $20 \%$ were lost to follow up.

Bupropion SR and nortriptyline seem effective in helping smokers with existing COPD to quit. We found a small but non-significant difference between bupropion SR and nortriptyline. Nortriptyline might therefore be a useful alternative to bupropion SR for smokers with existing COPD. Future research should replicate our findings and evaluate the efficacy of bupropion SR and nortriptyline in smokers at different stages of COPD, as well as in smokers (with. COPD) who are depressed, and evaluate how medication compliance is related to study outcome.

\section{Acknowledgments}

The authors gratefully acknowledge the contributions of Marlie Leerssen (screening, record keeping, patient contacts), Annie Hendriks (screening, registration of medication compliance, record keeping, patient contacts), Anja Schaefer (record keeping, patient contacts), Agnes de Jong (smoking cessation counseling), Karin Willems (smoking cessation counseling), Janneke Kennis (coding adverse events), Daniel Kotz (coding adverse events) and Ludovic van Amelsvoort (advice regarding statistical analysis).

\section{Funding/Support}

This study was funded by grants from the Dutch Asthma Foundation (NAF grant no. 3.2.00.21) and the Health Research and Development Council (ZorgOnderzoek Nederland, grant no. 2200.0111), The Netherlands. Lundbeck B.V. provided active nortriptyline free of charge. Lundbeck B.V. as well as GlaxoSmithKline B.V. played neither a role in the design and conduct of the study, nor in the interpretation and analysis of data. 


\section{References}

1. U.S. Surgeon General. The Health Consequences of Smoking: Chronic Obstructive Lung Disease. Washington DC: US Department of Health and Human Serwices, 1984.

2. Burchfiel $C$, Marcus $E_{\text {, }}$ Curb J, et al. Effects of smoking and smoking cessation on longitudinal decline in pulmonary function. Am J Respir Crit Care Med 1995; 151 (6): 1778-1785.

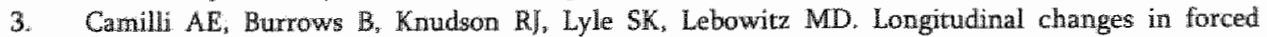
expiratory volume in ane second in adults. Am Rev Respir Dis 1987; 135: 794-799.

4. Fletcher $\mathrm{CM}$, Peto R, Tinker CM, Speizer FE. The natural history of chronic bronchitis and emphysema. Oxford: Oxford University Press, 1976.

5. Muers MF, Quitting smoking and lungs. Lancet 1999; 354: 177-178.

6. Pelkonen M, Notkola I-L. Tukiainen $H$, Tervahata $M$, Tuomilehto I. Nissinen A. Smoking cessation, decline in pulmonary function and total mortaliny: a 30 year follow up study anong the Finnish cohorts of the Seven Countries Sudy. Thorax 2001:56 (9):703 707.

7. Xu X, Dockery DW, Ware JH, Speizer FE, Ferris BG. Effects of cigarette smoking on rate of loss of pulmonary function in adults: a longitudinal assessment. Am Rev Respir Dis 1992; 146: 1345-1348.

8. Tashkin DP, Detels $\mathbb{R}$, Simmons $M$, et al. The UCLA population studies of chronic obstructive respiratory disease: XI. Impact of air pollution and smoking on amnual change in foxced expiratory volume in one second. Am J Respir Crit Care Med 1994; 149: 1209-1217.

9. Sherrill D, Holberg. C. Enright P, Lebowitz M, Burrows. B. Longitudinal analysis of the effects of smoking onset and cessation on pulmonary function. Am I Respir Crit Care Med 1994; 149 (3): 591 597

10. Soejima K, Yamaguchi $K$. Kohda E, et al. Longitudinal follow-up study of smoking-induced lung. density changes by high resolution computed tomography. Am J Respir Crit Care Med 2000; 161: 1264-1273.

11. Anthonisen NR, Connett JE, Kiley JP, et al. Effects of smoking intervention and the use of an inhaled anticholinergic bronchodilator on the rate of decline of FEV1. The Lung Health Study. JAMA 1994; 272 (19): 1497-1505.

12. Scanlon PD, Connett JE, Waller LA, et al. Smoking cessation and lung function in mild-tomoderate chronic obstructive pulmonary disease: the Lung Health Study. Am J Respir Crit Care Med 2000; 161:381-390.

13. Buist AS, Sexton GJ, Nagy IM, Ross BB. The effect of smoking cessation and modification on lung function. Am Rev Respir Dis 1976; 114: 115 122.

14. Wise RA, Kanner RE, Lindgren $P$, et al. The effect of smoking on intervention and inhaled bronchodilator on airways reactivity in COPD: the Lung Health Study. Chest 2003; 124: 449-458.

15. Van Manen JG, Bindels PJ , Dekker FW. IJzermans CJ, van der Zee JS, Schadé E. Risk of depression in patients with chronic obstructive pulmonary disease and its determinants. Thorax 2002; 57: 412416.

16. Wagena EI, van Amelswoort LGPM, Kant I Wouters EFM, wan Schayck CP, Swaen GMH. Risk of depression and anxiety in employees with chronic bronchitus: the modifying effect of cigaretre smoking. Psychosom Med 2004: 66: 729-734.

17. Wagena E., Arrindel!. WA, Wouters EFM, van Schayck CP. Are patients with COPD psychologically distressed? Eur Respir I 2005; in press.

18. Breslau $\mathbb{N}_{n}$ Johnson EO. Predicting smoking cessation and major depression in nicotine-dependent: smokers. Am J Public Health 2000; 90 (7): 1122-1127.

19. Killen JD, Fortmann SP, Kraemer HC. Varady AN, Davis L, Newman B. Interactive effects of depression symptoms, nicotine dependence, and weight change on late smoking relapse. J Consult Clin Psychol 1996; 64 (5): 1060-1067.

20. Kotlyat M, Golding M, Hatsukami DK, Jamerson BD. Effect of nonnicotine pharmacotherapy on smoking behavior. Pharmacotherapy 2001; 21: 1530-1548.

21. Benowitz NL, Peng MW. Non-nicotine pharmacotherapy for smoking cessation. CNS Drugs 2000; 13: $265-285$. 
22. Wagena EJ, Huibers MI, van Schayck CP. Antidepressants in the treatment of patients with COPD: possible associations between smoking cligarettes, COPD and depression. Thorax 2001; 56 (8): 587 . 588.

23. Huibers MJH, Chavannes NH, Wagena EI, Van Schayck CP. Antidepressants for smoking cessation: a promising new approach? Eur Respir J 2000; 16: 379-380.

24. Tashkin DP, Kanner $\mathbb{R}_{*}$ Bailey $W$, et al. Smoking cessation in patients with chronic obstructive pulmonary disease: a double-blind, placebo-controlled, randomised trial. Lancet 2001: 357 (9268): $1571-1575$.

25. Jiménez-Ruiz CA, Masa F, Miravidles M, et al. Smoking characteristics. Differences in atritudes and dependence between healthy smokers and smokers with COPD. Chest 2001; 119 (5): 1365-1370.

26. Wagena EJ, Knipschild P. Efficacy of bupropion for smoking cessation in relation to conflicts of interest and methodological quality: a systematic review and meta-analysis. Tobacco Control, accepted pending revision.

27. Wagena EI, Knipschild P, Zeegers MPA. Should nortriptyline be used as a first-line aid to help smokers quit? A systematic review and meta-analysis. Addiction 2005; 100 (3): 317-326.

28. Global Initiative for Chronic Obstructive Lung Disease. Global strategy for the diagnosis, management, and prevention of chronic obstructive pulmonary disease. NHLBL/NWHO Workshop Report., Update 2004. www.goldcopd.com.

29. Van der Molen T, Willemse BWM, Schokker S, Ten Hacken NHT, Postma DS, Juniper EF. Development, validity and responsiveness of dhe Clinical COPD Questionnaire. Health and Quality of Life Outcomes 2003; 1 (1): 13.

30. Siafakas NM, Vermeire $\mathbb{P}$, Pride NB, et al. Optimal assessment and management of chromic obstructive pulmonary disease (COPD). The European Respiratory Society "Task Force. Eur Respir I 1995; 8 (8): 1398-1420.

31. Pauwels RA, Buist AS, Ma P, Jenkins CR, Hurd SS. Global strategy for the diagnosis, management, and prevention of chronic obstructive pulmonary disease. NHLBU/WHO Global Iniciative for Chronic Obstructive Lung Disease (GOLD) Workshop summary. Am J Respir Crit Care Med 2001; 163: 1256-1276.

32. Jarvis MJ, Tunstall-Pedeo H, Feyerabend $C$, Vesy $C$, Salooje $Y$. Comparison of tests used to distinguish smokers from non-smokers. Am J Public Health 1987; 77: 1435-1483.

33. Heatherton TF, Kozlowski LT, Frecker RC. Fagerström KO. The Fagerström Test for Nicotine Dependence: a revision of the Fagerström Tolerance Questionnaire. Br I Addict 1991; 86: 1119 . 1127.

34. Beck AT, Steer RA, Garbin MG. Psychometric properties of the Beck Depression Inventory: Twenty-five years of evaluation. Clinical Psychology Review 1988; 8 (1): 77-100.

35. Beck AT, Ward CH, Mendelson M, Mock J, Erbaugh J. An inventory for measuring depression. Arch Gen Psychiatry 1961; 4: 561-571.

36. Kleinbaum DG. Survival analysis: A self-leaning text. New York: Springer-Verlag, 1996.

37. Bland IM, Altman DG. Survival probabilities (the Kaplan-Meier method). BMI 1998: 317: 1572.

38. Hall SM, Humfleet GL, Reus VI, Munoz RF, Hartz DT, Maude-Griffin R. Psychological intervention and antidepressant treatment in smoking cessation. Arch Gen Psychiatry 2002; 59 ; 930-936.

39. Altman DG, Schulz KF, Moher D. Turning a blind eye: Testing the success of blinding and the CONSORT statement. BM) 2004; 328: 1135 .

40. Schultz KF, Grimes DA. Blinding in randomised trials: hiding who got: what. Lancet 2002; 359:696700 .

41. Sackett DL. Turning a blind eye: Why we don't test for blindness at the end of our trials. BMI 2004: 328: 1136.

42. A.huwalia JS, Harris KV. Carley D, Okuyemi KS, Mayo MS. Sustained-release bupropion for smoking cessation in African Americans. JAMA 2002; 288 (4): $468-474$.

43. Prochazka AV. Weaver MT, Keller RT, Fryer GE, Licari PA, Lofaso D. A randomized trial of nortriptyline for smoking cessacion. Arch Intern Med 1998: 158 (18): 2035-2039. 
44. Hall SM, Reus VI, Muncz RF, et al. Nortriptyline and cognitive-behavioral therapy in the treatment of cigarette smoking. Arch Gen Psychiatry 1998; 55 (8): 683-690.

45. Jorenby DE, Leischow SI, Nides MA, et al. A controlled triall of sustained-release bupropion, a nicotine patch, or both for smoking cessation. N Engl J Med 1999; 340 (9): 685-691.

46. Lerman $C$, Shields $P G_{\mathrm{p}}$ Wileyto EP, et al. Phamacogenetic investigation of smoking cessation treatment. Pharmacogenetics 2002; 12:627-634. 


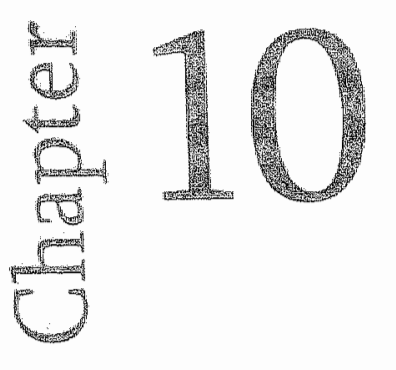

General Discussion 
In the first part of this thesis we have studied the relation between cigarette smoking, COPD and psychological problems. Moreover, because a positive association between, for example depression and cigarette smoking has been well established[1-4], we investigated the effects of cigarette smoking on the presence of such complaints in patients with COPD (see figure). In the introduction we hypothesized that smokers with COPD might benefit from using antidepressants for smoking cessation, because: 1) they seem to be at increased risk of depression[5-7], 2) nicotine addiction is often accompanied by co-morbid depression or depressive symptoms $[8,9]$, and 3) nicotine is expected to have antidepressant effects and regulate mood.[10-12] Here I will summarise the main findings, discuss the implications of our results and formulate directions for future research.

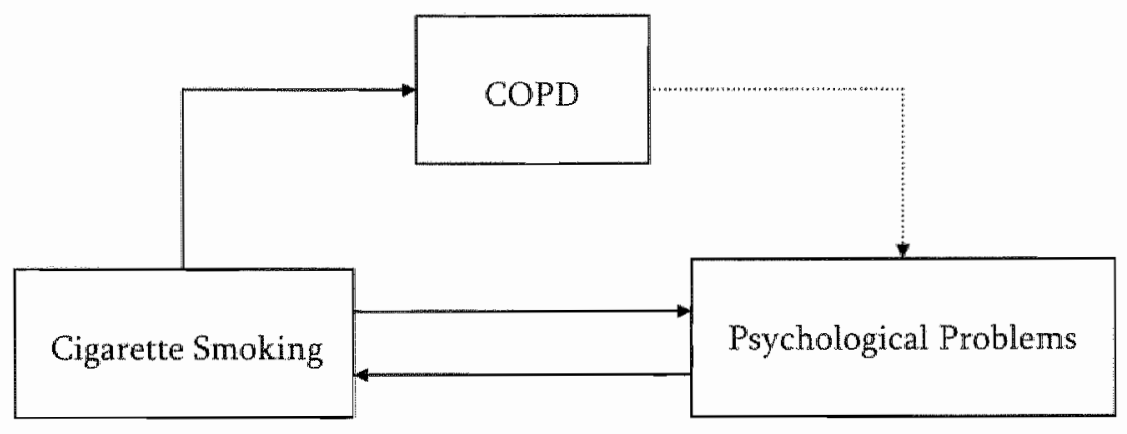

FIGURE Relation between cigarette smoking, COPD and psychological problems

\section{MAIN FINDINGS}

\section{Cigarette Smoking. COPD and Psychological Problems}

Most of the published research on psychological complaints and COPD has addressed the relation between depression or depressed mood and COPD. Van Ede and colleagues[13] concluded in their review in 1999 that the empirical evidence for a significant risk of depression in patients with COPD remains inconclusive. Since the publication of that review[13], further studies have addressed the presence of depression in patients with COPD (e.g. Lacasse et al.[14], Dahlén and Janson[15], Peruzza et al.[16], Yohannes et al.[17, 18], Dowson et al.[19], Stage et al.[20], Van Manen et al.[5], Aydin and Uluşahin[21], and Aghanwa and Erhabor[22]). However, few studies have evaluated whether patients with COPD are at increased risk of developing depressive complaints or a depression compared with a control group. [5, $16,21,22]$ Furthermore, in onlly one of these studies did the group of COPD patients as well as the control group(s) consist of more than 60 subjects. [5] Until then, to our knowledge, no study had been conducted in which the association between smoking cigarettes, COPD and psychological problems was investigated, neither cross- 
sectionally, nor longitudinally. In a population-based sample of Dutch employees we found that the percentage of subjects with asthma or COPD who felt down during most days of the two weeks preceding the study (i.e. subjects with depressed mood) was significantly higher compared to that in subjects without a chronic illness (see chapter 2). No differences were found between subjects with asthma or COPD and those with rheumatoid arthritis or subjects with heart disease, hypertension or myocardial infarction. In that same chapter we presented evidence regarding the modifying effect of cigarette smoking. Depressed mood was more present in smokers compared with non-smokers. Moreover, smoking subjects with asthma or COPD were approximately four times more likely to have a depressed mood compared with non-chronically ill smokers, and almost twice as likely when compared with smoking subjects with rheumatoid arthritis and subjects with heart disease, hypertension or myocardial infarction.

Although the presence of depression and anxiety, and its relation with cigarette smoking is hypothesized to be different in patients with COPD compared to patients with asthma, in chapter 2 we could not distinguish between both conditions. Systemic effects, which are common in COPD and contribute in important ways to the clinical syndromes these patients experience[23-26], are also expected to contribute to the presence of psychological problems. In chapter 3 we therefore investigated whether the prevalence of depression and anxiety in a population-based sample was different in subjects with COPD compared to that in subjects without any respiratory complaints and those with asthma. Secondly, we examined whether being a smoker was associated with a higher likelihood of being depressed or anxious compared with non-smokers. The results confirmed a higher likelihood of depression and anxiety in subjects with COPD, compared with healthy subjects and subjects with asthma. Of primary interest was the finding that the risk of having comorbid depression or anxiety was highest in subjects with COPD who smoke or used to smoke, and was significantly higher in these groups compared with the risk in healthy subjects.

In chapter 4 we extended the investigation of depression and anxiety in subjects with COPD by studying whether the incidence of both disorders was different in these subjects compared to the incidence in healthy subjects, stratified by smoking status. To our knowledge, all earlier studies addressing the relation between psychological problems and COPD have been of cross-sectional design (e.g., $[5,14-19,21,22,27]$ ). During the 18-month follow-up, we found a significant increase in depressed and anxious cases in subjects with COPD compared with healthy subjects. Moreover, the risk of developing these problems (i.e. depression or anxiety) was higher in smokers compared with non-smokers. 
According to the $4^{\text {th }}$ edition of the Diagnostic and Statistical Manual of Mental Disorders (DSM-TV-TR ${ }^{\mathrm{TM}}$ )[28], a (major) depressive disorder can be characterized by the presence of somatic symptoms like loss of energy, sleeping problems and fatigue. Since these symptoms are prevalent in patients with $C O P D$, in chapter 5 we explored whether the depressive symptoms reported by patients with severe or very severe COPD are different from the symptoms reported by patients with mild or moderate COPD and subjects without an irreversible limitation in airflow. We found that in patients with (severe or very severe) COPD, the presence of depressive symptoms could be explained mainly by the presence of somatic complaints. Patients with severe or very severe COPD scored significantly higher on the somatic subscales of the Beck Depression Inventory (BDI) $[29,30]$ when compared with patients with mild or moderate COPD and subjects without an irreversible limitation in airflow. We did not find any systematic differences between the groups on the cognitive/affective subscale.

\section{Smoking Cessation in COPD and the Use of Antidepressants}

The research presented in chapter 7 showed that bupropion is efficacious in helping smokers quit. However, studies that were financially supported by the manufacturer of bupropion found higher prolonged abstinence rates than the studies funded by other organizations. Trials that were financially supported by the manufacturer, found a $92 \%$ increase in abstinence rates compared with placebo, while the trials sponsored by other organizations found a (non-significant) increase of $27 \%$. This difference in prolonged abstinence rates does not seem to be caused by a difference in methodological quality. Our results did not reveal any (major) differences in methodological quality between trials supported financially by the manufacturer of bupropion and the trials supported by other organizations.

Nortriptyline also seems to have a positive effect on prolonged abstinence rates. Pooling the results of the trials on nortriptyline resulted in an estimated prolonged abstinence rate that was more than twice as high compared to placebo treatment, even though the absolute difference with placebo was rather small, somewhere between 7 per 100 and 15 per 100 smokers who achieved prolonged abstinence from smoking as a result of using nortriptyline (see chapter 8). Is bupropion more efficacious compared to nortriptyline? At the time we prepared our reviews, we found only one trial in which the efficacy of bupropion as well as nortriptyline was studied. Based on the results of that study[31], we can only answer this question by saying that no difference was found. Future research has to provide a definite answer to this question. And what about the efficacy of these antidepressants when patients with COPD, who want to stop smoking, will use them? Besides the randomized trial that we conducted ourselves, we found only one 
other published trial in which the efficacy of bupropion for smoking cessation in patients with COPD was studied (see chapter 6).[32] Tashkin and colleagues included patients with mild, moderate or severe COPD according to COPD-staging guidelines from the American Thoracic Society. They found a significant difference in prolonged abstinence rates from week 4 to 26 in favour of bupropion compared with placebo (16\% versus $9 \%$, respectively). The most striking finding of our trial was that bupropion resulted in higher prolonged abstinence rates compared to placebo, especially among participants with existing COPD (see chapter 9). The difference in prolonged abstinence rates between bupropion and placebo in our trial ( $27 \%$ versus $8 \%$, respectively) was, however, larger compared with the results presented by Tashkin et al.[32]

In our randomised trial, 24 (28\%) of the 86 participants receiving bupropion remained abstinent until week 26 , compared with $13(15 \%)$ of the 89 participants receiving placebo. When we combine the results of our trial with the studies presented in our review into the efficacy of bupropion for smoking cessation that were not sponsored by the manufacturer of bupropion, we find a $36 \%$ increase in prolonged abstinence rates, instead of a $27 \%$ increase we presented in chapter 7 . Although the difference with studies funded by the manufacturer is reduced, it is still rather large $(56 \%)$.

The results of our trial regarding the efficacy of nortriptyline for smoking cessation in smokers at risk for COPD or with existing COPD confirmed the positive effects of this drug. Prolonged abstinence rates from week 4 to the end of week 26 after the target quitting date were higher in the nortriptyline group compared to the placebo group ( $25 \%$ versus $15 \%$, respectively). When the results of our trial were stratified by COPD severity, results showed that in both the nortriptyline and placebo group, more smokers at risk for COPD remained abstinent from week 4 to 26 ( $32 \%$ versus $22 \%$, respectively), compared with smokers with stage I, II, or III COPD ( $21 \%$ versus $8 \%$, respectively). Although differences between nortriptyline and placebo were not statistically significant, the results should be viewed in the light of the existing evidence. Our systematic review showed that in general between 7 and 15 per 100 smokers are estimated to achieve prolonged abstinence from smoking for at least 6 months if they use nortriptyline. These findings corroborate the results of our trial. However, future studies in patients with COPD should reproduce the positive effects that we found, before we can conclude that this drug is efficacious in helping smokers at risk for or with existing COPD achieve prolonged abstinence from smoking. As we had expected beforehand, significant differences between bupropion and nortriptyline were not found. 
Smoking patients with COPD seem to be at increased risk of depression and anxiety (see the first part of this thesis and Wagena ex al., $[6,7]$ and Van Manen et al.[5]). Furthermore, the presence of psychological problems can be an additional barrier for success. Therefore, we used the data of our trial to explore the efficacy of bupropion and nortriptyline in smokers classified as depressed. The results presented in chapter 8 seem to indicate that bupropion, compared to placebo, is efficacious in helping smokers who are (classified as) depressed in achieving prolonged abstinence from smoking throughout the 26-week period. The number of depressed participants in the nortriptyline group was considered too low to study this relation. None of the studies that we included in our systematic review into the efficacy of smoking cessation strategies in patients with COPD, looked at the (prolonged) abstinence rates for depressed and non-clepressed patients separately.

In the introduction we mentioned that currently available pharmacological aids to smoking cessation seem to have only modestly improved on smoking cessation rates produced by behavioural interventions. [33, 34] Although few studies have been conducted to investigate the efficacy of smoking cessation strategies in patients with COPD[35], the results presented in this thesis show that the same applies for this patient population. If we (i.e. investigators ${ }_{\text {w }}$ health-care professionals and politicians) really want to reduce the number of smokers, more effective cessation methods are clearly needed. As stated earlier, chronic use of nicotine results in neuroadaptation, which is manifested as the development of tolerance and physiological dependence.[36] We have argued that tolerance to and physiological dependence on nicotine are not the only problems that nicotine addicts have to overcome when trying to quit. Quitting smoking does not seem to be a particularly significant accomplishment, but preventing relapse is. As a result, detoxification is, at best, a first step in achieving prolonged abstinence.[37] In other words, pharmacological interventions for smoking cessation, which either (partly) replace the nicotine delivered by cigarettes (nicotine replacement therapy) or act on sites in the central nervous system to reduce withdrawal symptoms during smoking cessation (e.g. bupropion and nortriptyline), but fail to attenuate or block the reinforcing effects of nicotine, will most likely have limited long term efficacy. [33, 38-40] Because the amount of nicotine reaching the brain and the rate at which it does so, are important determinants of the initiation and maintenance of smoking [41], a vaccine that prevents nicotine from acting on its receptor sites in the central nervous system could be a promising strategy. The results of our phase I trial (presented in chapter 10) that addressed the immunogenicity, safety and reactogenicity of a nicotine vaccine in smokers and non-smokers, justify the further development of this approach. 


\section{IMPLICATIONS}

\section{Psychological Problems in Patients with COPD}

Although many health-care professionals as well as researchers remain uncertain about the exact status of psychological problems in patients with COPD, the presence of disorders such as depression and anxiety in patients with a chronic illness is often regarded as a complication caused by the physical complaints. [42] As a result, the psychological problems are regularly overlooked, often remain undiagnosed and are rarely treated. $[42,43]$ The finding that the presence of these complaints could substantially reduce the chance of a successful quit attempt, led us to study the relation between cigarette smoking, COPD and psychological problems. But does this mean that we should only assess and treat these problems in patients with COPD who smoke? The answer, of course, is no. COPD is a highly incapacitating health problem and can disturb various aspects of a parient's life. The ability to function in day-to-day life may be further complicated by the presence of psychological problems. Earlier studies have shown, for example, that patients with COPD who are depressed, feel more impaired in daily life and experience less wellbeing and significant more distress due to respiratory symptoms compared with patients without depressive complaints (e.g. Felker et al.[44], Yohannes et al.[18], Jones[45], and Jones[46]). Furthermore, one of the main goals in the treatment of patients with COPD is to minimize patients' respiratory symptoms and improve their ability to function in day-to-day life.[47] Because it is recognized that up to now no intervention (except for smoking cessation) has generated a clinically relevant effect on the course of the forced expiratory volume in 1 second (FEVI), apart from an initial improvement during the first few months, health care professionals also try to improve the quality of life of these patients. However, the quality of life of a patient with COPD may be particularly complicated by a concurrent psychological disorder. Patients might find themselves in a vicious circle: depressed mood, for example, lowers the energy that is needed to cope with the chronic disease, the physical symptoms become less tolerable, whichn in turn could enforce the psychosocially debilitating effect of the disease. It is therefore important to bear in mind that even if the physical illness itself contributes to the severity of the psychological problems, these complaints will most likely not be resolved once the respiratory complaints are treated. If the presence of psychologicall problems determines how a patient experiences his or her daily functioning as well as his or her quality of life, addressing and treating these complaints should also be one of the primary treatment goals in non-smoking patients with COPD. 


\section{Nicotine Addiction as Bantier for Successful Smoking Cessation}

Our trial into the efficacy of bupropion and nortriptylime for smoking cessation shows that in general 13 per 100 smokers are estimated to achieve prolonged abstinence from smoking for at least 6 months as a result of using bupropion, and 10 per 100 when using nortriptyline. Furthermore, the efficacy of both drugs compared to placebo seems to be highest in patients with existing COPD (i.e. stage I, II or III). Although bupropion and norrriptyline seem promising in helping smokers with COPD quit, approximately $75-80 \%$ of the motivated to quit smokers, who are at risk for COPD or have existing COPD, will relapse within 6 months. This means that even when we combine pharmacotherapy with a behavioural intervention, there is still much room for improvement. In order to increase the abstinence rates, we need to establish what the barriers for a successful quit attempt are.

The most important physiological obstacle to quitting in general is the addictive nature of nicotine. Nicotine dependent smokers are particularly prone to relapse. $[8,9,48]$ Nicotine affects mood and performance, and can produce pleasure, stimulation and relaxation, as well as relief of depression and anxiety.[1, 2, 36, 4953] Since smokers with COPD are expected to be more dependent on nicotine compared with healthy smokers[54], they are expected to have more difficulty quitting. A high degree of nicotine dependence in smokers with COPD could be caused by inhalation patterns that differ from smokers without airflow obstruction. [55] Patients with COPD tend to inhale more deeply and rapidly.[48, 56] Deeper and more rapid inhalation might make these smokers more vulnerable to develop COPD in the first place. The characteristic chronic inflammation throughout the airways, parenchyma, and pulmonary vasculature of a patient with COPD is mainly caused by the inhalation of noxious particles and gases from cigarette smoke. "These particles and gases lead to tissue destruction, impair the defence mechanisms that serve to limit the destruction and disrupt the repair mechanisms, which can restore tissue structure.[57] The regional deposition of smoke constituents in the lung is of direct importance to the pathogenesis of lung disease. The particles in inhaled smoke are deposited at airway branch points.[58] Total particle deposition increases with slow and deep breathing[59] and breath holding. [60]

\section{Strategies to Increase Abstinence Rates}

Small differences in efficacy are most likely large enough to warrant use on a population basis, where small improvements in outcome could lead to potentially large benefits. But this does not mean that we should stop looking for ways to improve the effectiveness of smoking cessation interventions in daily practice. How 
can we increase abstinence rates? The obvious method of course is to look for the one intervention that can turn all smokers into permanent non-smokers. However, since it does not seem that we are close to finding that treatment, we believe that the development of patient-matched cessation treatments is a promising strategy for improving the success of existing smoking cessation interventions. Also because the efficacy of interventions for smoking cessation is expected to be less successful in patients with COPD than in patients at risk for COPD or in the general population of smokers. The development of patient-matched cessation treatments involves tailoring treatment based on characteristics of a specific population. The results presented in part 1 of this thesis indicate a higher likelihood of depression and anxiety in smokers with COPD compared with healthy smokers and other chronically ill smokers. Furthermore, earlier in this general discussion we have substantiated that smokers with COPD can be characterized by a high dependency on nicotine. By relying on abstinence rates achieved in a general population of (mostly healthy) smokers and not recognizing the potential barriers for successful smoking cessation, health-care professionals are likely to be disappointed by the efficacy of the strategies they use to help patients with COPD to stop smoking.

The research presented in this thesis was conducted to investigate whether antidepressants for smoking cessation are efficacious. An efficacious treatment is one that has the desired effects among those who receive it. [61] But, it must also do more good than harm in those to whom it is offered. Fletcher and colleagues call this the effectiveness of a treatment.[61] It is established by offering a treatment or program to patients and allowing them to accept or reject it as they might ordinarily do.[61] Effectiveness trials tend to evaluate the effects of the intervention in circumstances similar to those found by clinicians in their daily practice.[62] Interventions, which have shown to be efficacious, i.e. increase prolonged abstinence rates, are not necessarily effective in daily practice. Medical practitioners are crucial in establishing and increasing the effectiveness of smoking cessation interventions, especially with regard to the use of bupropion and nortriptyline. Nowadays, bupropion and nortriptyline can only be used on doctor's orders. Furthermore, both drugs are recommended to be used in combination with behavioural support. Guidelines on smoking cessation state that medical practitioners should monitor the smoking status of known smokers regularly, advise them to stop smoking, arrange follow-up visits for those who intend to make a quit attempt and provide assistance in the form of (brief) behavioural counselling. [63, 64] Whether they do so, remains however questionable. 
Another strategy to increase abstinence rates in daily practice, is to financially reimburse patients for the use of smoking cessation treatment. Research has shown that the use of behavioural and pharmacological aids results in higher prolonged abstinence rates compared to quitting cold turkey. [65] The costs associated with the use of these treatments might keep smokers from trying to quit with assistance. Recent research in the Netherlands has shown that complete reimbursement for avalable (efficacious) smoking cessation interventions not only results in an increase in the number of smokers who use smoking cessation treatment and who try to quit smoking, but also in higher (prolonged) abstinence rates. Whether reimbursing medical practitioners for the time they spend with smokers also results in higher success rates, is still unclear.

\section{RESEARCH DIRECTIONS}

The first part of this thesis was mainly devoted to the effects of cigarette smoking an the presence of psychological complaints in patients with COPD. In our studies we used self-administered questionnaires to assess the presence and severity of psychollogical problems. The validity of these questionnaires in patients with a medical condition might be unsatisfactory. The questionnaires contain items that deal with somatic symptoms often seen in chronic illness. [66] The inclusion of these items may lead to an inflation of the total score, caused by somatic complaints unrelated to mood. Because structured interviews and clinical assessment by a psychiatrist based on the DSM classification[28] are considered to be more valid compared to the use of questionnaires, future studies are needed in which the validity and reliability of the self-administered questionnaires in patients with COPD, is compared to structured interwiews and/or clinical assessments.

In the second part we used metamanalytical. techniques and presented the results of a randomized placebo-controlled trial to study the efficacy of bupropion and nortriptyline for smoking cessation. Results indicate that both drugs result in higher prolonged abstinence rates compared to placebo. Still the mechanism by which these drugs enhance the ability of patients to abstain from smoking is unknown. It is suggested that the mechanism of action of bupropion is mediated by noradrenergic and/or dopaminergic mechanisms also involved in psychological problems like depression (i.e. inhibition of the neuronal uptake of noradrenalin and/or dopamine). [67] Although the exact mechanism of action in the treatment of depression is unclear, nortriptyline, a tricyclic antidepressant, is thought to increase the synaptic concentration of norepinephrine and/or serotonin in the central nervous system. One theory suggests that these neurotransmitters are increased through inhibition of their reuptake by the presynaptic neuronal membrane. One putative explanation of the higher quit-rates in smokers treated with bupropion or 
nortriptyline is the following. Research has shown that smoking and psychological problems such as depression or anxiety are linked, and subsequent relief of these complaints may facilitate prolonged abstinence. Is the benefit of achieving prolonged abstinence mediated by changes in mood states? Ancillary analysis of our trial data showed that bupropion resulted in a higher difference in prolonged abstinence rates in depressed smokers compared to non-depressed smokers. To further explore the mechanism of action of these drugs future studies should address their efficacy in depressed and non-depressed smokers separately. Also, we should study the course of depression and other psychological problems in smokers who quit with the use of antidepressants and those who do not. In addition, because it is not clear whether the mechanism of action of bupropion and nortriptyline are identical, future studies need to assess whether smokers who profit from the use of bupropion are comparable to those who are able to quit with nortriptyline. Could it be that these drugs are beneficial for smokers with different characteristics?

As we stated earlier, approximately $75-80 \%$ of the motivated to quit smokers who use bupropion or nortriptyline will relapse, leaving much room for improvement. Moreover, it is even questionable whether these quit rates can be extrapolated to the general public. Interventions, which have shown to be efficacious, are not necessarily effective in daily practice. In all of the experimental studies into the efficacy of bupropion and nortriptyline, pharmacotherapy was combined with a rather intensive behavioural program. Because it is unlikely that smokers will receive the same degree of additional support in daily practice[68], we must be aware of the possibility that the effectiveness of bupropion as well as of nortriptyline is lower than has been found under more or less ideal circumstances. Because evidence on the efficacy of antidepressants for smoking cessation without an intensive behavioural program is lacking, new randomized trials are necessary to study this.

Another challenge for future research stems from the characteristics of smokers with COPD. Patients with COPD are expected to experience additional barriers for success in smoking cessation compared with healthy smokers and smokers with other chronic illnesses. Patients with COPD appear to have higher nicotine addiction scores[54] and a higher prevalence of psychological problems. [57] Furthermore, research seems to indicate that patients with severe COPD have more difficulty quitting smoking compared with patients with mild COPD or those at risk for COPD (this thesis and Tashkin et al.[32]). Randomised trials evaluating the short, intermediate and long-term effects of existing smoking cessation interventions in patients with severe COPD compared with patients with mild or moderate COPD, healthy smokers, or both, are therefore needed to establish the added value of different interventions in different patient populations. These studies 
need not only focus on the importance and role of nicotine addiction and psychological problems, but also on behavioural factors, which contribute to the difficulties smokers experience when trying to quit smoking and remain abstinent.[69, 70] Tobacco use can be considered a learned behaviour. Cigarettes become part of a smoker's daily routine, associated with particular events. For example, the smokers in the study conducted by Bancroft et al.[71], differentiated cigarettes they smoked in response to craving or in order to avoid symptoms of nicotine withdrawal, from those they smoked in order to handle negative emotions (e.g. anger or anxiety) or cope with stressful situations and boredom. These cigarettes were for the most part associated with particular contexts, including home, work and the social context.[71] These results indicate that, next to its reinforcing properties, nicotine also exerts effects in stressful situations.[72] It is proposed that stress can act as a stimulus for cigarette smoking; stressful situations enhance the craving to smoke (see for an overview of the literature Balfour and Ridley[72]). One can imagine that patients with a chronic illness are especially prone to encounter stressful events.

\section{EPILOGUE}

We hope the studies presented in this thesis will urge investigators to further study the effects of smoking on the presence of psychological problems in patients with COPD and translate these results into effective smoking cessation strategies for these patients. Since smoking cessation is the only intervention that reduces the rate of decline in FEV $\mathrm{FV}_{1}$ [3-78], improves long-term prognosis[79], and diminishes the symptoms of cough and sputum production[80], as well as the reactivity of the airways[81], we were surprised to find only five randomized trials[32, 75, 82-84] addressing the efficacy of smoking cessation interventions in this patient population. In view of the complexity caused by the relation between cigarette smoking, nicotine dependence and psychological problems, the hypotheses generated by this thesis must be tested in the near future. 


\section{References}

1. Glassman, A.H., J.E. Helzer, L.S. Covey, et al, Smoking, smoking cessation, and major depression. IAMA, 1990; 264 (12): 1546-1549.

2. Glassman, A.H., F. Stetner, B.T. Walsh, et al., Heavy smokers, smoking cessation, and clonidine. Results of a double-blind, randomized trial. JAMA, 1988; 259 (19): 2863-2866.

3. Lasser, K., J.W. Boyd, S. Woolhandler, et al., Smoking and mental illness: a population-based prevalence study. )AMA, 2000; $284(20): 2606-2610$.

4. Dierker, L.C., S. Avenevoli, M. Stolar, et al. Smoking and depression: an examination of mechanisms of comorbidity. Am I Psychiatry, 2002; 1.59 (6): 947-953.

5. Van Manen, J.G., P.J. Bindels, F.W. Dekker, et al., Risk of depression in patients with chronic obstructive pulmonary disease and its determinants. Thorax, $2002 ; 57: 412-416$.

6. Wagena, E.J., W.A. Arrindell. E.F.M. Wouters, et al., Are patients with COPD psychologically distressed? Eur Respir J, 2005; in press.

7. Wagena, E.J., L.G.P.M. van Amelswoort, I. Kant, et al., Risk of depression and anxiety in employees with chronic bronchitis: the modifying effect of cigarette smoking. Psychosom Med, 2004; 66: 729734.

8. Breslau, N. and E.O. Johnson, Predicting smoking cessation and major depression in taicotinedependent smokers. Am I Public Flealth, 2000; $90(7): 1122-1127$.

9. Killen, J.D., S.P. Fortmann, H.C. Kraemer, et: al., Interactive effects of depression symptoms, nicotine dependence, and weight change on late smoking relapse. J Consult Clin Psychol, 1996; 64 (5): $1050-1067$.

10. Kotlyar, M., M. Golding, D.K. Hatsukami, et al., Effect of nonnicotine pharmacotherapy on smoking behavior. Pharmacotherapy, 2001; 21: 1530-1548.

11. Benowitz: N.L. and M.W. Peng, Non-nicotine pharmacotherapy for smoking cessation. CNS Drugs, 2000; $13: 265-285$.

12. Picciotto, M.R., D.H. Brunzell. and B.J. Caldarone, Effect of nicotine and nicotinic receptors on anxiety and depression. Neuroreport, 2002; 13 (9): 1097-1106.

13. Van Ede, L., C.J. Yzermans, and H.J. Brouwer, Prevalence of depression in patients with chronic obstructive pulmonary disease: a systematic review. Thorax, 1999; 54 (8): 688-692.

1.4. Lacasse, Y., L. Rousseau, and F. Maltais, Prevalence of depressive symptoms and depression in patients with severe oxygen-dependent chronic obstructive pulmonary disease. I Cardiopulm Rehabil, 2001; 20: 80-86.

15. Dahlén, I. and C. Janson. Anxiety and depression are related to the outcome of emergency treatment in patients with obstructive pulmonary disease. Chest, 2002; 122: 1633-1637.

16. Peruzza, S., G. Sergi, A. Vianello, et al, Chronic obstructive pulmonary disease (COPD) in elderly subjects: mpact on functional status and quality of life. Respir Med, 2003: 97:612:617.

17. Yohannes, A.M., R.C. Baldwin, and M... Connolly, Depression and anxiety in elderly outparients with chronic obstructive pulmonary disease: prevalence, and validation of the BASDEC screening questionnaire. Int I Geriatr Psychiatry, 2000; 15: 1090-1096.

18. Yohannes, A.M., R.C. Baldwin, and M.J. Connolly, Prevalence of sub-threghold depression in elderly patients with chronic obstructive pulmonary disease. Int J Geriatr Psychiatry, 2003; 18: 412-416.

19. Dowson, C., R. Laing, R. Barraclough, et all, The use of the Hopsital Anxiety and Depression Scale (HADS) in patients with chronic obstructiwe pulmonary disease: a pillot study. NZ Med J, 2001; 114: 447-449.

20. Stage, K.B., T. Middelboe, and C. Pisinger, Measurement of depression in patients with chronic obstructive pulmonary disease (COPD). Nord I Psychiatry, 2003; 57: 297-301.

21. Aydin, 1.O. and A. Ulusahin, Depression, anxiety comorbidity, and disability in ruberculosis and chronic obstructive pulmonary disease patients: applicability of GHQ 12. Gen Hosp Psychiatry, 2001: $23: 77-83$. 
22. Aghanwa, H.S and G.E. Erhabor, Specific psychiatric morbidity among patients with chronic olustructive pulmonary digease in a Nigerian general hospital. J Psychosom Res, 2001. 50; p. 179. 183.

23. Buist, $A . S$. Similarities and differences between asthma and chronic obstructive pulmonary disease: treatment and early outcomes. Eur Respir ), 2003,21 (Suppl. 39): 30s-35s.

24. Barnes, P.I. Mechanisms in COPD. Differences from asthma. Chest, 2000; 117: 10s-14s.

25. Wouters, E.F.M. E.C. Creutaberg, and A.M.W.J. Schols, Systemic effects in COPD. Chest, 2002; $121(5): 1278-130 \mathrm{~S}$.

26. Wouterg, EF.M. Chronic obstructive pulmonary disease. 5: Systemic effects of COPD. Thorax, 2002; 57: 1067-1070

27. Stage, K. B., T. Middelboe, and C. Pisinger, Measurement of depression in patients with chronic obstructive pulmonary disease (COPD). Nord I Psychiatry. 2003; 57 (4): 297-301.

28. American Psychiatric Association, Diagnostic and statistical manual of mental disorders (4th ed, rev.). 1994, Washington D.C.: American Psychiatric Association.

29. Beck, A.T., R.A. Steer, and M.G. Garbin, Psychometric properties of the Beck Depression Inventory: Twenty-five years of evaluation. Clinical Psychology Review, 1988; 8 (1): 77-100.

30. Beck, A.T. CH. Ward, M. Mendelson, at al, An inventery for measuring depression. Arch Gen Psychiatry, 1961: 4: 561-571.

31. Hall, S.M., G.L. Humfleet, V.L. Reus, et al., Psychological intervention and antidepressant treatment in smoking cessation. Arch Gen Psychiatry, 2002; 59: 930-936.

32. Tashkin, D.P., R. Kanner. W. Bailey, et al., Smoking cessation in patients with chronic obstructive pulmonary disease: a double-blind, placebo-controlled, randomised trial. Lancet, 2001; 357 (9268): $1571-1575$.

33. Hughes, J.R., L.E. Stead, and T. Lancaster, Antidepressants for smoking cessation, in The Cochrane Library, Issue 1. 2004, John Willey \& Sons, Lid: Chicester, UK.

34. Sillagy, C., T. Lancaster, L.. Stead, et al., Nicotine replacement therapy for smoking cessation (Cochrane Rewiew), in The Cochrane Library, Issue 1, 2004, John Wiley \& Sons, Lrd: Chicester, UKK.

35. Wagena, E.J., R.M. van der Meer, RR.O. Ostelo, et al., Smoking cessation strategies in patients with COPD: a systienatic review. Respir Med, 2004; 98: 805-81.5.

36. Benowitz, N.L., Nicotine replacement therapy: what has been accomplished - can we do better? Drugs, 1993; 45 (2): $157-170$.

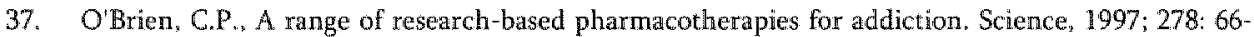
70.

3B. Sillagy, C, T, Lancaster, L. Stead, et al. Nicotine replacement therapy for smoking cessation (Cochrane Review), in The Cochrane Library, Issue 2. 2002, Update Software: Oxford.

39. Wagena, E.,., P. Knipschild, and M.P.A. Zeegers, Should nortriptyline be used as a first-line aid to help smokers quit? A systematic review and meta-analysis. Addiction, 2005; in press.

40. Wagena. E. I. and P. Knipschild, Efficacy of bupropion for smoking cessation in relation to conflicts of interest and methodological quality: a systematic review and meta-analysis. Tobacco Control, 2005; accepted pending revision.

41. Benowitz, N.L.s, Phandacology of nicotine: Addiction and therapeutics. Am Rev Pharmacol Toxicol, 1996: 36: 597-613.

42. Peveler, R. A. Carson, and G. Rodin, ABC of psychological medicine. Depression in medical patients. BMJ, 2002; 325: 149-152.

43. Spiczer, R.L. J.B.W. Williams, K. Kroenke, et al., Utility of a new procedure for diagnosing mental disorders in primary care. IAMA, 1994; 272: 1749-1756.

44. Jelker, B., W. Katon, S.C. Hedrick, et al., The association berween depressive symptoms and health stans in patients with chronic pulmonary disease. General Hospital Psychiatry, 2001; 23: 56-61.

45. Jones, P.W. Issues concerning health-related quality of life in COPD. Chest, 1995; 107 (5): 187s1938.

46. Jones, P.W., Health status measurement in chronic obstructive pulmonary disease. Thorax, 2001; 56: $880-887$. 
47. Oga, $T_{n} \mathbb{K}$. Nishimura, M. Tsukino, et al. Analysis of the factors related to mortality in chronic obstructive pulmonary disease Am I Respir Crit Care Med, 2003: 167: 544-549.

48. Killen, I.D., S.P. Formann. H.C. Kraemer, et al. Who will relapse? Symptoms of nicotine dependence predict long-term relapse after smoking cessation. I Consult Clin Psychol, 1992; 60 (5): 797-801.

49. Breslau, N., E.L. Peterson, L.R. Schultz, et al., Major depression and stages of smoking. A longitudinal investigation. Arch Gen Psychiatry, 1998; 55 (2): 161-166.

50. Covey, L.S., A.H. Glassman, and F. Stetner, Cigarette smoking and major depression. I Addict Dis, $1998 ; 17(1): 35-46$.

51. Glassman, A.H., L.S. Covey, F. Stemer, et al, Smoking cessation and the course of major depression: a follow-up study. Lancet, 2001; 357: 1929-1932.

52. Pomerleau, O.S.: Nicotine as a psychoactive drug: anxiety and pain reduction. Psychopharmacol Bull, 1986; 22: 865-869.

53. Gilbert, D.G. J.H. Robinson, C.L. Chamberlin, et al. Effects of smoking/nicotine on anxiery, heart rate, and lateralization of EEG during a stressful movie. Psychophysiol, 1989; 26: 311-320.

54. Jiménez Ruiz, C.A., F. Masa, M. Miravitlles, et al, Smoking characteristics. Differences in attindes and dependence between healthy smokers and smokers with COPD. Chest, 2001; 119 (5): 1365 1370 .

55. Medici, T.C., S. Unger, and M. Ruegger, Smoking pattern of smokers with and without tobaccosmoke-related lung diseases. Am Rev Respir Dis, 1985; 131: 385-388.

56. O'Donnell, D., Ventilatory limitations in chronic obstructive pulmonary disease. Medicine \& Science in Sports and Exercise, 2001; 33 (7): \$647-S655.

57. Pauwels, R.A., A.S. Busst, P.M. Calverley, et al., Global strategy for the diagnosis, management, and prevention of chronic obstructive pulmonary disease. NHLBI/WHO Global Initiative for Chronic Obstructive Lung Disease (GOLD) Workshop summary. Am J Respir Crir Care Med, 2001; 163 (5): $1.256-1276$.

58. Sethi, F.M. and C.L. Rochester, Smoking and chronic obstructive pulmonary disease. Clin Chest Med, 2000; 21 (1): 67-86.

59. American "Thoracic Society, Standards for the diagnosis and care of patients with chronic obstructive pulmonary disease. Am J Respir Crit Care Med, 1995; 152: \$77-\$121.

60. Palmes, E.D., B. Altshuler, and N. Nelson, Deposition of Aerosols in the Human Respiratory Tract During Breath Holding. 1966, Oxford, England: Pergamon.

61. Fletcher, R.H., S.W. Fletcher, and E.H. Wagner, Clinical epidemiology. The essentials. 3rd edition ed. 1996, Baltimore: Lippincott Williams \& Wilkins.

62. Jadad, A.R., Randomised controlled trials. 1998, London: BMI Books.

63. West, R, A. McNeill, and M. Raw, Smoking cessation guinelines for health professionalis: an update. Thorax, 2000; 55 (12): $987-999$.

64. Coleman, T. and A. Wilson, Anti-smoking advice from general practitioners: is a population-based approach to advice-giving feasible? British Jounal of General Practice, 2000; 50: 1001-1004.

65. West., R., Behavioural support progranmes for smoking cessation. Needs and opporthunitics. European yournal of Public Health, 2000; 10 (Suppl. 3): 25-29.

66. Gift, A.G. and S.H. MCCrone, Depression in patients with COPD. Heart Lung, 1993; 22 (4): 289 297.

67. Holm. K.J. and C.M. Spencer, Bupropion: a review of its use in the management of smoking cessation. Drugs, 2000:59 (4): 1007 1024.

68. Bouvy, M.L., H. Butrma, and A.C.G. Egberts, Determinants for successful smoking cessation with bupropion in daily practice. Pharm World Sci, 2003; 25 (5):207-211.

69. Emmons, K.M., Smoking cessation and tobacco control. Chest, 1999; 116: 490S-492S.

70. Rigotti, N.A., Treatment of tobacco use and dependence. N Engl I Med, 2002; 346 (7): 506-512.

71. Bancroft, A., S. Wiltshite, O. Parry, et al, It's like an addiction first thing, afterwards it's like at habin: daily smoking behaviour among people living in areas of depriwation. Soc Sci and Med, 2003; $56(6): 1261-1267$. 
72. Balfour, D.J.K and D.L. Ridley, The effects of nicotine on neural pathways implicated in depresision: a factor in nicotine addiction? Pharmacology Biochemistry and Behavior, 2000; 66 (1): 79.85 .

73. Soejima, K. K. Yamaguchi, E. Kohdia, et al. Longitudinal follow-up study of smoking-induced lung density changes by high resolution computed tomography. Am J Respir Crit Care Med, 2000; 161: $1264-1273$

74. Xu, X, D.W. Dockery, J.H. Ware, et al, Effects of cigarette smoking on rate of loss of pulmonary thuction in adiults: a longirudinal assessment. Am Rev Respir Dis, 1992; 146: 1345-1348.

75. Arthonisen, N.R. J.E. Connett, J.P. Kiley, et al., Effects of smoking intervention and the use of an inhaled anticholinergic bronchodilator on the rate of decline of FEV1. The Lung Health Study. IIAMA, 1994; $272(19): 1497-1505$.

76. Sherril, D., C. Holberg P. Enright, et al., Longitudinal analysis of the effects of smaking onset and cessation on pulmonary function. Am I Respir Crit Care Med, 1994; 149 (3); $591-597$.

77. Burchfiel, C., E. Marcus, J. Curb, et al., Effects of smoking and smoking cessation on longitudinal decline in pulmonary function. Am J Respir Crit Care Med, 1995; 151 (6): 1778-1785.

78. Camilli, A.E. B. Burrows, R.J. Kmudson, et al., Longitudinal changes in forced expiratory volume in one second in adultris. Am Rev Respir Dis, 1987; 135: 794-799.

79. Scanlon, P.D., J.E. Connett, L.A. Waller, et al, Smoking cessation and lung function in mild-tomoderate chronic obstructive pulmonary disease: the Lung Health Study. Am J Respir Crit Care Med, 2000; 161: 381-390.

80. Buist, A.S., G.J. Sexton, J.M. Nagy, et al., The effect of smoking cessation and modification on lnurg function. Am Rev Respir Dis, 1976; 114: 115-122.

81. Wise, R.A., R.F. Kanner, P. Lindgren, et al., The effect of smoking on intervention and inhaled bronchodilator on airways reactivity in COPD: the Lung Health Study. Chest, 2003; 124: 449-458.

82. Brandt, C.J., H. Ellegaard, M.B. Joensen, et al, Effect of diagnosis of "smoker's lung". Lancet, 1997: 349: 253.

83. Crowley, T.J., M.J. Macdonald, and M.I. Walter, Behavioral anti-smoking trial in chronic obstructive pulmonary disease patients. Psychopharmacology, 1995; 119 (2): 193-204.

84. Pederson, L.L., J.M. Wanklin, and N.M. Lefcoe, The effects of counseling on sinoking cessation among patients hospitalized with chronic obstructive pulmonary disease: a randomized clinical trial. International Journal of the Addictions, 1991; 26 (1): 107-119. 


\section{Samenvatting (Dutch Summary)}

COPD is de afkorting van het Engelstalige begrip Chronic Obstrictive Pulmonary Disease. In Nederland wordt doorgaans gesproken van chronisch obstructief longlijden, hoewel de afkorting COPD ook vaak wordt gebruikt. Het roken van sigaretten is de belangrijkste oorzaak voor het ontwikkelen van COPD. Schattingen laten zien dat roken verantwoordelijk is voor temminste $90 \%$ van de patiënten met COPD. De ontwikkeling van COPD kan dus in de meeste gevallen worden voorkomen. Stoppen met roken is echter niet alleen de meest effectieve interventie voor het verminderen van het risico op het ontwikkelen van COPD. Voor rokers met COPD is stoppen met roken de enige interventie die de achteruitgang in longfunctie vertraagt. Ondanks het feit dat veel rokers met COPD de schadelijke gevolgen van roken kennen, zijn er veel patiënten die niet willen stoppen. Anderen die wel willen stoppen en het proberen, vallen vaak weer terug. Veel wetenschappers en behandelaars zijn van mening dat zelfs met intensieve gedragsmatige en farmacologische ondersteuning slechts een klein percentage van de patiënten met COPD die willen stoppen met roken, het ook daadwerkelijk lukt. Zij veronderstellen dat patiënten met COPD bepaalde kenmerken vertonen die het succes van een stoppoging negatief beïnvloeden. Zo vormt de aanwezigheid van psychische problemen zoals een depressie of depressieve klachten een belangrijke belmmering voor rokers om te stoppen. Onderzoek heeft aangetoond dat de aanwezigheid van een depressie de kans op een succeswolle stoppoging aanzienlijk verkleint. Nicotine heeft naast een stimulerende werking, ook een positief effect op de ernst van de psychische klachten. Men veropndersteld daarom dat rokers met psychische problemen blijven roken om deze klachten te reduceren.

Het doel van dit proefschrift was tweeledig. In eerste instantie wilden wij het verband bestuderen tussen het roken van sigaretten, COPD en psychische problemen. De aanwezigheid van psychische problemen bij rokende patiënten met COPD zou een verklaring kunnen zijn voor een eventuele lage kans om te stoppen met roken. In tweede instantie wilden wij weten wat de effectiviteit is van antidepressiva voor stoppen met roken, voornamelijk indien deze gebruikt worden door patiënten met COPD.

Deel 1 van het proefschrift bevat drie studies waarin de relatie tussen het roken van sigaretten, COPD en psychische problemen wordt bestudeerd. Hiertoe makten wij gebruik van gegevens uit de Maastrichtse cohortstudie. Dit was een grootschalig, longitudinaal onderzoek met een heterogene populatie van werknemers uit Brabant en Limburg. In hoofdstuk 2 rapporteren we dat de rokers met astma en COPD een grotere kans hadden op een depressieve stemming dan de 
personen die niet rookten. Bovendien hadden de rokers met astma, chronische bronchitis of emfyseem een grotere kans zich depressie te voelen dan rokers die bekend waren met een hartziekte, hypertensie en/of een myocardinfarct en in vergelijking met personen met rheumatoïde artritis. Hoewel deze studie niet een causal verband kan aantonen, lewert het wel bewijs dat het hebben van een chronische longziekte samengaat met depressieve klachten, voornamelijk indien men rookt. De wraag blifft echter of patiënten met COPD een grotere kans hebben om depressief te zijn dan patiënten met astma. Hoewel astma ook gekenmerkt wordt door een chronische ontsteking van de luchtwegen, verschilt de aard van de ontsteking in vergelijking met die bij patiënten met COPD.

Aangezien in hoofdstuk 2 gegevens met betrekking tot angst ontbraken en uit de literatuur bekend is dat er een sterke relatie bestaat tussen angst, depressie en roken, hebben we onder de deelnemers aan de Maastrichtse cohortstudie aanvullend onderzoek uitgevoerd. In hoofdstuk 3 vergeleken we de prevalentie van psychische problematiek (angst en depressie) in de groep patiënten met COPD met de prevalentie in de groep astmapatiënten en personen zonder luchtwegklachten. We vonden dat patiènten met COPD een grotere kans hadden op het hebben van depressieve of angstsymptomen dan de patiënten met astma en de personen zonder luchtwegklachten. Correctie voor de aanwezigheid van een of meer (andere) chronische ziekten gaf geen verandering in de sterkte van het verband. Vervolgens. onderzochten we of de kans op depressieve of angstsymptomen afhankelijk was van de rookstatus van personen. Dit bleek inderdaad zo te zijn. We zagen dat de kans op depressieve of angstsymptomen in de groep patiënten met COPD ten opzichte van de personen zonder luchtwegklachten aanzienlijk verhoogd was onder de rokers en ex-rokers. Vanwege de relatief kleine groep astmapatiënten in de studie konden we niet bestuderen of de kans op depressieve of angstsymptomen in deze groep verschilde wan die in de groep patiënten met COPD.

In de hooldstukken 2 en 3 hebben we de relatie tussen het roken van sigaretten, COPD en psychische problemen bestudeerd. We hebben beschreven hoeveel personen met chronische luchtwegklachten psychische problemen rapporteerden in vergelijking met andere chronisch zieke patiënten en gezonde personen. Daarmaast hebben we onderzocht of rokers meer psychische klachten rapporteerden in vergelijking met personen die niet rookten. In beide hoofdstukken waren alle onderzoeksvariabelen op hetzelfde tijdsmoment gemeten. Relaties konden dus niet in de tijd worden bestudeerd. In hoofdstuk 4 hebben we bestudeerd. of patiënten met COPD een verhoogd risico lopen op het ontwikkelen van depressieve of angstsymptomen. Daarnaast wilden we weten of de incidentie van deze symptomen hoger was onder de rokers in vergelijking met de niet-rokers. We konden aantonen dat de patienten met COPD niet alleen een grotere kans hebben 
om depressieve symptomen te ontwikkelen, maar ook een grotere kans hebben om angstig te worden. Verder zagen we dat het roken van sigaretten deze problemen. lijkt te versterken.

Bij pariënten met een chronische (lichamelijke) aandoening zoals COPD, wordt de aanwezigheid van psychische klachten vaak over het hoofd gezien. Veel zorgverleners beoordelen deze klachten namelijk als kenmerkend voor de chronische ziekte. Dit is begrijpelijk omdat bijvoorbeeld een depressie ook gekenmerkt wordt door de aanwezigheid van somatische klachten zoals vermoeidheid, gebrek an energie, slapeloosheid en somatische preoccupatie, klachten die verondersteld worden veelvuldig voor te komen bij patiënten met een ernstige obstructie van de luchtwegen. In hoofdstuk 5, het laatste hoofdstuk van deel 1 , bestuderen we welk type symptomen (somatisch of cognitief/affectief) kenmerkend zijn voor depressie bij patiënten met en personen zonder chronische obstructie van de luchtwegen. We konden aantonen dat bij patiënten met emstig COPD, de aanwezigheid en ernst van de depressieve symptomen vooral veroorzaakt worden door somatische klachten. Patiënten met ermstige COPD rapporteerden meer somatische klachten dan patiënten met mild tot matig ernstige COPD en personen zonder chronische obstructie van de luchtwegen. Bovendien vonden we geen verschillen tussen de drie groepen met betrekking tot de cognitief/affectieve symptomen. Omdat de toename in depressieve symptomen vooral werd veroorzaakt door de aanwezigheid en ernst van somatische klachten, bestaat de kans dat patiënten met (ernstige) COPD ten onrechte als depressief worden gekarakteriseerd. Voordat de diagnose depressie wordt gesteld, dienen we ons er van te verzekeren dat de somatische klachten (ook) een psychische oorzaak hebben en niet (enkel) veroorzaakt worden door een somatische aandoening.

In deel 2 van dit proefschrift wordt het onderzoek beschreven naar de effectiviteit van antidepressiva voor stoppen met roken en of deze middelen van nut zijn voor patiënten met COPD die willen stoppen met roken. Tot op heden is enkel voor het antidepressivum bupropion registratie aangevragd en verkregen voor de indicatie stoppen met roken. Sinds de registratie van bupropion voor stoppen met roken is er veel klinisch experimenteel onderzoek uitgevoerd naar de effectiviteit van dit middel. Opvallend is dat ongeveer evenveel overzichtsartikelen zijn verschenen waarin het gebruik van bupropion voor stoppen met roken sterk werd aanbevolen. Een aantal overzichtsartikelen blijkt echter slechts een willekeurige selectie van de uitgevoerde experimenten te bevatten. Daarnaast zijn andere overzichtsartikelen over bupropion geschreven door medewerkers van de fabrikant van het middel of zijn wetenschappers betaald door de fabrikant om een overzichtsartikel te schrijven. Deze bevindingen waren voor ons aanleiding vraagtekens te plaatsen bij de resultaten van veel van het (experimenteel) onderzoek 
naar de effectiviteit van bupropion. Wij hebben daarom een onderzoek vitgevoerd naar de effectiviteit van bupopion in relatie tot financiële ondersteuning door de fabrikant van het middel en methodologische kwaliteit van de afzonderlijke experimenten. Wij wilden weten of de klinische experimenten die gesponsord waren door de fabrikant, een groter positief effect vonden van bupropion voor stoppen met roken in vergelijking met de experimenten die niet door de fabrikant. zijn ondersteund. Bovendien wilden we weten of de methodologische kwaliteit van de experimenten die gefinancierd zijn door de fabrikant, beter of slechter is dan die van de andere experimenten. In hoofdstuk 6 rapporteren we dat zowel de experimenten die gesponsord zijn door de fabrikant als de overige experimenten het gebruik van bupropion voor de indicatie stoppen met roken ondersteunen. De experimenten die financieel waren ondersteund door de fabrikant, vonden echter wel een groter positief effect van bupropion dan de overige experimenten. Rokers die wilden stoppen met roken en deelnamen aan de studies die gesponsord waren door de fabrikant hadden gemiddeld een 1.9 keer zo grote kans om na minimaal 6 maanden nog steeds gestopt te zijn in vergelijking met de rokers die een nepmiddel kregen. De rokers die deelnamen aan de overige studies hadden gemiddeld slechts een 1.3 keer zo grote kans dan de rokers die een nepmiddel kregen om het stoppen met roken minimaal 6 maanden vol te houden. Dit verschil in effectiviteit konden we niet verklaren door een verschil in kwaliteit van de studies. Hoewel bupropion een effectief middel blijkt te zijn om rokers te ondersteunen tijdens een stoppoging, lijkt het effect toch aanzienlijk kleiner dan in veel artikelen is verondersteld.

Een jaar nadat de eerste studie naar de effectiviteit van bupropion voor stoppen met roken was gepubliceerd, verschenen in 1998 de resultaten van de eerste studie naar de effectiviteit van nortriptyline voor deze indicatie. De onderzoekers vonden een positief effect van nortriptyline en concludeerden dat het een veelbelovend middel was om rokers te ondersteunen tijdens een stoppoging. In de jaren die volgden is echter aanzienlijk minder onderzoek uitgevoerd naar de efectiviteit van nortriptyline dan naar bupropion. Nortriptyline is een generiek antidepressivum en is veel goedkoper dan bupropion. Het is claarom de moeite waard om te bepalen of nortriptyline effectief is als hulpmiddel voor stoppen met roken. Voomamelijk ook omdat het onderzoek dat is beschreven in hoofdstuk 6 aantoont dat ongeveer $80 \%$ van de rokers die willen stoppen met roken en bupropion gebruikt, niet slagen. In hoofdstuk 7 geven we antwoord op de vraag of nortriptyline een effectief middel is om rokers te ondersteunen tijdens een stoppoging en of nortriptyline meer of minder effectief is dan bupropion. Op basis van de tot dit moment gepubliceerde experimenten, blijkt nortriptyline een effectief middel voor stoppen met roken. In vergelijking met rokers die een nepmiddel gebruikten, hadden rokers die nortriptyline gebruikten gemiddeld een 2.4 keer zo 
grote kans om te stoppen met roken en dit minimaal 6 maanden vol te houden. We vonden echter slechts een experiment waarin de effectiviteit van nortriptyline was vergeleken met die van bupropion. In de betreffende studie kon geen verschil in effectiviteit worden aangetoond. Voor rokers die willen stoppen met roken, kan nortriptyline een goed alternatief zijn in plaats van bupropion.

Stoppen met roken is de meest effectieve interventie voor het verminderen van het risico op het ontwikkelen van COPD. Bovendien is het de enige interventie die de achteruitgang in longfunctie vertraagt. Veel wetenschappers en behandelaars zijn van mening dat slechts een klein percentage van de patiënten met COPD dat wil stoppen met roken, ook daadwerkelijk slaagt. Of dit veroorzaakt zou kunnen worden door een gebrek aan effectieve interventies voor stoppen met roken voor deze groep patiënten, is echter onduidelijk. In hoofdstuk 8 presenteren we de resultaten van een literatuurstudie naar het effect van gedragsmatige interventies, farmacologische interventies en combinaties van beide, indien deze gebruikt worden door patiënten met COPD. We vonden slechts vijf experimenten naar de effectiviteit van interventies voor stoppen met roken bij rokers met COPD. De resultaten suggereren dat een intensieve gedragsmatige interventie, gecombineerd met nicotinekauwgom en een programma om terugval te voorkomen, de meest effectieve interventie is om rokers met COPD van het roken af te helpen. Na 5 jaar leverde deze interventie ruim 15\% meer succesvolle stoppers op in vergelijking met geen interventie. De rokers die de betreffende interventie ontvingen, hadden ongeveer een 4 keer zo grote kans om na 5 jaar nog steeds niet te roken dan de rokers die geen interventie ontvingen. Of bupropion gebruikt zou moeten worden om rokers met COPD te ondersteunen tijdens een stoppoging, is nog de vraag. In een van de vijf experimenten werd het gebruik van bupropion vergeleken met een nepmiddel. Hoewel rokers met COPD die bupropion gebruikten wel een grotere kans hadden om na 6 maanden niet te roken, was dit verschil na 12 maanden verdwenen. Of rokers met ernstige COPD meer bat hebben bij het gebruik van bupropion in vergelijking met rokers met minder enstige COPD, is eveneens nog onduidelijk. We vonden geen experiment waarin het effect van nortriptyline was bestudeerd.

De observatie dat: 1) rokers met COPD een verhoogde kans hebben om een depressie te ontwikkelen, 2) nicotineverslaving en een depressie of depressieve symptomen regelmatig tegelijkertijd voorkomen en 3) nicotine antidepressieve effecten heeft, is reden het gebruik van antidepressiva voor stoppen met roken door patiënten met COPD te stimuleren. Zoals hierboven aangegeven zijn er weinig tot geen aanwijzingen die het gebruik van dergelijke medicamenten door patiënten met COPD rechtvaardigen. Om antwoord te geven op de vraag of bupropion en nortriptyline effectieve hulpmiddelen zijn orn rokers met COPD te ondersteunen 
tijdens een stoppoging, presenteren we in hoofdstuk 9 de resultaten van een door ons uitgevoerd experiment. Met dit experiment wilden we bovendien bestuderen of de effectiviteit van deze middelen afhankelijk is van de ernst van de luchtwegobstructie en de emst van depressieve symptomen. In vergelijking met het gebruik van een nepmiddel, leverde het gebruik van bupropion na zes maanden ongeveer $19 \%$ meer stoppers op en het gebruik van nortriptyline iets meer dan $13 \%$. Zoals verwacht hadden de rokers met COPD meer problemen met stoppen met roken in vergelijking met de rokers zonder chronische obstructie. De resultaten lijken er op te wijzen dat vooral de rokers met COPD profiteren van het gebruik van bupropion en nortriptyline. Bovendien vonden we onder de rokers die als depressief waren geclassificeerd, dat het gebruik van bupropion tot bijna 15\% meer stoppers leidde dan het gebruik van een nepmiddel. Het aantal depressieve rokers in de nortriptyline groep was te klein om te bestuderen of dit ook het geval was bij gebruik wan nortriptyline.

Hoofdstuk 10 bevat de algemene discussie van het proefschrift. Na een korte samenvatting van de belangrijkste bevindingen van de studies in dit proefschrift richt het hoofdstuk zich op de implicaties van de gevonden resultaten en worden aanbevelingen gedaan voor toekomstig onderzoek naar psychische klachten bij patiënten met COPD en hoe deze informatie kan worden gebruikt om de effectiviteit van interventies voor stoppen met roken te vergroten. 


\section{Dankwoord (Acknowledgements in Dutch)}

Allereerst wil ik Paul Knipschild, hoogleraar Epidemiologie, bedanken. Hoewel tegenwoordig het functioneren van wetenschappers mede blijkt af te hangen van oppervlakkigheden die niets met wetenschap van doen hebben, heeft hij zich daardoor nooit laten afleiden in zijn rol als mentor en begeleider. Paul, bedankt woor alle lessen op het gebied van de epidemiologie en daar buiten.

Onno van Schayck, hoogleraar Extra Mural Health Care Research en promotor, wil ik bedanken voor de ruimte die hij mij heeft gegeven zodat ik niet alleen mijn eigen visie heb kunnen ontwikkelen, maar deze ook concreet vorm heb kunnen geven.

Miel Wouters, hoogleraar Pulmonologie en promotor, ben ik veel dank verschuldigd betreffende de rode draad in mijn werk. Hoewel wij relatief weinig gesprekken hebben gevoerd, waren ze erg bepalend voor de inhoud van mijn proefschrift. Ik heb genoten van onze openhartige gesprekken over inhoudelijke zaken en de integriteit van wetenschappers.

IJmert Kant en Gerard Swaen, ten tijde van onze samenwerking respectievelijk universitair docent en universitair hoofddocent, wil ik bedanken voor de mogelijkheid die zij mij hebben gegeven gebruik te maken van het pva cohort. Daarnaast wil ik beide heren en in het bijzonder Ludovic van Amelsvoort, universitair docent, bedanken voor hun bijdrage aan de publicaties die daaruit zijn voortgekomen. Ludo, ik hoop dat wij onze discussies over wetenschap, het klimmen en de biertjes na afloop, in de toekomst zullen voortzetten.

Rab Mostert, directeur van Astmacentrum Hornerheide, wil ik bedanken voor het vertrouwen dat hij in mij heeft gehad betreffende mijn werk in Homerheide en de ruimte die ik heb gekregen om mijn proefschrift af te maken.

Tot slot een speciaal woord van dank voor de onderzoeksassistentes Marlie Leerssen, Annie Hendriks, Anja Schaefer en Ellen de Goeij. Jullie tomeloze inzet, collegialiteit, diplomatie, vertrouwen, inzicht, vastberadenheid, integriteit, onvoorwaardelijke betrokkenheid, creatieve oplossingen voor ogenschijnlijk onoplosbare problemen, aanstekelijk optimisme, waardevolle kritische commentaren en niet te vergeten jullie humor, hebben het onderzoek tot een succes gemaakt. Ik mis jullie. 


\section{About the author}

Edwin Wagena was born on November 13, 1969 in Zwolle. He grew up in Heerde, where he passed secondary school in 1989. From 1990 to 1997 he studied Health Sciences at Groningen University. He took several courses in Work and Experimental. Psychology at Groningen University in 1995 and 1996. Between 1993 and 1995 he combined his college education with a position as product manager Benelux for Messe-News Strobel GmbH, Stuttgart, Germany. In 1997 he obtained his Master of Arts in Health Sciences, specializing in Work and Health.

In October 1997, he moved to Nijmegen, where he joined the Department of Work and Organizational Psychology at Nijmegen University. For two years he participated in The Netherlands concerted action on 'Fatigue at Work' granted by the Netherlands Organization for Scientific Research (NWO). Because of his preference for clinical experimental research, he left Nijmegen University in January 2000 and moved to Mastricht to work on his thesis at the Department of General Practice of Maastricht University. Next to his doctoral research, he acquired funding for and supervised experimental research into the safety and immunogenicity of a nicotine vaccine and the efficacy of reimbursement for smoking cessation treatment. In Mai 2004 he was appointed assistant editor of Addiction, a scientific journal published by the Society for the Study of Addiction to Alcohol and Other Drugs. In that same month he accepted a position as behavioural scientist at Pulmonary Rehabilitation Centre Hornerheide in Horn, where he was involved in clinical research and psychosocial healthcare of patients with chronic obstructive pulmonary disease (COPD).

Since March 2005 he works as a clinical trial manager neurosciences at Solvay Pharmaceuticals B.V. in Weesp, and lives together with Ingrid de Groot in Zwolle. 


\section{List of publications}

\section{PUBLICATIONS IN ENGLISH}

Wagena EJ, Knipschild P, Zeegers MPA. Should nortriptyline be used as a first-line aid to help smokers quit? Results from a systematic review and meta-analysis. Addiction, 2005; 100: 317-326.

Wagena EI. Management of patients with COPD. Lancet, 2004; 364: 2015-2016.

Wagena EJ, Kant IJ, van Amelsvoort LGPM, Wouters EFM, van Schayck CP, Swaen GMH. Risk of depression and anxiety in employees with chronic bronchitis: the modifying effect of cigarette smoking. Psychosomatic Medicine, 2004; 66: $729-734$.

Wagena EJ, van der Meer RVDM, Ostelo R, Jacobs Al, van Schayck CP. Smoking cessation strategies in patients with COPD: a systematic review. Respiratory Medicine, 2004; 98(9): 805-815.

Wagena EJ, Kant IJ, Huibers MJH, Swaen GMH, Wouters EFM, van Schayck CP. Psychological distress and depressed mood in employees with asthma, chronic bronchitis or emphysema: a population-based observational study on prevalence and the relationship with smoking cigarettes. European Journal of Epidemiology, 2004; 19: 147-153.

Wagena EJ. Narrative reviews can be misleading: Bupropion for smoking cessation is not effective in patients with COPD. British Medical Journal (www.bmj.com, published March 22, 2004).

Wagena EI, Zeegers MPA, van Schayck CP, Wouters EFM. Benefits and risks of pharmacological smoking cessation therapies in chronic obstructive pulmonary disease. Drug Safety, 2003; 26(6): 381-403.

Wagena EI, Huibers MJH, van Schayck CP. Antidepressants in the treatment of patients with COPD: possible associations between smoking cigarettes, COPD and depression. Thorax, 2001; 56(8): 587-588.

Wagena EJ, Knipschild P. Do drug firms hoodwink medical journals? Or is something wrong with the contribution and integrity of declared authors? Journal of Medical Ethics, 2005; in press.

Wagena EJ. The scandal of unfair behaviour of senior faculty: Misappropriation of authorship needs to be abolished. Journal of Medical Ethics, 2005; in press.

Wagena EI, Arrindell WA, Wouters EFM, van Schayck CP. Are patients with COPD psychologically distressed? European Respiratory Journal, 2005; in press. 
Wagena EJ, wan Amelswoort LGPM, Kant IJ, Wouters EFM. Chronic bronchitis, cigarette smoking and the subsequent onset of depression and anxiety: Results from a prospective population-based cohort study. Psychosomatic Medicine, 2005; in press.

Wagena EI, Knipschild P. Efficacy of bupropion for smoking cessation in relation to conflicts of interest and methodological quality: a systematic review and meta-analysis. Tobacco Control, accepted pending revision.

Kaper I, Wagena E], Van Schayck CP, Severens $\mathbb{H}$. Health care financing systems for increasing utilisation of tobacco dependence treatment (Cochrane Review). The Cochrane Library; Issue 1. Oxford: update software; 2005.

Van der Meer R, Wagena EJ, Ostelo R, Jacobs J, Van Schayck CP. Smoking cessation for people with chronic obstructive pulmonary disease (Cochrane review). The Cochrane Library; Issue 2. Oxford: update software; 2003.

Kaper J, Wagena EJ, Willemsen MC, Van Schayck CP. Is reimbursement for smoking cessation treatment effective in changing smoking behavior? Results of a randomized trial. Addiction, 2005; in press.

Van Schayck CP, Loozen JMC, Wagena EJ, Akkermans R, Wesseling GJ. Detecting patients at a high risk of developing chronic obstructive pulmonary disease in general practice: cross sectional case finding study. British Medical Journal, 2002; 324: 1370-1373.

Huibers MJH, Chavannes NH, Wagena EJ, Van Schayck CP. Antidepressants for smoking cessation: a promising new approach? European Respiratory Journal, 2000; 16: 379-380.

\section{PUBL.ICATIONS IN DUTCH}

Wagena EI, De Graaf L, Chavannes NH, van Schayck CP. Onrust over de veiligheid van bupropion als middel om te stoppen met roken onterecht. Nederlands Tijdschrift voor Geneeskunde, 2001; 145 (31): 1489-1492.

Wagena EJ, Huibers MJH, van Schayck CP. Therapieën voor stoppen met roken (antidepressiva, nicotinevervanging en counseling) en implicaties voor de behandeling van patiënten met chronische obstructieve longziekte. Nederlands Tijdschrift voor Geneeskunde, 2001; 145 (31): 1492-1496.

Wagena EJ, Zeegers MPA, Huibers MJH, Chavannes NH, van Schayck CP. Bupropion: een effectief nieuw hulpmiddel bij het stoppen met roken. Nederlands Tijdschrift voor Geneeskunde, 2001; 145 (2): 103-104.

Wagena EJ. Het belang van stoppen met roken voor patiënten met COPD. Stivoro Visie, 2001; 6(1): 4.

Wagena EJ, Geurts SAE. SWING: ontwikkeling en validering van de 'Survey Werkthuis Interferentie-Nijmegen. Gedrag en Gezondheid, 2000; 28: 138-158. 
Willemsen MC, Wagena EJ, Van Schayck CP. De effectiviteit van stoppenmmetroken methoden. Longkruid, 2004; 196: 6-11.

Willemsen MC, Wagena EJ, van Schayck CP. De effectiviteit van stoppen-metroken methoden die in Nederland beschikbaar zijn: een systematische review op basis van Cochrane gegevens. Nederlands Tijdschrift voor Geneeskunde, 2003; 147 (19): 922-927.

Schayck CP van, Loozen JMC, Wagena E, Akkermans RP en Wesseling GI. Het opsporen van mogelijke patiënten met chronisch obstructieve longziekte onder rokers in de huisartspraktijk; een dwarsdoorsnedeonderzoek. Nederlands Tijdschrift voor Geneeskunde, 2003; 147: 208-212.

\section{MANUSCRIPTS SUBMITTED FOR PUBLICATION}

Wagena EJ, Knipschild PG, Huibers MJH, Wouters EFM, van Schayck CP. The efficacy of bupropion and nortriptyline for smoking cessation among people who are at risk for or have chronic obstructive pulmonary disease.

Wagena EI, Arrindell WA, Wouters EFM. Depression in patients with COPD: do somatic complaints cause these patients to be classified as depressed?

Wagena EI, Kotz D, Sachs APE. Smoking GPs seem more active in helping smokers quit compared to non-smoking GPs. Results from a national survey.

Wagena EJ, Knipschild P. Clinical trials registers are no guarantee that trials are registered: A review of a clinical trials register of a major pharmaceutical company.

Kotz D, Wagena EJ. Smoking cessation practices and smoking behaviour of Dutch general practitioners, cardiologists and lung physicians. A comparison based on national surveys.

Kaper J. Wagena EI, van Schayck CP, Severens IL. The cost-effectiveness of encouraging smokers to quit by reimbursing the costs of smoking cessation treatment. 